\author{
Universidade de São Paulo \\ Instituto de Astronomia, Geofísica e Ciências Atmosféricas \\ Departamento de Astronomia
}

Oscar Cavichia de Moraes

\title{
Populações e evolução do bojo e região central da Galáxia
}

São Paulo 

Oscar Cavichia de Moraes

\section{Populações e evolução do bojo e região central da Galáxia}

Tese apresentada ao Departamento de Astronomia do Instituto de Astronomia, Geofísica e Ciências Atmosféricas da Universidade de São Paulo como requisito parcial para a obtenção do título de Doutor em Ciências. Versão corrigida. A original encontra-se disponível na unidade.

Área de Concentração: Astronomia

Orientador: Prof. Dr. Roberto Dell'Aglio Dias da Costa

São Paulo 

Dedico esta tese aos meus pais. 



\section{Agradecimentos}

À minha família por sempre acreditarem em mim e me apoiarem, estando sempre ao meu lado nas horas mais difíceis. O apoio dos meus pais, Edson e Sonia, foi essencial para eu conseguir chegar até aqui.

Gostaria de agradecer ao meu orientador, prof. Dr. Roberto Costa por todos estes anos de trabalho. Além de um excelente orientador, eu o considero uma pessoa muito boa, com uma vasta cultura. Seus ensinamentos contribuíram muito para o meu crescimento profissional e pessoal.

Muitas partes deste trabalho não seriam possíveis sem a ajuda do prof. Dr. Walter Maciel. Seu incentivo foi fundamental para a realização desta tese.

Me gustaría agradecer a Dra. Mercedes Mollá, por recibirme en Madrid y ayudarme con los modelos de evolución química. Sin tu ayuda, esta parte del trabajo sería imposible. Además, fue muy agradable la estancia en Madrid y ya estoy echando de menos. También tengo que agradecer todos los amigos del CIEMAT por toda ayuda, en especial Aurelio Carnero.

Aos professores do IAG, com quem tive o prazer de ser aluno. Em especial aos excelentes cursos ministrados pelos professores Dr. Walter Maciel, Dr. Jacques Lépine, e Dra. Cláudia Mendes de Oliveira. Ao prof. Dr. Jácques Lépine novamente, pelas discussões científicas e comentários. Ao prof. Dr. Gastão Lima Neto pelas ajudas com programação.

À todos os amigos que estão ou que não se encontram mais no IAG: Felipe Santos, Tatiana Laganá, Raimundo Oliveira, Marcio Avellar, Vinicius Placco, Tiago Ricci (ainda estilista), Sergio Scarano, Alessandro Moisés, Raul Puebla (Compaaadre), Monica Midori, Mairan Teodoro, Daniel Moser, Fernanda Urrutia, Gleidson da Silva, Gustavo Rocha, Grzegorz Kowal, Rubens Machado, Marina Trevisan, Bruno Dias, Pedro Beaklini, Reinaldo 
Santos, Rodrigo Vieira, Rafael Santucci.

Aos amigos com quem dividi a sala no IAG: Marcus Vinicius, Felipe Navarete, Juan Luna, Sergio Flores.

Ao pessoal do LNA e SOAR pelo suporte técnico durante as observações. Em especial ao Dr. Sergio Scarano pela ajuda com as observações remotas com o SOAR.

Ao pessoal do IAG: informática, secretaria, biblioteca, limpeza, café, segurança, gráfica. Sem a competência e ajuda dessas pessoas com certeza este trabalho não chegaria ao final.

Ao assessor anônimo da FAPESP pelos comentários e sugestões nos relatórios.

À FAPESP pelo apoio financeiro sob o projeto $n^{o}$ : 2007/07704-2, e à CAPES pelo apoio financeiro proc. 3026-10-8.

Based on observations obtained at the Southern Astrophysical Research (SOAR) telescope, which is a joint project of the Ministério da Ciência, Tecnologia, e Inovação (MCTI) da República Federativa do Brasil, the U.S. National Optical Astronomy Observatory (NOAO), the University of North Carolina at Chapel Hill (UNC), and Michigan State University (MSU).

Esta tese foi escrita em IATEX com a classe IAGTESE, para teses e dissertações do IAG. 
"Por tanto tempo, desvairado e aflito,

Fitei naquela noite o firmamento, Que inda hoje mesmo, quando acaso o fito,

Tudo aquilo me vem ao pensamento.

Saí, no peito o derradeiro grito Calcando a custo, sem chorar, violento... E o céu fulgia plácido e infinito, E havia um choro no rumor do vento...

Piedoso céu, que a minha dor sentiste! A áurea esfera da lua o ocaso entrava, Rompendo as leves nuvens transparentes; E sobre mim, silenciosa e triste, A via-láctea se desenrolava Como um jorro de lágrimas ardentes" Canto XXIX de Olavo Bilac

"É preciso, antes de mais nada, querer."

Amyr Klink 



\section{Resumo}

O presente trabalho propõe uma abordagem abrangente para descrever a evolução da região central da Via Láctea, compreendendo-se aí o bojo, a barra e as interfaces dos mesmos com o limite interno do disco e com a região central do halo. Pretende-se investigar as propriedades químicas e cinemáticas destas estruturas, que são interconectadas, com o objetivo de separá-las e aplicar os resultados daí obtidos a um modelo de formação e evolução do bojo e da região interna do disco que descreva simultaneamente distintos aspectos da evolução da região central da Galáxia.

Na primeira parte do trabalho, uma amostra de nebulosas planetárias (NPs) localizadas no disco interno e no bojo da Galáxia é utilizada para encontrar a distância galactocêntrica que melhor separa estas duas populações, do ponto de vista das abundâncias. Foram utilizadas escalas de distâncias estatísticas para o estudo da distribuição das abundâncias na interface bojo-disco. A aplicação do teste Kolmogorov-Smirnov mostrou que, em média, a população interna não segue o gradiente radial de abundâncias do disco na direção do centro galáctico. Baseado neste estudo, propõe-se uma distância galactocêntrica de 1.5 kpc para definir a interface bojo-disco.

$\mathrm{Na}$ segunda parte do trabalho, foram realizadas observações espectrofotométricas de 21 NPs localizadas na direção do centro da Galáxia com o telescópio SOAR. Estes objetos estão localizados próximos ao plano galáctico na direção central da Via Láctea, onde não existem dados de NPs na literatura. Os resultados mostram que as NPs localizadas nesta região apresentam baixas abundâncias de oxigênio comparadas com as NPs do disco interno e de outras regiões do bojo. Os resultados indicam que o bojo apresenta uma complexa composição de populações estelares. Por um lado, a presença de nebulosas com baixas abundâncias mostra que o bojo pode ter se formado a partir de um disco galáctico antigo 
através de uma evolução secular. Por outro lado, existem alguns objetos do bojo para os quais as abundâncias coincidem com o limite do gradiente radial do disco nesta região. Esta é uma evidência para um bojo composto por duas ou mais populações: uma originada do disco fino, e outra originada do disco espesso.

Na última parte do trabalho propõe-se a inclusão de fluxos radiais de gás em um modelo de evolução química para simular os efeitos de uma barra localizada no centro da Galáxia nas distribuições de abundâncias, densidade de gás e taxa de formação estelar (SFR). Os resultados das simulações indicam que os modelos com fluxos de gás apresentam uma SFR mais alta no bojo e que os perfis da SFR e da densidade de gás na região central são melhor reproduzidos após a inclusão dos fluxos radiais no modelo. As simulações indicam ainda que o gradiente de abundâncias do disco é mais plano para o caso da inclusão da barra. Estes resultados indicam que a barra e os fluxos de gás exercem um importante papel na formação de estrelas no centro das galáxias espirais barradas. 


\section{Abstract}

This project proposes a comprehensive approach to describe the evolution of the central region of the Galaxy, comprising the bulge, the bar and their interfaces with the inner disk and the central region of the halo. We intend to investigate the chemical and kinematic properties of these structures, which are interconnected, aiming to separate them and apply these results to a model for the formation and evolution of the bulge and inner disk, capable to describe simultaneously distinct aspects of the evolution of the central region of the Galaxy.

First, a sample of planetary nebulae (PNe) located in the inner-disk and bulge of the Galaxy is used in order to find the galactocentric distance that better separates these two populations, from the point of view of abundances. Statistical distance scales were used to study the distribution of abundances across the disk-bulge interface. A KolmogorovSmirnov test was used to find the distance in which the chemical properties of these regions better separates. The results of the statistical analysis indicate that, on the average, the inner population has lower abundances than the outer. Additionally, for the $\alpha$-elements abundances, the inner population does not follow the disk radial gradient towards the galactic centre. Based on our results, we suggest a bulge-disk interface at $1.5 \mathrm{kpc}$, marking the transition between the bulge and inner-disk of the Galaxy, as defined by the intermediate mass population.

Second, we present spectrophotometric observations for a sample of 21 PNe located towards the galactic centre of the Galaxy. The abundances are derived based on observations in the optical domain made at the SOAR telescope. Their location is interesting since there are no observations of PNe in this region. The data show lower oxygen abundances compared to those from $\mathrm{PNe}$ located in the inner disk and other bulge regions. The results 
show that the bulge has a complex composition of stellar populations. The presence of PNe with low abundances indicates that the bulge might be formed from an old galactic disk through secular evolution. On the other hand, other objects from our sample have abundances compared to those from inner disk PNe. This is an evidence that the bulge might be composed by two or more populations: one originated from the thin disk, and the other from the thick disk.

Last, we propose a chemical evolution model that includes radial gas flows. This is done in order to mimic the effects of the galactic bar on the chemical abundances distributions and the gas density profiles and the star formation rate (SFR). The results of the models with radial flows point to a high SFR in the bulge and, additionally, the SFR and gas density profiles in the inner Galaxy are better reproduced after the inclusion of radial gas flows in the model. After including a specific velocity pattern for the bar, the results show a flattening of the radial abundance gradient. Our results indicate that radial gas flows may play an important role in the star formation near the centre of barred spiral galaxies. 


\section{Lista de Figuras}

1.1 Posição do bojo da Via Láctea no diagrama de Binney (1978) . . . . . . . 25

1.2 Representação da concepção atual da estrutura da Via Láctea. . . . . . . . 28

1.3 Distribuição das NPs do bojo e disco interno. . . . . . . . . . . . . . . . . 33

2.1 Distribuição das distâncias galactocêntricas. . . . . . . . . . . . . . . . . . 47

2.2 Abundâncias médias das NPs pertencentes aos grupos I e II. . . . . . . . . 48

2.3 Igual a figura 2.2 para a escala de Z95 . . . . . . . . . . . . . . . . . . . . 49

2.4 Probabilidade Kolmogorov-Smirnov para cada elemento. . . . . . . . . . 50

2.5 Distribuição de abundâncias para os grupos I e II utilizando a escala de Z95. 52

2.6 O mesmo que a figura 2.5 para a escala de SSV08. . . . . . . . . . . . 53

3.1 Exemplos de imagens flat-field para as diferentes redes. . . . . . . . . . . 57

3.2 Esquema do espectrógrafo Goodman. . . . . . . . . . . . . . 57

3.3 Razão entre as emissividades em função da temperatura. . . . . . . . . . . 67

3.4 Razão entre as emissividades para uma densidade constante. . . . . . . . . 68

3.5 Espectro da Nebulosa Planetária JaSt 42 observada com o SOAR. . . . . . 70

3.6 Campo da Nebulosa Planetária JaSt 42 observada com o SOAR. . . . . . . 71

3.7 Espectro da nebulosa planetária PTB 13. . . . . . . . . . . . . . . . 74

3.8 Espectro da nebulosa planetária JaSt 23. . . . . . . . . . . . . . . . . . . . 76

3.9 Comparação entre as temperaturas do NII para os método 1 e 2. . . . . . . 77

3.10 Comparação entre as abundâncias de hélio para os métodos 1 e 2 . . . . . 78

3.11 O mesmo que a figura 3.10 para o nitrogênio. . . . . . . . . . . . . . . 79

3.12 Análogo à figura 3.11 para o oxigênio. . . . . . . . . . . . . . . . . . 79

3.13 Análogo à figura 3.10 para o argônio. . . . . . . . . . . . . . . . . . . 80 
3.14 Análogo à figura 3.10 para o enxofre. . . . . . . . . . . . . . . . . 80

3.15 Comparação entre as abundâncias de oxigênio para os diferentes métodos. . 83

3.16 Correlação entre $\log (\mathrm{N} / \mathrm{O})$ e hélio. . . . . . . . . . . . . . . . . . . . 84

3.17 Correlação entre as abundâncias de enxofre e oxigênio. . . . . . . . . . . . 85

3.18 O mesmo que a figura 3.17 para o argônio. . . . . . . . . . . . . . . 85

3.19 Gradiente radial de oxigênio. . . . . . . . . . . . . . . . 87

3.20 Distribuição de oxigênio. . . . . . . . . . . . . . . . . . . . . 88

4.1 Esquema para os fluxos de gás na camada $k$. . . . . . . . . . . . . . . 101

4.2 Perfil radial da densidade superficial de gás para o modelo MD05. . . . . . 104

4.3 SFR como função da distância galactocêntrica para o modelo MD05. . 105

4.4 Gradiente radial de ferro para o modelo MD05. . . . . . . . . . . . . . . 105

4.5 Perfil radial da abundância de oxigênio do modelo MD05. . . . . . . . . . . 106

4.6 Gradiente de oxigênio do modelo MD05 e dados de Henry et al. (2010). . 106

4.7 Evolução temporal do gradiente radial de oxigênio para o modelo de MD05. 107

4.8 Distribuição de ferro para o modelo MD05. . . . . . . . . . . . . . . 108

4.9 Previsões do modelo de MD05 para a razão $\alpha /$ Fe. . . . . . . . . . . . . . . 109

4.10 Padrão de velocidades adotado para o modelo C. . . . . . . . . . . . . . . 114

4.11 Perfil radial da densidade superficial de gás e modelos com fluxos. . . . . . 115

4.12 Perfil radial da SFR para modelos com fluxos. . . . . . . . . . . . . . 116

4.13 Gradiente radial de ferro para os modelos com fluxos. . . . . . . . . . . . 117

4.14 Perfil radial da abundância de oxigênio dos modelos com fluxos. . . . . . . 118

4.15 Gradiente de O/H dos modelos com fluxos e dados de Henry et al. (2010). 119

4.16 Evolução temporal do gradiente de $\mathrm{O} / \mathrm{H}$ para modelos com fluxos. . . . . . 120

4.17 Distribuição de ferro para modelos com fluxos. . . . . . . . . . . . . . . . . 121

4.18 Perfil da SFR para modelos com fluxos. . . . . . . . . . . . . . . . . 122

4.19 Previsões dos modelos com fluxos para a razão $\alpha / \mathrm{Fe} . . . .123$

4.20 Distribuição de ferro para as estrelas anãs e subgigantes do bojo. . . . . . . 124 


\section{Lista de Tabelas}

2.1 Distâncias galactocêntricas das NPs da amostra. . . . . . . . . . . . . . . . 42

2.1 Continuação . . . . . . . . . . . . . . . . . . . . . . . 43

2.1 Continuação . . . . . . . . . . . . . . . . . . . . . . . . . 44

2.2 Novas distâncias. . . . . . . . . . . . . . . . . . . . . 46

2.3 Probabilidades Kolmogorov-Smirnov. . . . . . . . . . . . . . . . 50

2.4 Abundâncias médias dos grupos I e II para cada escala de distância. . . . . 52

3.1 Log das observações realizadas com o SOAR . . . . . . . . . . . . . . . 59

3.2 Coeficientes para a parametrização das emissividades do HeI. . . . . . . . . 66

3.3 Coeficientes para a correção colisional do HeI. . . . . . . . . . . . . . . . . 67

3.4 Excesso de cor e parâmetros físicos para as NPs observadas (método 1). . . 73

3.5 Abundâncias químicas das NPs observadas para o método 1. . . . . . . . . 75

3.6 Excesso de cor e parâmetros físicos para as NPs observadas (método 2). . . 76

3.7 Abundâncias químicas das NPs observadas utilizando o método 2. . . . 77

3.8 Abundâncias químicas das NPs observadas utilizando o método $3 . \quad$. . . . 82

4.1 Parâmetros utilizados nos modelos. . . . . . . . . . . . . . . . . 113 



\section{Sumário}

1. Introdução . . . . . . . . . . . . . . . . . . . . . . . . . . . . . . 19

1.1 A Via Láctea . . . . . . . . . . . . . . . . . . . . . . . . . . . 19

1.1.1 História da Via Láctea . . . . . . . . . . . . . . . . . . . . 19

1.1.2 Como a Via Láctea se formou? . . . . . . . . . . . . . . . . . . 20

1.1.3 A Via Láctea como uma espiral barrada . . . . . . . . . . . . . 24

1.2 Nebulosas planetárias . . . . . . . . . . . . . . . . . . . . . . . 29

1.2.1 População do disco . . . . . . . . . . . . . . . . . . . . . 30

1.2.2 População do bojo . . . . . . . . . . . . . . . . . . . . . 31

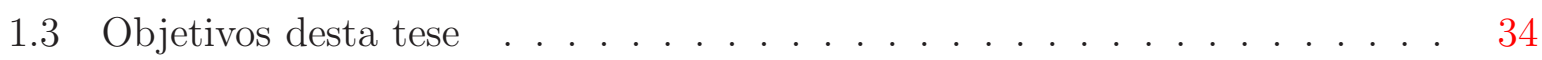

2. A conexão bojo-disco da Via Láctea . . . . . . . . . . . . . . . . . . . . . . . . . 39

2.1 Introdução . . . . . . . . . . . . . . . . . . . . . . . . . 39

2.2 A amostra de nebulosas planetárias e novas distâncias . . . . . . . . . . . . 41

2.3 Determinação da interface bojo-disco . . . . . . . . . . . . . . . . . 46

2.3.1 Teste Kolmogorov-Smirnov . . . . . . . . . . . . . . . . . . . 49

2.3.2 Distribuição de abundâncias . . . . . . . . . . . . . . 51

3. Nebulosas planetárias na direção central da Via Láctea . . . . . . . . . . . . . . 55

3.1 Observações . . . . . . . . . . . . . . . . . . . . 55

3.1.1 Configuração instrumental . . . . . . . . . . . . . . 55

3.1.2 A amostra de nebulosas planetárias . . . . . . . . . . . . 58

3.2 Redução dos dados e cálculo das abundâncias (PNePack) . . . . . . . . . . 59

3.2.1 Redução dos dados: PNeReduc . . . . . . . . . . . . . . . . 60 
3.2.2 Extração dos fluxos: PNeFlux . . . . . . . . . . . . . . . . . . 61

3.2.3 Correção da extinção interestelar: PNeDeredden . . . . . . . . . . . 62

3.2.4 Diagnóstico de plasma e cálculo das abundâncias: PNeCalc . . . . . 63

3.3 Resultados . . . . . . . . . . . . . . . . . . . 69

4. A evolução química da Via Láctea com fluxos radiais de gás . . . . . . . . . . . 91

4.1 O modelo . . . . . . . . . . . . . . . . . . . 92

4.1 .1 Tempo de colapso . . . . . . . . . . . . . . . 93

4.1.2 Eficiências de formação estelar e nuvens . . . . . . . . . . . . . . 94

4.1 .3 As equações do modelo . . . . . . . . . . . . . . . . . 96

4.1 .4 Fluxos radiais de gás . . . . . . . . . . . . . . . . . 100

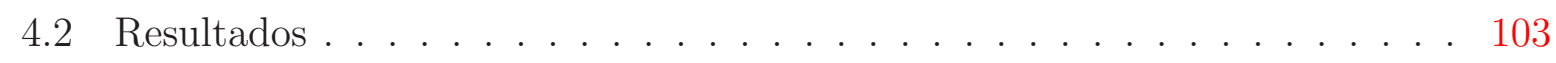

4.2 .1 Modelo sem fluxos de gás . . . . . . . . . . . . . . 103

4.2.2 Modelos com fluxos radiais de gás . . . . . . . . . . . . . . . . . . 111

5. Conclusões e perspectivas . . . . . . . . . . . . . . . . . 127

5.1 Abundâncias na conexão bojo-disco . . . . . . . . . . . . . . . 127

5.2 Abundâncias químicas de NPs na direção central da Via Láctea .... 129

5.3 A evolução química da Via Láctea com fluxos radiais de gás . . . . . . . . 131

5.4 Considerações finais . . . . . . . . . . . . . . . . . . . 132

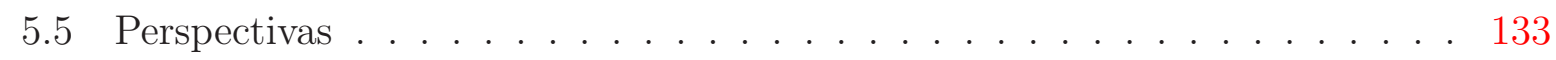

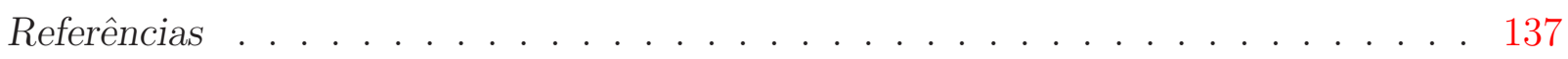

$\begin{array}{ll}\text { Apêndice } & 157\end{array}$ 
Capítulo 1

\section{Introdução}

\subsection{A Via Láctea}

\subsubsection{História da Via Láctea}

O nome Via Láctea surgiu na antiguidade e foi adotado pelos romanos para dar nome a uma faixa de estrelas que corta o céu de um extremo ao outro. Mas o nome usado por um povo do deserto do Kalahari, na África do Sul representa melhor a verdadeira natureza desta faixa luminosa: "a espinha dorsal da noite". A Via Láctea nada mais é do que estrutura completa da nossa galáxia observada de perfil. A primeira observação científica foi feita por Galileo Galiei em 1610 com o auxílio de uma luneta desenvolvida por ele próprio. Apontando sua luneta para a faixa brilhante da Via Láctea, se deu conta de que seu brilho leitoso deve-se a uma multidão de estrelas individuais.

Uma das maiores contribuições para o avanço do entendimento da estrutura da Via Láctea veio do astrônomo inglês William Herschel. Utilizando alguns telescópios construídos por ele próprio e com a ajuda de seus irmãos, sendo o maior de $1.30 \mathrm{~m}$ de diâmetro e $13 \mathrm{~m}$ de comprimento, Herschel desenvolveu um trabalho de contagem de estrelas em várias direções do céu. Como em algumas direções a contagem de estrelas era maior do que em outras, Herschel concluiu que a maior concentração de estrelas em algumas direções era devido à maior extensão da Galáxia nestas mesmas direções. Ele concluiu também que o Sol ficava no centro da Galáxia e que esta tinha um formato lenticular. Posteriormente, em 1922 o astrônomo holandês Jacobus Kapteyn aperfeiçoou o modelo de Herschel obtendo um diâmetro de $18 \mathrm{kpc}$ e uma espessura de $3.5 \mathrm{kpc}$, mas ainda o Sol permanecia no centro da Galáxia. 
O Sol passou a ocupar uma posição mais periférica somente após os estudos iniciados em 1915 por Harlow Shapley do Observatório do Monte Wilson na Califórnia. Observando a distribuição espacial dos aglomerados globulares com o auxílio das distâncias das estrelas RR Lyrae, Shapley constatou que esta distribuição não era homegênea. Concluiu então que o centro da distribuição de aglomerados globulares deveria ser o centro da Galáxia e que este estava a $15 \mathrm{kpc}$ de distância do Sol. O modelo de Shapley somente veio a ser aceito pela comunidade científica da época após a descoberta da poeira interestelar por Robert Trumpler em 1930.

O conceito de populações estelares foi introduzido por Walter Baade em 1944 para classificar as diferentes propriedades dos conjuntos de estrelas observadas na Galáxia. Estudando galáxias vizinhas, em particular M31, Baade percebeu que as estrelas localizadas nos braços espirais são mais azuis que as localizadas nos sistemas esferoidais próximos ao centro das galáxias. Surgiram então os termos população I, para designar as estrelas pertencentes aos discos espirais que são geralmente azuis acompanhadas por gás e poeira, e população II, para designar as estrelas mais velhas e deficientes em metais localizadas nas componentes esferoidais. Este conceito de populações estelares sofreu algumas alterações nas últimas décadas, e outros tipos de populações foram identificados: população do disco extrema, população do disco fino, população do disco espesso, população do halo interno, população do halo externo, e população do bojo.

\subsubsection{Como a Via Láctea se formou?}

Décadas atrás os cenários de formação da Galáxia eram focados nas populações do disco e halo, pois estas componentes eram as mais bem conhecidas e estudadas. Por exemplo, nos trabalhos clássicos de Eggen et al. (1962) e Searle e Zinn (1978) o bojo não era mencionado.

Atualmente, olhando-se para os mapas no infravermelho próximo feitos pelo satélite $\mathrm{COBE}^{1} / \mathrm{DIRBE}^{2}$ (Weiland et al., 1994) ou o levantamento $2 \mathrm{MASS}^{3}$, é evidente que a Via Láctea é uma galáxia espiral com um bojo achatado em seu centro.

Bojos galácticos são sistemas esferoidais encontrados no centro da maioria das galáxias espirais e, usualmente, possuem metalicidade e propriedades fotométricas e cinemáticas

\footnotetext{
${ }^{1}$ Cosmic Backgroud Explorer

${ }^{2}$ Diffuse Infrared Background Experiment

3 Two Micron All Sky Survey
} 
que os separam das componentes do disco. O estudo da evolução do bojo da Galáxia é de interesse geral devido à similaridade de sua luz integrada com as galáxias elípticas e outros bojos de galáxias espirais (Maraston et al., 2003), pois estes estão localizados na mesma região do plano fundamental das galáxias elípticas (Jablonka et al., 1996).

A região central da Via Láctea é chamada bojo. A partir de seu raio e a massa, pode-se concluir que o bojo é a estrutura da Galáxia que contém a maior densidade de matéria bariônica. Os maiores obstáculos para o estudo desta estrutura são: extinção grande e variável, e campo de objetos extremamente populoso. A grande distância que o bojo se encontra, da ordem de 8 kpc (Nishiyama et al., 2006), faz com que a observação dos objetos que compõem esta estrutura seja muito difícil. Em alguns casos, a extinção pode chegar a 30 magnitudes na banda V. Todos estes efeitos mais a superposição de múltiplas estruturas ao longo da linha de visada, fazem os estudos das regiões internas da Galáxia um desafio.

Porém, também existem vantagens em se estudar o bojo galáctico: pode-se resolver as estrelas individualmente, obtendo-se movimentos e posicões em 3D e abundâncias químicas detalhadas para estas estrelas, o que não é possível em outras galáxias com exceção das mais próximas no grupo local; pode-se datar e separar as diferentes componentes da Galáxia a partir dos diagramas de cor-magnitude das diferentes populações estelares.

A maior parte da população rica em metais do bojo é velha, com uma idade $T=10 \pm 2.5$ Gyr (Ortolani et al., 1995; Zoccali et al., 2003). Apesar disto, existem traços de uma população mais jovem como estrelas $\mathrm{OH} / \mathrm{IR}$, estrelas AGB brilhantes, entre outras, que aparecem a maior parte confinadas no plano galáctico (van Loon et al., 2003).

Observações das distribuições de metalicidades das estrelas do bojo e da razão entre os elementos químicos permitem vincular a escala de tempo de formação, a taxa de formação estelar (SFR), a função de massa inicial, a queda de material primordial, e a possível ocorrência de acresção de subsistemas menores. A população do bojo está longe de ser considerada uma população estelar simples. Pelo contrário, as estrelas do bojo possuem uma larga distribuição de metalicidades (McWilliam e Rich, 1994; Fulbright et al., 2006; Zoccali et al., 2007). A razão $[\alpha / \mathrm{Fe}]$ é alta para as estrelas do bojo (Zoccali et al., 2006; Lecureur et al., 2007), indicando um enriquecimento químico por estrelas massivas progenitoras das supernovas tipo II (SNe II), com pouca contribuição das supernovas tipo Ia (SNe Ia). Este resultado também indica uma curta escala de tempo de formação do bojo 
com relação ao disco fino e espesso.

De fato, como resumido por Wyse e Gilmore (1992), os cenários propostos para a formação do bojo incluem:

(i) Acresção de outros sistemas estelares que eventualmente se localizavam no centro galáctico;

(ii) Acumulação de gás no centro da Galáxia e uma evolução subsequente com uma rápida e/ou lenta formação estelar;

(iii) Acumulação de gás enriquecido no centro da Galáxia vindo do halo, ou disco espesso ou fino.

Elmegreen et al. (2008) propuseram a formação do bojo pela coalescência de grandes aglomerações de gás nas galáxias primordiais. O cenário (i) de acresção de satélites é inconsistente com a distribuição de metalicidades do bojo, como mostrado por Wyse (1998). Além disso, McWilliam et al. (2003) encontraram uma discrepância entre as abundâncias de Mn do bojo e das estrelas da anã esferoidal Sagitário, mostrando que a química deste satélite da Via Láctea é diferente da do bojo.

Nos outros dois cenários, o bojo se formaria rapidamente no princípio da formação da Galáxia. Isto é considerado nos modelos mais recentes que descrevem a formação do bojo (Ballero et al., 2007; Cescutti e Matteucci, 2011; Tsujimoto e Bekki, 2012). Como a formação estelar é muito intensa neste sistema, a metalicidade do bojo rapidamente alcança um valor solar devido ao colapso nuclear das estrelas massivas que leva as SNe e à produção de ferro. Então, quando as SNe Ia, que produzem a maior parte do ferro, começam a explodir, ocorre uma mudança da inclinação da curva $[\alpha / \mathrm{Fe}] \mathrm{x}[\mathrm{Fe} / \mathrm{H}]$ em $[\mathrm{Fe} / \mathrm{H}] \sim 0$ dex.

Mollá et al. (2000) propõem um modelo multifases no contexto do cenário dissipativo de Eggen et al. (1962). Neste modelo, a formação do bojo ocorre com dois principais episódios de infall: do halo para o disco com uma escala de tempo de 0.7 Gyr, e o segundo do bojo para a população do núcleo em uma escala de tempo maior que a anterior. As três zonas, halo bojo e núcleo, interagem por meio de ventos de SNe e infall de gás. Os autores concluem que não é necessário fusão e/ou acresção de material externo para reproduzir as 
principais propriedades do bojo, e que não existe uma analogia do bojo com as galáxias elípticas.

O disco da Via Láctea apresenta algumas características um pouco diferentes das do bojo, como por exemplo um gradiente radial de abundâncias traçado pelos elementos $\mathrm{O}, \mathrm{Ne}$, $\mathrm{S}, \mathrm{Ar}$, e Fe. Os gradientes dos elementos $\alpha$ são em geral obtidos em nebulosas planetárias, referidas como NPs, (Henry et al., 2004; Perinotto e Morbidelli, 2006; Maciel et al., 2008; Stanghellini e Haywood, 2010; Henry et al., 2010) e regiões HII (Deharveng et al., 2000; Esteban et al., 2005; Rudolph et al., 2006). O gradiente radial de oxigênio e ferro também pode ser medido com estrelas cefeidas (Andrievsky et al., 2004; Luck e Lambert, 2011), enquanto que as estrelas anãs tipo B (Smartt et al., 2001) são úteis para a determinação do gradiente de oxigênio. O gradiente radial de ferro é ainda traçado por aglomerados abertos (Friel et al., 2002; Chen et al., 2003). A maioria dos trabalhos encontram que o gradiente de abundâncias de oxigênio é linear e geralmente está entre -0.01 a -0.07 dex/kpc.

Um bom acordo entre as previsões dos modelos e as propriedades observadas do disco é geralmente obtido por modelos que assumem uma formação do disco através de infall de gás (Matteucci e Francois, 1989; Ferrini et al., 1994; Chiappini et al., 1997; François et al., 2004). Os modelos que melhor reproduzem o gradiente de metalicidades do disco fino assumem uma escala de tempo de formação que depende da distância galactocêntrica. Nestes casos, o disco é formado de dentro para fora (formação inside-out). O modelo de Colavitti et al. (2009) não considera uma formação inside-out mas utiliza uma lei de infall cosmológica que prevê uma SFR maior nas regiões mais internas da Galáxia. Este modelo consegue reproduzir os gradientes de metalicidades, mas não reproduz a distribuição radial da densidade de gás.

O modelo de Chiappini et al. (1997) foi o primeiro a sugerir dois episódios de infall para a formação do disco. Neste modelo, o primeiro episódio de infall é responsável pela formação do halo e do disco espesso por um processo rápido de colapso dissipativo. O segundo episódio de infall forma o disco fino em uma escala de tempo maior do que a do disco espesso. Os autores também incluem no modelo um valor mínimo da densidade de gás para que a formação estelar ocorra. Com esta prescrição, é possível reproduzir a maioria das propriedades observadas da Via Láctea.

Portanto, o disco fino da Via Láctea é originado de forma mais lenta do que o bojo, e o 
modelo de formação inside-out é necessário para explicar a formação de um gradiente de abundâncias químicas no disco.

\subsubsection{A Via Láctea como uma espiral barrada}

As barras estão presentes em dois terços das galáxias com disco no Universo local, desta forma o fato da Via Láctea ser uma galáxia barrada não é excepcional. Barras também foram observadas em galáxias com altos redshifts e a fração de galáxias discoidais contendo uma barra aumenta com o aumento do redshift (Sheth et al., 2008). Recentes observações indicam que a Galáxia possui uma barra com $\sim 2.5 \mathrm{kpc}$ de raio orientada entre 15-30 graus com respeito a linha de visada na direção do centro galáctico (por exemplo Dwek et al., 1995; Stanek et al., 1997; Bissantz e Gerhard, 2002; Babusiaux e Gilmore, 2005; Cabrera-Lavers et al., 2007; Rattenbury et al., 2007) com o lado mais próximo na direção das longitudes positivas.

A classificação do bojo galáctico como sendo um bojo clássico ou um pseudo-bojo é motivo de grande debate atualmente. Um bojo é uma estrutura que, observada em duas dimensões, apresenta um brilho superficial variando com o raio elevado a um quarto (lei de De Vaucouleurs) e um disco é uma estrutura cujo brilho superficial radial diminui exponencialmente. Galáxias espirais de tipo precoce têm grandes bojos e espirais em geral são caracterizadas por suas razões bojo/disco. Um bojo clássico se forma a partir de uma combinação de colapso dissipativo (Eggen et al., 1962) e fusões (Toomre, 1977) de galáxias. A medida que o Universo se expande e se esfria as fusões tornam-se menos comuns (Toomre, 1977; Conselice et al., 2003). Haverá um momento em que os processos seculares, que são mais lentos do que as fusões, serão dominantes.

No começo dos anos 1980, Kormendy e Illingworth (1982); Kormendy (1982) argumentaram que alguns bojos, ao menos em galáxias espirais de tipo tardio, apresentam características de discos. Eles argumentaram isto com base em inúmeras evidências:

- Perfis de luminosidade exponencial.

- Formatos mais achatados que os bojos clássicos.

- Baixas dispersões de velocidades $(\sigma)$ com respeito à correlação Faber-Jackson entre $\sigma$ e a luminosidade do bojo. 
- Apresentam espirais, anéis e até mesmo barras, as quais são características dos discos.

Quando possível determinar a geometria fora do plano, estes bojos aparentam ser achatados ao invés de esferoidais. Medidas cinemáticas mostraram que estes bojos são suportados por rotação ao invés de pressão como ocorre em bojos normais. Além disto, estes bojos apresentam rotação cilíndrica.

Estas estruturas, que são parecidas com bojos no sentido de apresentar um aumento da densidade de estrelas na direção do centro da galáxia, foram chamadas de "pseudo-bojos"e suas propriedades foram descritas em Kormendy e Kennicutt (2004). Estas estruturas são originadas lentamente por discos a partir do material destes. Atualmente sabe-se que os bojos achatados não são propriamente bojos, mas sim barras vistas de perfil (Combes e Sanders, 1981; Athanassoula, 2005).

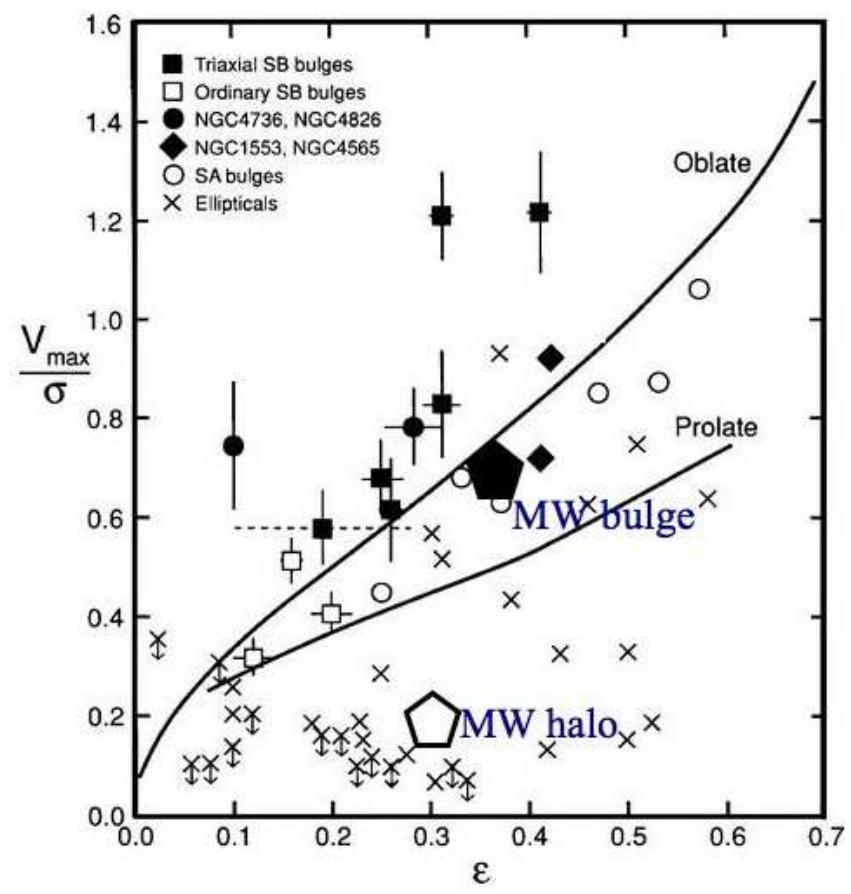

Figura 1.1: Posição do bojo da Via Láctea no diagrama de Binney (1978). Figura extraída de Minniti e Zoccali (2008).

A cinemática do bojo galáctico é intermediária entre um sistema puramente rotante tal como o disco e um sistema quente não rotante como o halo, que é suportado pela dispersão de velocidades. O diagrama $V_{\max } / \sigma$ sugerido por Binney (1978), onde $V_{\max }$ é a velocidade máxima de rotação e $\sigma$ é a dispersão de velocidade média, é uma medida de 
quão quente cinematicamente é um particular sistema estelar. Este diagrama é mostrado na figura 1.1, onde é destacada a posição do bojo galáctico. O diagrama indica que o bojo galáctico é cinematicamente mais quente que o disco da Via Láctea onde $\mathrm{V}_{\max } / \sigma \sim 2.2$ (Minniti e Zoccali, 2008), mas mais frio que o halo. Recentemente, Howard et al. (2009) encontraram que as estrelas do bojo apresentam rotação cilíndrica, como fazem os bojos achatados de outras galáxias.

A importância de se classificar corretamente um bojo como sendo clássico ou pseudobojo tem repercussão em nossos conceitos de evolução galáctica. Esta classificação implica em diferentes cenários para a formação de bojos. Os dois métodos padrão para modelar a formação de bojos eram, até recentemente, o modelo clássico de Jarvis e Freeman (1985b) no qual o bojo se forma a partir de um rápido colapso radial no início da vida da galáxia, e o modelo de fusão no qual os bojos de galáxias espirais formam-se essencialmente da mesma maneira que as elípticas se formam por este cenário, ou seja, através da fusão de duas galáxias menores em uma interação que produz um bojo. Este bojo é produzido como resultado do gás arrastado gravitacionalmente para o centro por um curto período de intensa formação estelar (ver por exemplo Jarvis e Freeman, 1985a).

No cenário de evolução secular, uma maneira das galáxias evoluírem seria por meio da formação de barras devido a instabilidades nos discos, como descrevem por exemplo Kormendy e Kennicutt (2004). Este processo é seguido de uma concentração de estrelas na região central da galáxia impelida por instabilidades nas próprias barras. Em uma galáxia sem um bojo ou com um pequeno bojo inicial, um disco interno poderia surgir a partir do resultado deste tipo de processo.

Em resumo, do ponto de vista da cinemática o bojo galáctico se assemelha a um pseudo-bojo (Shen et al., 2010), porém a análise de abundâncias químicas e populações estelares mostram que o bojo galáctico se assemelha a um bojo clássico. A maior parte das estrelas ricas em metais do bojo são velhas, com uma idade de 10 Gyr (Ortolani et al., 1995; Zoccali et al., 2003). Porém, existem traçadores de populações jovens como estrelas $\mathrm{OH} / \mathrm{IR}$, estrelas variáveis brilhantes, entre outros (van Loon et al., 2003). Portanto, o processo de formação do bojo galáctico ainda é uma questão em aberto. Neste sentido, são necessários mais dados observacionais para se entender melhor a origem desta estrutura. Sobretudo na região do bojo mais próxima ao plano da Galáxia, que pode fornecer indícios 
se o bojo é uma continuação do disco interno ou se realmente é uma outra estrutura que evoluiu independentemente.

Uma concepção atual da estrutura da Via Láctea é mostrada na figura 1.2. Nesta figura, a Galáxia possui dois principais braços espirais (Scutum-Centaurus e Perseus) e dois braços menos densos e menores (Sagittarius e Norma). Os dois braços mais proeminentes começam nas extremidades de uma barra localizada no centro da Via Láctea. Nesta concepção, a barra é composta na verdade por duas estruturas: uma barra mais longa e fina confinada no plano galáctico com $|b|<2^{\circ}$ com um ângulo de posição de $43.0 \pm 1.8^{\circ}$, e um bojo triaxial distinto que se estende pelo menos até $|b|<7.5^{\circ}$ com um ângulo de posição de $12.6 \pm 3.2^{\circ}$ (Cabrera-Lavers et al., 2007).

Aproximadamente $70 \%$ das galáxias espirais são barradas, ou ao menos apresentam uma componente não axi-simétrica (Martin, 1998). As barras têm uma importante influência sobre o potencial gravitacional nas galáxias. Como consequência, movimentos não circulares de fluxos de gás podem ser induzidos no disco das galáxias. Estes fluxos podem transportar grandes quantidades de gás através das galáxias em um curto período de tempo (Friedli et al., 1994). As barras também alteram o perfil radial de abundâncias: na região do disco ocorre um achatamento do gradiente (Friedli et al., 1994) e uma quebra do gradiente próximo à corrotação da barra (Martinet e Friedli, 1997). Adicionalmente, Martin e Roy (1994) notaram que a inclinação do gradiente de oxigênio para galáxias barradas diminui com a força da barra. A força da barra é definida como:

$$
\epsilon_{b a r}=10(1-b / a)
$$

sendo $b / a$ a razão de eixos da barra.

Uma regressão linear da inclinação do gradiente em função da razão de eixos b/a resulta em:

$$
\mathrm{d}(\mathrm{O} / \mathrm{H}) / \mathrm{dR} \simeq-0.140(b / a)+0.033 .
$$

Henry et al. (2010) publicaram um estudo detalhado sobre o gradiente radial de oxigênio para a Via Láctea utilizando nebulosas planetárias, e obtiveram:

$$
\epsilon(O)=(9.09 \pm 0.05)-(0.058 \pm .006) \times R
$$

Utilizando a inclinação do gradiente fornecida pela equação 1.3 e a relação fornecida pela equação 1.2 , obtem-se que a razão de eixos da barra para a Via Láctea é $b / a \simeq 0.65$. 


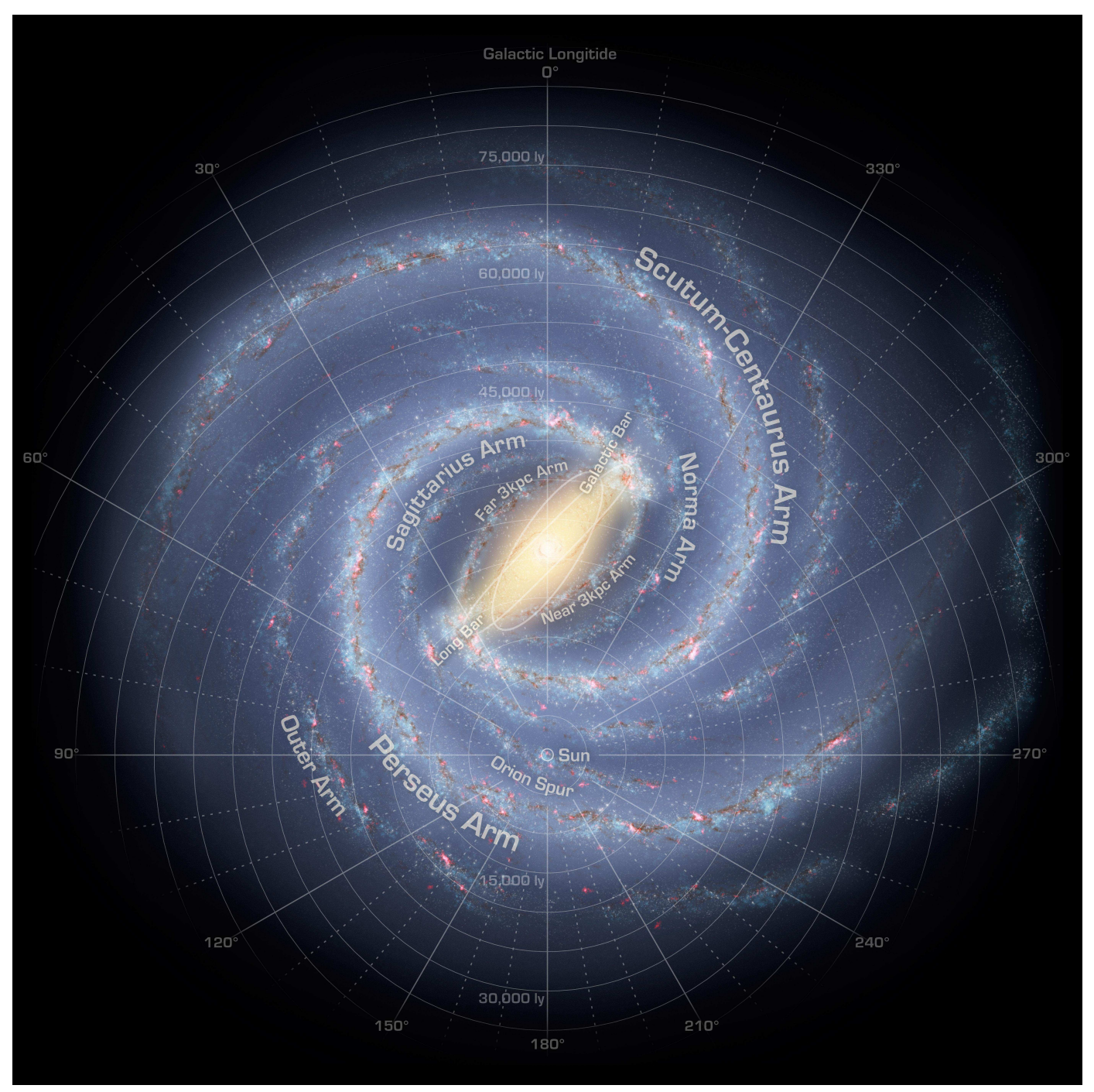

Figura 1.2: Representação da concepção atual da estrutura da Via Láctea. A figura representa uma visão superior da Galáxia, mostrando a localização do Sol no disco, os dois braços espirais mais proeminentes (Scutum-Centaurus e Perseus) assim como dois outros braços menos densos (Sagittarius e Norma). Na região central destaca-se o sistema bojo/barra. Créditos: NASA.

Adotando uma inclinação da barra com respeito a linha de visada como sendo $\phi \simeq 25^{\circ}$, Merrifield (2004) obteve $b / a \simeq 0.6$, valor que concorda com o resultado encontrado a partir da equação 1.2 .

Estes resultados claramente indicam que uma mistura do gás em larga escala induzida pelas barras tem forte influência na distribuição de elementos nas galáxias espirais. Isto foi proposto pela primeira vez por Tinsley e Larson (1978) e implementado em um modelo de evolução química por Lacey e Fall (1985). Os autores deste último trabalho argumentam que fluxos radiais de gás podem ser originados por diversos mecanismos, tais como: o 
gás que cai no disco tem um momento angular menor que o gás que está circulando e, ao se misturar com este último, inflows radiais de gás são induzidos com velocidades de até alguns $\mathrm{km} \mathrm{s}^{-1}$; a viscosidade entre as camadas de gás induz inflows radiais nas partes internas do disco e outflows nas partes externas, com velocidades de $0.1 \mathrm{~km} \mathrm{~s}^{-1}$; interações gravitacionais entre o gás e as densidades de braços espirais produzem choques, dissipação e então inflows de gás nas partes internas e outflows nas partes externas do disco, com velocidades típicas de $0.3 \mathrm{~km} \mathrm{~s}^{-1}$.

Mais recentemente, Elmegreen et al. (2009) publicaram um estudo sobre os fluxos de gás na galáxia barrada NGC 1365. Baseados na estrutura dos filamentos de gás e poeira nas imagens no óptico desta galáxia, os autores mostram que os fluxos de gás movem-se na direção central da galáxia dentro da corrotação da barra, e na direção oposta fora da corrotação da barra. Eles encontram uma velocidade de $80 \mathrm{~km} \mathrm{~s}^{-1}$ para o fluxo na direção central da galáxia. Tal fluxo provoca surtos de formação estelar nas regiões próximas da ressonância interna de Lindblad. As barras exercem fortes torques negativos dentro de seus raios de corrotação, que são tipicamente 1.2 a 1.4 raios da barra. Dentro da corrotação, o gás se choca com a barra formando filamentos de poeira (Athanassoula, 1992). O choque então diminui o momento angular e a energia orbital do gás, que cai ao longo da barra para as regiões da ressonância interna de Lindblad. Como descrevem Elmegreen (2012), após se acumular suficientemente, o gás se torna instável e formam-se estrelas. Frequentemente isto ocorre em um anel de gás ou em dois apertados braços espirais.

Em resumo, os fluxos radiais de gás podem apresentar um importante papel na evolução químicas das galáxias espirais que precisa ser melhor investigado, sobretudo na região mais interna dos discos, onde se formam as barras.

\subsection{Nebulosas planetárias}

A primeira nebulosa planetária (NP) foi observada por Charles Messier em 1764 e a ela foi dado o número 27 em seu catálogo de nebulosas. O nome "nebulosa planetária" foi cunhado por William Herschel, devido à aparência desses objetos se assemelhar a um esverdeado disco de um planeta em um pequeno telescópio. Com o aumento da resolução dos telescópios, as nebulosas que são compostas por estrelas, como por exemplo as galáxias, foram separadas das demais nebulosas gasosas. Posteriormente, as NPs foram distinguidas 
das demais nebulosas por apresentarem uma estrutura definida e são comumente associadas com uma estrela central. O primeiro espectro de uma NP (NGC 6543) foi obtido por William Huggins em 1864. O espectro de uma NP é dominado por linhas de emissão e não apresenta um contínuo como no caso das estrelas.

Atualmente sabe-se que as NPs são originadas de estrelas de baixa massa e massa intermediária com $\sim 0.8-8 \mathrm{M}_{\odot}$, e que dão origem a $\sim 80 \%$ das anãs brancas (Drilling e Schoenberner, 1985). O estudo teórico das NPs começou com Shklovsky (1956), que sugeriu que as NPs são progenitoras das anãs brancas e descendentes das gigantes vermelhas. A visão moderna da origem e evolução desses objetos começa com a perda de massa no ramo assintótico das gigantes (AGB em inglês). Um rápido vento estelar varre por um período de $10^{6}$ anos o envelope circunstelar que é criado pelo processo de perda de massa da estrela progenitora, dando origem a uma estrutura semelhante a um envoltório externo. A interação entre os dois ventos cria uma bolha de alta temperatura que exerce pressão no envoltório e causa sua expansão. O núcleo da estrela AGB, que já perdeu seu envelope, tem sua temperatura aumentada a medida que o fino envelope de $\mathrm{H}$ remanescente é queimado por processos nucleares. O aumento do fluxo de fótons UV gradualmente ioniza o envoltório ejetado, que ao mesmo tempo aumenta a sua massa à medida que o material da estrela AGB é varrido pelos ventos. Quando o envelope estelar de H é exaurido, o núcleo sofre um processo de resfriamento e sua luminosidade é diminuída até se tornar uma anã branca. Este cenário de ventos interagentes para a formação de uma NP e foi proposto por Kwok et al. (1978); Kwok (1982) e revisado por Kwok (2000).

\subsubsection{População do disco}

A população de NPs do disco é frequentemente usada para a determinação do gradiente radial de abundâncias do mesmo (Henry et al., 2004; Maciel et al., 2006; Henry et al., 2010; Stanghellini e Haywood, 2010). As abundâncias químicas dos elementos $\alpha$ destes objetos traçam a composição original da estrela progenitora e, portanto, a evolução química do disco galáctico. Perinotto e Morbidelli (2006) revisam todos os gradientes de metalicidade publicados desde 1970, e encontram um gradiente radial obtido pela população de NPs do disco de $-0.016 \mathrm{dex} / \mathrm{kpc}$, que é mais plano do que os gradientes obtidos previamente (Faundez-Abans e Maciel, 1987; Pasquali e Perinotto, 1993). Uma boa contribuição para 
a incerteza no gradiente das NPs vem das incertezas nas distâncias destes objetos. As distâncias das NPs são, em sua maioria, estimadas por escalas de distância estatísticas, calibradas com algumas poucas distâncias conhecidas de NPs (Maciel e Pottasch, 1980; Cahn et al., 1992; Zhang, 1995; Stanghellini et al., 2008). Porém, um consenso entre todos os trabalhos sobre o gradiente de abundâncias do disco é a existência de uma gradiente radial de abundâncias negativo (Henry et al., 2010).

Como o produto da evolução de estrelas com um largo intervalo de massas $(\sim 0.8-$ $\left.8 \mathrm{M}_{\odot}\right)$, as NPs são representativas da composição química do meio interestelar em diferentes idades da Galáxia. Um estudo sobre a variação temporal do gradiente de abundâncias de oxigênio foi conduzido por Maciel et al. (2003) utilizando NPs de diferentes grupos de idades. As idades das NPs foram estimadas a partir da relação idade-metalicidade e da correlação entre a idade da estrela e a massa da estrela na sequência principal. Eles encontraram um achatamento do gradiente de -0.11 dex/kpc até -0.06 dex/kpc durante os últimos $9 \mathrm{Gyr}$, ou de -0.08 dex/kpc até -0.06 dex/kpc durante os últimos 5 Gyr. Posteriormente, outros elementos como enxofre, argônio e neônio foram analisados por Maciel et al. (2005), todos indicando um achatamento do gradiente nos últimos 6 a 8 Gyr. Em um estudo independente, Stanghellini e Haywood (2010) separaram as NPs em diferentes grupos de idade de acordo com os tipos I, II e III segundo a classificação de Peimbert (1978). Em contradição com o estudo de Maciel et al. (2003), os autores encontram um aumento da inclinação do gradiente com o tempo. Isto pode ser devido à incerteza na classificação de idades utilizando os tipos I, II, e III de Peimbert (1978). Contudo, dependendo do modelo de evolução química do disco, os dois cenários são previstos: Hou et al. (2000) prevê um achatamento temporal, enquanto que o modelo de Chiappini et al. (2001) prevê um aumento da inclinação.

\subsubsection{População do bojo}

As nebulosas planetárias do bojo galáctico são especialmente importantes, pois estes objetos fornecem abundâncias químicas precisas para diversos elementos químicos difíceis de serem estudados em estrelas (ver por exemplo Escudero et al., 2004; Exter et al., 2004; Górny et al., 2004; Gutenkunst et al., 2008). A base de dados de abundâncias químicas de NPs do bojo obtidas pelo grupo do IAG/USP é uma das maiores da literatura, permitindo 
uma modelagem precisa da evolução química desta estrutura (Escudero, 2005; Escudero et al., 2004; Costa et al., 2008; Cavichia et al., 2010). Adicionalmente, os dados de NPs do bojo foram usados para estabelecer vínculos observacionais à relação $[\mathrm{O} / \mathrm{Fe}] \times[\mathrm{Fe} / \mathrm{H}]$ para o bojo galáctico (Maciel, 1999).

Determinações prévias de abundâncias químicas de NPs do bojo mostraram que, em média, estes objetos apresentam abundâncias similares às NPs do disco (Chiappini et al., 2009; Escudero et al., 2004; Escudero e Costa, 2001; Liu et al., 2001; Cuisinier et al., 2000). Do ponto de vista observacional, deve-se notar que apesar da descoberta de muitos objetos novos na região do bojo, o número total de NPs do bojo com abundâncias precisas ainda é pequeno. Atualmente, estima-se que aproximadamente 200 NPs do bojo têm abundâncias químicas determinadas (Chiappini et al., 2009), de um total de 800 NPs conhecidas nesta região (Acker et al., 2006). Peyaud et al. (2006) estimam a existência de 3500 NPs no bojo galáctico.

Devido à sua natureza, as NPs têm um tempo de vida curto, dissipando-se no meio interestelar em uma escala de tempo de 10000 a 50000 anos. Desta forma, os resultados observacionais atualmente disponíveis são fortemente tendenciosos pois eles são focados em objetos brilhantes e compactos e, portanto, mais jovens. As abundâncias dos elementos hélio e nitrogênio sofrem alterações durante a evolução das estrelas progenitoras, sendo que estes processos dependem da massa da progenitora. van den Hoek e Groenewegen (1997) estimam um aumento de $28 \%$ nas abundâncias de nitrogênio para uma estrela de $1 \mathrm{M}_{\odot}$ e $37 \%$ para uma estrela com massa $\geq 3 \mathrm{M}_{\odot}$. Desta forma, a observação de nebulosas mais evoluídas e de menor brilho superficial é importante para um melhor entendimento desta fase da evolução estelar. Neste sentido, os novos surveys utilizando técnicas modernas para a descoberta de novas NPs juntamente com o auxílio de telescópios maiores, contribuíram para o aumento da população conhecida de NPs na Galáxia. Até a uma década atrás conheciam-se aproximadamente 1800 NPs na Galáxia sendo a principal referência o catálogo de Acker et al. (1992). Atualmente os trabalhos de Jacoby e Van de Steene (2004); Boumis et al. (2006); Parker et al. (2006); Miszalski et al. (2008) contribuíram para que o número de NPs conhecidas praticamente dobrasse, totalizando mais de 3000 em toda a Galáxia.

Estes novos catálogos abrem a perspectiva para o estudo de abundâncias químicas 


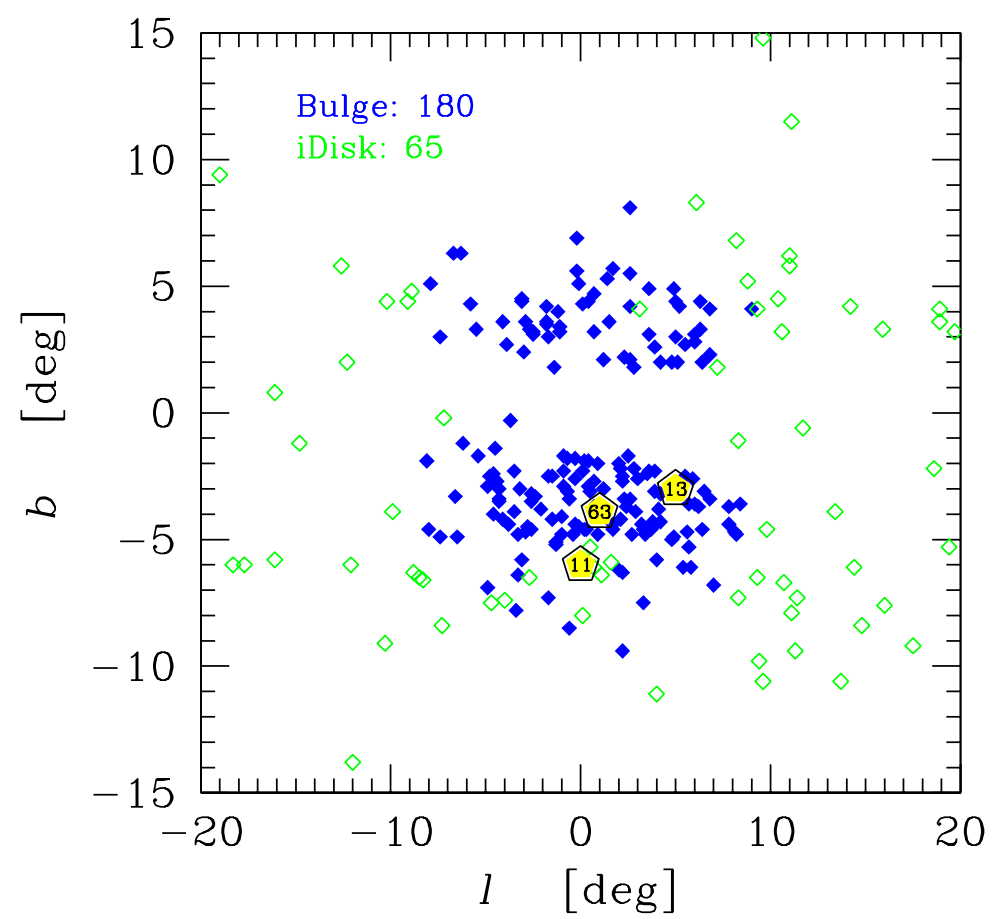

Figura 1.3: Distribuição das NPs do bojo e disco interno em um diagrama de latitude galáctica versus longitude galáctica. Figura extraída de Chiappini et al. (2009).

de NPs de baixo brilho superficial e mais evoluídas com relação aos objetos até agora estudados. Adicionalmente, a região do bojo galáctico com latitude galáctica $|\mathrm{b}|<3^{\circ}$ ainda possui poucos objetos com abundâncias determinadas. Isto pode ser visto na figura 1.3 extraída de Chiappini et al. (2009). A ausência de NPs com abundâncias químicas determinadas na região do bojo com $|\mathrm{b}|<3^{\circ}$ se deve ao efeito de seleção introduzido pela extinção interestelar. Estima-se que nesta região a extinção é superior a 10 magnitudes na banda V. Porém a caracterização química desta região é muito importante para o entendimento sobre a formação do bojo.

Adicionalmente, as NPs do bojo têm sido úteis para a determinação de sua estrutura, como pode ser visto em Cavichia et al. (2011), e a da sua dinâmica, como estudado por Beaulieu et al. (2000) e Peyaud et al. (2006). Em particular, as NPs são excelentes traçadores para estudos dinâmicos pois são menos afetadas por uma têndencia com a metalicidade que outros objetos. Por exemplo, as estrelas $\mathrm{OH} / \mathrm{IR}$, Miras, e gigantes M provavelmente apresentam uma tendência para metalicidades mais altas: a distribuição radial desses objetos decresce mais rapidamente do que a distribuição da luz integrada do bojo, e a cinemática desses objetos reflete a cinemática da componente do bojo mais rica em metais (Sevenster 
et al., 1997). Adicionalmente, as NPs posssuem linhas de emissão intensas permitindo a determinação de velocidades com precisão.

As NPs também têm sido utilizadas como vínculos aos modelos de evolução química do bojo, como por exemplo nos modelos de Escudero (2005); Costa et al. (2008), Ballero et al. (2007). Em particular, as distribuições de abundâncias de oxigênio, enxofre, argônio podem vincular a perda de massa por ventos no bojo (Escudero, 2005), e o diagrama [N/O] x $[\mathrm{O} / \mathrm{H}]$ pode ser útil como vínculo para a correta escolha de sua IMF (Ballero et al., 2007).

\subsection{Objetivos desta tese}

O principal objetivo deste trabalho é entender melhor a formação e evolução da região central da Via Láctea, compreendidos aí o bojo, a barra, e o disco interno da Galáxia. Em particular, pretende-se investigar a influência da barra da Galáxia nas distribuições de abundâncias químicas, densidade de gás, e taxa de formação estelar na região do bojo e nas áreas adjacentes.

Esta tese possui duas linhas de trabalho: uma teórica e uma observacional. Na parte teórica, pretende-se modelar a influência da barra na evolução química do bojo e do disco interno levando-se em conta fluxos radiais de gás. Pretende-se então investigar a influência da barra comparando-se os resultados obtidos do modelo com as observações de distribuição química, densidade de gás, taxa de formação estelar desta região. Na parte observacional, pretende-se realizar observações de NPs localizadas na direção do centro da Galáxia, numa região onde não existem dados de abundâncias químicas disponíveis na literatura. Pretende-se utilizar estes dados como vínculo aos modelos de formação e evolução do bojo galáctico.

Um aspecto importante do estudo das populações do bojo galáctico diz respeito à localização dos objetos. Estudos de propriedades estatísticas de amostras normalmente usam a posição no céu como critério de seleção para verificar se determinado objeto pertence ou não ao bojo, assumindo que objetos que estejam dentro de 15 ou 20 graus da direção do centro galáctico pertencem ao bojo. É muito importante, porém, verificar se os objetos de uma amostra pertencem fisicamente ao bojo ou se são objetos da região interna do disco. Pretende-se então identificar as NPs do disco interno e do bojo, separando-se os objetos de cada região para um melhor entendimento da formação e evolução destas estruturas. 
Mais ainda, a presença de uma barra na região central certamente implica numa perturbação na distribuição de abundâncias e de velocidades que deve ser quantificada. Isto é descrito por Soto et al. (2007) que encontram evidência de uma segregação de abundâncias induzida pela presença de uma barra. Rattenbury et al. (2007), por sua vez, encontram anisotropias nas dispersões de velocidade que são compatíveis com o modelo de uma barra na região central. Vários outros trabalhos têm mostrado que o bojo possui ou já possuiu uma barra. Esta barra acarretaria um inevitável acréscimo de matéria das regiões internas do disco para o bojo. Apesar de existirem vários trabalhos com o enfoque em simulações numéricas que descrevem a interação entre o bojo e o disco, ainda não existe um estudo da distribuição das abundâncias e propriedades cinemáticas de uma amostra abrangente de objetos desta região que procure distinguir as propriedades de distintas subestruturas.

A população de nebulosas planetárias do bojo pode ser usada como vínculo observacional para modelar esta região. Beaulieu et al. (2000) usaram as propriedades cinemáticas de uma amostra de planetárias do bojo (limitada aos objetos descobertos até o final dos anos 90) e compararam-nas com o fluxo do bojo no infravermelho próximo obtido do experimento COBE/DIRBE e com simulações da cinemática do bojo num modelo de N-corpos submetido a um potencial axi-simétrico, como descrito por Saha (1998).

Em particular, determinações de abundâncias químicas de objetos desta região trazem importantes informações a respeito de sua evolução. O estudo de PNs da conexão bojodisco traz informações importantes a respeito das abundâncias de elementos leves (He, O, N, Ne, Ar, S) e da evolução destas abundâncias, associadas à evolução das estrelas de massa intermediária. Estudos das propriedades estatísticas das PNs do bojo, como os desenvolvidos por Escudero e Costa (2001), Escudero et al. (2004), ou Exter et al. (2004) são representativos deste tipo de informação. Da mesma forma, estudos da distribuição de abundâncias a partir de estrelas gigantes, como os de Rich e Origlia (2005), Cunha e Smith (2006), Fulbright et al. (2006, 2007), Rich et al. (2007), Zoccali et al. (2006), e Lecureur et al. (2007) trazem também uma grande quantidade de informação a respeito das populações presentes no bojo.

No contexto das perspectivas observacionais, a publicação do catálogo Macquaire/ AAO/Strasbourg (MASH) de nebulosas planetárias (Parker et al., 2006) e a recente extensão deste catálogo por Miszalski et al. (2008) abre uma perspectiva nova. Mais de 
1200 novos objetos são nele identificados, dos quais cerca de 500 na região do bojo. Tais objetos fornecem uma base de dados muito mais ampla como vínculo observacional das propriedades cinemáticas da região central da Galáxia. Peyaud et al. (2006) descrevem um uso desta base dados na determinação das propriedades cinemáticas do bojo, porém sem abordar o problema de sua interconexão com as outras estruturas presentes na região central da Galáxia. Adicionalmente, esta nova base de dados abre uma perspectiva de ampliação considerável da amostra de abundâncias químicas de nebulosas planetárias nesta região. Deve-se notar que nebulosas planetárias podem também ser usadas para determinar a presença de distintas populações na região do bojo, como fazem por exemplo Górny et al. (2004) que, através análise das abundâncias de uma amostra de 164 nebulosas planetárias da região, distinguem distintas populações, uma pertencente ao bojo e outra ao disco interno

Estes dados, assim como as abundâncias químicas e propriedades cinemáticas das amostras de nebulosas planetárias e estrelas descritas acima, serão, como continuação deste trabalho, aplicados como vínculos observacionais a um modelo de formação e evolução do bojo e da região interna do disco que possibilite estudar a influência da barra nas propriedade químicas da região central da Via Láctea.

O modelo proposto deverá também seguir o esquema básico para descrever a evolução química do bojo, tal como é descrito em detalhe por Escudero et al. (2007) e Costa e Maciel (2006), onde é feita a descrição de um modelo para o bojo, modelo este desenvolvido também por nosso grupo. Tais modelos devem combinar a taxa de formação estelar, a função de massa inicial, os yields estelares para distintas massas, a fração de sistemas binários, a taxa de supernovas e efeito dos ventos estelares, reproduzindo assim as propriedades obtidas dos vínculos observacionais.

Pretende-se assim descrever simultaneamente a evolução dinâmica e química da região central da Galáxia, separando as propriedades das distintas estruturas presentes na região central, o que levará a uma melhor compreensão das propriedades estatísticas do conjunto de objetos presentes nesta região, bem como da evolução da Galáxia como um todo.

Em síntese, com este trabalho pretende-se responder distintas questões ainda em aberto sobre a evolução do bojo galáctico, tais como:

- Como os cenários de evolução dinâmica e/ou secular devem ser invocados para ex- 
plicar as características detectadas no bojo?

- Quais as origens das distintas populações identificadas no bojo?

- Existem populações associadas à barra, ao bordo interno do disco ou ao centro do halo que podem ser encontradas dentro do bojo? Quais as características de cada uma delas?

- Quais as dimensões do bojo, da barra e da interconexão bojo-disco?

Esta tese está estruturada da seguinte forma: no Capítulo 2 são apresentados os resultados de um método desenvolvido para a determinação da transição entre o bojo e o disco da Galáxia, bem como a determinação da distância que isto ocorre; no Capítulo 3 são apresentados os resultados das observações com o telescópio SOAR de nebulosas planetárias localizadas na direção do centro da Via Láctea; o Capítulo 4 descreve um modelo de evolução química adaptado para a inclusão de fluxos radiais de gás, assim como os resultados obtidos para este modelo; no Capítulo 5 as conclusões e perspectivas deste trabalho são delineadas e no apêndice são listados os artigos publicados e em preparação. 
Capítulo 2

\section{A conexão bojo-disco da Via Láctea}

\subsection{Introdução}

O bojo e o disco da Galáxia apresentam diferentes padrões de abundâncias químicas. No disco, a existência de um gradiente radial de abundâncias é bem estabelecida (Carigi et al., 2005; Daflon e Cunha, 2004; Andrievsky et al., 2004; Maciel et al., 2005; Henry et al., 2010). No bojo, existe uma grande dispersão de abundâncias (Rich, 1988; Zoccali et al., 2003, 2006). Mais recentemente, Bensby et al. (2011) analisaram a distribuição de metalicidades para 26 estrelas anãs e subgigantes do bojo por efeito de microlentes gravitacionais. Eles encontraram uma distribuição bimodal para a distribuição de metalicidades do bojo. Por estas evidências entre outras, o bojo e o disco podem ter diferentes histórias de evolução, como descrito por exemplo pelo cenário de infall múltiplos (Mollá et al., 2000; Costa et al., 2005, 2008) ou pelo modelo de formação inside out do disco de Chiappini et al. (2001). Como consequência, espera-se que estas diferenças de formação sejam notadas nas propriedades químicas de cada componente.

Do ponto de vista das NPs, os resultados de Gutenkunst et al. (2008) apontam para uma descontinuidade no gradiente de abundâncias na direção do centro galáctico. As abundâncias do bojo não seguem a tendência das abundâncias do disco, como pode ser visto na figura 4 daquele trabalho. Górny et al. (2004) também notaram que o gradiente de oxigênio da população de NPs do disco é mais achatado nas regiões mais internas da Galáxia, e pode até mesmo mudar de sinal. Por outro lado, Chiappini et al. (2009) comparam as abundâncias de NPs localizadas no bojo, disco interno, e Grande Nuvem de Magalhães. Os resultados não mostram nenhuma diferença clara entre os objetos do bojo e disco interno. 
Outros estudos prévios do bojo galáctico baseados em abundâncias de NPs como Ratag et al. (1992), Cuisinier et al. (2000), Escudero e Costa (2001), Escudero et al. (2004), Exter et al. (2004), encontram que as NPs do bojo apresentam abundâncias similares às do disco. Estes trabalhos mostram que as abundâncias de $\mathrm{He}, \mathrm{O}, \mathrm{Si}, \mathrm{Ar}$, e Ca são similares às do disco, favorecendo uma evolução galáctica mais lenta do que a indicada por estrelas.

Portanto, a distribuição de abundâncias na região interna da Galáxia ainda é uma questão em aberto, especialmente com relação à conexão bojo-disco. Por outro lado, uma comparação detalhada das populações do disco interno e bojo é importante para a caracterização do bojo galáctico como um "pseudo-bojo", como sugerido por evidências fotométricas e cinemáticas (Howard et al., 2009; Shen et al., 2010), em oposição a um bojo clássico como sugerido por Binney (2009).

Considerando estes pontos, a partir dos resultados observacionais e teóricos, esperase que exista uma distância galactocêntrica que melhor separe as populações do bojo e disco interno. Contudo, esta transição ainda está para ser determinada do ponto de vista das abundâncias químicas. Pretende-se neste capítulo utilizar um método estatístico desenvolvido por O. Cavichia durante seu projeto de mestrado para realizar uma análise das abundâncias químicas na conexão bojo-disco da Galáxia. Durante o mestrado, este método foi aplicado a três escalas de distância estatísticas: Maciel (1984), Cahn et al. (1992), e Zhang (1995). As duas últimas escalas se mostraram mais adequadas para a determinação da distância de transição do disco para o bojo, resultando em uma distância de 2.9 e $1.5 \mathrm{kpc}$, respectivamente. Independentemente da escala usada, tal separação mostrou que em média as NPs do bojo apresentam menores abundâncias se comparadas as do disco interno. Contudo esta separação não é superior aos erros na obtenção nas abundâncias. Recentemente, Stanghellini et al. (2008) publicaram uma nova escala de distância estatística baseada em uma recalibração da escala de Cahn et al. (1992) utilizando NPs das Nuvens de Magalhães. Os autores argumentam que esta escala é a mais precisa da literatura, com erros individuais nas distâncias de aproximadamente 30\%. Portanto, se faz necessária uma reanálise da distribuição de abundâncias químicas na conexão bojodisco com esta escala. Adicionalmente, os novos dados publicados pelo grupo do IAG/USP (Cavichia et al., 2010, de agora em diante CCM10) abrem a perspectiva para uma análise estatística mais precisa das abundâncias desta região interna da Galáxia. Este artigo pode 
ser visto no apêndice desta tese.

\subsection{A amostra de nebulosas planetárias e novas distâncias}

Um grande número de escalas de distância estatísticas foi proposto na literatura, e duas delas foram adotadas para o estudo da distribuição das abundâncias químicas na região interna da Galáxia. Utiliza-se nesta tese as escalas de Stanghellini et al. (2008), referido como SSV08, e Zhang (1995), referido como Z95. Estas escalas são baseadas no método de Shklovsky mas com a introdução de uma relação entre a massa ionizada e o raio da nebulosa, como proposto por Maciel e Pottasch (1980).

Os critérios de seleção aplicados para buscar os objetos nos dois catálogos (SSV08 e Z95) foram:

- NPs com fluxo em $5 \mathrm{GHz}$ menor que 100 mJy.

- Diâmetro óptico menor que 12".

- Coordenadas galácticas no intervalo $|\ell| \leq 10^{\circ}$ e $|b| \leq 10^{\circ}$.

As coordenadas galácticas foram utilizadas para restringir a amostra às NPs localizadas na direção do centro galáctico. A combinação dos outros dois critérios garante a exclusão de 90-95\% das NPs que estão na direção do centro galáctico, mas apresentam distâncias galactocêntricas maiores que 4 kpc (ver por exemplo Stasińska et al., 1998). Estes critérios são usados comumente por outros autores para selecionar objetos do bojo, como por exemplo Exter et al. (2004), Chiappini et al. (2009), portanto a maioria dos objetos selecionados devem estar próximos ou no bojo. Parte das abundâncias químicas foi selecionada dos trabalhos publicados pelo grupo do IAG/USP (Cavichia et al., 2010; Escudero et al., 2004; Escudero e Costa, 2001; de Freitas Pacheco et al., 1992). Outra parte foi selecionada de outros trabalhos da literatura como Ratag et al. (1997), Exter et al. (2004), Górny et al. (2004), Perinotto et al. (2004), Köppen et al. (1991), Samland et al. (1992), Cuisinier et al. (2000). Todos estes trabalhos estudam a mesma região de interesse deste projeto e, além disso, apresentam amostras significativas e homogeneas. Para mais detalhes sobre estes trabalhos consultar CCM10. Adicionando os dados da literatura aos dados publicados por CCM10, a presente amostra contém 140 objetos, como listados na tabela 2.1. Nesta 
tabela, as colunas indicam o número PN G (Acker et al., 1992), o nome da nebulosa, e as distâncias galactocêntricas em kpc para as escalas de SSV08 e Z95.

Tabela 2.1 - Distâncias galactocêntricas das NPs da amostra.

\begin{tabular}{|c|c|c|c|}
\hline $\mathrm{PN} \mathrm{G}$ & Nome & $\mathrm{R}_{\mathrm{SSV} 08}(\mathrm{kpc})$ & $\mathrm{R}_{\mathrm{Z} 95}(\mathrm{kpc})$ \\
\hline 000.1-01.1 & M3-43 & - & 1.81 \\
\hline $000.2-01.9$ & M2-19 & -0.30 & 0.63 \\
\hline 000.3-04.6 & M2-28 & - & -0.70 \\
\hline 000.4-02.9 & M3-19 & 0.31 & -0.73 \\
\hline $000.7-02.7$ & M2-21 & -2.20 & - \\
\hline 000.7-03.7 & M3-22 & 0.50 & -0.63 \\
\hline $000.7+03.2$ & Hen 2-250 & - & 1.07 \\
\hline 000.9-04.8 & M3-23 & 3.78 & 3.45 \\
\hline $001.0+01.9$ & K1-4 & 6.06 & - \\
\hline $001.2-03.0$ & H1-47 & - & -2.07 \\
\hline $001.2+02.1$ & Hen $2-262$ & -1.57 & 1.39 \\
\hline $001.4+05.3$ & H1-15 & -1.29 & 0.73 \\
\hline 001.7-04.6 & H1-56 & - & -3.06 \\
\hline $001.7+05.7$ & H1-14 & 1.73 & 2.24 \\
\hline $002.0-02.0^{*}$ & H1-45 & -7.12 & -0.36 \\
\hline 002.0-06.2 & M2-33 & -1.09 & -1.02 \\
\hline $002.1-02.2$ & M3-20 & 0.44 & 2.71 \\
\hline $002.1-04.2$ & H1-54 & -4.39 & -0.57 \\
\hline $002.2-02.7$ & M2-23 & 3.75 & -0.51 \\
\hline $002.2-09.4$ & Cn1-5 & 2.83 & 3.70 \\
\hline $002.4+05.8$ & NGC6369 & 6.92 & - \\
\hline 002.6-03.4 & M1-37 & - & -0.62 \\
\hline $002.6+08.1$ & H1-11 & 1.19 & 1.30 \\
\hline $002.7-04.8$ & M1-42 & 2.53 & 3.15 \\
\hline $002.7+01.6$ & $\mathrm{H} 2-20$ & - & 0.53 \\
\hline $002.8-02.2$ & Pe2-12 & - & -4.12 \\
\hline $003.1+02.9$ & $\mathrm{Hb} 4$ & 2.98 & - \\
\hline $003.1+03.4$ & H2-17 & - & -0.98 \\
\hline 003.2-06.1 & M2-36 & 2.03 & 1.29 \\
\hline 003.3-04.6 & Ap1-12 & 3.42 & - \\
\hline 003.4-04.8 & H2-43 & - & 3.03 \\
\hline 003.5-04.6 & NGC6565 & 3.37 & 3.68 \\
\hline $003.6-02.3$ & M2-26 & -0.40 & -1.46 \\
\hline 003.7-04.6 & M2-30 & -1.55 & -0.68 \\
\hline $003.8-04.3$ & H1-59 & -1.53 & -3.18 \\
\hline $003.8-04.5$ & H2-41 & -0.85 & -6.23 \\
\hline $003.8+05.3$ & $\mathrm{H} 2-15$ & -7.40 & -8.96 \\
\hline 003.9-02.3 & M1-35 & 1.93 & 3.38 \\
\hline 004.0-03.0 & M2-29 & -0.75 & -2.01 \\
\hline 004.0-05.8 & Pe1-12 & 1.66 & -2.33 \\
\hline $004.1-04.3$ & H1-60 & -2.24 & -0.82 \\
\hline $004.6+06.0$ & H1-24 & - & 0.89 \\
\hline 004.8-05.0 & M3-26 & 0.82 & -0.82 \\
\hline $004.8+02.0$ & $\mathrm{H} 2-25$ & -3.45 & -4.22 \\
\hline $004.9+04.9$ & M1-25 & 1.50 & 3.11 \\
\hline $005.0+04.4$ & H1-27 & 0.65 & -2.94 \\
\hline $005.2+05.6$ & M3-12 & - & 1.24 \\
\hline $005.5-02.5^{*}$ & M3-24 & 1.34 & - \\
\hline $005.7-05.3$ & M2-38 & 1.24 & -1.01 \\
\hline 005.8-06.1 & NGC6620 & -1.19 & 1.61 \\
\hline $005.8+05.1$ & H2-16 & 2.81 & - \\
\hline 006.0-03.6 & M2-31 & - & 3.14 \\
\hline $006.1+08.3^{*}$ & M1-20 & -1.12 & 2.34 \\
\hline 006.4-04.6* & Pe2-13 & 1.92 & - \\
\hline $006.4+02.0$ & M1-31 & 2.94 & 4.10 \\
\hline 006.8-03.4* & $\mathrm{H} 2-45$ & 1.89 & - \\
\hline $006.8+04.1$ & M3-15 & - & 3.94 \\
\hline 007.0-06.8 & VY2-1 & 0.86 & 2.57 \\
\hline $007.0+06.3^{*}$ & M1-24 & -1.00 & - \\
\hline $007.1-06.0$ & H1-66 & - & -1.70 \\
\hline $007.2+01.8^{*}$ & Hb6 & 3.78 & - \\
\hline $007.5+07.4$ & M1-22 & - & -4.02 \\
\hline 007.8-04.4 & H1-65 & - & -2.25 \\
\hline $008.0+03.9$ & NGC6445 & 6.64 & - \\
\hline
\end{tabular}


Tabela 2.1 - Continuação

\begin{tabular}{|c|c|c|c|}
\hline $\mathrm{PN}$ G & Nome & $\mathrm{R}_{\mathrm{SSV} 08}(\mathrm{kpc})$ & $\mathrm{R}_{\mathrm{Z95}}(\mathrm{kpc})$ \\
\hline $008.1-04.7$ & M2-39 & -4.02 & -2.21 \\
\hline $008.2-04.8$ & M2-42 & -1.48 & 0.66 \\
\hline $008.2+06.8^{*}$ & Hen $2-260$ & -12.23 & -3.62 \\
\hline $008.3-07.3^{*}$ & NGC6644 & 2.18 & 4.01 \\
\hline $009.0+04.1$ & Th4-5 & - & 1.69 \\
\hline $009.4-05.0$ & NGC6629 & 5.67 & - \\
\hline $009.4-09.8$ & M3-32 & 1.85 & 1.57 \\
\hline 009.6-10.6 & M3-33 & -1.45 & - \\
\hline $009.8-04.6$ & $\mathrm{H} 1-67$ & 0.64 & 0.80 \\
\hline $010.4+04.5$ & M2-17 & - & 0.85 \\
\hline 010.7-06.4 & IC4732 & 1.51 & 3.22 \\
\hline $010.7-06.7$ & Pe1-13 & -1.37 & - \\
\hline $010.7+07.4^{*}$ & $\mathrm{Sa} 2-230$ & 1.41 & - \\
\hline $010.8-01.8$ & NGC6578 & 4.42 & - \\
\hline $011.0+05.8$ & NGC6439 & 1.89 & - \\
\hline $350.5-05.0^{*}$ & H1-28 & -1.93 & - \\
\hline $350.9+04.4$ & H2-1 & 2.45 & - \\
\hline $351.1+04.8$ & M1-19 & -2.75 & 0.71 \\
\hline $351.2+05.2$ & M2-5 & - & 0.80 \\
\hline $351.6-06.2^{*}$ & $\mathrm{H} 1-37$ & -1.81 & - \\
\hline $352.0-04.6$ & H1-30 & - & 2.88 \\
\hline $352.1+05.1$ & M2-8 & -1.39 & 1.05 \\
\hline $352.6+03.0$ & H1-8 & -0.91 & - \\
\hline $353.7+06.3$ & M2-7 & 1.19 & -1.00 \\
\hline $354.2+04.3$ & M2-10 & - & -2.73 \\
\hline 355.1-02.9 & H1-31 & - & -3.78 \\
\hline $355.1-06.9$ & M3-21 & - & 2.55 \\
\hline $355.4-02.4$ & M3-14 & 2.33 & 1.58 \\
\hline $355.4-04.0$ & Hf2-1 & 1.92 & - \\
\hline $355.7-03.0$ & H1-33 & -4.05 & -1.23 \\
\hline $355.7-03.4^{*}$ & H1-35 & 2.15 & 2.03 \\
\hline 355.9-04.2 & M1-30 & - & 2.18 \\
\hline $355.9+03.6^{*}$ & H1-9 & 2.19 & - \\
\hline $356.2-04.4$ & Cn2-1 & -0.56 & 1.91 \\
\hline $356.3-06.2 *$ & M3-49 & -5.33 & - \\
\hline $356.5-02.3$ & M1-27 & 3.41 & 4.27 \\
\hline 356.5-03.9 & H1-39 & -7.28 & -2.08 \\
\hline $356.7-04.8$ & H1-41 & 2.37 & 1.51 \\
\hline $356.8-05.4^{*}$ & H2-35 & 1.86 & - \\
\hline $356.9-05.8$ & M2-24 & -1.52 & -3.86 \\
\hline $356.9+04.4$ & M3-38 & -6.07 & -0.65 \\
\hline $356.9+04.5$ & M2-11 & - & 1.08 \\
\hline $357.1-04.7$ & H1-43 & -5.33 & -3.59 \\
\hline $357.1+03.6$ & M3-7 & 1.73 & 2.62 \\
\hline $357.2-04.5$ & H1-42 & 1.94 & 3.22 \\
\hline $357.2+07.4$ & M4-3 & - & -0.37 \\
\hline $357.3+03.3$ & M3-41 & - & 3.87 \\
\hline $357.3+04.0$ & H2-7 & - & -1.32 \\
\hline $357.4-03.2$ & M2-16 & 1.05 & 2.18 \\
\hline $357.4-03.5$ & M2-18 & -7.74 & -1.48 \\
\hline $357.4-04.6$ & M2-22 & -0.79 & -1.97 \\
\hline $357.5+03.2$ & M3-42 & 1.17 & -1.78 \\
\hline $357.6+01.7$ & H1-23 & -1.74 & 1.89 \\
\hline $357.6+02.6$ & H1-18 & - & 0.72 \\
\hline 357.9-05.1 & M1-34 & - & 2.15 \\
\hline $358.2+03.5$ & H2-10 & -5.35 & -0.50 \\
\hline $358.2+03.6$ & M3-10 & -1.40 & 1.72 \\
\hline $358.2+04.2$ & M3-8 & 0.96 & 0.78 \\
\hline $358.3-02.5$ & M4-7 & 1.66 & 2.81 \\
\hline $358.3+03.0^{*}$ & H1-17 & 0.42 & -0.59 \\
\hline $358.5-04.2^{*}$ & H1-46 & -0.75 & 1.04 \\
\hline $358.6+01.8$ & M4-6 & - & 1.76 \\
\hline $358.6+07.8$ & M3-36 & - & -6.05 \\
\hline $358.7-05.2^{*}$ & H1-50 & -3.03 & 0.79 \\
\hline $358.8+03.0$ & Th3-26 & 0.66 & - \\
\hline $358.9+03.2$ & H1-20 & 0.64 & 2.91 \\
\hline $358.9+03.3^{*}$ & H1-19 & -2.95 & -0.51 \\
\hline 359.1-01.7 & M1-29 & - & 4.70 \\
\hline $359.1-02.3$ & M3-16 & 1.30 & 1.50 \\
\hline 359.3-03.1 & M3-17 & -3.60 & -1.10 \\
\hline $359.4-03.4$ & H2-33 & 0.54 & -1.78 \\
\hline
\end{tabular}


Tabela 2.1 - Continuação

\begin{tabular}{lccc}
\hline \hline PN G & Nome & $\mathrm{R}_{\text {SSV08 }}(\mathrm{kpc})$ & $\mathrm{R}_{\text {Z95 }}(\mathrm{kpc})$ \\
\hline $359.7-02.6$ & H1-40 & 0.84 & 0.36 \\
$359.8+03.7$ & Th3-25 & -6.52 & - \\
$359.8+06.9$ & M3-37 & -8.69 & -5.50 \\
$359.9-04.5$ & M2-27 & -4.45 & 2.68 \\
$359.9+05.1$ & M3-9 & 4.70 & - \\
\hline
\end{tabular}

Nem todos os objetos desta amostra apresentavam distâncias calculadas por estas escalas. Desta forma, novas distâncias foram derivadas para estes objetos e os resultados são descritos a seguir. Um asterisco marca estas novas distâncias na tabela 2.1. As distâncias galactocêntricas dos objetos localizados além do centro galáctico são listadas com um sinal negativo. A extinção nesta região é muito alta, e as incertezas nas distâncias são grandes, alcançando $30 \%$ em alguns casos. Por exemplo, um objeto com distância heliocêntrica de $8 \mathrm{kpc}$ de acordo com estas escalas pode ter a distância real entre 5.6 e 10.4 kpc. Portanto é improvável que estes objetos com distâncias negativas estejam localizados na realidade a uma distância muito além do bojo. Isto é um artefato produzido pelas incertezas nas distâncias estatísticas.

Distância é um parâmetro chave para o estudo da distribuição das abundâncias químicas na Galáxia. Como dito anteriormente, alguns dos objetos de nossa amostra não apresentam distâncias publicadas por Stanghellini et al. (2008). Sendo assim, com o objetivo de incluílos em na presente análise sobre a distribuição das abundâncias químicas na conexão bojodisco, foram calculadas novas distâncias para estes objetos. Nos casos onde o fluxo em 5 GHz não estava disponível, o fluxo equivalente a partir do fluxo $\mathrm{H} \beta$ foi calculado usando a equação (6) de Cahn et al. (1992), a qual é mostrada na equação 2.1.

$$
\log F(5 G H z)=26-16.452+\log F(H \beta)+c_{\alpha},
$$

onde coeficiente de extinção logarítmico $c_{\alpha}$ é definido como (Aller, 1984):

$$
\left[\frac{I(H \alpha)}{I_{\circ}(H \beta)}\right]_{e x p}=\left[\frac{F(H \alpha)}{F(H \beta)}\right]_{o b s} \times 10^{c_{\alpha} f(H \alpha)} .
$$

A razão de fluxos do lado esquerdo desta equação é a razão dos fluxos corrigidos pela extinção interestelar e a razão do lado direito é a dos fluxos observados.

Utilizando a definição da lei de extinção, pode-se mostrar que:

$$
c_{\alpha} f(H \alpha)=0.4 E(B-V) \times \frac{A_{H \beta}}{E(B-V)} \times\left[\frac{A_{\lambda} / E(B-V)}{A_{H_{\beta}} / E(B-V)}-1\right],
$$


com

$$
f(H \alpha)=\frac{A_{H \alpha} / E(B-V)}{A_{H \beta} / E(B-V)}-1
$$

$\mathrm{e}$

$$
c_{\alpha}=0.4 E(B-V) \times \frac{A_{H \beta}}{E(B-V)} .
$$

Considerando a lei de extinção de Fitzpatrick (1999), tem-se que $A_{H \beta} / E(B-V)=$ 3.615. Substituindo este valor na equação 2.5, obtém-se:

$$
c_{\alpha}=1.446 \times E(B-V) .
$$

Substituindo 2.6 em 2.1, obtém-se o fluxo em $5 \mathrm{GHz}$ em função do fluxo $H_{\beta}$ :

$$
\log F(5 \mathrm{GHz})=26-16.452+\log F(H \beta)+1.446 \times E(B-V) .
$$

As distâncias são calculadas a partir das equações de Stanghellini et al. (2008), a saber:

$$
\begin{gathered}
\log D_{\mathrm{SSV}}=3.06+0.37 \log \theta-0.68 \log F(5 \mathrm{GHz}), \text { se } \tau<2.1 \\
\log D_{\mathrm{SSV}}=3.79-0.6 \log \theta-0.2 \log F(5 \mathrm{GHz}), \text { se } \tau>2.1
\end{gathered}
$$

O parâmetro $\tau$ é o parâmetro de profundidade óptica, e foi calculado a partir da equação (2) de Stanghellini et al. (2008), que é mostrada na equação 2.10.

$$
\tau=\log \frac{4 \theta^{2}}{F(5 \mathrm{GHz})}
$$

Os raios angulares foram retirados da literatura, a maioria de Acker et al. (1992). Alguns trabalhos mais recentes como Tylenda et al. (2003) e Ruffle et al. (2004) também forneceram raios angulares para o cálculo das distâncias. A coluna 6 da tabela 2.2 mostra as novas distâncias obtidas para estes objetos. Nesta tabela, a coluna 1 indica o número PN G, a coluna 2 o nome, a coluna 3 o diâmetro angular, a coluna 4 o fluxo em 5 GHz, e a coluna 5 o parâmetro de profundidade óptica.

As distâncias heliocêntricas foram convertidas em distâncias galactocêntricas adotandose a distância solar ao centro da Galáxia como $R_{0}=8 \mathrm{kpc}$, como sugerido por trabalhos recentes (Gillessen et al., 2009; Nishiyama et al., 2006; Malkin, 2012).

A figura 2.1 mostra as distribuições das NPs com respeito à distância galactocêntrica para a escala de distância de SSV08 (histograma da direita) e para a escala de distância de Z95 (histograma da esquerda). A figura também mostra um ajuste gaussiano para 
Tabela 2.2 - Novas distâncias.

\begin{tabular}{lccccc}
\hline \hline PN G & Nome & $\theta(\operatorname{arcsec})$ & $\mathrm{F}(\mathrm{mJy})$ & $\tau$ & $\mathrm{d}(\mathrm{kpc})$ \\
\hline $002.0-02.0$ & H1-45 & 0.8 & 20 & 2 & 15.1 \\
$005.5-02.5$ & M3-24 & 5.1 & 4.9 & 4.3 & 6.7 \\
$006.1+08.3$ & M1-20 & 0.8 & 50 & 1.7 & 8.1 \\
$006.4-04.6$ & Pe2-13 & 6.6 & 3.4 & 4.7 & 6.2 \\
$006.8-03.4$ & H2-45 & 4.6 & 9.7 & 3.9 & 6.2 \\
$007.0+06.3$ & M1-24 & 3.2 & 6.2 & 3.8 & 8.5 \\
$007.2+01.8$ & Hb6 & 2.5 & 240 & 2 & 4.3 \\
$008.2+06.8$ & Hen 2-260 & 0.5 & 10 & 1.9 & 20.4 \\
$008.3-07.3$ & NGC6644 & 1.3 & 100 & 1.8 & 6.1 \\
$010.7+07.4$ & Sa2-230 & 5 & 4 & 4.4 & 7.1 \\
$350.5-05.0$ & H1-28 & 3.9 & 1.5 & 4.6 & 9.9 \\
$351.6-06.2$ & H1-37 & 4.3 & 1.3 & 4.7 & 9.7 \\
$355.7-03.4$ & H1-35 & 1 & 90 & 1.7 & 5.9 \\
$355.9+03.6$ & H1-9 & 3.5 & 30 & 3.2 & 5.9 \\
$356.3-06.2$ & M3-49 & 4.9 & 0.2 & 5.7 & 13.2 \\
$356.8-05.4$ & H2-35 & 5.4 & 0.9 & 5.1 & 9.1 \\
$358.3+03.0$ & H1-17 & 0.5 & 40 & 1.4 & 7.9 \\
$358.5-04.2$ & H1-46 & 0.6 & 40 & 1.5 & 8.5 \\
$358.7-05.2$ & H1-50 & 0.7 & 30 & 1.8 & 10.9 \\
$358.9+03.3$ & H1-19 & 0.7 & 30 & 1.9 & 10.9 \\
\hline
\end{tabular}

cada histograma, cuja média e o desvio padrão são, respectivamente: $(0.6 \pm 0.3) \mathrm{kpc}$ e $(2.6 \pm 0.3) \mathrm{kpc}$ para a escala de SSV08, e $(0.6 \pm 0.2) \mathrm{kpc}$ e $(2.5 \pm 0.2)$ kpc para a escala de Z95. Para ambas as escalas, a média da gaussiana é consistente com as mais recentes determinações de distância do centro galáctico, que estão próximas de 8 kpc (Gillessen et al., 2009; Nishiyama et al., 2006), enquanto que as dispersões são maiores do que a esperada para o bojo (1.2 kpc). Isto é devido ao fato de que a dispersão encontrada é a convolução da real distribuição gaussiana do bojo, com um espalhamento extra introduzido pela relação massa-raio, usada para calcular as distâncias estatísticas.

\subsection{Determinação da interface bojo-disco}

A partir desta nova escala de distâncias estatísticas para NPs pode-se recalcular os resultados para a distribuição de abundâncias químicas do bojo e do disco interno obtidos por O. Cavichia em sua dissertação de mestrado. O método desenvolvido consiste na adaptação do método de Maciel et al. (2006) para o estudo da variação temporal do gradiente de abundâncias da Via Láctea. Primeiramente uma distância galactocêntrica $R_{L}$ é escolhida, a qual define um limite para a amostra de NPs da região interna da 


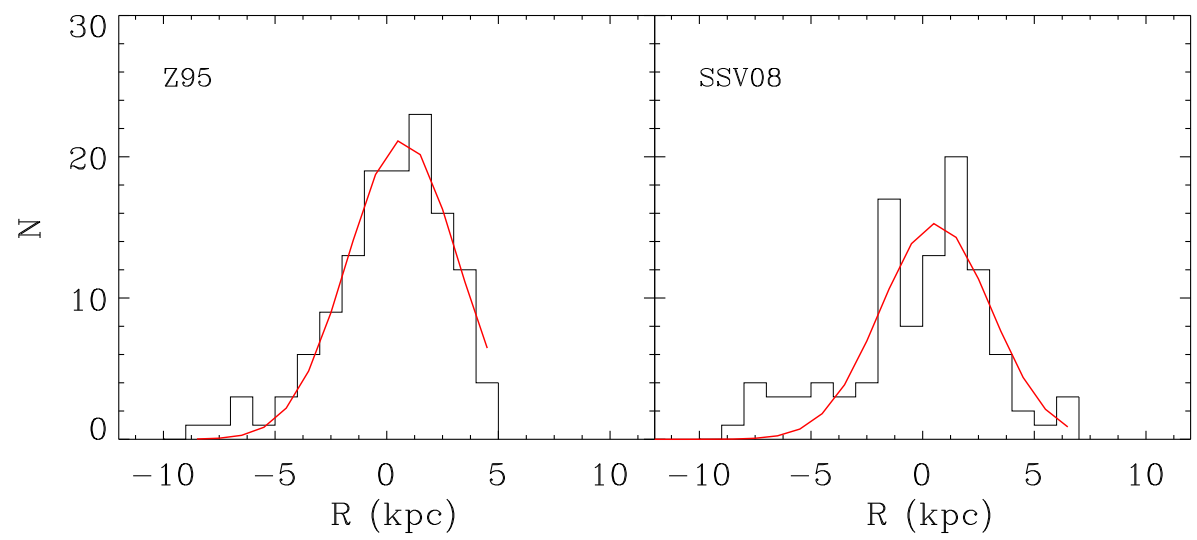

Figura 2.1: Distribuição das distâncias galactocêntricas para a escala de Z95 (esquerda) e para a escala de SSV08 (direita). Para cada histograma um ajuste gaussiano é mostrado. Ver o texto para mais detalhes.

Galáxia. Desta forma, a amostra é dividida em dois grupos: o grupo I é composto pelas NPs com distâncias galactocêntricas menores que $R_{L}$. O grupo II é composto pelas NPs com distâncias galactocêntricas maiores que $R_{L}$. Para cada grupo, a média das abundâncias e o desvio padrão da média são computados para cada elemento disponível: He, O, N, S, Ar, e Ne. Posteriormente a distância $R_{L}$ é variada, considerando-se distâncias no intervalo de 0.1 a $3.6 \mathrm{kpc}$, em passos de $0.7 \mathrm{kpc}$ para cada escala de distância estatística.

Os resultados são mostrados nas figuras 2.2 e 2.3 para as escalas de SSV08 e Z95, respectivamente. Em cada figura, o grupo I é representado por círculos preenchidos unidos por linhas contínuas e o grupo II por quadrados unidos por linhas tracejadas. Cada par de círculo/quadrado em cada gráfico representa a abundância média para aquele elemento adotando-se um dado limite para a interface bojo-disco. Portanto, cada par de pontos mostra como as diferenças entre os dois grupos evoluem em função da distância de separação $R_{L}$. Considerando os elementos mais pesados que o He, pode ser constatado que, em média, as abundâncias do grupo I são menores que as abundâncias do grupo II para ambas as escalas de distância. Isto é, na maioria dos casos os objetos do grupo I, que estão mais próximos do centro galáctico, tem abundâncias sistematicamente menores comparadas às do grupo II, para todos os valores de $R_{L}$. As principais exceções são as abundâncias de hélio para ambas as escalas, e as de argônio para a escala de Z95. Neste caso, estes elementos apresentam distribuições similares para os dois grupos. No caso do hélio, estes resultados não são uma surpresa, pois (a) este elemento é igualmente contaminado pelas estrelas progenitoras das NPs do bojo e do disco, e (b) o hélio não apresenta 
nenhum gradiente radial mensurável (Maciel, 2000), em contraste com os demais elementos considerados.
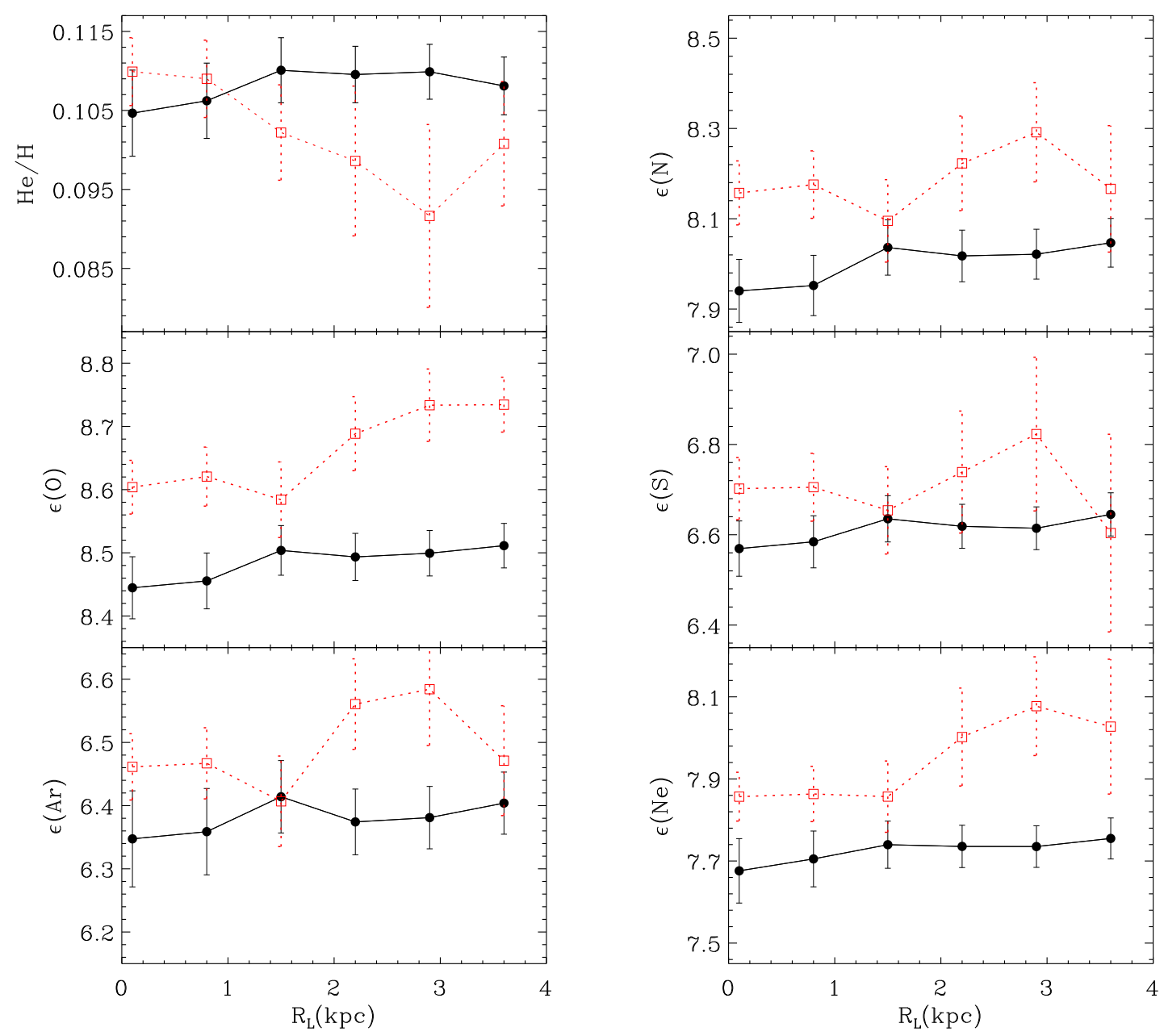

Figura 2.2: Abundâncias médias das NPs pertencentes ao grupo I (círculos ligados por linhas contínuas) e ao grupo II (quadrados ligados por linhas tracejadas) para a escala de SSV08. A abcissa fornece a distância galactocêntrica $\mathrm{R}_{\mathrm{L}}$ que divide a amostra, considerada no intervalo $0-4 \mathrm{kpc}$. As barras de erro indicam o erro padrão da média para cada subamostra.

Examinando a figura 2.2, pode-se ver que para os elementos $\alpha(\mathrm{O}, \mathrm{S}$, e Ar), as diferenças entre as duas amostras alcançam um mínimo para $1.5<R_{L}<2.5 \mathrm{kpc}$, onde ela é da ordem de 0.1 dex ou menor. Na figura 2.3, para os elementos $\alpha$ a diferença mínima ocorre para $1.5<R_{L}<2$ kpc. Para o neônio, a diferença entre as abundâncias dos dois grupos é da ordem de 0.2 dex, enquanto que para os outros elementos esta diferença é da ordem de 0.15 dex. Para o argônio esta diferença não é clara, o que é esperado já que os fatores de correção de ionização (ver seção 3.2 do próximo capítulo) usados para calcular as abundâncias deste 
elemento estão sujeitos a grandes incertezas.
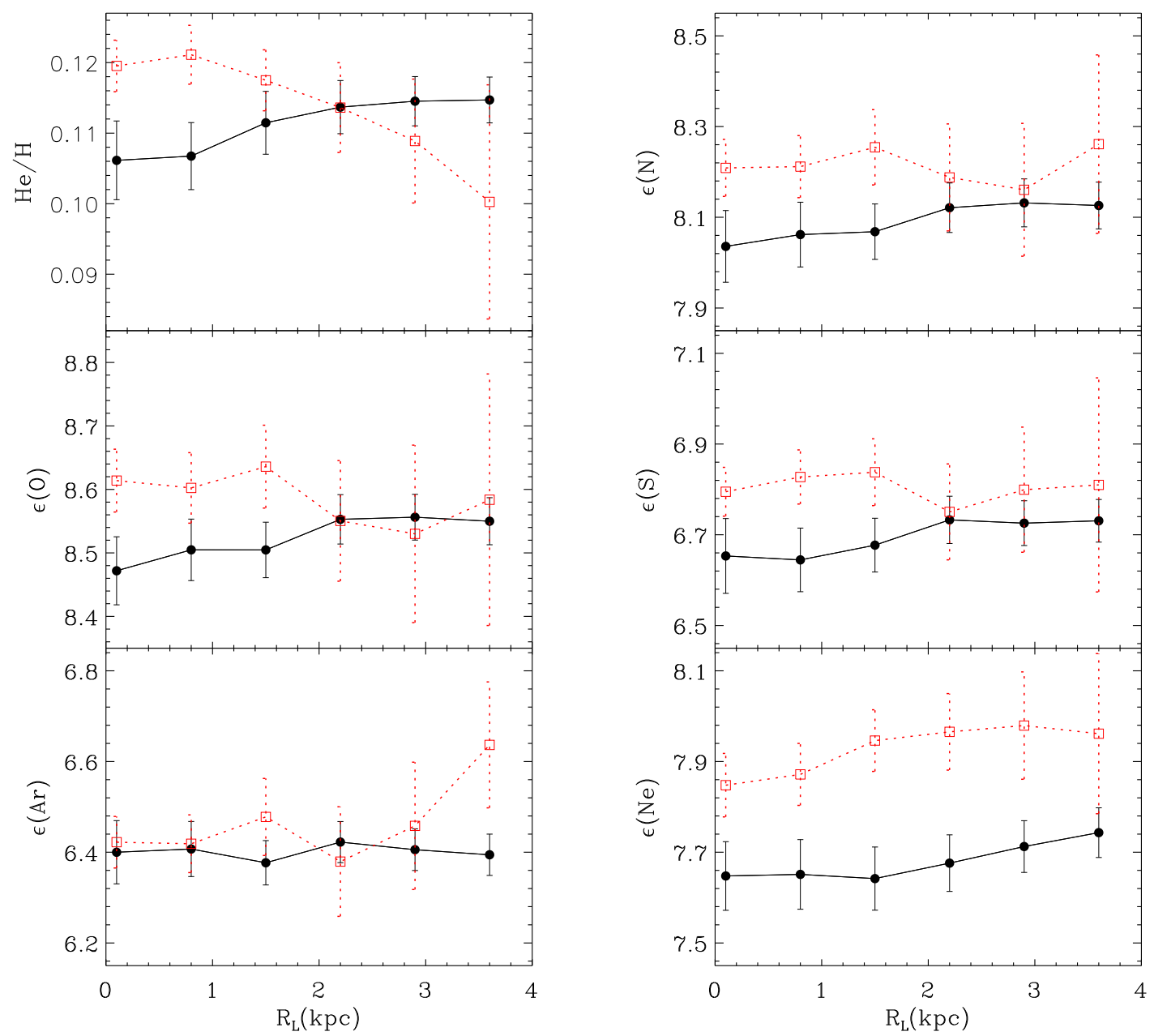

Figura 2.3: Igual a figura 2.2 para a escala de Z95.

\subsubsection{Teste Kolmogorov-Smirnov}

Pretende-se nesta seção encontrar a distância que melhor separa os dois grupos. Neste caso, será possível estabelecer um valor para a distância galactocêntrica da interface bojodisco da população de massa intermediária representada pela amostra de NPs. Com o objetivo de encontrar esta distância, foi utilizado o teste Kolmogorov-Smirnov para os grupos I e II em cada passo do procedimento descrito anteriormente. O teste retorna a probabilidade das duas populações terem sido originadas da mesma distribuição. Pequenas probabilidades mostram que a distribuição cumulativa do grupo I é significativamente diferente do grupo II. Os resultados são mostrados na figura 2.4. Para cada elemento, as 
probabilidades são mostradas em função da distância $R_{L}$. Para cada passo de distância, a barra da esquerda representa a probabilidade para a escala de SSV08 e a barra da direita a probabilidade da escala de Z95. As menores probabilidades são alcançadas para as distância de 1.5 kpc para a escala de Z95 para os elementos O, S, Ar, e Ne.

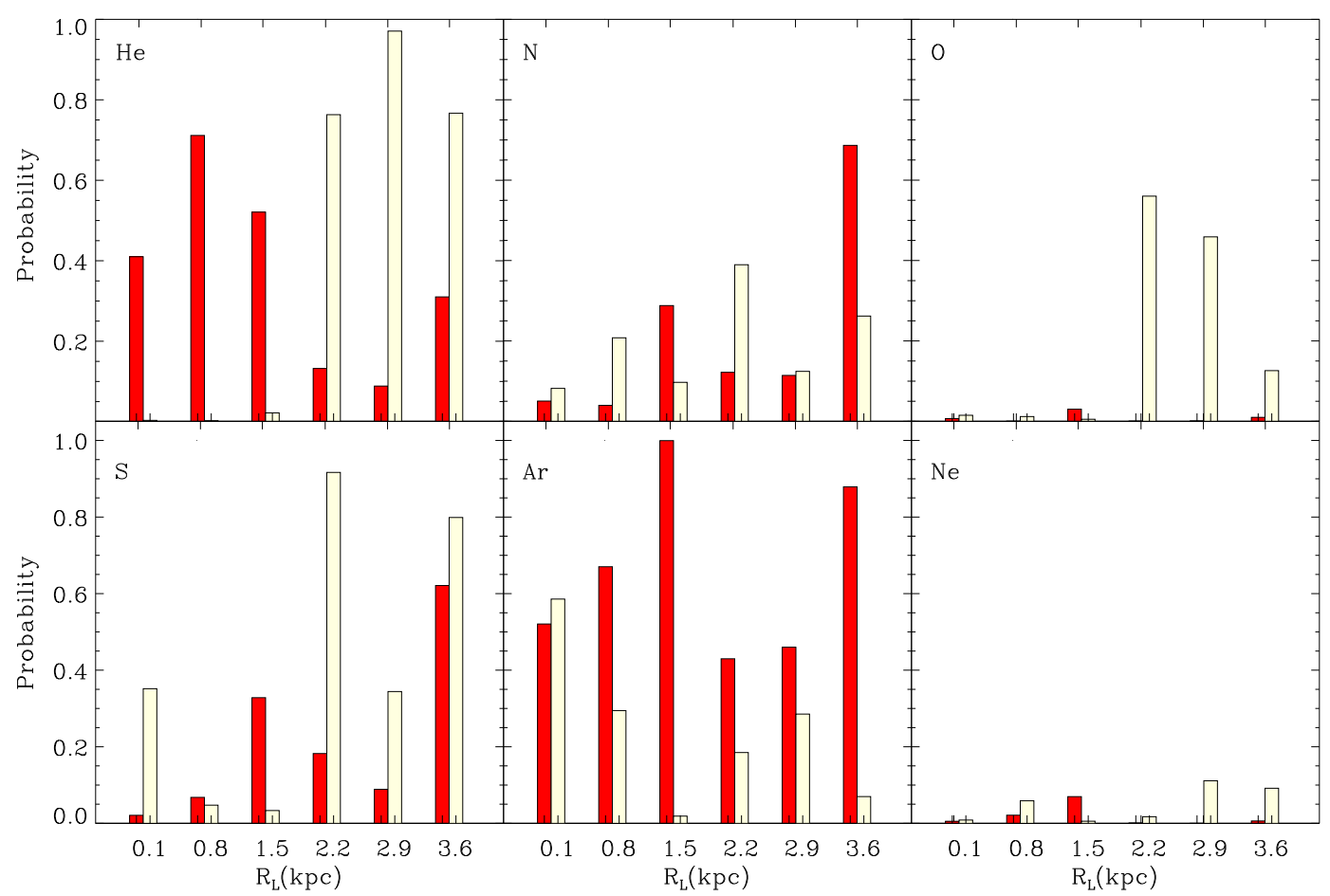

Figura 2.4: Probabilidade Kolmogorov-Smirnov para cada elemento como função da distância limite $\mathrm{R}_{\mathrm{L}}$ dos grupos I e II. Para cada distância $R_{L}$, as barras da esquerda e direita correspondem as escalas de SSV08 e Z95, respectivamente.

Tabela 2.3 - Probabilidades Kolmogorov-Smirnov.

\begin{tabular}{|c|c|c|c|c|c|c|c|c|c|c|c|c|}
\hline \multirow[b]{2}{*}{$\mathrm{R}_{\mathrm{L}}(\mathrm{kpc})$} & \multicolumn{6}{|c|}{$\mathrm{P}\left(\mathrm{R}_{\mathrm{L}}\right) \mathrm{SSV} 08$} & \multicolumn{6}{|c|}{$\mathrm{P}\left(\mathrm{R}_{\mathrm{L}}\right) \mathrm{Z} 95$} \\
\hline & 0.1 & 0.8 & 1.5 & 2.2 & 2.9 & 3.6 & 0.1 & 0.8 & 1.5 & 2.2 & 2.9 & 3.6 \\
\hline $\mathrm{He}$ & 0.574 & 0.865 & 0.379 & 0.118 & 0.080 & 0.293 & 0.003 & 0.0026 & 0.022 & 0.763 & 0.971 & 0.767 \\
\hline $\mathrm{N}$ & 0.053 & 0.075 & 0.335 & 0.103 & 0.099 & 0.647 & 0.0819 & 0.208 & 0.097 & 0.390 & 0.124 & 0.262 \\
\hline $\mathrm{O}$ & 0.014 & 0.001 & 0.058 & 0.001 & 0.001 & 0.008 & 0.015 & 0.012 & 0.0051 & 0.560 & 0.459 & 0.126 \\
\hline S & 0.022 & 0.074 & 0.370 & 0.154 & 0.077 & 0.583 & 0.352 & 0.047 & 0.0334 & 0.917 & 0.344 & 0.799 \\
\hline $\mathrm{Ar}$ & 0.720 & 0.864 & 0.989 & 0.394 & 0.508 & 0.845 & 0.586 & 0.295 & 0.0188 & 0.185 & 0.285 & 0.070 \\
\hline $\mathrm{Ne}$ & 0.014 & 0.046 & 0.128 & 0.001 & 0.000 & 0.007 & 0.009 & 0.059 & 0.0056 & 0.017 & 0.111 & 0.092 \\
\hline
\end{tabular}

As probabilidades para cada elemento são listadas na tabela 2.3 e os menores valores são listados em negrito. A partir desta tabela, é evidente que para a escala de Z95 as menores probabilidades acontecem para a distância de $1.5 \mathrm{kpc}$ para todos os elementos 
$\alpha$. Por outro lado, a escala de SSV08 não mostra apenas um único valor para as menores probabilidades. De fato, considerando apenas os elementos $\alpha$, nenhuma distância é igual. Por outro lado, examinando a figura $2.2 \mathrm{em}$ detalhe, percebe-se que existe um degrau nas distribuições radiais de abundâncias para os elementos $\alpha$ em $2.2 \mathrm{kpc}$. A partir deste resultado e da tabela 2.3, a conclusão mais segura que se pode ter é que $R_{L}<2.9 \mathrm{kpc}$ baseado na escala de SSV08.

\subsubsection{Distribuição de abundâncias}

As figuras 2.5 e 2.6 mostram as distribuições de abundâncias para as escalas de Z95 e SSV08 adotando-se as distâncias da interface bojo-disco $R_{L}$ como 1.5 e $2.2 \mathrm{kpc}$, respectivamente. Os histogramas não preenchidos representam as distribuições de abundâncias do grupo I e os histogramas preenchidos representam as dos objetos do grupo II. O número de objetos em cada grupo é mostrado em cada gráfico. Na figura 2.5 pode-se notar que a distribuição de oxigênio para o grupo I é mais larga que para o grupo II, enquanto que a maioria dos objetos do grupo II apresentam abundâncias centradas em 8.5 dex. Os outros elementos $\alpha$ também apresentam este comportamento onde o grupo I está deslocado para abundâncias menores comparadas às abundâncias do grupo II. Contudo estas diferenças não são superiores aos erros individuais nas abundâncias.

Entre os elementos $\alpha$, o neônio mostra a maior diferença entre as duas distribuições. No entanto, é preciso cautela com este resultado. Em um estudo recente, Milingo et al. (2010) encontraram algumas evidências que as abundâncias de neônio apresentam alteração durante a evolução da estrela progenitora. Esta alteração poderia ser explicada considerandose a reação de troca de carga: $\mathrm{O}^{++}+\mathrm{H}^{0} \rightarrow \mathrm{O}^{+}+\mathrm{H}^{+}$(ver Peimbert et al., 1995, e referências aí contidas). Como o ICF do neônio depende inversamente da abundância do íon $\mathrm{O}^{++}$, a reação de troca de carga poderia aumentar a abundância elemental do neônio. Se esta alteração for real, a abundância do neônio não representa a abundância do meio interestelar na época da formação da estrela progenitora. Portanto, a distribuição de neônio deve ser interpretada com cautela.

Na figura 2.6 são mostradas as distribuições de abundâncias para a escala de SSV08. A distribuição de oxigênio é mais larga para os objetos do grupo I e os valores estão entre 8.0 e 9.3 dex. O mesmo comportamento é visto que para o caso da escala de Z95: comparadas 

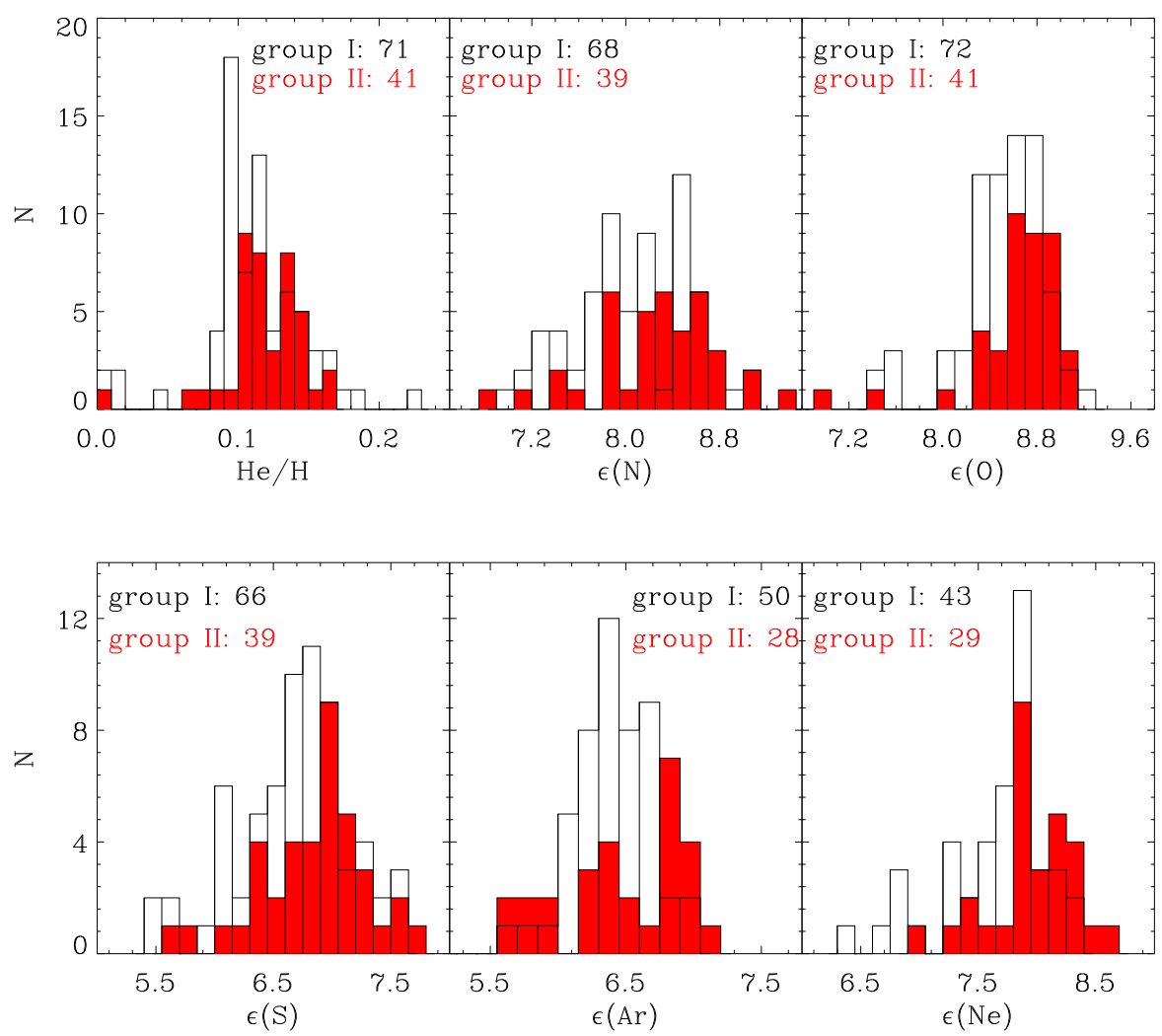

Figura 2.5: Distribuição de abundâncias para os grupos I e II utilizando a escala de Z95. O grupo I é representado pelos histogramas não preenchidos. Os histogramas preenchidos representam o grupo II. O número de objetos em cada grupo é mostrado no topo.

com os objetos do grupo I, as distribuições dos elementos $\alpha$ do grupo II mostram uma tendência para abundâncias maiores.

Tabela 2.4 - Abundâncias médias dos grupos I e II para cada escala de distância.

\begin{tabular}{|c|c|c|c|c|}
\hline \multirow[b]{2}{*}{ Elemento } & \multicolumn{2}{|c|}{ SSV08 } & \multicolumn{2}{|c|}{ Z95 } \\
\hline & Grupo I & Grupo II & Grupo I & Grupo II \\
\hline$\overline{\mathrm{He} / \mathrm{H}}$ & $0.110 \pm 0.004$ & $0.099 \pm 0.009$ & $0.111 \pm 0.004$ & $0.117 \pm 0.004$ \\
\hline$\epsilon(\mathrm{N})$ & $8.02 \pm 0.06$ & $8.22 \pm 0.10$ & $8.07 \pm 0.06$ & $8.25 \pm 0.08$ \\
\hline$\epsilon(\mathrm{O})$ & $8.49 \pm 0.04$ & $8.69 \pm 0.06$ & $8.50 \pm 0.04$ & $8.64 \pm 0.07$ \\
\hline$\epsilon(\mathrm{S})$ & $6.62 \pm 0.05$ & $6.74 \pm 0.14$ & $6.68 \pm 0.06$ & $6.84 \pm 0.07$ \\
\hline$\epsilon(\mathrm{Ar})$ & $6.37 \pm 0.05$ & $6.56 \pm 0.07$ & $6.38 \pm 0.05$ & $6.48 \pm 0.08$ \\
\hline$\epsilon(\mathrm{Ne})$ & $7.74 \pm 0.05$ & $8.00 \pm 0.12$ & $7.64 \pm 0.07$ & $7.95 \pm 0.07$ \\
\hline
\end{tabular}

A tabela 2.4 mostra as abundâncias médias e o erro padrão da média para os grupos I e II, adotando-se as distâncias de separação $R_{L}$ de 1.5 e $2.2 \mathrm{kpc}$ para as escalas de Z95 e SSV08, respectivamente. Apesar destas abundâncias serem similares, refletindo a grande dispersão de abundâncias nesta região, algumas importantes diferenças aparecem. Em 

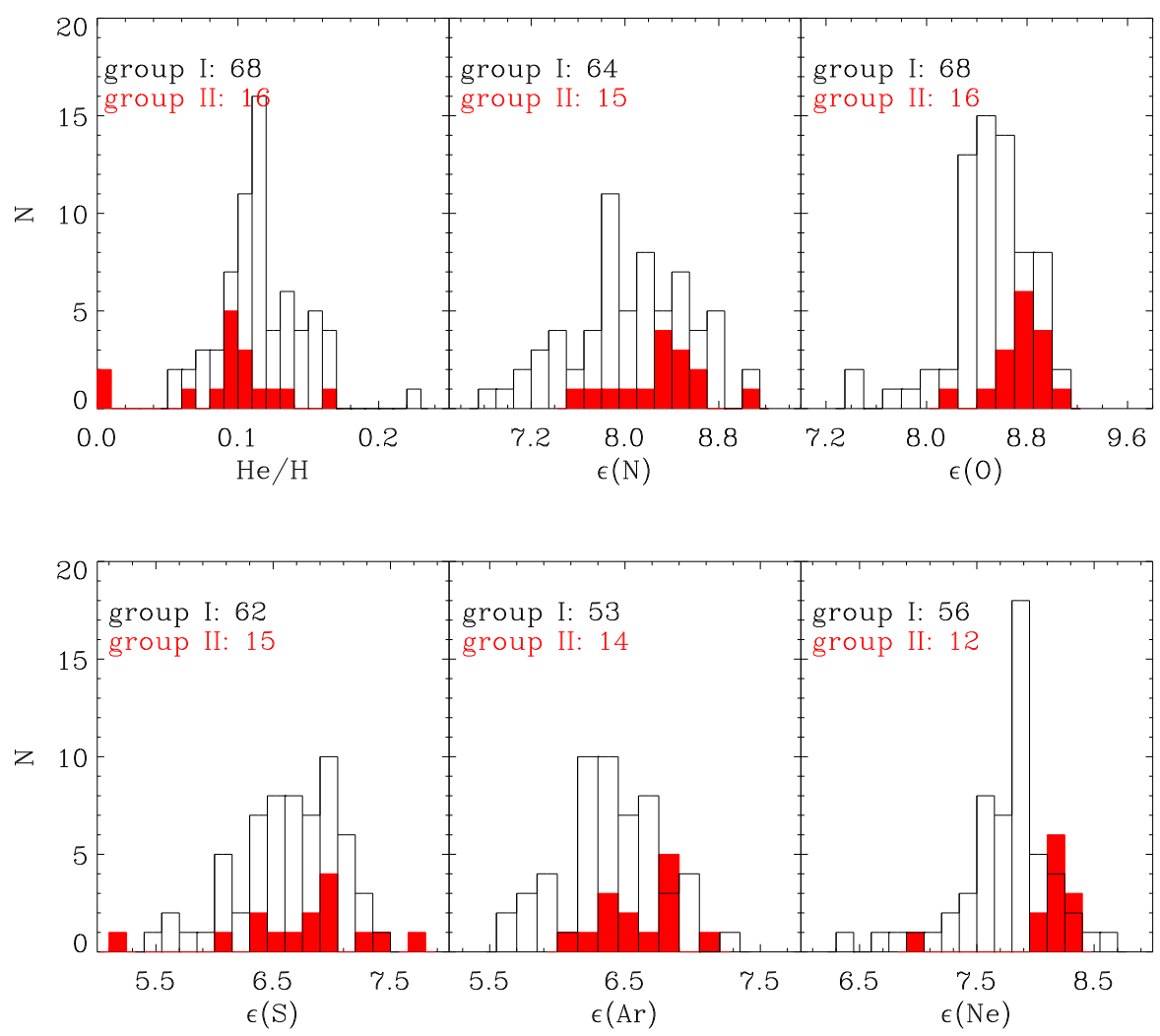

Figura 2.6: O mesmo que a figura 2.5 para a escala de SSV08.

particular, as abundâncias de N, O, S, Ar, e Ne são menores para o grupo I comparadas às do grupo II para as duas escalas de distância. Considerando a escala de SSV08, para os elementos $\mathrm{N}$ e $\mathrm{O}$, a diferença entre os dois grupos é 0.20 dex. Para S, Ar, e Ne ela é $0.12,0.19$, e 0.26 dex, respectivamente. Apesar do fato dessas diferenças não serem maiores que os erros individuais das abundâncias, pode-se obter importantes conclusões a respeito desses resultados. O erro padrão da média é pequeno uma vez que ambos os grupos apresentam um número elevado de objetos e, portanto, a diferença entre os dois grupos é estatisticamente significativa. Isto pode ser visto considerando-se os limites de confidência de $90 \%$ e $68 \%$ para cada grupo. Apesar de existirem algumas sobreposições entres as distribuições, para os elementos N, O, Ar, e Ne, as diferenças são estatisticamente significativas considerando-se o limite de confidência de $68 \%$ para cada grupo utilizando-se a escala de SSV08. Somente a distribuição de enxofre não é estatisticamente diferente considerando-se este método. Para a escala de distância de Z95, as distribuições de N, O, e S para cada grupo são significantemente diferentes considerando-se os mesmos limites 
de confidência. As distribuições de neônio são estatisticamente diferentes considerandose o limite de confidência de $90 \%$ para esta escala. Estes resultados são uma indicação importante que as NPs do bojo (grupo I) não seguem as tendências daquelas pertencentes ao disco interno (grupo II), como será discutido mais adiante.

Relaxar a hipótese adotada que os objetos com distâncias negativas pertencem ao bojo, não mudaria as principais conclusões obtidas. Foram realizados alguns testes excluindose estes objetos da amostra, sendo as principais conclusões mantidas: os objetos do bojo apresentam menores abundâncias de elementos $\alpha$ comparados aos objetos do disco interno. Adotar distâncias positivas para estes objetos faz a separação entre os grupos ser menos clara, pois a mistura entre as duas populações é aumentada. Mas, mesmo neste caso, os objetos do bojo apresentam menores abundâncias comparados aos objetos do disco interno.

As distâncias galactocêntricas de 1.5 e $2.2 \mathrm{kpc}$ para as escalas de Z95 e SSV08 marcam o limite entre os grupos I e II de tal forma que estes grupos apresentam a separação mais provável do ponto de vista das abundâncias químicas, como mostrado através do teste Kolmogorov-Smirnov. A distância de $2.2 \mathrm{kpc}$ para a escala de SSV08 foi encontrada através de uma inspeção visual na distribuição radial de abundâncias. Em ambos os casos, os objetos do grupo I apresentam menores abundâncias que os objetos do grupo II, cujas distâncias galactocêntricas são maiores que a distância limite $R_{L}$.

Dado que o bojo e o disco apresentam características químicas distintas, como por exemplo o gradiente radial de abundâncias encontrado no disco, ou o grande espalhamento de abundâncias do bojo, espera-se a existência de uma distância galactocêntrica $R_{L}$ que melhor separe estas duas populações. A análise realizada neste projeto aponta para $R_{L}=$ $1.5 \mathrm{kpc}$ para a escala de Z95 e $R_{L}<2.9 \mathrm{kpc}$ para a escala de SSV08. Portanto, através desta análise, pode-se assinalar que os objetos pertencentes ao grupo I fazem parte do bojo da Galáxia, enquanto que os objetos pertencentes ao grupo II são parte do disco interno. Discussões sobre as implicações deste resultado no entendimento da estrutura da Galáxia serão feitas nas considerações finais deste trabalho.

Os resultados deste capítulo estão publicados (Cavichia et al., 2011) e o artigo decorrente dos resultados aqui discutidos pode ser visto no apêndice desta tese. 
Capítulo 3

\section{Nebulosas planetárias na direção central da Via Láctea}

Neste capítulo, são apresentados os resultados das observações de uma amostra de nebulosas planetárias localizadas na direção central da Via Láctea. Devido ao fato das nebulosas planetárias fornecerem abundâncias com boa precisão de vários elementos que são difíceis de ser estudados em estrelas, estes resultados proverão uma visão muito mais precisa da distribuição de abundâncias do bojo da Galáxia, melhorando consideravelmente os vínculos observacionais para os modelos de evolução de estrelas de massa intermediária, bem como para os modelos de evolução química da Galáxia. Devido à sua natureza, as nebulosas planetárias têm um tempo de vida curto e, portanto, as abundâncias já derivadas apresentam um favorecimento para objetos mais brilhantes e jovens. Estes novos dados obtidos com o telescópio SOAR nos permitirão uma extensão considerável de nossa base de dados, incluindo objetos antigos do bojo e de baixo brilho superficial, que se encontram no limite inferior da função de luminosidade das nebulosas planetárias desta estrutura esferoidal.

\subsection{Observações}

\subsubsection{Configuração instrumental}

Durante este projeto, ao longo de 3 anos foram feitas observações de nebulosas planetárias localizadas na direção do centro galáctico. As observações foram realizadas nos anos de 2009, 2010, e 2011 no telescópio SOAR de 4.1 m de diâmetro, localizado em Cerro Pachón no Chile a uma altitude de 2.701 m. Em 2009 foram concedidas 13h de observação no modo fila, enquanto que as demais foram realizadas por observação remota utilizando-se a sala de observação remota do IAG/USP durante duas noites para cada ano. Em 2009 
esta sala ainda estava em fase de testes, por isto o modo fila foi utilizado. Porém este modo de observação não se mostrou adequado para os objetos deste projeto. Isto se deve ao fato de não existirem observações fotométricas ou espectrofotométricas destes objetos na literatura. Desta forma não foi possível estimar os tempos de integração para estas NPs previamente às observações. Como nesta região de observação existe uma extinção interestelar muito alta, os tempos de integração deveriam ser ajustados para que a parte azul do espectro tivesse uma razão sinal-ruído $(\mathrm{S} / \mathrm{N})$ adequada para os cálculos das abundâncias químicas. Com o modo fila isto não foi possível, e a maioria dos tempos de exposição foram subestimados. Portanto, para a execução deste projeto os tempos de integração deveriam ser estimados no momento da observação, calculando-se a razão sinal ruído $(\mathrm{S} / \mathrm{N})$ das linhas mais fracas, sobretudo a linha $[\mathrm{NII}] \lambda 5755 \AA$, que é muito importante para a determinação da temperatura eletrônica do [NII]. Isto pôde ser feito com as observações remotas em 2010 e 2011, onde os tempos de integração foram estimados para que estas linhas mais fracas atingissem $\mathrm{S} / \mathrm{N} \sim 5$.

Nestas observações, utilizou-se o espectrógrafo Goodman com redes VPH de 300 l/mm e $600 \mathrm{l} / \mathrm{mm}$ e fendas de 1.35" e 1.68". Este espectrógrafo conta com um CCD Fairchild $4 \mathrm{k} \times 4 \mathrm{k}$, o qual foi utilizado com duas configurações de binagem: 2 x 2 e 1 x 2, com uma frequência de leitura em $100 \mathrm{KHz}$. Nesta configuração, a escala do plano focal é de 0.30 " / pix e a dispersão média é $2.63 \AA$ /pix para a rede de 300 l/mm e $1.3 \AA$ /pix para a rede de $600 \mathrm{l} / \mathrm{mm}$. Com a rede de $300 \mathrm{l} / \mathrm{mm}$, o elemento de resolução para a fenda de 1.35" é 4.5 pixels ou $11.84 \AA$, e o comprimento de onda central é $6235 \AA$. Desta forma, a resolução média da observação é de $\mathrm{R}=527$. Com a rede de $600 \mathrm{l} / \mathrm{mm}$ e a mesma fenda, obtém-se uma resolução média de $\mathrm{R}=1030$. A princípio, por ter uma cobertura espectral grande (da ordem de $5370 \AA$ ) , a rede de 300 l/mm seria mais adequada para a observação dos objetos deste projeto. No entanto, a eficiência desta rede é da ordem de $30 \%$ menor do que para a rede de $600 \mathrm{l} / \mathrm{mm}$. Além disto, a rede de $300 \mathrm{l} / \mathrm{mm}$ apresenta muitas franjas de interferência na parte vermelha do espectro e um grande espalhamento de luz na região azul do espectro, como é mostrado na figura 3.1.

Combinando-se estes efeitos com a ineficiência da rede de $300 \mathrm{l} / \mathrm{mm}$, optou-se em utilizar nas observações de 2011 a rede de 600 l/mm. Os ângulos originais desta rede e da câmera tiveram que ser alterados para os valores $10.414^{\circ}$ e $21.438^{\circ}$, respectivamente. Estes 


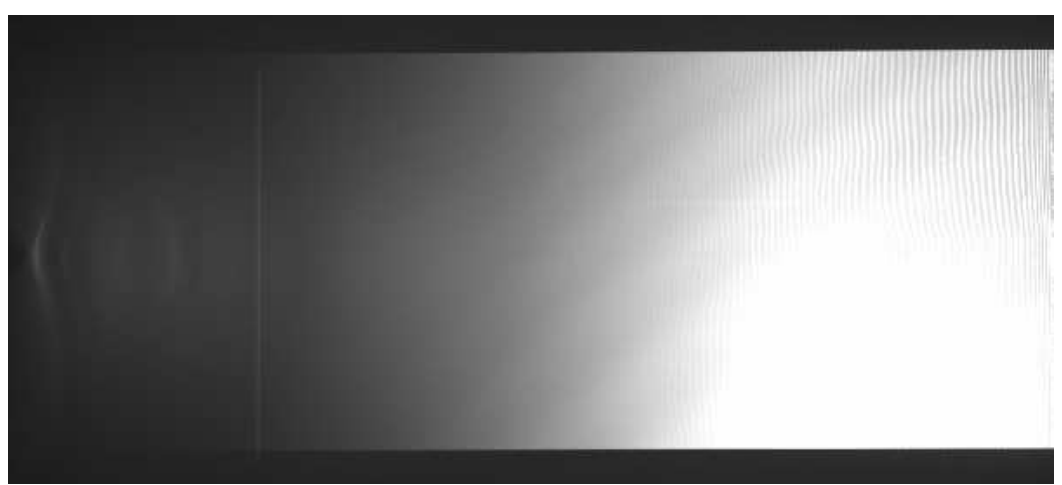

Figura 3.1: Exemplos de imagens flat-field com a rede de 300 l/mm (imagem superior) e com a rede de $600 \mathrm{l} / \mathrm{mm}$ (imagem inferior).

novos ângulos permitiram uma cobertura espectral adequada que garantiu a observação das linhas $\mathrm{H} \beta \lambda 4861 \AA$ e o par $[\mathrm{OII}] \lambda 7320+30 \AA$. A primeira é muito importante para a determinação extinção interestelar e para o cálculo das abundâncias relativas ao hidrogênio. Já o par do [OII] é importante para a determinação da abundância iônica do oxigênio $\mathrm{O}^{+}$.

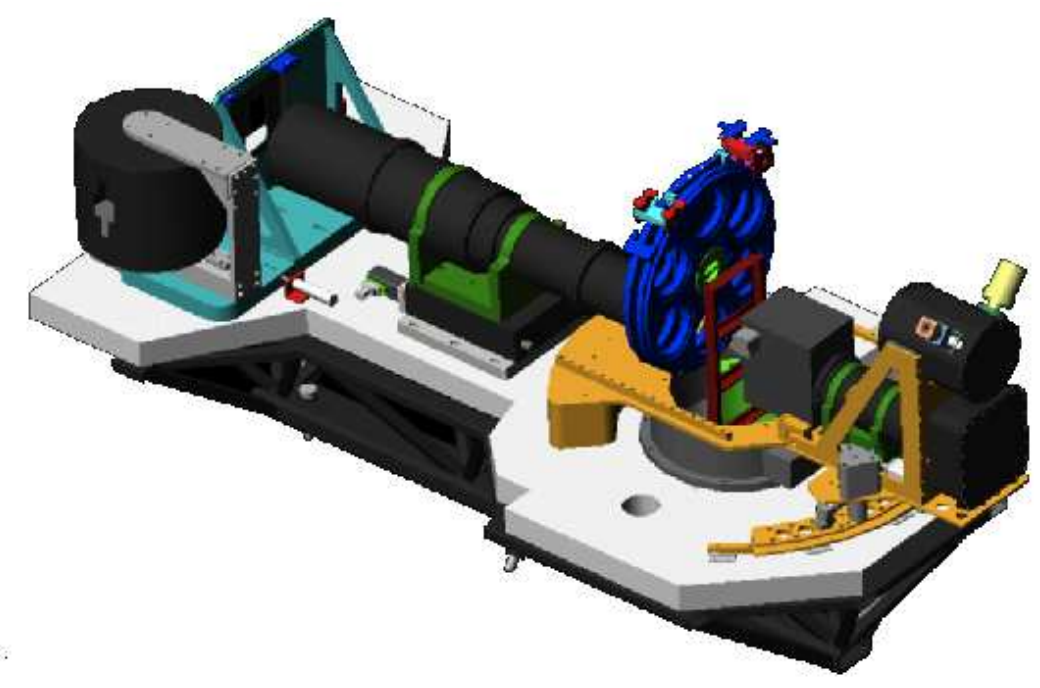

Figura 3.2: Esquema do espectrógrafo Goodman. 
Um esquema do espectrógrafo Goodman é mostrado na figura 3.2. A luz entra no espectrógrafo pela parte superior esquerda e passa pelos seguintes componentes até chegar à câmera localizada na parte inferior direita:

1. Montagem onde as fendas são trocadas (azul claro)

2. Tubo colimador (grande tubo cinza)

3. Roda de filtros (roda azul escura)

4. Rede de difração(entre a roda de filtros e o obturador, em vermelho)

5. Obturador (caixa cinza na frente da câmera óptica)

6. Câmera óptica (tubo cinza no lado direito)

A montagem amarela é um componente que gira a câmera em até 90 graus, e os compensadores de flexão são os componentes cinzas localizados perto das extremidades da câmera óptica.

\subsubsection{A amostra de nebulosas planetárias}

Os objetos foram selecionados em sua maior parte do trabalho de Jacoby e Van de Steene (2004) e alguns do catálogo MASH (Parker et al., 2006). A maioria dos objetos está na direção do centro da Galáxia com $\ell \sim 0$ e $|\mathrm{b}|<3^{\circ}$. Como mencionado anteriormente, esta região ainda é pobre em objetos com abundâncias químicas calculadas. Um dos fatores é a alta extinção interestelar nesta região. A luz precisa atravessar todo o plano do disco para que se possa observar estas NPs, desta forma há uma grande perda da luz original emitida. Além disto, as densidades de objetos, gás e poeira aumentam consideravelmente na direção do centro da Galáxia, colaborando para a extinção interestelar.

O registro das observações pode ser visto na tabela 3.1, onde a coluna 1 lista o PN G, a coluna 2 o nome de cada NP, as colunas 3 e 4 a ascensão reta e declinação, as colunas 5 e 6 as coordenadas galácticas longitude e latitude, a coluna 7 o tempo de exposição, e a coluna 8 a data de observação. Em cada noite foram observadas duas estrelas padrão espectrofométricas para a calibração em fluxo. Também foram feitas 40 imagens bias e 10 imagens flat-field com a fenda de 1.35" para as observações de 2010 e com a fenda de 1.68 " 
para as observações de 2011. Foram feitas também 10 imagens flat-field com a fenda de 10" para as estrelas padrão.

Tabela 3.1 - Log das observações realizadas com o SOAR.

\begin{tabular}{cccccccc}
\hline \hline PN G & Nome & RA (J200) & DEC (J200) & $\ell$ (graus) & b (graus) & Texp (s) & Data \\
\hline $000.1-01.2$ & JaSt 75 & 175048.01 & -292443.80 & 000.1762 & -01.2141 & 2400 & Jun 27,11 \\
$000.2+01.7$ & JaSt 19 & 173939.38 & -274722.58 & 000.28 & +01.72 & 2400 & Jun 08, 10 \\
$000.2-01.4$ & JaSt 79 & 175153.63 & -293053.41 & 000.21 & -01.47 & 2400 & Jun 08, 10 \\
$000.3+04.2$ & RPZM 21 & 173012.3 & -262101 & 000.36 & +04.27 & 2400 & Jun 07, 10 \\
-1 & JaSt 23 & 174023.32 & -274911.7 & 000.3448 & +01.5656 & 2400 & Jun 28, 11 \\
$000.4+01.1$ & JaSt 36 & 174225.20 & -275536.36 & 000.49 & +01.13 & 1800 & Jun 07, 10 \\
$000.5+01.9$ & JaSt 17 & 173931.22 & -272746.77 & 000.5453 & +01.9181 & 2400 & Jun 28, 11 \\
$000.6-01.0$ & JaSt 77 & 175111.65 & -285627.20 & 000.63 & -01.05 & 1200 & Jun 07, 10 \\
$001.0+01.3$ & JaSt 41 & 174249.96 & -272119.68 & 001.03 & +01.35 & 2400 & Jun 08, 10 \\
$001.5+01.5$ & JaSt 46 & 174330.43 & -264732.3 & 001.5836 & +01.5188 & 2400 & Jun 28, 11 \\
$001.6+01.5$ & JaSt 42 & 174317.06 & -264417.67 & 001.60 & +01.59 & 2400 & Jun 08, 10 \\
$001.7+01.3$ & JaSt 52 & 174437.30 & -264725.23 & 001.72 & +01.31 & $1 \times 3001 \times 2400$ & Jun 08, 10 \\
$004.3-01.4$ & - & 180118.9 & -255321 & 004.39 & -01.45 & 1800 & Jun 07, 10 \\
$008.8+03.8$ & PTB 13 & 175108.7 & -192547 & 008.8031 & +03.8176 & 2400 & Jun 28, 11 \\
$351.5-03.4$ & - & 173811.0 & -375341 & 351.5653 & -03.4046 & 300 & Jun 27, 11 \\
$358.4+01.7$ & JaSt 2 & 173500.96 & -292215.7 & 358.4026 & +01.7314 & 2400 & Jun 27, 11 \\
$358.5-01.7$ & JaSt 64 & 174856.04 & -310641.95 & 358.51 & -01.74 & $2 \times 900$ & Jun 07, 10 \\
$358.9-01.5$ & JaSt 65 & 174920.02 & -303605.57 & 358.99 & -01.55 & 1800 & Jun 07, 10 \\
$359.5-01.2$ & JaSt 66 & 174922.10 & -295927.00 & 359.52 & -01.24 & 2400 & Jun 08, 10 \\
$359.5-01.2$ & JaSt 66 & 174922.10 & -295927.00 & 359.52 & -01.24 & 2400 & Jun 27, 11 \\
$359.5-01.3$ & JaSt 68 & 174949.1 & -300303.00 & 359.5184 & -01.3584 & 2400 & Jun 28, 11 \\
\hline
\end{tabular}

${ }^{1}$ SSTGLMC 000.3447+01.5656

\subsection{Redução dos dados e cálculo das abundâncias (PNePack)}

Durante este projeto foi desenvolvido em colaboração com Daniel Moser (IAG/USP) um script utilizando as linguagens IRAF e Python, para a redução de dados espectrofotométricos dos telescópios LNA e SOAR. O pacote do IRAF desenvolvido recebeu o nome de PNePack e realiza a redução dos dados e calibração em comprimento de onda e fluxo (PNeReduc), extração automática ou manual dos fluxos das linhas (PNeFlux), cálculos da extinção interestelar (PNeDeredden), cálculos de parâmetros físicos e abundâncias (PNeCalc). A seguir são descritos os processos realizados por cada task do programa. 


\subsubsection{Redução dos dados: PNeReduc}

O primeiro passo na redução dos dados com o PNeReduc é criar as listas de objetos, estrelas padrão, imagens flat para os objetos, imagens flat para as estrelas padrão, imagens bias, e lâmpadas de calibração.

O PNeReduc irá corrigir os dados adquiridos pelo CCD de erros aditivos (bias) e multiplicativos (flat). Para corrigir os erros aditivos, que na verdade são originados de ruídos de leitura do CCD, tipicamente são feitas 30 exposições de tempo nulo com o obturador fechado no começo e no final da missão. Os CCDs usados são resfriados a temperaturas criogênicas $(77 \mathrm{~K})$ e, portanto, os dados não necessitam de correção de dark (corrente de escuro). Posteriormente as imagens bias são combinadas pela mediana e esta imagem combinada é então subtraída das imagens científicas.

Os erros multiplicativos podem surgir de várias fontes: diferenças de eficiência quântica pixel a pixel, diferenças de iluminação (vignetting), e imagens dos grãos de poeira que estão no espelho do telescópio. As imagens flat são obtidas com o obturador aberto e a luz captada pelo telescópio provém da luz de uma lâmpada incandescente no caso do LNA e de uma lâmpada de quartzo no caso do SOAR. Se comparadas com o fundo do céu escuro, estas lâmpadas são usualmente mais vermelhas e possuem uma componente infravermelha significativa. Isto introduz altas contagens na região vermelha do CCD se comparado à região azul. Como as imagens científicas são divididas por estas imagens normalizadas de flat, isto aumentará as contagens do lado azul do espectro e diminuirá as contagens do lado vermelho. Este efeito é corrigido com uma task do IRAF chamada boxcar, que tem como propósito suavizar os efeitos de iluminação nas imagens flat, removendo o padrão de iluminação em grande escala, porém conservando os efeitos de resposta em pequenas escalas, isto é, pixel a pixel. As imagens flat são combinadas, e o resultado é dividido por esta imagem suavizada, criando-se então uma imagem flat normalizada. Por último as imagens científicas foram divididas pela imagem flat normalizada.

Posteriormente é necessário obter o perfil espectral (imagens com uma dimensão espacial). Primeiramente é preciso encontrar o espectro na imagem. Isto é feito manualmente, examinando um corte ao longo do eixo espacial e indicando o pico apropriado com o cursor, pois, no caso das NPs estudadas neste projeto, nem sempre o espectro do objeto de interesse é o mais intenso na imagem. Em seguida define-se a janela de extração e o céu. 
Contudo, para NPs na direção do bojo, onde o campo é muito rico em objetos, a região do céu deve ser definida em pequenas faixas entre os objetos.

Pode-se assumir que o eixo espacial é exatamente ao longo das colunas, porém o espectro não será exatamente perpendicular ao eixo espacial (isto é, o espectro não é exatamente paralelo ao eixo de dispersão teórico definido), pois na maioria das vezes o acoplamento do CCD com o espectrógrafo não está alinhado para tal configuração. Além disso, o centro exato do perfil espacial mudará um pouco ao longo do eixo de dispersão conforme a posição do telescópio, devido aos desvios na estrutura óptica do telescópio, do espectrógrafo e da câmara CCD. Portanto é preciso traçar o centro do perfil espacial como função do eixo de dispersão.

Em cada ponto ao longo do eixo de dispersão, as colunas dentro da janela de extração são somadas e o céu é subtraído. Esta soma é feita utilizando-se como peso estatístico a variância, que privilegia os valores com alta razão sinal-ruído. A etapa de subtração do céu não é feita nas lâmpadas de calibração, que são lâmpadas de He-Ar para o LNA e de HgAr ou CuAr para o SOAR, utilizadas na calibração em comprimento de onda.

Cada objeto teve um espectro de lâmpada de calibração medido. Estas lâmpadas possuem o comprimento de onda das linhas de emissão tabelados, o que permite fazer uma correlação entre o comprimento de onda e o pixel correspondente. Tal correlação foi feita utilizando uma função Chebyshev de ordem entre 4 e 5. O PNeReduc utiliza a calibração anterior como referência para a próxima imagem, simplificando a etapa de identificação de linhas.

A calibração em fluxo, última etapa do PNeReduc é realizada encontrando-se a função sensibilidade do sistema como uma função do comprimento de onda, ou seja, uma correlação entre as contagens e o fluxo para cada comprimento de onda. Esta função é determinada a partir de uma média entre as funções obtidas para cada estrela-padrão. Na medição de cada objeto utiliza-se sua massa de ar para a correção da extinção atmosférica, e a função sensibilidade para a calibração final do fluxo.

\subsubsection{Extração dos fluxos: PNeFlux}

O usuário do programa tem duas opções para extrair os fluxos: manualmente ou automaticamente. Caso o espectro seja de baixo sinal-ruído, é recomendável a extração manual 
dos fluxos. Neste caso, os fluxos salvos no arquivo splot.log serão automaticamente lidos pelo programa. Se o usuário optar pela extração automática, existe na base de dados do programa uma lista de linhas emissão que será usada para a extração dos fluxos. Nesta etapa, o programa calculará a diferença de comprimento de onda do espectro observado e do espectro em repouso e se a diferença da linha encontrada pela linha de laboratório não for superior a $4 \AA$, o programa extrairá a linha identificada. São feitas 5 tentativas para o ajuste gaussiano da linha, cada vez em um nível diferente de contínuo. Em todos os casos, a linha somente será aceita se o fluxo não for nulo, e o valor da largura à meia altura $(\mathrm{FWHM})<25 \AA$ A . Se todos os fluxos forem válidos, o fluxo final será a mediana dos 5 fluxos. Caso contrário, o fluxo computado é a média dos ajustes. Se em um determinado ajuste a linha apresentar um fluxo maior ou menor que a média dos ajustes anteriores por um fator dois ou mais, este fluxo é considerado ruído e não será computado.

\subsubsection{Correção da extinção interestelar: PNeDeredden}

Os fluxos obtidos necessitam de mais uma correção: a extinção interestelar. Em uma nebulosa planetária, as densidades e temperaturas eletrônicas típicas são da ordem de 5000 partículas $/ \mathrm{cm}^{3}$ e $10000 \mathrm{~K}$, respectivamente. Para estes valores a razão $H \alpha / H \beta$ não varia significativamente com relação às flutuações de densidade e temperatura da região (Osterbrock, 1989), podendo-se adotar 2.85 como um valor típico, de acordo com a teoria de recombinação. A correção da extinção interestelar é feita aplicando-se a relação

$$
\log \left[\frac{\mathrm{F}(\lambda)}{\mathrm{F}(\mathrm{H} \beta)}\right]_{\text {teórico }}=\log \left[\frac{\mathrm{F}(\lambda)}{\mathrm{F}(\mathrm{H} \beta)}\right]_{\text {observado }}+0.4 \mathrm{E}(\mathrm{B}-\mathrm{V})\left[\frac{\mathrm{A}_{\lambda}-\mathrm{A}_{\mathrm{H} \beta}}{\mathrm{E}(\mathrm{B}-\mathrm{V})}\right] .
$$

Com esta expressão o valor do excesso de cor E(B-V) é determinado a partir das razões $\mathrm{H} \alpha / \mathrm{H} \beta$ teórica e observada, aplicando-se a curva de extinção $\left(\mathrm{A}_{\lambda}-\mathrm{A}_{\mathrm{H} \beta}\right) / \mathrm{E}(\mathrm{B}-\mathrm{V})$ dada por Fitzpatrick (1999). Esta curva de extinção é um polinômio de grau 7 da seguinte forma

$$
\begin{aligned}
{\left[\frac{\mathrm{A}_{\lambda}}{\mathrm{E}(\mathrm{B}-\mathrm{V})}\right]=} & 0.00001+0.22707 x+1.95243 x^{2}-2.67596 x^{3}+2.6507 x^{4}- \\
& -1.26812 x^{5}+0.27549 x^{6}-0.02212 x^{7}
\end{aligned}
$$

sendo $x=1 / \lambda\left[\mu \mathrm{m}^{-1}\right]$.

Portanto, substituindo a curva de extinção para cada comprimento de onda dada pela equação 3.2 na equação 3.1, pode-se corrigir os fluxos observados pela extinção interestelar. 
O programa PNeDeredden também utiliza a lei de Cardelli et al. (1989) para a correção da extinção interestelar caso o usuário deseje.

\subsubsection{Diagnóstico de plasma e cálculo das abundâncias: PNeCalc}

A densidade eletrônica pode ser determinada considerando-se dois níveis de energia $k$ e $j$, com $E_{k}>E_{j}$. O coeficiente de emissão de Einstein $A_{j k}$ exprime a probabilidade por unidade de tempo de que um átomo no estado de excitação $k$ sofra espontaneamente uma transição para o estado $j$, de menor energia, com emissão de um fóton. Portanto, o produto $n_{k} A_{k j}$ denota o número de transições espontâneas do nível $k$ para o nível $j$, por unidade de volume, por unidade de tempo. Sendo assim, para um íon com três níveis de energia 1,2 e 3 , como é o caso do $S^{+}\left({ }^{4} S_{3 / 2},{ }^{2} D_{3 / 2}\right.$ e ${ }^{2} D_{5 / 2}$, respectivamente), tendo em conta apenas colisões com elétrons, pode-se expressar a razão das intensidades emitidas nas transições $3 \rightarrow 1$ e $2 \rightarrow 1$ como

$$
\frac{I_{31}}{I_{21}}=\frac{n_{3} A_{31} E_{31}}{n_{2} A_{21} E_{21}}=\frac{g_{3} A_{31} \nu_{31}}{g_{2} A_{21} \nu_{21}}\left[\frac{1+\left(A_{21} / n_{e} \gamma_{21}\right)}{1+\left(A_{31} / n_{e} \gamma_{31}\right)}\right] e^{-E_{32} / k T_{e}},
$$

onde $E_{k j}=h \nu_{k j}$ é a energia do fóton liberado na transição.

A diferença de energia entre os níveis ${ }^{2} D_{5 / 2}$ e ${ }^{2} D_{3 / 2}$ é de aproximadamente $0.004 \mathrm{eV}$, e, para um temperatura típica de uma nebulosa planetária da ordem de $10^{4} \mathrm{~K}$, o produto $k T_{e}$ é da ordem de 0.86 eV. Portanto, o termo exponencial da equação 3.3 é aproximadamente 1 . Desta forma, esta equação depende essencialmente da densidade eletrônica e de parâmetros atômicos. Logo, conhecendo-se a razão das intensidades das linhas $6716 \AA$ e $6730 \AA$, é possível estimar a densidade eletrônica da NP.

A temperatura eletrônica é encontrada de maneira similar à densidade eletrônica, a partir das razões de linhas do [OIII] $\lambda 4959,5007 / 4363 \AA$ ou das razões de linhas do [NII] $\lambda 6548,6584 / 5754 \AA$. No caso deste projeto, as NPs estão sujeitas a uma grande extinção interestelar, e as linhas de emissão localizadas na região azul do espectro são de difícil observação. Logo, a linha do [OIII] 4363 Å, necessária para o cálculo da temperatura eletrônica do [OIII], não pôde ser observada em nenhum dos espectros coletados. Desta forma, a determinação da temperatura eletrônica foi feita apenas pelas linhas do [NII], localizadas mais para o vermelho no espectro.

No limite de baixas densidades, toda excitação colisional resultará na emissão de um fóton, e os estados superiores somente podem ser povoados por excitação colisional a partir 
do estado fundamental. Neste caso a probabilidade de transição entre os níveis $3 \rightarrow 2,3 \rightarrow 1$, $2 \rightarrow 3,2 \rightarrow 1$ através de excitação colisional é essencialmente zero.

A razão entre as intensidades das linhas $6548+6584 \AA$ e $5755 \AA$ é dada por:

$$
\frac{I_{6548}+I_{6584}}{I_{5755}}=\frac{I_{21}}{I_{32}}=\frac{n_{2} \nu_{21} A_{21}}{n_{3} \nu_{32} A_{32}} .
$$

Pode-se mostrar que existe uma relação entre o coeficiente de desexcitação colisional $\gamma_{k j}$ e a força de colisão $\Omega_{j k}$ (Maciel, 2002, p. 128) dada por:

$$
\gamma_{k j}=\frac{h^{2} \Omega_{j k}}{g_{k}\left(2 \pi m_{e}\right)^{3 / 2}\left(k T_{e}\right)^{1 / 2}}
$$

onde $g_{k}$ é o peso estatístico, $m_{e}$ a massa do elétron, e $h$ a constante de Planck.

Logo, a equação 3.4 pode ser reescrita em termos desses parâmetros:

$$
\frac{I_{6548}+I_{6584}}{I_{5755}}=\frac{\Omega_{12}}{\Omega_{13}}\left(\frac{\nu_{21}}{\nu_{32}}\right) \frac{A_{31}+A_{32}}{A_{32}} e^{E_{32} / k T_{e}} .
$$

Esta equação é valida somente para baixas densidades. No caso mais geral, para densidades mais altas, introduz-se um fator de correção para desexcitação colisional. Tal fator de correção é expressado por $\frac{A_{21}}{\gamma_{21}+A_{21}}$.

Incluindo este fator de correção na equação 3.6, encontra-se:

$$
\frac{I_{6548}+I_{6584}}{I_{5755}}=\frac{\Omega_{12}}{\Omega_{13}} \frac{A_{31}+A_{32}}{A_{32}} \frac{\nu_{21}}{\nu_{32}}\left\{\frac{A_{21}}{h^{2} \Omega_{12} /\left[g_{2}\left(2 \pi m_{e}\right)^{3 / 2}\left(k T_{e}\right)^{1 / 2}\right]+A_{21}}\right\} e^{E_{32} / k T_{e}} .
$$

Esta equação depende essencialmente de parâmetros atômicos e da temperatura e, portanto, pode ser utilizada para obter a temperatura eletrônica através da razão das intensidades das linhas do [NII]. Substituindo os valores dos parâmetros atômicos e constantes físicas, a equação 3.7 resulta em:

$$
\frac{I_{654.8}+I_{658.3}}{I_{575.5}}=\frac{6.91 \times e^{2.50 \times 10^{4} / T_{e}}}{1+2.5 \times 10^{-3} n_{e} / T_{e}^{1 / 2}} .
$$

O cálculo dos parâmetros físicos é realizado através da sub-rotina temden, provida pelo pacote externo STSDAS do IRAF. Esta sub-rotina deriva a temperatura eletrônica $T_{e}$ dada uma densidade eletrônica $n_{e}$, ou $n_{e}$ dado $T_{e}$, de um gás nebular ionizado através da aproximação de N-níveis. O método utilizado pelo PNeCalc é iterativo: primeiramente é assumido $T_{e}=10000 \mathrm{~K}$. Então a densidade eletrônica do [SII] é calculada para esta temperatura. Em seguida, calcula-se $T_{e}$ para a densidade encontrada, ou assume-se 
$n_{e}=5000 \mathrm{~cm}^{-3}$. O método é repetido até que a razão entre a temperatura atual e a anterior $\left(T_{1} / T_{2}\right)$ seja: $T_{1} / T_{2}<0.9999$ ou $T_{1} / T_{2}>1.0001$. Os limites de temperatura para o programa são: $6000<T_{e}<20000$.

O PNeCalc utiliza o método empírico para o cálculo das abundâncias, onde se calculam as abundâncias iônicas das espécies presentes no espectro através de um modelo atômico simples e a seguir estimam-se as abundâncias elementais correspondentes com a aplicação de Fatores de Correção de Ionização (ICFs) para levar-se em conta os íons não observados. Com este método obtém-se um tratamento homogêneo de conjuntos grandes de objetos com resultados satisfatórios, como pode ser visto, por exemplo, em Costa et al. (2004), Escudero et al. (2004), e Cavichia et al. (2010).

As abundâncias iônicas relativas ao $\mathrm{H}^{+}$podem ser calculadas a partir da razão da intensidade das linhas proibidas observadas relativas à emissividade $\mathrm{H} \beta$. O programa PNeCalc utiliza a sub-rotina do IRAF ionic para o cálculo das abundâncias iônicas dos elementos oxigênio, nitrogênio, enxofre, argônio, e neônio. A utilização desta sub-rotina está vinculada ao pacote nebular do STSDAS. Por este motivo, é necessário que este pacote esteja atualizado com os parâmetros atômicos mais recentes. A última versão deste pacote até o momento da redação desta tese é a 3.14 (Agosto de 2011).

Para o cálculo das abundâncias iônicas do hélio a sub-rotina PNeCalc utiliza as mais recentes emissividades do HeI de Porter et al. (2005). A abundância ionica $X_{i}$ de um íon $i$ está relacionada com a intensidade de sua linha por:

$$
\frac{n\left(X_{i}\right)}{n\left(\mathrm{H}^{+}\right)}=\frac{I_{\lambda}}{I_{\lambda 4861}} \times \frac{j_{\lambda 4861}^{*}}{j_{\lambda}^{*}}
$$

sendo que $j^{*}$ é a emissividade por unidade de densidade do íon e por unidade de densidade do elétron. Esta emissividade está relacionada com a verdadeira emissividade volumétrica por:

$$
j_{\lambda}^{*}=\frac{4 \pi j_{\lambda}}{n_{e} n_{\text {ion }}} .
$$

Porter e Ferland (2007) fornecem parametrizações convenientes para as emissividades do HeI. Estas emissividades são funções da temperatura dadas por:

$$
\frac{4 \pi j_{\lambda}}{n_{e} n_{\mathrm{He}^{+}}}=\left[a+b\left(\ln T_{e}\right)^{2}+c \ln T_{e}+\frac{d}{\ln T_{e}}\right] T_{e}^{-1} \times 10^{-25} \mathrm{ergs} \mathrm{cm}^{3} \mathrm{~s}^{-1} .
$$

A tabela 3.2 mostra os parâmetros $a, b, c$, e $d$ para cada linha do HeI considerada. 
Tabela 3.2 - Coeficientes para a parametrização das emissividades do HeI.

\begin{tabular}{ccccc}
\hline \hline$\lambda(\AA)$ & $a \times 10^{5}$ & $b \times 10^{2}$ & $c \times 10^{3}$ & $d \times 10^{5}$ \\
\hline 4471 & -0.35209 & -4.5168 & 8.536 & 0.091635 \\
5876 & 2.062 & 1.7479 & -13.548 & -7.3492 \\
6678 & 0.67315 & 0.75157 & -4.7101 & -2.3610 \\
\hline
\end{tabular}

Os parâmetros da tabela 3.2 introduzem novos erros que são desprezíveis, e reproduzem as predições do código de fotoionização CLOUDY (Ferland et al., 1998) com desvios da ordem de $0.03 \%$ para $5000<T_{e}(\mathrm{~K})<25000$. Contudo, o cálculo das abundâncias do HeI requer a emissividade da linha $\mathrm{H} \beta$. Aver et al. (2010) publicam a emissividade $\mathrm{H} \beta$ em termos de uma parametrização cedida por Porter e Ferland (2007) através de comunicações privadas. A parametrização é dada por:

$$
\frac{4 \pi j_{\lambda 4861}}{n_{e} n_{\mathrm{H}^{+}}}=\left[-2.6584 \times 10^{5}-1420.9\left(\ln T_{e}\right)^{2}+35546 \ln T_{e}+\frac{6.5669 \times 10^{5}}{\ln T_{e}}\right] T_{e}^{-1} .
$$

As abundâncias iônicas do HeI foram corrigidas por efeitos colisionais a partir dos termos de correção de Porter e Ferland (2007), os quais são calculados de maneira similar a Kingdon e Ferland (1995). Esta correção colisional é calculada como:

$$
\frac{C}{R}=\left(1+\frac{3552 t_{4}^{-0.55}}{n_{e}}\right)^{-1} \sum_{i} a_{i} t_{4}^{b_{i}} \exp \left(\frac{c_{i}}{t_{4}}\right),
$$

onde $t_{4}=T_{e} / 10000$, e os coeficientes $a_{i}, b_{i}$, e $c_{i}$ são mostrados na tabela 3.3.

Deste modo, a abundância iônica final do hélio é calculada da seguinte forma:

$$
\frac{n\left(X_{i}\right)}{n\left(H^{+}\right)}=\frac{I_{\lambda}}{I_{\lambda 4861}} \times \frac{j_{\lambda 4861}^{*}}{j_{\lambda}^{*}} \times\left(1+\frac{C}{R}\right)^{-1} .
$$

A emissividade do HeII $\lambda 4686$ foi retirada de Osterbrock e Ferland (2006). Os autores não fornecem uma parametrização para a emissividade, mas apenas valores tabelados. A figura 3.3 mostra a razão entre as emissividades $\mathrm{H} \beta$ e HeII em função da temperatura para três valores de densidades. Pode-se notar que para o intervalo de densidade entre $10^{3}$ e $10^{4}$ esperado para NPs, a razão entre as emissividades não depende fortemente da densidade.

Portanto, como uma primeira aproximação, adotou-se os valores para a emissividade do HeII de Osterbrock e Ferland (2006) com uma densidade constante de $10^{4}$. Para estes 
Tabela 3.3 - Coeficientes para a correção colisional do HeI.

\begin{tabular}{ccccc}
\hline \hline$\lambda(\AA)$ & $i$ & $a_{i}$ & $b_{i}$ & $c_{i}$ \\
\hline 4471 & 1 & 4.4397 & -0.2954 & -4.5449 \\
& 2 & 0.1341 & -0.7331 & -4.8839 \\
& 3 & 0.7546 & -0.5041 & -4.9012 \\
5876 & 1 & 6.7937 & -0.1116 & -3.7761 \\
& 2 & 0.1808 & -0.8306 & -4.5122 \\
& 3 & 1.3478 & -0.4017 & -4.5459 \\
& 4 & 0.4792 & -0.4062 & -4.9012 \\
6678 & 1 & 0.4340 & -0.7808 & -3.7766 \\
& 2 & 0.1942 & -0.7687 & -4.5459 \\
& 3 & 0.1263 & -1.1108 & -4.9012 \\
& 4 & 0.0549 & 1.8948 & -4.9013 \\
& 5 & 0.0785 & 2.0453 & -5.0942 \\
& 6 & 0.0935 & 2.0461 & -5.0942 \\
\hline
\end{tabular}

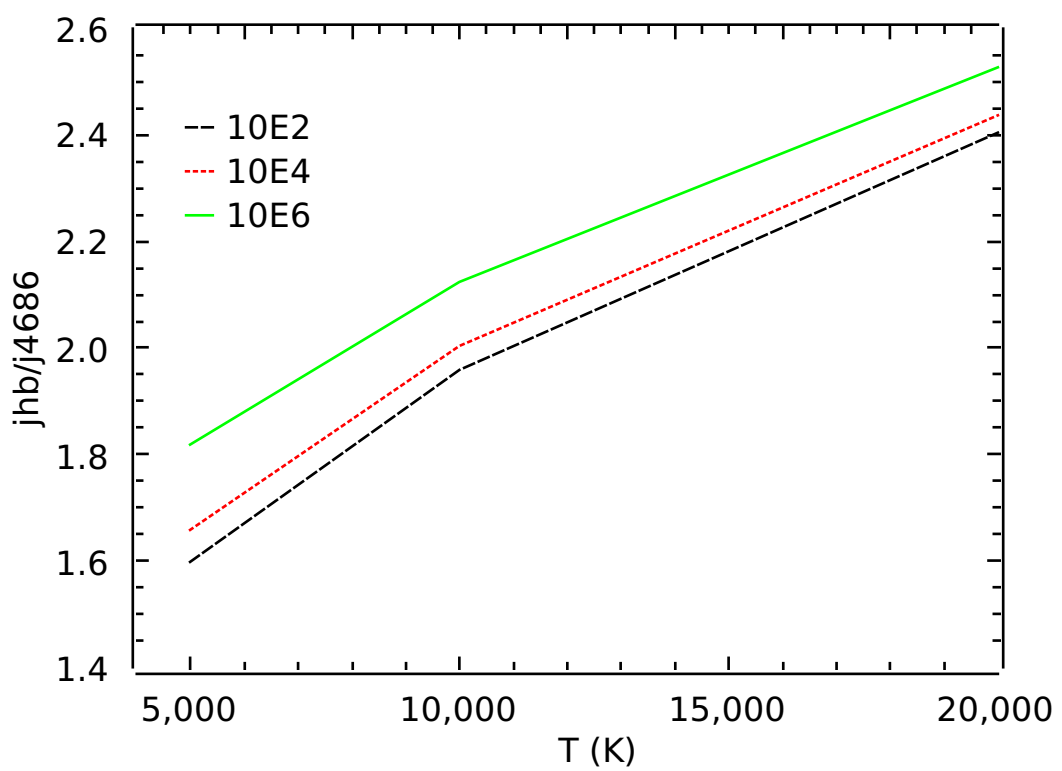

Figura 3.3: Razão entre as emissividades $\mathrm{H} \beta$ e HeII $\lambda 4686 \AA$ em função da temperatura para três densidades diferentes.

valores de emissividade ajustou-se um polinômio de grau 2 como é mostrado na figura 3.4. Os resultados do ajuste polinomial são mostrados na equação 3.15.

$$
\frac{j(\mathrm{H} \beta)}{j(\mathrm{HeII})}=5.1340-5.062 \times 10^{-4} T_{e}+1.4280 \times 10^{-8} T_{e}^{2}
$$




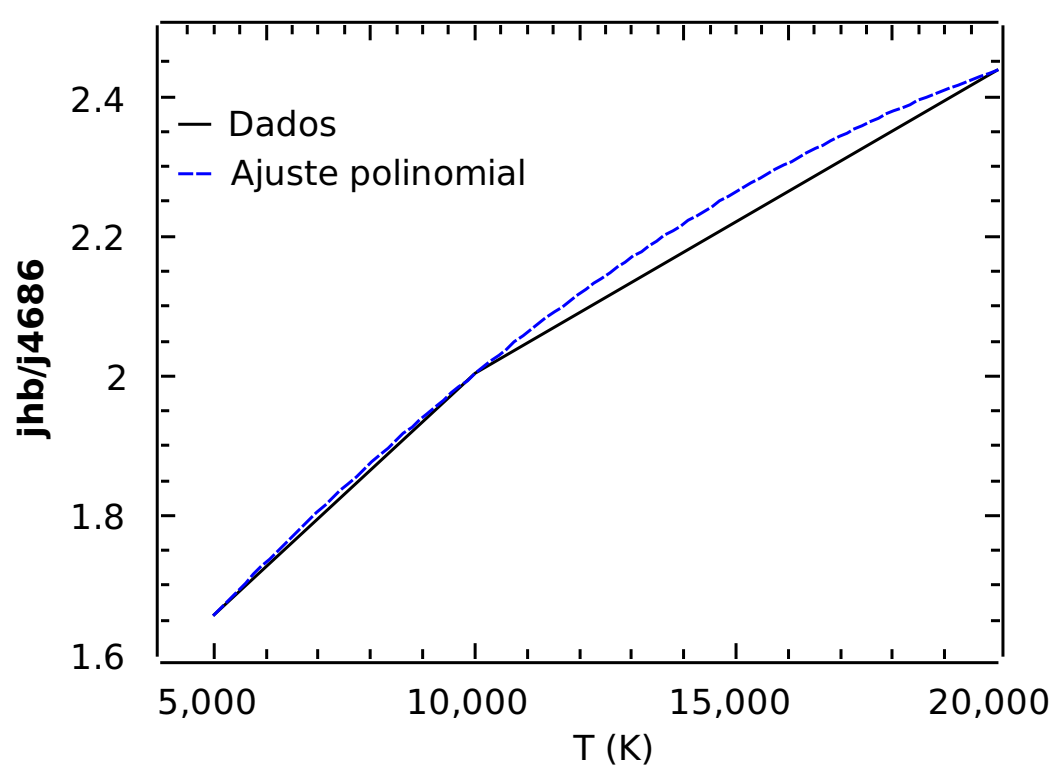

Figura 3.4: Razão entre as emissividades $\mathrm{H} \beta$ e HeII $\lambda 4686 \AA$ em função da temperatura para uma densidade constante $n_{e}=10^{4} \mathrm{~cm}^{-3}$. A linha tracejada é um ajuste polinomial de grau 2 .

As abundâncias elementais foram calculadas a partir dos ICFs obtidos por Kingsburgh e Barlow (1994). Os ICFs para estas abundâncias dependem da abundância do hélio. Como nos cálculos das abundâncias de HeI e HeII são usadas as mais recentes e precisas emissividades para estes íons, estamos também aumentando a precisão das abundâncias elementais de N, O, Ar, S, e Ne. Os ICFs obtidos por Kingsburgh e Barlow (1994) são usados para encontrar as abundâncias elementais a partir das abundâncias iônicas previamente determinadas.

Para o caso do hélio em particular, tem-se a determinação do $\mathrm{He}^{+}$e $\mathrm{He}^{++}$. De acordo com os critérios definidos por Torres-Peimbert e Peimbert (1977), não há contribuição substancial do hélio neutro na abundância total do hélio quando $\log \left(\mathrm{O}^{+} / \mathrm{O}\right)<-0.4$. Neste caso, a abundância total do hélio pode ser escrita como:

$$
\frac{\mathrm{He}}{\mathrm{H}}=\frac{\mathrm{He}^{+}}{\mathrm{H}^{+}}+\frac{\mathrm{He}^{++}}{\mathrm{H}^{+}} .
$$

A abundância total do oxigênio pode ser determinada a partir da soma das abundâncias dos íons $\mathrm{O}^{+}$e $\mathrm{O}^{++}$corrigida pela razão entre a abundância de $\mathrm{He}$ com $\mathrm{He}^{+}$:

$$
\frac{\mathrm{O}}{\mathrm{H}}=\left(\frac{\mathrm{O}^{++}}{\mathrm{H}^{+}}+\frac{\mathrm{O}^{+}}{\mathrm{H}^{+}}\right) \frac{\mathrm{He}}{\mathrm{He}^{+}}
$$

O cálculo da abundância química total do nitrogênio é feito a partir das similaridades 
entre os potenciais de ionização do nitrogênio e o oxigênio:

$$
\frac{\mathrm{N}}{\mathrm{H}}=\frac{\mathrm{N}^{+}}{\mathrm{H}^{+}} \frac{\mathrm{O}}{\mathrm{O}^{+}}
$$

A abundância química do enxofre depende das abundâncias iônica e elemental do oxigênio é obtida de:

$$
\frac{\mathrm{S}}{\mathrm{H}}=\left(\frac{\mathrm{S}^{++}}{\mathrm{H}^{+}}+\frac{\mathrm{S}^{+}}{\mathrm{H}^{+}}\right)\left(1-\left(1-\frac{\mathrm{O}^{+}}{\mathrm{O}}\right)^{3}\right)^{-1 / 3}
$$

O argônio, juntamente com o enxofre, é um dos elementos com menor precisão na determinação dos dados. Sua determinação em nebulosas planetárias é feita a partir de uma única linha $\left(\mathrm{Ar}^{++}\right)$:

$$
\frac{\mathrm{Ar}}{\mathrm{H}}=1.34 \times \frac{\mathrm{Ar}^{++}}{\mathrm{H}^{+}} \frac{\mathrm{O}}{\mathrm{O}^{++}}
$$

O fator de correção para o neônio é baseado na semelhança entre o potencial de ionização do oxigênio, e é um dos menos estudados e determinados na literatura. Sua expressão é:

$$
\frac{\mathrm{Ne}}{\mathrm{H}}=\frac{\mathrm{Ne}^{++}}{\mathrm{H}^{+}} \frac{\mathrm{O}}{\mathrm{O}^{++}}
$$

Recentemente, Henry et al. (2012) discutiram o problema da "anomalia do enxofre". Esta anomalia foi identificada pela primeira vez por Henry et al. (2004), e consiste no fato das abundâncias de enxofre observadas em NPs galácticas serem sistematicamente menores que as observadas em regiões HII de metalicidades equivalentes, onde as metalicidades são calibradas pelas abundâncias de oxigênio. Pottasch e Bernard-Salas (2006), BernardSalas (2006) e Shaw et al. (2010) mostraram que a observação direta da linha do íon $\mathrm{S}^{+3}$ localizada no infravermelho próximo ameniza, porém não resolve este problema. Como argumentam Henry et al. (2012), isto sugere que os estágios de maior ionização que $\mathrm{S}^{+3}$, não levados em conta no ICF do enxofre, têm um importante papel na determinação de sua abundância elemental. Portanto, as abundâncias de enxofre devem ser analisadas cautelosamente, sobretudo em análises onde os valores absolutos são importantes.

\subsection{Resultados}

As NPs observadas apresentam uma alta extinção interestelar como se pode ver através do excesso de cor $(\mathrm{E}(\mathrm{B}-\mathrm{V}))$ na tabela 3.4. Em sua maioria, elas apresentam uma extinção 
de 7 magnitudes, mas em alguns casos a extinção no visível pode chegar a 10 magnitudes. Esta alta extinção é refletida nos espectros observados. Nenhum objeto apresenta linhas de emissão para comprimentos de onda menores que $\mathrm{H} \beta$ ( $\lambda 4861)$. Isto pode ser visto na figura 3.5, onde é mostrado um exemplo de um espectro observado com o SOAR. Nesta figura é mostrada o espectro da NP JaSt 42, uma NP localizada na direção do centro da Galáxia com uma extinção de 7 magnitudes no visível.

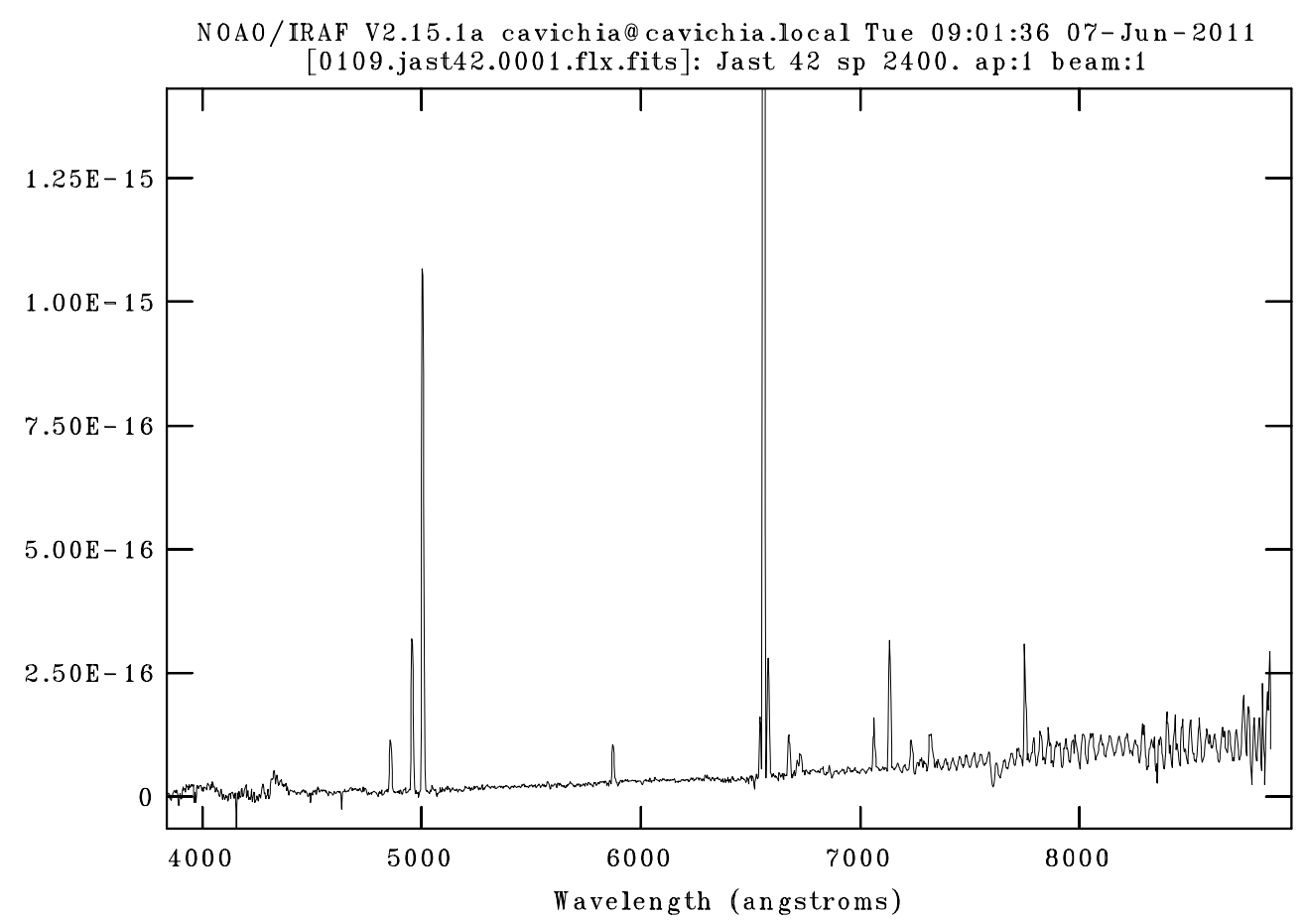

Figura 3.5: Espectro da Nebulosa Planetária JaSt 42 observada com o SOAR. A linha $\mathrm{H} \alpha(\lambda 6563 \AA)$ não é mostrada na escala do gráfico para uma melhor visualização do espectro. O tempo de integração é de 2400 s.

A extinção interestelar associada ao grande número de objetos na direção do centro da Galáxia fazem da identificação e observação das NPs nesta região um grande desafio. Na figura 3.6 é mostrada uma imagem do campo da NP JaSt 42 onde é destaca a posição da NP com uma seta.

A extinção interestelar foi calculada utilizando-se a curva de extinção de Fitzpatrick (1999), assumindo o caso B da teoria de recombinação (Osterbrock, 1989). Neste caso, a razão $\mathrm{H} \alpha / \mathrm{H} \beta$ não varia muito para as temperaturas e densidades típicas encontradas em NPs, e pode ser adotada como sendo 2.85. A correção da extinção foi realizada com o 


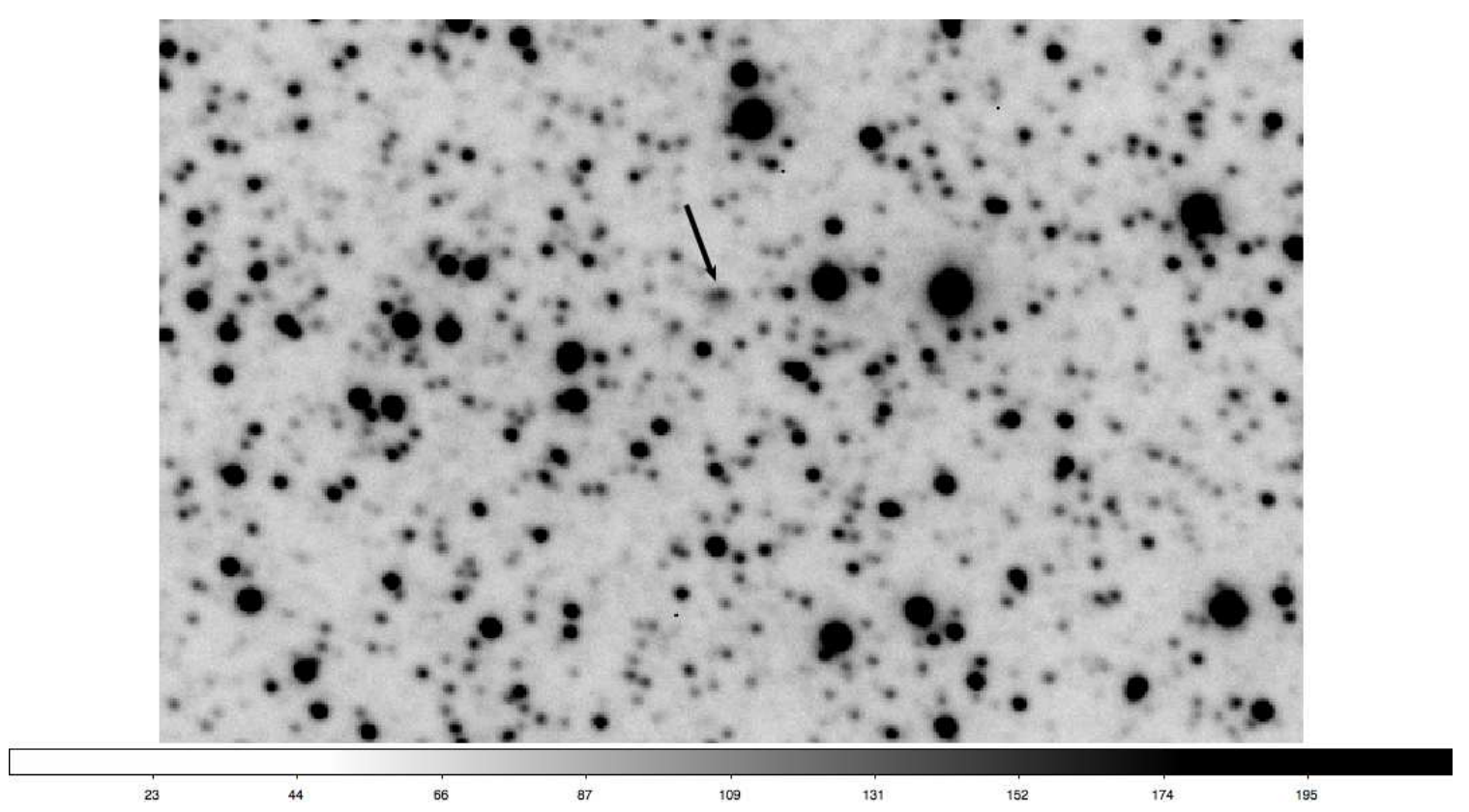

Figura 3.6: Campo da Nebulosa Planetária JaSt 42 observada com o SOAR. A posição da NP é identificada pela seta verde. O tempo de integração é de $10 \mathrm{~s}$.

programa PNePack, com a sub-rotina PNeDeredden, como descrito anteriormente.

O cálculo dos parâmetros físicos densidade e temperatura eletrônicas foi realizado com o pacote PNePack descrito anteriormente. Esta sub-rotina deriva a temperatura eletrônica $\mathrm{T}_{e}$ dada uma densidade eletrônica $\mathrm{n}_{e}$, ou $\mathrm{n}_{e}$ dado $\mathrm{T}_{e}$, de um gás nebular ionizado através da aproximação de N-níveis. Para isto, o programa necessita da razão das linhas de diagnóstico. A densidade eletrônica pode ser calculada a partir da razão de linhas do $[\operatorname{ArIV}] \mathrm{I}(\lambda 4711) / \mathrm{I}(\lambda 4740)$, ou do $[\mathrm{SII}] \mathrm{I}(\lambda 6716) / \mathrm{I}(\lambda 6731)$.

Já a temperatura eletrônica pode ser calculada a partir da razão de linhas do [NII] $\mathrm{I}(\lambda 6548+6583) / \mathrm{I}(\lambda 5755),[\mathrm{OIII}] \mathrm{I}(\lambda 4959+5007) / \mathrm{I}(\lambda 4363)$, ou $[\mathrm{OI}] \mathrm{I}(\lambda 6300+6363) / \mathrm{I}(\lambda 5577)$. Contudo, devido à alta extinção, as linhas do oxigênio 4363 e $5577 \AA$ não são visíveis nos espectros das NPs observadas. Isto inviabiliza a obtenção da temperatura eletrônica a partir das linhas do [OI] e [OIII], restando apenas as linhas do [NII]. Portanto, nos casos que a linha do [NII] $\lambda 5755$ A é visível, pode-se obter a temperatura eletrônica e calcular as abundâncias a partir da mesma. Porém, em alguns casos esta linha não é observada, pois apresenta baixo sinal-ruído. Nestes casos, são apresentados três métodos distintos para o cálculo das abundâncias:

1) utilização de uma temperatura de $10^{4} \mathrm{~K}$; 
2) utilização do limite do $\mathrm{S} / \mathrm{N}$ dos espectros como estimativa do fluxos da linha [NII] $\lambda 5755 \AA$.

3) utilização do método estatístico de obtenção de abundâncias em nebulosas.

A seguir são apresentados detalhadamente cada método utilizado.

Como mencionado anteriormente, o método 1 consiste na utilização de uma temperatura eletrônica de $10^{4} \mathrm{~K}$, a qual é um valor típico para NPs (Osterbrock, 1989). O ponto fraco deste método é que a abundância do oxigênio depende fortemente da temperatura. Uma variação na temperatura de $10^{3} \mathrm{~K}$ provoca uma variação de até 0.2 dex na abundância do oxigênio. As abundâncias de enxofre, argônio, e neônio também são sensíveis à temperatura, pois as abundâncias iônicas destes elementos dependem da temperatura e, além disto, seus ICFs dependem das abundâncias iônicas do oxigênio. Por outro lado, as abundâncias de hélio e nitrogênio são pouco sensíveis à temperatura eletrônica. Os resultados para este método são mostrados na tabela 3.4.

Nesta tabela, a coluna 1 indica o PN G de cada nebulosa planetária, a coluna 2 o nome, a coluna 3 o excesso de cor, as colunas 4 e 5 as densidades eletrônicas calculadas a partir das linhas do [ArIV] e [SII], respectivamente, e as colunas 6 e 7 mostram as temperaturas calculadas a partir das linhas do [NII] e [OIII]. Chama a atenção as altas densidades eletrônicas da ordem de $n_{e} \approx 19000 \mathrm{~cm}^{-3}$ encontradas para muitos objetos da amostra. Para estes objetos, a razão das linhas $[\mathrm{SII}] \mathrm{I}(\lambda 6716) / \mathrm{I}(\lambda 6731)$ é da ordem de 0.5. Nestes casos, elas entram na região de saturação na curva de determinação da densidade eletrônica, onde uma pequena variação na razão das linhas provoca uma grande variação na densidade eletrônica. Os espectros observados têm uma razão $\mathrm{S} / \mathrm{N} \sim 2$ para estas linhas, o que é suficiente para a determinação dos fluxos com um erro relativo de $\sim 15 \%$. Desta forma, o erro na razão das linhas é $\sim 6 \%$. Tal incerteza pode provocar uma variação na densidade de $50 \%$ na região de saturação, onde uma pequena variação na razão de linhas provoca uma grande variação na densidade. Felizmente, as abundâncias químicas dependem fracamente da densidade e, desta forma, esta variação na densidade não influencia na precisão das abundâncias. Alguns dos objetos observados tiveram suas temperaturas eletrônicas calculadas acima de $2 \times 10^{4} \mathrm{~K}$. Não são esperadas temperaturas acima deste limite para as NPs. Temperaturas tão altas podem ser causadas por propriedades intrínsecas da nebulosa, como por exemplo grandes variações de densidade ou a 
Tabela 3.4 - Excesso de cor e parâmetros físicos para as NPs observadas. As densidades eletrônicas estão em unidades de $\mathrm{cm}^{-3}$ e as temperaturas em K. Os parâmetros físicos foram calculados utilizando-se o método 1 para os casos onde não se pode observar a linha $[\mathrm{NII}] \lambda 5755 \AA$ (ver texto).

\begin{tabular}{lcccccc}
\hline \hline PN G & Nome & $\mathrm{E}(\mathrm{B}-\mathrm{V})$ & $\mathrm{n}_{\mathrm{e}}[\mathrm{ArIV}]$ & $\mathrm{n}_{\mathrm{e}}[\mathrm{SII}]$ & $\mathrm{T}_{\mathrm{e}}[\mathrm{NII}]$ & $\mathrm{T}_{\mathrm{e}}[\mathrm{OIII}]$ \\
\hline $000.1-01.2$ & JaSt 75 & 3.59 & 0 & 1990 & 11105 & 11105 \\
$000.2+01.7$ & JaSt 19 & 2.08 & 0 & 5000 & 10000 & 10000 \\
$000.2-01.4$ & JaSt 79 & 2.26 & 0 & 19064 & 20000 & 20000 \\
$000.3+04.2$ & RPZM 21 & 1.82 & 0 & 5000 & 10000 & 10000 \\
- & JaSt 23 & 2.59 & 0 & 16796 & 20000 & 20000 \\
$000.4+01.1$ & JaSt 36 & 2.72 & 0 & 19064 & 10000 & 10000 \\
$000.5+01.9$ & JaSt 17 & 1.87 & 0 & 5690 & 12863 & 12863 \\
$000.6-01.0$ & JaSt 77 & 3.47 & 0 & 19477 & 14902 & 14902 \\
$001.0+01.3$ & JaSt 41 & 2.25 & 0 & 3365 & 10000 & 10000 \\
$001.5+01.5$ & JaSt 46 & 2.17 & 0 & 7432 & 10264 & 10264 \\
$001.6+01.5$ & JaSt 42 & 2.24 & 0 & 3824 & 10000 & 10000 \\
$001.7+01.3$ & JaSt 52 & 2.18 & 0 & 4888 & 16389 & 16389 \\
$004.3-01.4$ & - & 2.69 & 0 & 10742 & 10000 & 10000 \\
$008.8+03.8$ & PTB 13 & 1.05 & 0 & 18 & 10000 & 10000 \\
$351.5-03.4$ & - & 1.11 & 0 & 344 & 9219 & 9219 \\
$358.4+01.7$ & JaSt 2 & 2.34 & 0 & 12223 & 12691 & 12691 \\
$358.5-01.7$ & JaSt 64 & 2.83 & 17143 & 19835 & 17551 & 19409 \\
$358.9-01.5$ & JaSt 65 & 2.72 & 0 & 5000 & 20000 & 20000 \\
$359.5-01.2$ & JaSt 66 & 3.15 & 0 & 3177 & 10000 & 10000 \\
$359.5-01.2$ & JaSt 66 & 3.13 & 0 & 12181 & 10000 & 10000 \\
$359.5-01.3$ & JaSt 68 & 3.35 & 0 & 19064 & 20000 & 20000 \\
\hline & & & & & & \\
& & 0 & 0 & & \\
0
\end{tabular}

presença de material envolvido em choques. Isto poderia causar uma mudança na razão observada dos fluxos das linhas do [NII], fazendo-as inapropriadas para a obtenção da temperatura. Nestes casos, as temperaturas foram aproximadas pelo limite superior para a obtenção das abundâncias iônicas $\left(2 \times 10^{4} \mathrm{~K}\right)$.

O objeto PTB 13 apresenta uma densidade eletrônica $n_{e}=18 \mathrm{~cm}^{-3}$, o que é um valor muito baixo para as NPs. As linhas do [SII] para este objeto em particular apresentam uma alta razão $\mathrm{S} / \mathrm{N}$, como pode ser visto no figura 3.7. Dada a baixa densidade eletrônica deste objeto, é provável que a sua natureza seja uma região HII compacta ao invés de uma nebulosa planetária. É necessária uma investigação adicional para descobrir a verdadeira natureza deste objeto, como por exemplo observações fotométricas no infravermelho. Anderson et al. (2012) mostram que as nebulosas planetárias e as regiões HII apresentam diferentes cores no infravermelho de $8 \mu \mathrm{m}$ a $500 \mu \mathrm{m}$. Como a natureza deste objeto não 


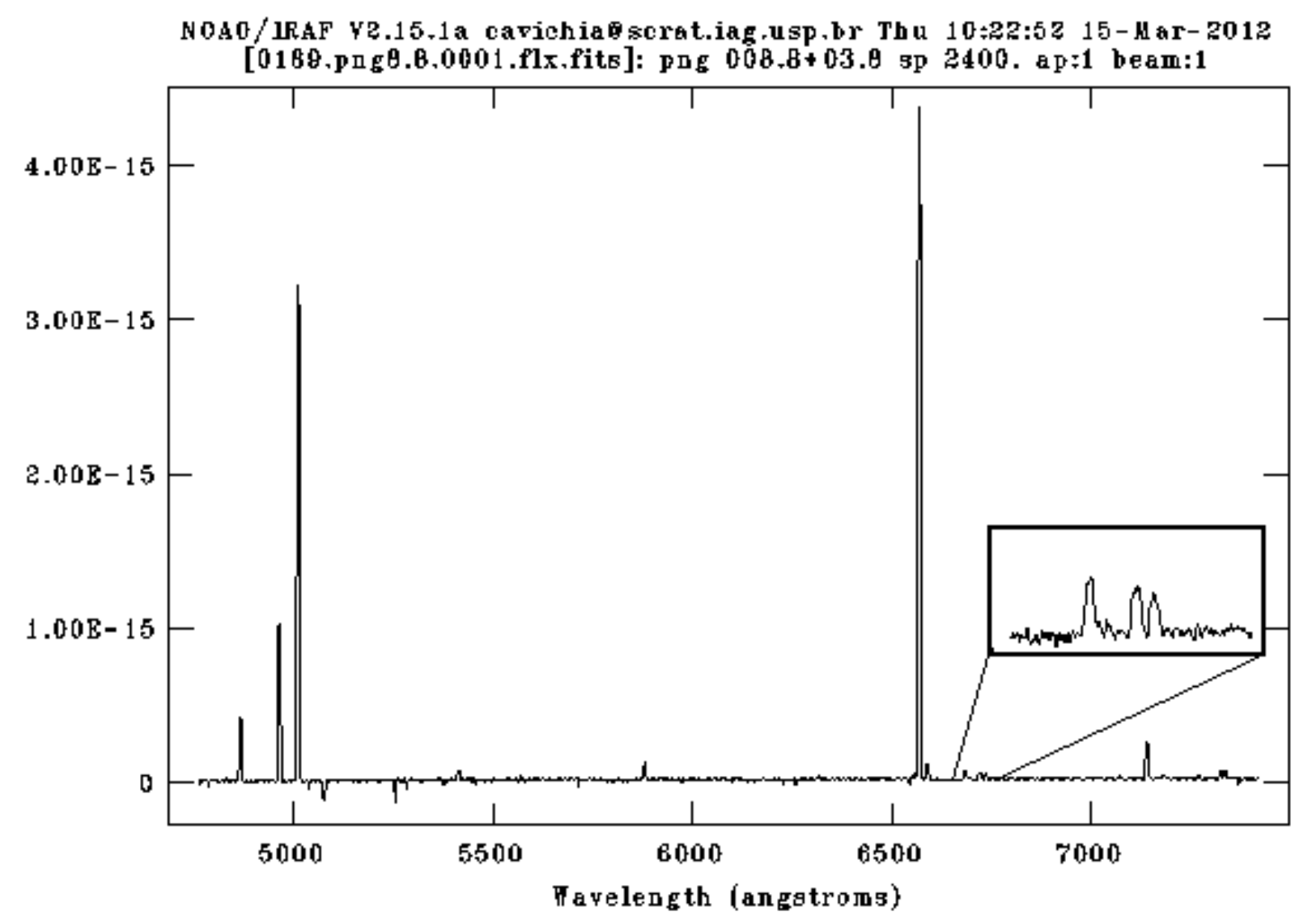

Figura 3.7: Espectro da nebulosa planetária PTB 13. A caixa a direita destaca as linhas do [SII] 6716 e $6730 \AA$ (par mais a direita) juntamente com a linha do HeI $6678 \AA$.

está clara, ele não será utilizado na análise das abundâncias a ser realizada.

As abundâncias químicas calculadas a partir das temperaturas eletrônicas obtidas com o método 1 para os casos onde não pode observar a linha [NII] $\lambda 5755 \AA$ podem ser vistas na tabela 3.5. Nesta tabela são mostrados o PN G de cada NP, o nome, a abundância do hélio em número, as abundâncias de oxigênio, nitrogênio, enxofre, argônio, e neônio na notação $\epsilon(X)=\log (X / H)+12$, onde $\mathrm{X}=\mathrm{O}, \mathrm{N}, \mathrm{S}, \mathrm{Ar}$, Ne. É importante notar que a nebulosa JaSt 23 apresenta uma abundância muito baixa de hélio. O espectro deste objeto pode ser visualizado na figura 3.8, onde é possível notar as intensas linhas de [NII] 65548 e $6584 \AA$, e a ausência de linhas com potencial de ionização mais elevado, como as linhas do [OIII]. Estas características espectrais são das NPs de baixa excitação. Neste caso, uma grande fração do hélio pode estar neutro e, portanto, a aproximação de da equação 3.16 não é válida para este objeto em particular. Por este motivo, este objeto não será considerado 
Tabela 3.5 - Abundâncias químicas das NPs observadas utilizando o método 1 para os casos onde não pode observar a linha $[\mathrm{NII}] \lambda 5755 \AA$. As abundâncias estão na notação $\epsilon(X)=$ $\log (X / H)+12$.

\begin{tabular}{lccccccc}
\hline \hline PN G & Nome & $\mathrm{He} / \mathrm{H}$ & $\epsilon(\mathrm{O})$ & $\epsilon(\mathrm{N})$ & $\epsilon(\mathrm{S})$ & $\epsilon(\mathrm{Ar})$ & $\epsilon(\mathrm{Ne})$ \\
\hline $000.1-01.2$ & JaSt 75 & 0.123 & 8.52 & 7.71 & 6.54 & 5.76 & 0.00 \\
$000.2+01.7$ & JaSt 19 & 0.145 & 8.64 & 6.86 & 0.00 & 6.34 & 0.00 \\
$000.2-01.4$ & JaSt 79 & 0.135 & 7.79 & 7.03 & 6.46 & 6.05 & 0.00 \\
$000.3+04.2$ & RPZM 21 & 0.115 & 8.11 & 7.13 & 6.06 & 6.32 & 0.00 \\
- & JaSt 23 & 0.052 & 7.08 & 7.15 & 6.14 & 0.00 & 0.00 \\
000.4+01.1 & JaSt 36 & 0.121 & 8.65 & 7.52 & 6.53 & 5.97 & 9.29 \\
000.5+01.9 & JaSt 17 & 0.147 & 7.95 & 7.48 & 5.76 & 5.98 & 0.00 \\
$000.6-01.0$ & JaSt 77 & 0.117 & 8.22 & 7.16 & 6.02 & 0.00 & 0.00 \\
$001.0+01.3$ & JaSt 41 & 0.115 & 8.67 & 7.39 & 6.74 & 0.00 & 0.00 \\
$001.5+01.5$ & JaSt 46 & 0.143 & 8.28 & 8.16 & 6.55 & 6.44 & 0.00 \\
$001.6+01.5$ & JaSt 42 & 0.102 & 8.47 & 7.35 & 5.08 & 6.19 & 0.00 \\
$001.7+01.3$ & JaSt 52 & 0.075 & 7.84 & 6.91 & 5.89 & 6.35 & 0.00 \\
$004.3-01.4$ & - & 0.088 & 7.99 & 7.77 & 6.52 & 6.29 & 0.00 \\
$008.8+03.8$ & PTB 13 & 0.081 & 8.55 & 6.62 & 6.65 & 6.34 & 0.00 \\
$351.5-03.4$ & - & 0.132 & 8.79 & 8.89 & 6.63 & 5.93 & 0.00 \\
$358.4+01.7$ & JaSt 2 & 0.161 & 7.65 & 7.63 & 4.99 & 5.95 & 0.00 \\
$358.5-01.7$ & JaSt 64 & 0.095 & 7.73 & 7.27 & 5.95 & 5.68 & 0.00 \\
$358.9-01.5$ & JaSt 65 & 0.094 & 7.65 & 6.03 & 5.93 & 5.67 & 0.00 \\
$359.5-01.2$ & JaSt 66 & 0.139 & 8.35 & 6.98 & 6.34 & 5.74 & 0.00 \\
$359.5-01.2$ & JaSt 66 & 0.118 & 8.28 & 7.47 & 6.41 & 5.57 & 0.00 \\
$359.5-01.3$ & JaSt 68 & 0.087 & 7.62 & 6.88 & 5.95 & 5.48 & 0.00 \\
\hline & & & & & & &
\end{tabular}

nas análises das abundâncias químicas mais adiante.

O método 2 consiste em utilizar o limite do $\mathrm{S} / \mathrm{N}$ dos espectros observados para estimar o limite superior para o fluxo da linha do [NII] $\lambda 5755 \AA$ A . Neste caso, será estimado um limite superior para as temperaturas. Este método não pode ser empregado para a linha do [OIII] $4363 \AA$, pois a extinção na região azul do espectro é muito intensa. Desta forma, os erros nas temperaturas eletrônicas seriam muito grandes. A tabela 3.6 mostra os parâmetros físicos obtidos a partir deste método.

É interessante notar que o método 2 não funcionou para os dois primeiros objetos da tabela, ou seja, as NPs JaSt 19 e PN G 000.3+04.2. Isto acontece porque elas apresentam as linhas do [NII] muito fracas e, portanto, a razão das linhas [NII] I $(\lambda 6548+6583) / \mathrm{I}(\lambda 5755)$ é menor que 18.4, o limite inferior para que o método de determinação da temperatura funcione. Nos casos em que a razão destas linhas é menor que este limite, o programa 


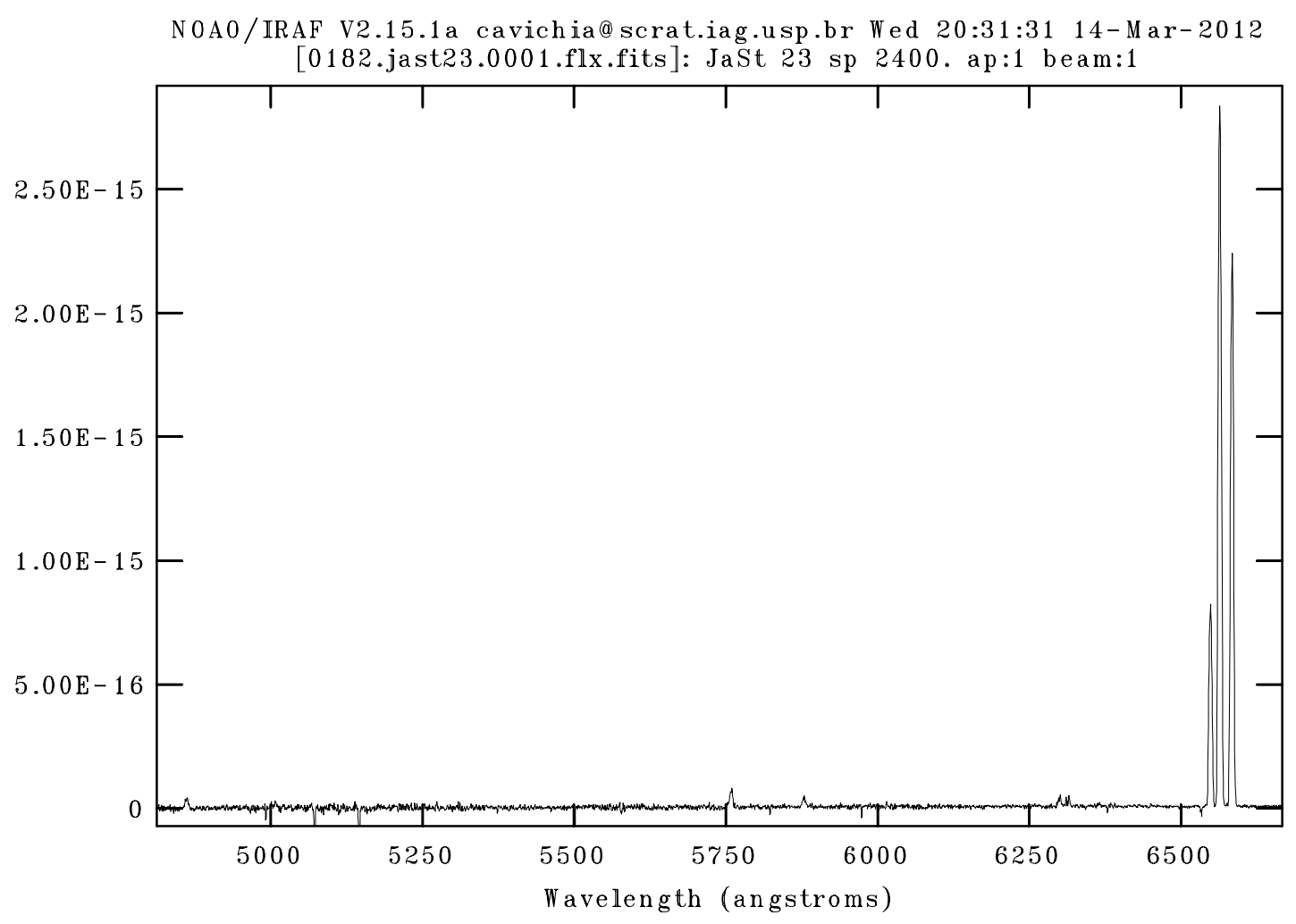

Figura 3.8: Espectro da nebulosa planetária JaSt 23.

Tabela 3.6 - Excesso de cor e parâmetros físicos para as NPs observadas. Os parâmetros físicos foram calculados utilizando-se o método 2 para os casos onde não pode observar a linha $[\mathrm{NII}] \lambda 5755 \AA$ (ver texto).

\begin{tabular}{lcccccc}
\hline \hline PN G & Nome & $\mathrm{E}(\mathrm{B}-\mathrm{V})$ & $\mathrm{n}_{\mathrm{e}}[\mathrm{ArIV}]$ & $\mathrm{n}_{\mathrm{e}}[\mathrm{SII}]$ & $\mathrm{T}_{\mathrm{e}}[\mathrm{NII}]$ & $\mathrm{T}_{\mathrm{e}}[\mathrm{OIII}]$ \\
\hline $000.2+01.7$ & JaSt 19 & 2.05 & 0 & 5000 & 20000 & 20000 \\
$000.3+04.2$ & RPZM 21 & 1.82 & 0 & 5000 & 20000 & 20000 \\
$000.4+01.1$ & JaSt 36 & 2.72 & 0 & 19092 & 10487 & 10487 \\
$001.0+01.3$ & JaSt 41 & 2.25 & 0 & 3654 & 12509 & 12509 \\
$001.6+01.5$ & JaSt 42 & 2.24 & 0 & 3979 & 11167 & 11167 \\
$004.3-01.4$ & - & 2.65 & 0 & 9872 & 6863 & 6863 \\
$359.5-01.2$ & JaSt 66 & 3.15 & 0 & 3153 & 9798 & 9798 \\
\hline
\end{tabular}

aproxima a temperatura eletrônica para $2 \times 10^{4} \mathrm{~K}$. 


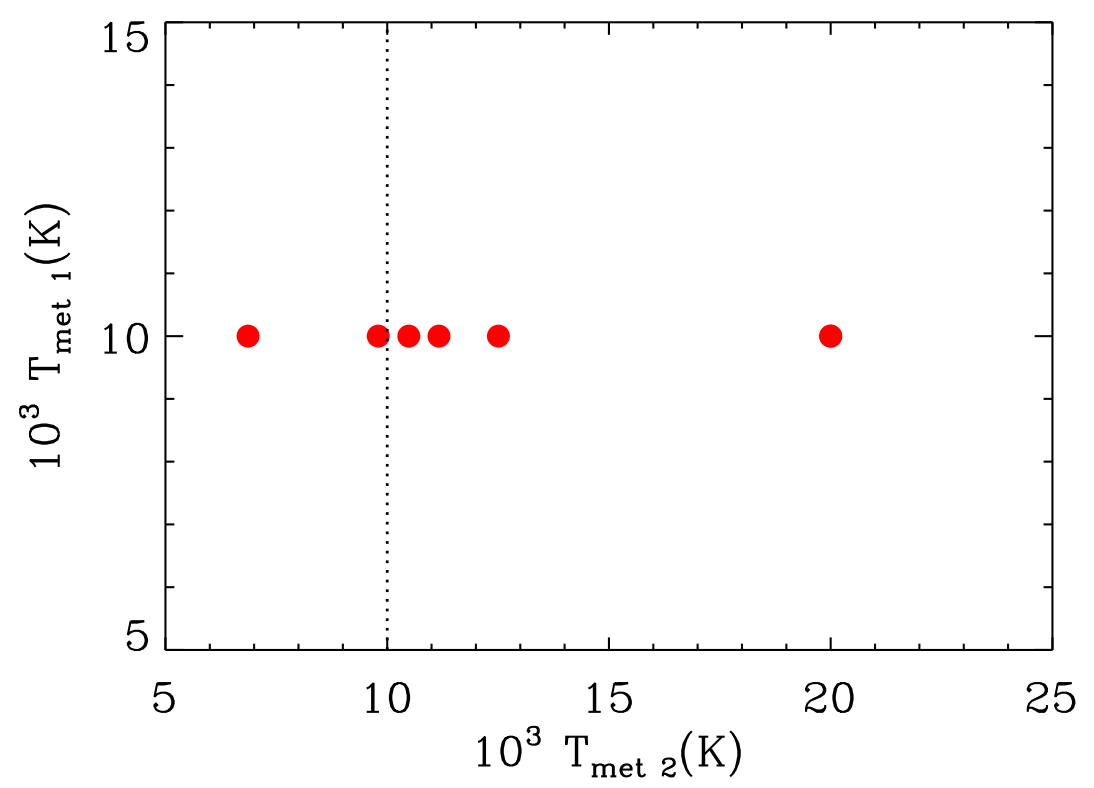

Figura 3.9: Comparação entre as temperaturas do [NII] para os método 1 (eixo Y) e 2.

Os demais objetos da tabela 3.6 apresentam temperaturas próximas a $10^{4} \mathrm{~K}$. Isto é ilustrado na figura 3.9. Nesta figura, pode-se notar que a aproximação para a temperatura de $10^{4} \mathrm{~K}$ é razoável. Na tabela 3.7 são mostradas as abundâncias químicas calculadas a partir do método 2 .

Tabela 3.7 - Abundâncias químicas das NPs observadas utilizando o método 2 .

\begin{tabular}{lccccccc}
\hline \hline PN G & Nome & $\mathrm{He} / \mathrm{H}$ & $\epsilon(\mathrm{O})$ & $\epsilon(\mathrm{N})$ & $\epsilon(\mathrm{S})$ & $\epsilon(\mathrm{Ar})$ & $\epsilon(\mathrm{Ne})$ \\
\hline $000.2+01.7$ & JaSt 19 & 0.124 & 7.79 & 6.87 & 0.00 & 5.75 & 0.00 \\
$000.3+04.2$ & RPZM 21 & 0.095 & 7.21 & 6.92 & 5.08 & 5.66 & 0.00 \\
$000.4+01.1$ & JaSt 36 & 0.118 & 8.57 & 7.51 & 6.45 & 5.93 & 9.21 \\
$001.0+01.3$ & JaSt 41 & 0.109 & 8.33 & 0.00 & 0.00 & 0.00 & 0.00 \\
$001.6+01.5$ & JaSt 42 & 0.101 & 8.29 & 7.35 & 4.98 & 6.07 & 0.00 \\
$004.3-01.4$ & - & 0.091 & 8.89 & 8.01 & 7.33 & 7.02 & 0.00 \\
$359.5-01.2$ & JaSt 66 & 0.139 & 8.39 & 6.99 & 6.36 & 5.76 & 0.00 \\
\hline
\end{tabular}

Note que as duas primeiras NPs da tabela 3.7 apresentam abundâncias dos elementos $\alpha$ mais baixas que os outros objetos. Isto se deve ao fato de as temperaturas eletrônicas para estes objetos terem sido aproximadas para $2 \times 10^{4} \mathrm{~K}$.

Pode-se comparar diretamente as abundâncias químicas calculadas para os métodos 1 e 2. Estas comparações são mostradas nas figuras 3.10 a 3.14, para os elementos hélio, 
nitrogênio, oxigênio, argônio, e enxofre, respectivamente.

Como mencionado anteriormente, as abundâncias químicas dos elementos hélio e nitrogênio não dependem fortemente da temperatura. Isto é visto na comparação entre os métodos 1 e 2 nas figuras 3.10 e 3.11, que apresentam uma boa correlação entre as abundâncias.

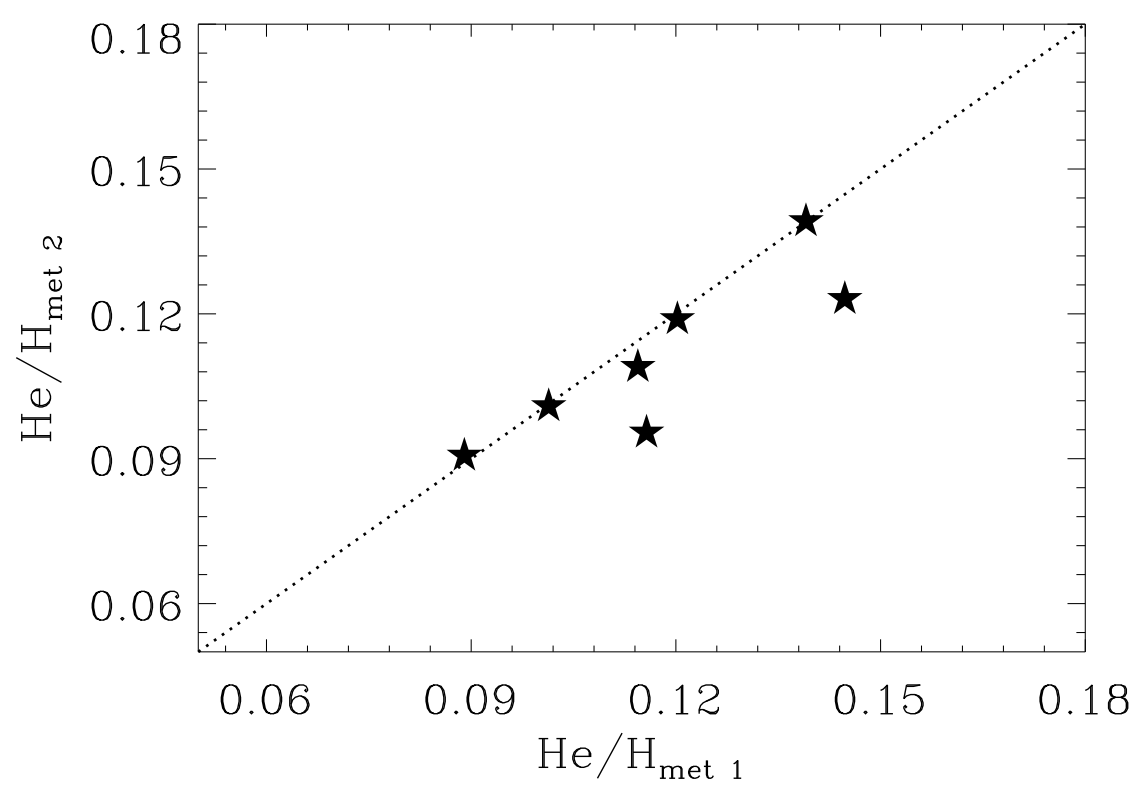

Figura 3.10: Comparação entre as abundâncias de hélio para os métodos 1 e 2.

Na figura 3.12 é mostrada a correlação entre as abundâncias de oxigênio para os dois métodos. Os círculos destacam as NPs que no método 2 tiveram suas temperaturas superiores para o [N II] igual a $2 \times 10^{4} \mathrm{~K}$. Nestes dois casos, a diferença entre as abundâncias do oxigênio são maiores, sendo de 0.87 dex e 0.99 dex. Para os outros objetos a diferença é menor, exceto no caso do objeto PN G004.3-01.4, que apresenta uma temperatura eletrônica de $6863 \mathrm{~K}$ para o método 2. Em particular, para o caso desta NP, a aproximação de $10^{3}$ K não é boa.

A correlação para o argônio pode ser vista na figura 3.13. Nesta figura, a correlação é boa entre os dois métodos exceto para os casos em que $\mathrm{T}_{e}=2 \times 10^{4} \mathrm{~K}$ e para o caso da nebulosa PN G004.3-01.4 com $\mathrm{T}_{e}=6863 \mathrm{~K}$, como já foi discutido anteriormente.

Por último, a figura 3.14 mostra a correlação entre as abundâncias de enxofre considerando os dois métodos. Novamente as NPs que apresentam as abundâncias mais discor- 


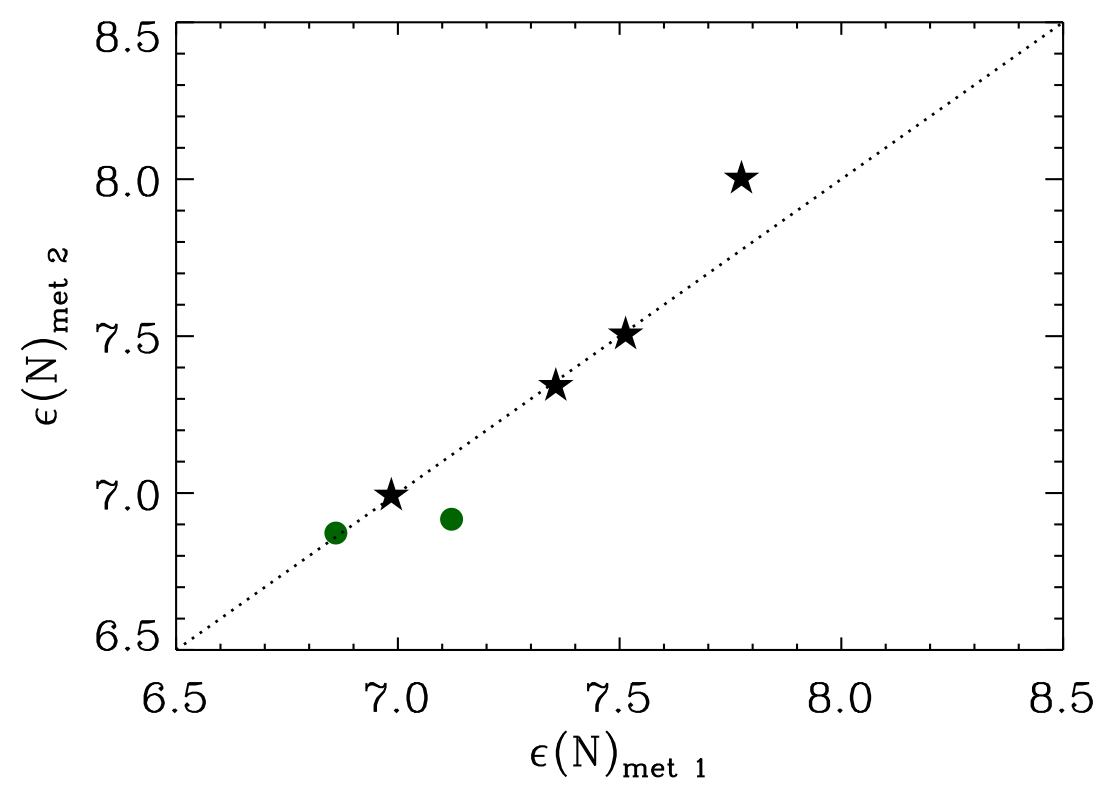

Figura 3.11: O mesmo que a figura 3.10 para o nitrogênio. Os círculos correspondem às NPs $\operatorname{com} \mathrm{T}_{e}=2 \times 10^{4} \mathrm{~K}$.

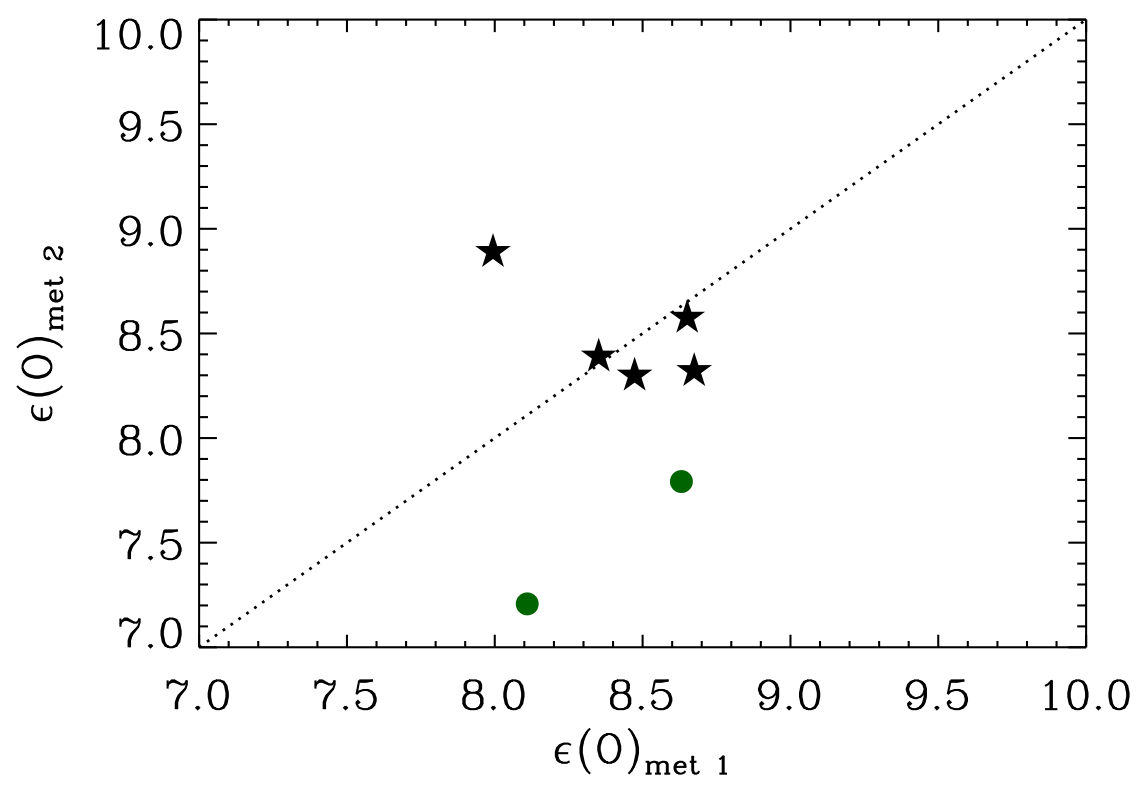

Figura 3.12: Análogo à figura 3.11 para o oxigênio.

dantes são as que foi assumido $\mathrm{T}_{e}=2 \times 10^{4} \mathrm{~K}$ e a PN G004.3-01.4, que tem como limite superior $\mathrm{T}_{e}=6863 \mathrm{~K}$. 


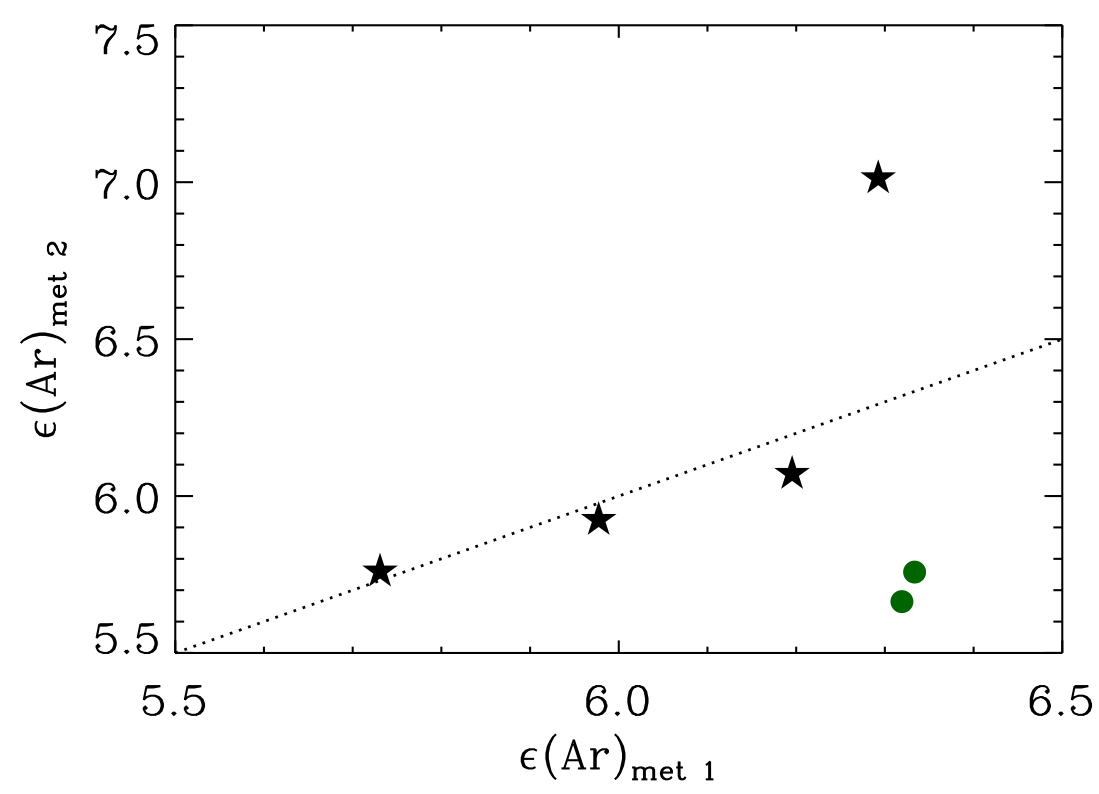

Figura 3.13: Análogo à figura 3.10 para o argônio.

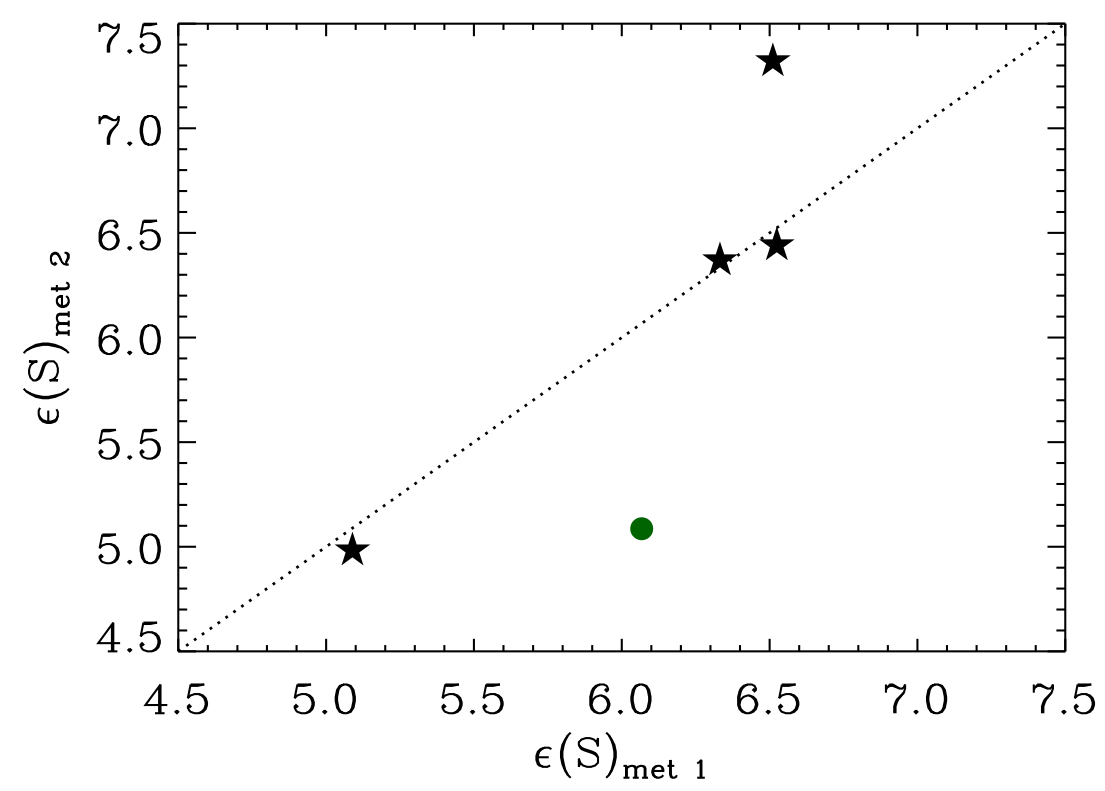

Figura 3.14: Análogo à figura 3.10 para o enxofre.

O terceiro e último método consiste na utilização de um método estatístico para o cálculo das abundâncias de oxigênio. Este método foi sugerido para regiões HII primeira- 
mente por Pagel et al. (1979), onde é empregada uma relação entre as linhas mais intensas no espectro e a abundância química da nebulosa. Esta relação é calibrada utilizando-se as abundâncias de regiões HII para as quais pode-se determinar as temperaturas eletrônicas. O método estatístico assume que todas as nebulosas são caracterizadas somente por suas metalicidades e que o parâmetro de ionização está ligado a ela que, ao menos estatisticamente, tem se revelado verdadeiro (Stasińska, 2006). Para nebulosas planetárias, onde as temperaturas efetivas variam de $2 \times 10^{4} \mathrm{~K}$ a $2 \times 10^{5} \mathrm{~K}$, a aplicação de métodos estatísticos é mais incerta. Porém, como uma primeira aproximação eles podem ser usados para a determinação das abundâncias de oxigênio.

Alloin et al. (1979) propuseram um método estatístico baseado na intensidade das linhas do [OIII] e [NII]. Neste método, a abundância de oxigênio é calculada através da relação:

$$
\epsilon(\mathrm{O})=8.73-0.32 \times 03 N 2
$$

onde:

$$
O 3 N 2=\log \left(\frac{[\mathrm{OIII}] \lambda 5007 / \mathrm{H} \beta}{[\mathrm{NII}] \lambda 6583 / \mathrm{H} \alpha}\right) .
$$

Pettini e Pagel (2004) encontraram que este método apresenta uma forte correlação linear para:

$$
-1.0<O 3 N 2<1.9
$$

Na tabela 3.8 são mostradas as quantidades $O 3 N 2$ e as abundâncias de oxigênio utilizando a equação 3.22 .

Na figura 3.15 é mostrada uma comparação entre as abundâncias químicas do oxigênio para os métodos tradicional (determinação direta da temperatura do [NII]) e estatístico (método 3). Na figura somente são mostradas as abundâncias que satisfazem a equação 3.24. Pode-se ver na figura uma baixa correlação entre os métodos tradicional e 3. De fato, como o método 3 não depende da temperatura, a variação de abundâncias de oxigênio é muito menor que no caso do método 2. É importante notar que o método 3 fornece abundâncias mais altas que o método tradicional para a maior parte da amostra. Como na comparação com o método 2 somente três objetos satisfazem a equação 3.24, não é possível comparar diretamente os dois métodos.

A partir destas análises pode-se constatar que as NPs apresentam grandes variações de temperaturas eletrônicas e, mais importante, as abundâncias de oxigênio, enxofre, e 
Tabela 3.8 - Abundâncias químicas das NPs observadas utilizando o método 3 .

\begin{tabular}{lccc}
\hline \hline PN G & Nome & O3N2 & $\epsilon(\mathrm{O})$ \\
\hline $000.1-01.2$ & JaSt 75 & 1.827 & 8.185 \\
$000.2+01.7$ & JaSt 19 & 2.877 & 7.849 \\
$000.2-01.4$ & JaSt 79 & 1.715 & 8.221 \\
$000.3+04.2$ & RPZM 21 & 1.612 & 8.255 \\
- & JaSt 23 & -0.339 & 8.881 \\
$000.4+01.1$ & JaSt 36 & 2.359 & 8.015 \\
$000.5+01.9$ & JaSt 17 & 1.707 & 8.224 \\
$000.6-01.0$ & JaSt 77 & 2.481 & 7.976 \\
$001.0+01.3$ & JaSt 41 & 2.452 & 7.985 \\
$001.5+01.5$ & JaSt 46 & 0.999 & 8.451 \\
$001.6+01.5$ & JaSt 42 & 2.122 & 8.092 \\
$001.7+01.3$ & JaSt 52 & 0.534 & 8.599 \\
$004.3-01.4$ & - & 0.905 & 8.481 \\
$008.8+03.8$ & PTB 13 & 2.437 & 7.991 \\
$351.5-03.4$ & - & 0.698 & 8.546 \\
$358.4+01.7$ & JaSt 2 & 1.386 & 8.326 \\
$358.5-01.7$ & JaSt 64 & 1.772 & 8.204 \\
$358.9-01.5$ & JaSt 65 & 2.047 & 8.115 \\
$359.5-01.2$ & JaSt 66 & 1.909 & 8.158 \\
$359.5-01.2$ & JaSt 66 & 1.862 & 8.175 \\
$359.5-01.3$ & JaSt 68 & 2.278 & 8.041 \\
\hline
\end{tabular}

argônio dependem das temperaturas adotadas. Como consequência, o método 2 onde a temperatura eletrônica é aproximada por um valor superior é o mais adequado entre os três métodos.

Um teste importante para a averiguação da precisão dos dados são as correlações entre as abundâncias químicas. Estas correlações também são importantes para o entendimento da evolução das estrelas progenitoras das NPs. As correlações entre as abundâncias químicas não sintetizados pela estrela progenitora trazem importantes informações a respeito da formação e evolução da Galáxia, como pode ser visto em Ballero et al. (2007).

Os elementos hélio e nitrogênio têm suas abundâncias alteradas durante a evolução da estrela progenitora da NP. Na correlação entre $\log (\mathrm{N} / \mathrm{O})$ e hélio é esperado que a razão N/O deva crescer com o aumento da abundância de hélio, pois as estrelas progenitoras de maior massa apresentam maiores abundâncias de nitrogênio e hélio. O hélio é produzido nas estrelas progenitoras através dos ciclos p-p ou CNO, onde as estrelas convertem hidrogênio 


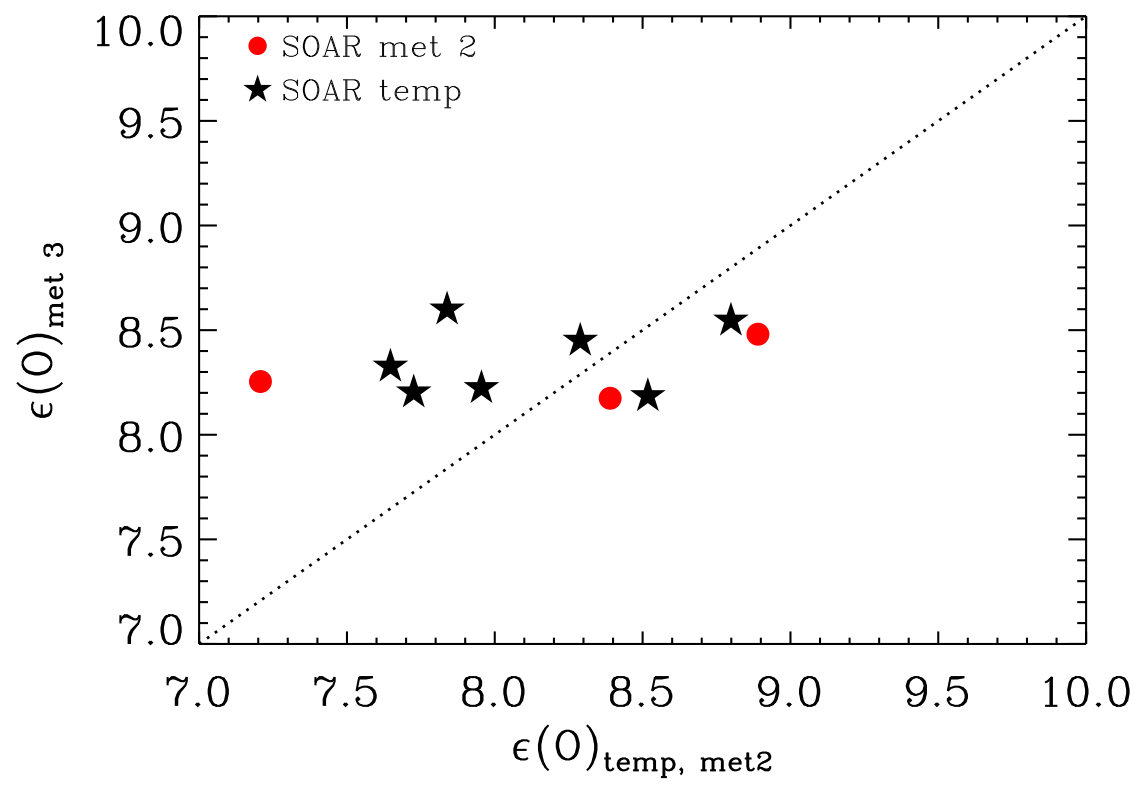

Figura 3.15: Comparação entre as abundâncias de oxigênio para o método estatístico (eixo Y) em função dos métodos tradicional (estrelas) e 2 (círculos).

em hélio durante a fase de sequência principal. Os yields de nitrogênio para as estrelas de massa intermediária são maiores quanto mais massiva for a estrela (van den Hoek e Groenewegen, 1997; Marigo, 2001).

A figura 3.16 mostra a correlação entre $\log (\mathrm{N} / \mathrm{O})$ e a abundância de hélio para nossa amostra utilizando o método tradicional (estrelas) e o método 2 (triângulos). Na figura também são mostrados os dados de Cavichia et al. (2010), aqui referido como CCM10. Há uma boa concordância entre os dados deste trabalho e os de CCM10. É possível ver que uma fração dos objetos da amostra deste trabalho apresenta $\log (\mathrm{N} / \mathrm{O})$ próximos de -1. Isto significa que não houve uma produção significativa de nitrogênio nestas nebulosas. Como o enriquecimento deste elemento está conectado com a massa da estrela progenitora e consequentemente com as idades, este conjunto de nebulosas foi originado de estrelas de menor massa e, portanto, mais velhas. Além disto, Cuisinier et al. (2000) mostraram que a razão N/O é mais baixa para objetos do bojo se comparados com os do disco. É provável que haja contaminação de NPs pertencentes ao disco interno na amostra de CCM10, como dito anteriormente. Por estas evidências, os resultados obtidos parecem indicar que os objetos observados pertencem verdadeiramente ao bojo galáctico. 


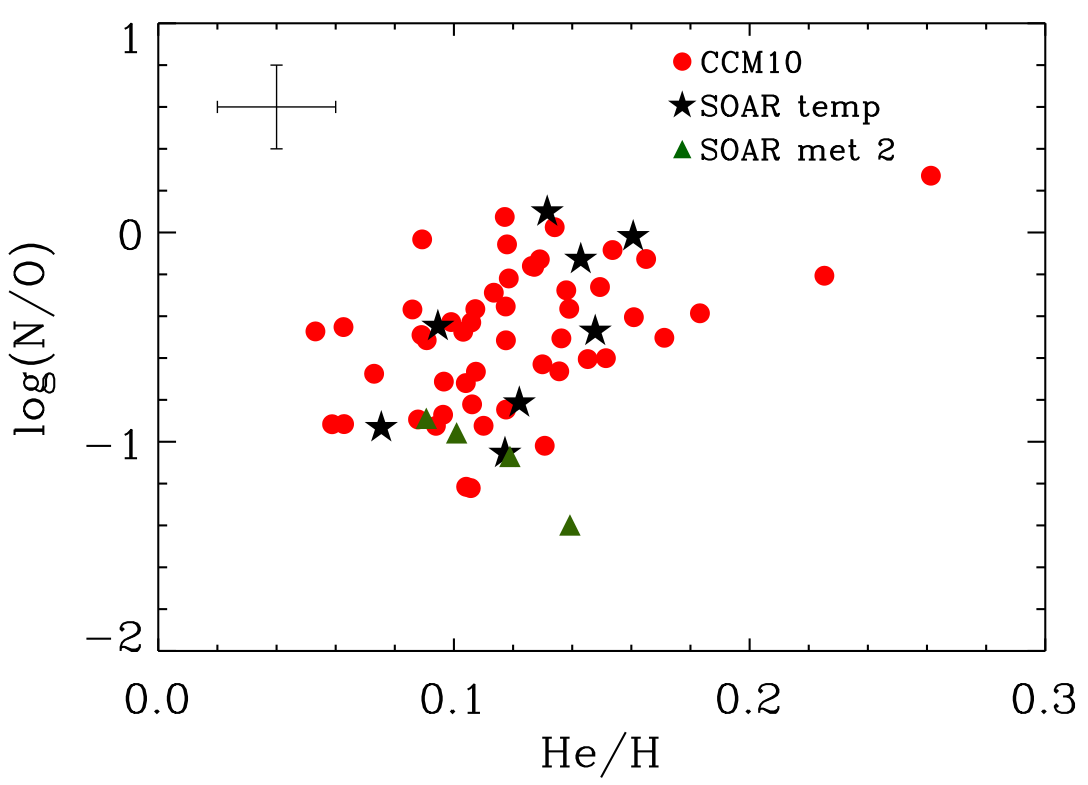

Figura 3.16: Correlação entre $\log (\mathrm{N} / \mathrm{O})$ e hélio para a amostra deste trabalho (estrelas e triângulos), e nosso trabalho anterior (CCM10, círculos). As barras de erro indicam os erros médios para a amostra de CCM10.

A correlação entre os elementos enxofre, argônio e o oxigênio são importantes porque, como mencionado anteriormente, estes elementos não são produzidos na estrela progenitora da NP, mas são gerados em explosões de supernovas tipo II. Portanto, espera-se uma correlação positiva entre os mesmos. As figuras 3.17 e 3.18 mostram as correlações entre estes elementos.

Nestas figuras pode-se ver que as correlações entre os elementos $\alpha$ são praticamente lineares tanto para os nossos dados utilizando os dois métodos, como para os dados de CCM10. No caso do argônio, é de se esperar um maior espalhamento das abundâncias na figura 3.18, pois suas abundâncias estão sujeitas a erros maiores uma vez que seu ICF é mais incerto que os demais.

Utilizando as NPs que tiveram as abundâncias do oxigênio determinadas pelo método tradicional, ou seja, calculando-se as temperaturas eletrônicas, juntamente com as abundâncias que foram determinadas pelo método 2 , pode-se calcular mais precisamente a média das abundâncias de oxigênio para a amostra observada com o SOAR. Neste caso, foram excluídas as NPs cujas temperaturas calculadas através do método 2 fossem $2 \times 10^{4} \mathrm{~K}$, juntamente com a NP PN G004.3-01.4, que apresenta uma temperatura de $6863 \mathrm{~K}$. A 


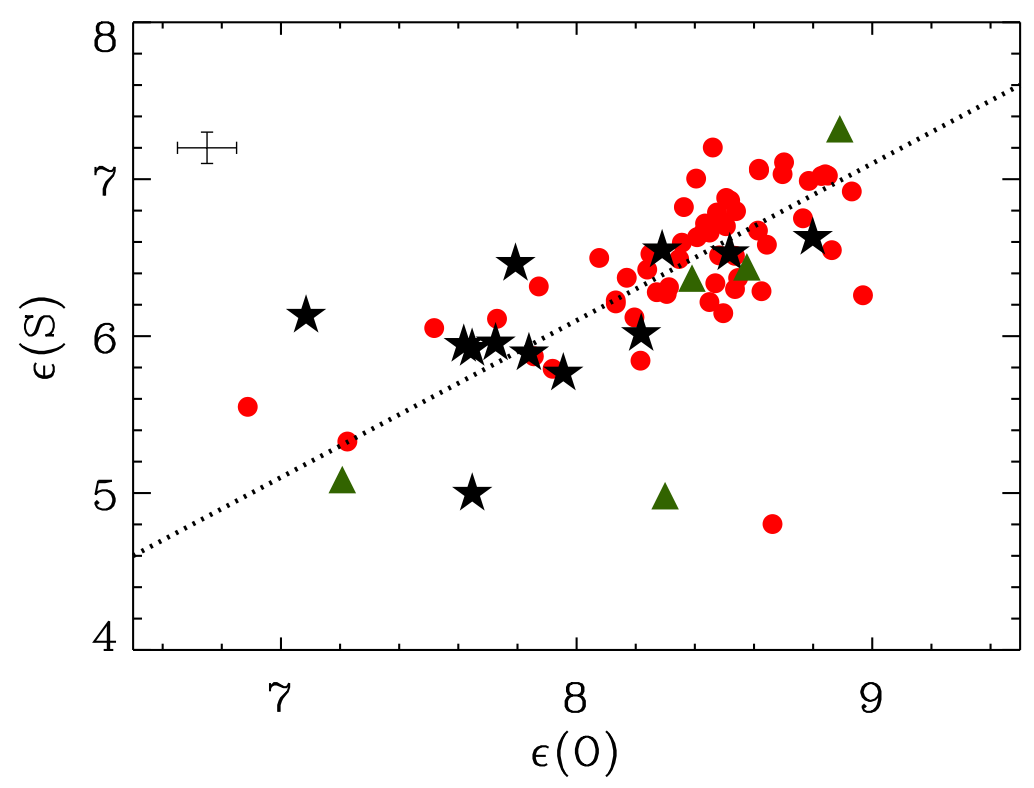

Figura 3.17: Correlação entre as abundâncias de enxofre e oxigênio para os dados deste trabalho (estrelas e triângulos) e os dados de CCM10 (círculos). As barras de erro simbolizam os erros para os dados de CCM10. A linha tracejada representa uma reta com coeficiente angular igual a 1 .

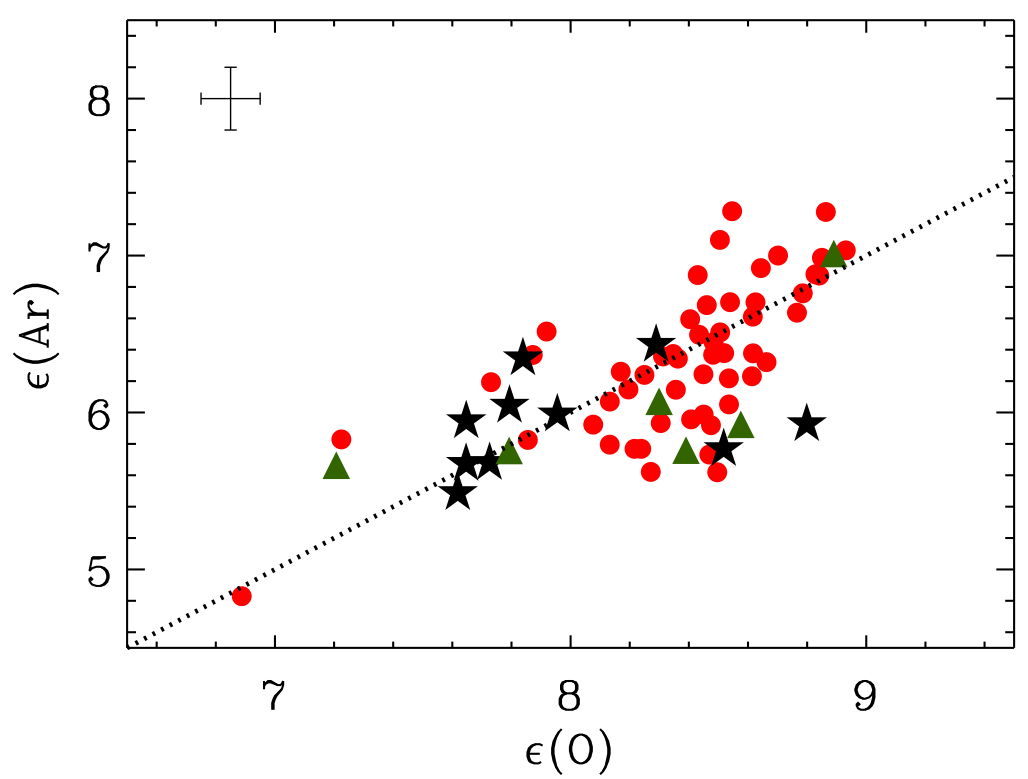

Figura 3.18: O mesmo que a figura 3.17 para o argônio. 
abundância de oxigênio média para nossa amostra é $8.2 \pm 0.5$ dex.

Os resultados são apresentados na figura 3.19, que mostra o gradiente de oxigênio para os dados de Stanghellini e Haywood (2010). A linha tracejada e pontilhada é um ajuste linear aos dados. Os triângulos são as abundâncias químicas para a amostra do presente trabalho calculadas a partir do método 2, como mencionado acima. As estrelas são as abundâncias de oxigênio utilizando o método tradicional de determinação de temperatura. O círculo próximo a $0 \mathrm{kpc}$ representa a abundância média de oxigênio para a amostra do SOAR, sendo as barras de erro verticais o desvio padrão das abundâncias, e as barras de erros horizontais o desvio padrão esperado para os objetos do bojo. A figura mostra que as abundâncias das NPs deste trabalho não podem ser reproduzidas por uma simples extrapolação do gradiente de abundâncias do disco. De fato, a média de abundâncias para os objetos deste trabalho está 0.63 dex abaixo deste limite. Ainda são necessários mais dados para confirmar este resultado, porém os resultados apontam para que o bojo da Galáxia tenha se formado a partir do método clássico de formação de bojos, ou seja, a partir de um rápido colapso radial no início da vida da galáxia. Neste cenário espera-se que a maioria da população do bojo seja velha, com uma idade próxima à idade da Galáxia.

Adicionalmente, estes resultados concordam com resultados prévios obtidos por nosso grupo em Cavichia et al. (2011). Neste trabalho, foi constatado que as abundâncias das NPs do bojo são menores que as do disco interno da Galáxia. Isto foi feito através de uma análise estatística das abundâncias juntamente com a mais precisa escala de distâncias estatísticas disponível atualmente, como descrito no capítulo 2.

A figura 3.20 mostra o histograma das abundâncias de oxigênio deste trabalho (histograma com linhas contínuas) e o histograma dos dados de CCM10 (histograma tracejado). Os histogramas foram normalizados para uma melhor comparação. Nesta figura, é possível notar que o pico dos dois histogramas ocorre na mesma posição, ou seja, para abundâncias de 8.4 dex. Entretanto, o histograma da presente amostra tem mais objetos com menores abundâncias do que o histograma de CCM10. Um teste Kolmogorov-Smirnov entre as duas distribuições, retorna o valor p de 0.14. O limite comumente usado para rejeitar a hipótese nula de que as distribuições foram originadas da mesma distribuição é 0.05. Portanto, com o valor encontrado não se pode rejeitar que as duas amostras foram originadas da mesma distribuição, porém é baixo o suficiente para garantir uma investigação adicional 


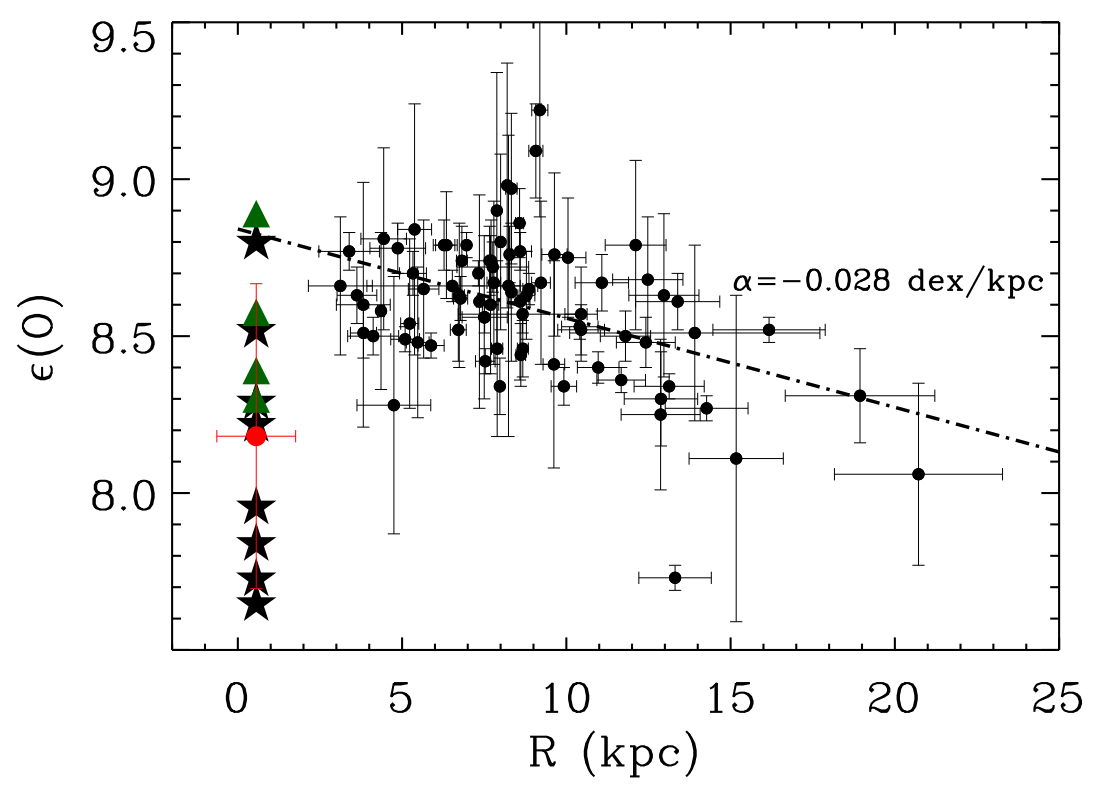

Figura 3.19: Gradiente radial de oxigênio para a amostra de Stanghellini e Haywood (2010) (círculos) comparado com as abundâncias de nossa amostra calculadas com o método tradicional de temperatura (estrelas) e o método 2 (triângulos). O círculo próximo a $0 \mathrm{kpc}$ representa a média das abundâncias para os dados do SOAR. O valor da inclinação do gradiente é mostrado na figura.

aos objetos localizados na direção do centro galáctico.

Existem algumas explicações para um número de NPs da presente amostra apresentarem menores abundâncias do que encontrado por CCM10.

1. A primeira seria a contaminação por objetos do disco em CCM10. De fato, como são NPs de maior brilho superficial, é provável que haja uma contaminação maior de objetos do disco naquela amostra. Cavichia et al. (2011) mostram que aproximadamente $24 \%$ da amostra é contaminada por objetos do disco interno.

2. As abundâncias dos objetos com abundâncias menores na presente amostra estão sujeitas a erros maiores. Na figura 3.19 pode-se constatar que os objetos com menores abundâncias tiveram suas temperaturas calculadas a partir do método tradicional, ou seja, através da determinação direta da temperatura eletrônica do [NII]. Portanto estes objetos são os que apresentam a maior precisão na determinação das abundâncias, com um erro na abundância de oxigênio de 0.14 dex (Cavichia et al., 2010). 


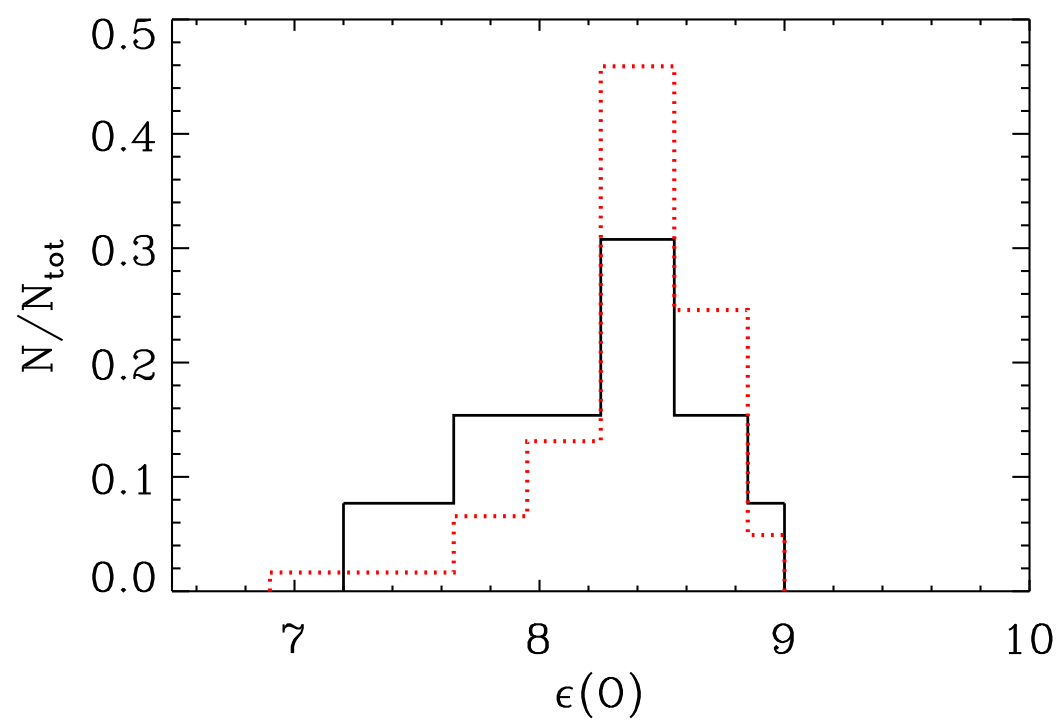

Figura 3.20: Distribuição de oxigênio para os dados de CCM10 (histograma tracejado) e os dados deste trabalho (histograma contínuo).

3. Bensby et al. (2011) argumentam que existem duas populações coexistindo no bojo: uma rica em metais e outra pobre. Desta forma, a presente amostra é representada pela população mais rica em metais, com uma parcela significativa da amostra representada pela população pobre em metais.

É interessante notar que existem evidências observacionais de estrelas indicando que as abundâncias na região central da Galáxia são menores que as do disco interno. Cunha et al. (2007) encontram que as abundâncias de Ca, Fe, e O de estrelas do centro galáctico não seguem o gradiente radial de abundâncias do disco em direção ao centro da Galáxia. Porém, segundo os autores daquele estudo, os resultados não são conclusivos pois não existem abundâncias de estrelas na região $\mathrm{R}<4 \mathrm{kpc}$. Os resultados daquele trabalho também apontam para uma razão $[\alpha / \mathrm{Fe}]$ menor para as estrelas do centro galáctico do que para as do disco. De acordo com os autores, uma IMF que privilegia as estrelas mais massivas na região central poderia explicar estes resultados. Um segundo cenário seria a auto poluição por SNe II do meio onde se formaram os aglomerados através da formação estelar. Neste caso, as gerações posteriores de estrelas se formariam a partir de um ambiente previamente enriquecido em elementos $\alpha$. Uma terceira hipótese é levantada 
pelos autores: o gás que gera a formação estelar no centro da Galáxia seria provindo de uma reservatório externo.

A análise das abundâncias químicas na região central da Galáxia mostra que o bojo apresenta uma complexa composição de populações estelares. Por um lado, a presença de nebulosas com baixas abundâncias mostra que o bojo pode ter se formado a partir de um disco galáctico antigo através de uma evolução secular (Genzel et al., 2008). Uma evolução secular precoce poderia alimentar a região central da Galáxia com gás e estrelas e, desta forma, construir um disco exponencial e um bojo massivo, mesmo sem a necessidade de fusões. Neste caso, o bojo se formaria simultaneamente com o disco, mas separadamente. Em um outro cenário, o bojo se formaria a partir do disco espesso, como mostram as simulações de Bournaud et al. (2009). Este cenário explicaria as similaridades entre o bojo e o disco espesso. Por outro lado, é interessante notar que na figura 3.19 existem alguns objetos do bojo para os quais as abundâncias coincidem com o limite do gradiente radial do disco nesta região. Isto poderia ser interpretado como um bojo composto por duas ou mais populações nesta região: uma originada do disco fino, e outra originada do disco espesso. Bensby et al. (2011) também encontram evidências de que o bojo é composto por uma população rica e outra pobre em metais. Como eles argumentam, estas são evidências para um bojo formado a partir de um disco, como indicam os resultados do survey BRAVA que apontam para um pseudobojo (Shen et al., 2010).

Adicionalmente, Babusiaux et al. (2010) também encontram duas populações para o bojo: uma rica e outra pobre em metais. Estas populações distintas, argumentam os autores, sugerem dois cenários diferentes para a formação do bojo: um bojo clássico formado com uma curta escala de tempo, onde a maior parte das estrelas são velhas e apresentam uma rotação isotrópica; e um pseudobojo, com rotação característica da população da barra e formado com uma escala de tempo mais longa a partir da evolução secular do disco. Portanto, espera-se que a população da componente esferoidal seja velha enquanto que a população da componente do pseudobojo possa conter estrelas velhas e jovens. As estrelas velhas seriam provindas do disco interno redistribuídas pela barra, e a população jovem seria formada pelos fluxos de gás induzidos pela barra.

A coexistência dos dois cenários para o bojo, um clássico e um pseudobojo é suportada pelas observações em outras galáxias por Prugniel et al. (2001); Peletier et al. (2007); Erwin 
(2008). Simulações de N corpos também suportam estas evidências (Samland e Gerhard, 2003; Athanassoula, 2005). Mais detalhes sobre a coexistência de um bojo clássico e um pseudobojo serão discutidos no capítulo 4. 
Capítulo 4

\section{A evolução química da Via Láctea com fluxos radiais}

\section{de gás}

Neste capítulo são descritos os resultados de um modelo de evolução química desenvolvido para o estudo da influência dos fluxos radiais de gás na evolução da Via Láctea. Em especial, pretende-se estudar como a barra da Via Láctea altera as propriedades químicas, a densidade de gás, e a taxa de formação estelar na região $R<4$ kpc. Pretende-se também estudar qual a influência da barra na formação e evolução do bojo e região central da Galáxia.

Este modelo foi desenvolvido através de um estágio sanduíche realizado em Madri sob supervisão da Dra. Mercedes Mollá do Instituto CIEMAT da Universidade Complutense de Madri, com apoio da CAPES. O objetivo deste estágio foi o aperfeiçoamento de um modelo de evolução química já existente para a Via Láctea, visando a construção de um modelo que inclui os possíveis efeitos que uma barra localizada no centro da Galáxia. Em particular, uma vez que uma barra acarretaria um inevitável acréscimo de matéria das regiões internas do disco para o bojo, estudou-se os efeitos que a sua existência poderia exercer sobre a distribuição de abundâncias químicas do bojo e do disco interno da Galáxia.

A colaboração entre o grupo do IAG/USP e o grupo de Madri foi muito proveitosa para o entendimento da evolução química da Galáxia, pois são poucos os trabalhos que buscam estudar a região central da Galáxia de forma conjunta. No modelo de Mollá e Díaz (2005), de agora em diante MD05, por exemplo, o disco e o bojo são tratados separadamente. Dependendo do cenário de evolução do bojo, esta diferenciação acarreta vários problemas na descrição da evolução química e dinâmica destas estruturas, que estão certamente interceptadas, e é exatamente a interconexão destas estruturas que merece 
especial atenção, já que nestes pontos deve haver o encontro das características individuais de cada uma. Por outro lado, uma das vantagens deste modelo é a inclusão de uma taxa de formação estelar mais realista que os modelos clássicos de evolução química, pois esta formação se dá em dois passos: primeiramente se formam as nuvens moleculares; posteriormente se formam as estrelas. Desta forma, a inclusão de fluxos radiais de gás, que é a contribuição descrita nesta tese, e portanto a interação entre as estruturas da Galáxia, torna o modelo do grupo de Madri ainda mais realista frente a outros modelos de evolução química existentes. Mais ainda, por ser um modelo generalizado, posteriormente os resultados obtidos poderão ser aplicados em outras galáxias espirais, não somente na Via-Láctea.

Nesta colaboração, as abundâncias químicas e propriedades cinemáticas das amostras de nebulosas planetárias obtidas por nosso grupo utilizando o telescópio de 1,60m do LNA e o telescópio SOAR, foram aplicados como vínculos observacionais ao modelo de formação e evolução do bojo e da região interna do disco. Em particular, este modelo foi útil para responder algumas questões sobre a natureza do bojo da Galáxia, como por exemplo como uma barra localizada na região central da Galáxia poderia modificar o gradiente de abundâncias químicas do disco, ou quais a dimensões e idade que esta barra deveria ter para podermos reproduzir o atual gradiente de abundâncias observado no disco. Também foi útil para determinar o limite interno do disco do ponto de vista das abundâncias químicas. A seguir são apresentados o modelo desenvolvido e os resultados obtidos.

\subsection{O modelo}

O modelo de multifases de MD05 é uma generalização do modelo desenvolvido por Ferrini et al. (1992) para a vizinhança solar, e mais tarde aplicado para toda a Galáxia (Ferrini et al., 1994), ao bojo galáctico (Molla e Ferrini, 1995), a outras galáxias espirais (Mollá et al., 1996; Mollá e Roy, 1999), e a outros bojos (Mollá et al., 2000). O material enriquecido é originado das estrelas ao final de sua evolução, considerando suas nucleosínteses, função de massa inicial (IMF) e portanto a restituição tardia, e o destino final através de uma evolução silenciosa, ou através de explosões de supernovas tipo I (SNe I) e II (SNe II). O modelo adota uma IMF de Ferrini et al. (1990), mostrada na equação 4.1, muito similar com a de Scalo e Struck-Marcell (1986). 


$$
\log \Phi(m)=0.3395-\frac{(0.73+\log m \times(1.92+2.07 \times \log m))^{0.5}}{m^{1.52}} .
$$

O modelo original foi modificado por MD05 para usar yields dependentes de metalicidade. Os yields de estrelas massivas são de Woosley e Weaver (1995), enquanto que os de estrelas de baixa massa são o conjunto de Gavilán et al. (2005). Para explosões de supernovas do tipo I é usado o modelo W7 de Nomoto et al. (1984), como revisado por Iwamoto et al. (1999).

No modelo original de Mollá e Díaz (2005), cada galáxia é descrita como um sistema de duas fases com um halo e um disco. No presente modelo, adicionalmente a estas duas fases foi incluído um bojo. É assumido que o halo tem uma massa total que inicialmente está na fase de gás. A massa total, $M$ e a sua distribuição radial $M(R)$, são calculadas das curvas de rotação correspondentes derivadas a partir da curva de rotação universal de Persic et al. (1996). A galáxia é dividida em regiões cilíndricas concêntricas com 2 kpc de largura. A partir da curva de rotação, pode-se calcular a distribuição radial de massa, $\mathrm{M}(\mathrm{R})$, com a expressão $\mathrm{M}(\mathrm{R})=2.32 \times 10^{5} \mathrm{R} V(\mathrm{R})^{2}$. O gás do halo colapsa para cair no disco equatorial, formando um disco ou um bojo como uma estrutura secundária. O infall de gás do halo é parametrizado por $f_{g_{H}}$, onde $g_{H}$ é a massa de gás do halo e $f$ é a taxa de infall. A massa que não cai sobre o disco permanece no halo e resulta em uma razão $\mathrm{M}_{\text {halo }} / \mathrm{M}_{\text {disco }}$ para a componente bariônica.

\subsubsection{Tempo de colapso}

A escala de tempo de colapso, que define também a taxa de infall de gás, depende da distância galactocêntrica através da expressão:

$$
\tau(R)=\tau_{0} \times \exp \left(\frac{\mathrm{R}-\mathrm{R}_{\mathrm{c}}}{\lambda \mathrm{R}_{\mathrm{d}}}\right),
$$

onde é assumido que a densidade superficial de massa total segue o perfil exponencial de brilho superficial do disco. Nesta equação, $\tau_{0}=4 \mathrm{Gyr}, \mathrm{R}_{\mathrm{d}}=2 \mathrm{kpc}$ é o fator de escala da distribuição de brilho superficial do disco, e $\mathrm{R}_{\mathrm{c}}=\mathrm{R}_{\mathrm{opt}} / 2=6.5 \mathrm{kpc}$ é o raio característico para o disco. $\lambda$ é um parâmetro de escala para o tempo de colapso exponencial, e a princípio se esperaria $\lambda=2 R_{\mathrm{d}}$. Porém, como mostrado por Ferrini et al. (1994) e discutido por MD05, tal valor para $\lambda$ produz uma dependência radial final das abundâncias elementais 
em desacordo com as observações. Para mais detalhes sobre a escala de tempo de colapso, ver por exemplo Mollá e Díaz (2005) e Ferrini et al. (1994). O bojo é descrito seguindo o modelo de Kent (1992), no qual ele é descrito como um esferóide oblato achatado no plano galáctico, com semieixos maior e menor $x=2 \mathrm{kpc}$ e $z=1.5 \mathrm{kpc}$, respectivamente, e uma massa $M_{B}=1.8 \times 10^{10} M_{\odot}$. Para o bojo, a distribuição de metalicidades das estrelas gigantes é reproduzida com $\tau=0.7 \mathrm{Gyr}$, sendo este tempo de colapso mais curto do que a escala de tempo de colapso do disco para $\mathrm{R}=0 \mathrm{kpc}$.

O gás do halo colapsa no disco ou bojo com uma taxa que é inversamente proporcional ao tempo de colapso. O gás é acretado mais rapidamente nas regiões mais centrais do que nas partes mais externas dos disco, resultando em uma formação do tipo inside-out. Um perfil de acresção de gás na Galáxia pode ser obtido de simulações cosmológicas, como mostram Naab e Ostriker (2006) e Colavitti et al. (2008). Porém, no estágio atual estas simulações ainda são incertas e, como mostrado por Colavitti et al. (2008), um perfil exponencial de acresção de gás está em acordo com as simulações cosmológicas.

\subsubsection{Eficiências de formação estelar e nuvens}

A matéria em um sistema galáctico pode ser agregada em diferentes fases, e na presente versão do modelo de evolução química são considerados três tipos:

1. Uma população estelar, na qual se podem distinguir dois setores: estrelas que podem induzir formação estelar (mais massivas que $4 \mathrm{M}_{\odot}$ ) e estrelas que não contribuirão para a formação estelar.

2. Remanescentes de estrelas que removerão massa da evolução química.

3. Matéria interestelar (ISM), onde são distinguidas duas componentes na região do disco e bojo: difusa e não difusa. Enquanto que para o halo somente uma fase está presente.

A evolução do sistema, isto é, a dependência temporal da fração de massa total em cada fase e as abundâncias químicas no ISM e nas estrelas, são determinadas pelas interações que ocorrem entre estas várias fases, e a taxa de formação estelar (SFR) é consequência desta mesma evolução. A massa nas diferentes fases de cada região muda pelos seguintes 
processos de conversão relacionados com a formação e morte estelar, sendo os índices 1 e 2 correspondentes às estrelas de baixa e alta massa, respectivamente, e os índices D e B correspondentes ao disco e bojo, respectivamente:

- formação estelar pela fragmentação espontânea de gás no halo $\left(K_{1,2} g_{H}^{n}\right)$;

- formação de nuvens de gás no disco ou bojo a partir do gás difuso $\left(\mu g_{D, B}^{n}\right)$;

- formação estelar induzida no disco ou bojo via interação entre estrelas massivas e nuvens de gás $\left(H_{1,2} c_{D, B}^{2}\right)$;

- restituição de gás difuso a partir destes processos de formação de nuvens e estrelas $\left(a^{\prime} c_{D, B} s_{2 D, B}\right)$;

- formação do disco ou bojo através da acumulação de gás difuso do halo $\left(f g_{H}\right)$.

No halo, a taxa de formação estelar segue uma lei de Schmidt para o gás difuso $g_{H}$, com uma potência $n=1.5$ e um fator de proporcionalidade $K$. No disco, as estrelas se formam em dois passos: primeiramente, as nuvens moleculares, $c_{D}$, se formam do gás difuso, $g_{D}$, também por uma lei de Schmidt com $n=1.5$ e um fator de proporcionalidade chamado $\mu$. Então, a colisão entre nuvens produz estrelas por um processo espontâneo a uma taxa proporcional a um parâmetro $H$. A taxa de formação estelar, determinada de forma autoconsistente pela evolução das fases, é dada por:

$$
\begin{aligned}
& \psi_{H}(r)=\left(K_{1}+K_{2}\right) g_{H}^{n}, \\
& \psi_{D, B}(t)=\left(H_{1}+H_{2}\right) c_{D, B}^{2}+\left(a_{1}+a_{2}\right) c_{D, B} s_{2 D, B} .
\end{aligned}
$$

No presente modelo, estes parâmetros não podem ser considerados livres. O parâmetro de infall é definido pela distribuição radial de massa total. Os parâmetros $K, \mu, H$, e $a$ têm as suas dependências radiais estimadas por Ferrini et al. (1994):

$$
\begin{aligned}
K & =\epsilon_{K}\left(G / V_{H}\right)^{1 / 2} \\
\mu & =\epsilon_{\mu}\left(G / V_{D}\right)^{1 / 2} \\
H & =\epsilon_{H}\left(\text { cte } / V_{D}\right) \\
a & =\epsilon_{a}\left(G \rho_{c}\right)^{1 / 2} /\left\langle m_{s_{2}}\right\rangle
\end{aligned}
$$


sendo $G$ a constante gravitacional universal, $V_{H}$ e $V_{D}$ são os volumes do halo e do disco para cada região radial, $\rho_{c}$ é a densidade de nuvens média, e $\left\langle m_{s_{2}}\right\rangle$ é a massa média das estrelas de maior massa. Os fatores de proporcionalidade são eficiências que representam as probabilidades associadas com estes processos. Desta forma, os parâmetros livres $K$, $\mu, H$, e $a$, são funções da distância galactocêntrica nas leis de formação estelar e nuvens. Estes parâmetros são computados através das eficiências de formação estelar no halo $\epsilon_{K}$, formação de nuvens $\epsilon_{\mu}$, colisão entre nuvens $\epsilon_{H}$, e interação entre estrelas massivas e nuvens $\epsilon_{a}$. Apenas uma eficiência para cada processo precisa ser selecionada para toda a Galáxia. As eficiências $\epsilon_{H}$ e $\epsilon_{\mu}$ variam entre 0 e 1 e, a princípio, deveriam variar independentemente uma da outra, o que aumentaria o número de parâmetros para cada modelo. Contudo, Mollá e Díaz (2005) mostram que existe uma tendência entre os dois parâmetros de aumentarem ou diminuírem conjuntamente. Mais especificamente, estes parâmetros variam entre galáxias de diferentes tipos morfológicos, mas mantendo uma razão $\left\langle\ln \epsilon_{\mu} / \ln \epsilon_{H}\right\rangle \sim 0.4$.

O modelo usa como parâmetros de entrada a escala de tempo de colapso para formar o disco, a qual depende da massa total da galáxia, e as eficiências para formar as nuvens moleculares e estrelas. A distribuição radial da massa total constitui um parâmetro fundamental de entrada para o modelo de multifases.

\subsubsection{As equações do modelo}

São definidas as seguintes quantidades:

$$
g=\frac{M_{\text {gás }}}{M_{\mathrm{tot}}}, \quad c=\frac{M_{\mathrm{nuv}}}{M_{\mathrm{tot}}}, \quad s=\frac{M_{\star}}{M_{\mathrm{tot}}}, \quad r=\frac{M_{\mathrm{rem}}}{M_{\mathrm{tot}}},
$$

onde $M_{\text {tot }}$ é a massa total do sistema, $M_{\text {nuv }}$ é a massa de gás na forma de nuvens, $M_{\text {rem }}$ é a massa de gás presa nos remanescentes estelares, e $M_{\star}$ é a massa de estrelas. Na fase de estrelas, são distinguidas duas classes de acordo com a massa:

$$
s_{1}: m_{\min }<m<m_{*}, \quad \text { e } \quad s_{2}: m_{*}<m<m_{\max },
$$

pois somente as estrelas massivas $\left(s_{2}\right)$ interagem com as nuvens induzindo a formação estelar, sendo a massa $m_{*}$ uma variável de integração. Os limites de massa $m_{\min }$ e $m_{\max }$ são definidos para serem 0.1 e $100 \mathrm{M}_{\odot}$, respectivamente, enquanto que a transição entre $s_{1}$ e $s_{2}$ ocorre em $4 \mathrm{M}_{\odot}$. 
O sistema de equações diferenciais acopladas não lineares é dado por:

$$
\begin{aligned}
& \frac{d s_{1 H}}{d t}=K_{1} g_{H}^{n}-D_{1 H} \\
& \frac{d s_{2 H}}{d t}=K_{2} g_{H}^{n}-D_{2 H} \\
& \frac{d g_{H}}{d t}=-\left(K_{1}+K_{2}\right) g_{H}^{n}-f g_{H}+W_{H} \\
& \frac{d s_{1 D, B}}{d t}=H_{1} c_{D, B}^{2}+a_{1} c_{D, B} s_{2 D, B}-D_{1 D, B} \\
& \frac{d s_{2 D, B}}{d t}=H_{2} c_{D, B}^{2}+a_{2} c_{D, B} s_{2 D, B}-D_{2 D, B} \\
& \frac{d s_{1 D, B}}{d t}=H_{1} c_{D, B}^{2}+a_{1} c_{D, B} s_{2 D, B}-D_{1 D, B} \\
& \frac{d g_{D}}{d t}=-\mu g^{n}+a^{\prime} c_{D} s_{2 D}+H^{\prime} c_{D}^{2}+f g_{H}+W_{D} \\
& \frac{d c_{D, B}}{d t}=\mu g^{n}-\left(a_{1}+a_{2}+a^{\prime}\right) c_{D, B} s_{2 D, B}-\left(H_{1}+H_{2}+H^{\prime}\right) c_{D, B}^{2} \\
& \frac{d r_{H}}{d t}=D_{1 H}+D_{2 H}-W_{H} \\
& \frac{d r_{D, B}}{d t}=D_{1 D, B}+D_{2 D, B}-W_{D, B} \\
& \frac{d X_{i H}}{d t}=\frac{W_{i H}-X_{i H} W_{H}}{g_{H}} \\
& \frac{d X_{i D, B}}{d t}=\frac{W_{i D, B}-X_{i D, B} W_{D, B}+f g_{H}\left(X_{i H}-X_{i D, B}\right)}{g_{D, B}+c_{D, B}}
\end{aligned}
$$

Os subíndices D, B, e H denotam as quantidades do disco, bojo, e halo, respectivamente. $X_{i}$ é a abundância por massa de 14 elementos químicos: $\mathrm{H}, \mathrm{D},{ }^{3} \mathrm{He},{ }^{4} \mathrm{He},{ }^{12} \mathrm{C},{ }^{13} \mathrm{C},{ }^{16} \mathrm{O}$, 
${ }^{14} \mathrm{~N},{ }^{20} \mathrm{Ne},{ }^{24} \mathrm{Mg},{ }^{28} \mathrm{Si},{ }^{32} \mathrm{~S},{ }^{40} \mathrm{Ca},{ }^{56} \mathrm{Fe}$, mais os isótopos ricos em neutrons sintetizados a partir de ${ }^{12} \mathrm{C},{ }^{13} \mathrm{C},{ }^{16} \mathrm{O}, \mathrm{e}{ }^{14} \mathrm{~N}$.

A restituição de matéria no meio interestelar é descrita pelos termos dependentes do tempo: $D_{1,2 ; H, D, B}(t)$, a taxa de morte no tempo $t$ para as estrelas em cada classe e zona, isto é, a fração total de massa que deixa a fase estelar no tempo $t$, e $W_{i ; H, D, B}(t)$, a fração de massa ejetada no gás interestelar como elemento $i$ a partir de estrelas que estão morrendo no tempo $t$. A fração de todos os elementos é dada por $W_{H, D, B}=\sum_{i} W_{i ; H, D, B}(t)$.

Estes termos são computados a partir das hipóteses feitas para a evolução estelar e nucleossíntese dos elementos. O cenário adotado para a evolução estelar é:

1. Evolução "silenciosa" - Estrelas isoladas com massa no intervalo entre $0.1<\mathrm{M}<$ $8 \mathrm{M} \odot$ evoluem através dos processos gravitacionais e nucleares permitidos para cada massa, e terminam suas evoluções como anãs brancas de hélio ou de carbono-oxigênio de massa $\mathrm{M}_{\mathrm{WD}}<1.4 \mathrm{M}_{\odot}$.

2. Supernovas tipo $I I$ - Estrelas isoladas com massa $\mathrm{M} \geq 8 \mathrm{M}_{\odot}$ evoluem rapidamente com um tempo de vida médio $\tau_{m} \leq 10^{7}$ yr e terminam como supernovas tipo II, com diferentes características dependendo da massa da progenitora, deixando como remanescentes objetos compactos altamente degenerados (estrela de nêutrons ou um buraco negro).

3. Supernovas tipo I - Supernovas do tipo Ia (SNe Ia) são originadas de um sistema binário com massa total no intervalo $3 \leq \mathrm{M}_{\mathrm{B}} \leq 16 \mathrm{M}_{\odot}$ onde a estrela primária (de maior massa) evolui de maneira usual até que se torne uma anã branca de C-O. Quando a estrela secundária evolui até o ramo assintótico das gigantes (RGB), ela transfere uma fração de sua massa para para a companheira anã branca através do lóbulo de Roche, causando a deflagração de C na anã branca, quando esta atinge a massa de Chandrasekhar (Whelan e Iben, 1973). A deflagração envolve somente a massa da estrela primária, não deixa um remanescente e transforma todo o material em elementos pesados, principalmente ferro. Desta forma, o tempo para ocorrer a deflagração é controlado pelo tempo de vida da estrela secundária. Para as supernovas tipo Ib, é assumido que também são originadas de anãs brancas de C-O, mas a deflagração é acionada pela detonação do hélio após uma fusão com uma estrela 
secundária não degenerada de hélio (Iben et al., 1987; Matteucci e Tornambe, 1987). A massa total deste sistema é similar à massa das SNe Ia, e as SNe Ib produzem metade do ferro que as SNe Ia produzem e nenhum elemento de massa intermediária. As SNe Ib representam metade do número total de supernovas (van den Bergh et al., 1987).

Para as estrelas isoladas, é assumido que sua morte e a consequente perda de massa ocorre imediatamente após a mesma completar a evolução de sua sequência principal, que é de fato a fase mais longa da evolução estelar. É assumido no modelo que os sistemas binários capazes de produzir SNe I são representados pela distribuição de massa $\phi_{B}(m)$ definida como (Matteucci e Greggio, 1986):

$$
\phi_{B}(m) d m=\alpha(m) \phi(m) d m
$$

sendo que

$$
\phi(m)=\left\{\begin{array}{rc}
\alpha_{0}=0.1, & \text { se } 3 \leq m \leq 16 \mathrm{M}_{\odot} \\
0, & \text { caso contrário. }
\end{array}\right.
$$

O valor de $\alpha_{0}$ é escolhido para que a taxa atual de SNe I observada seja reproduzida.

As taxas de morte de estrelas são dadas por:

$$
\begin{gathered}
D_{1 ; H, D, B}(t)=\int_{m_{\min }}^{m_{*}} \Psi_{H, D, B}\left(t-\tau_{m}\right) \phi^{\prime}(m) \mathrm{d} m, \\
D_{2 ; H, D, B}(t)=\int_{m_{*}}^{m_{\max }} \Psi_{H, D, B}\left(t-\tau_{m}\right) \phi^{\prime}(m) \mathrm{d} m,
\end{gathered}
$$

sendo $\tau_{m}$ o tempo de vida na sequência principal de uma estrela de massa $m$, para o qual é assumido (Burkert e Hensler, 1987):

$$
\tau_{m}=\left\{\begin{array}{c}
8.0 m^{-2.8} \mathrm{Gyr}, \quad \text { se } m \leq 10 \mathrm{M}_{\odot} \\
0.05 m^{-0.6} \mathrm{Gyr}, \quad \text { se } m>10 \mathrm{M}_{\odot} .
\end{array}\right.
$$

As taxas de restituição $W_{i ; H, D, B}$ da matéria processada e não processada pelas estrelas, são calculadas através das matrizes de restituição $Q_{i j}(m)$ definidas como a fração de massa de um elemento $j$ inicialmente presente em uma estrela de massa $m$ que é transformada no elemento $i$ e ejetada (Talbot e Arnett, 1973). A quantidade $\tilde{Q}_{i j}(m)$ define o peso da contribuição das estrelas que evoluem normalmente (incluindo as estrelas que explodem 
como SNe II) e das estrelas binárias que terminam como SNe I. Desta forma, para as taxas de restituição, tem-se:

$$
W_{i ; H, D, B}(t)=\int_{m_{\min }}^{m_{\max }}\left[\sum_{j} \tilde{Q}_{i j}(m) X_{j}\left(t-\tau_{m}\right)\right] \Psi_{H, D, B}\left(t-\tau_{m}\right) \mathrm{d} m .
$$

As taxas de ocorrência de SNe I e SNe II são computadas através de:

$$
\begin{aligned}
& \frac{d N_{S N e I I}}{d t}=\int_{8 M_{\odot}}^{m_{\max }} \frac{\phi^{\prime}(m)}{m} \Psi_{H, D, B}\left(t-\tau_{m}\right) \mathrm{d} m, \\
& \frac{d N_{S N e I}}{d t}=\int_{m_{\min }}^{8 M_{\odot}} \frac{\phi_{s}^{\prime}(m)}{m} \Psi_{H, D, B}\left(t-\tau_{m}\right) \mathrm{d} m,
\end{aligned}
$$

onde $\phi_{s}^{\prime}(m)$ é a fração de massa nas secundárias quando a primária tem massa menor ou igual a $8 \mathrm{M}_{\odot}$.

A evolução temporal das abundâncias químicas é dada de acordo com a prescrição de Tinsley (1980):

$$
\begin{gathered}
\frac{d\left(X_{i H} g_{H}\right)}{d t}=-\Psi_{H} X_{i H}-f g_{H} X_{i H}+W_{i H}, \\
\frac{d\left[X_{i D, B}\left(g_{D, B}+c_{D, B}\right)\right]}{d t}=-\Psi_{H} X_{i D, B}-f g_{D, B} X_{i D, B}+W_{i D, B},
\end{gathered}
$$

\subsubsection{Fluxos radiais de gás}

A inclusão de fluxos radiais de gás segue o modelo de Portinari e Chiosi (2000) e se dá através da transferência de massa de gás entre as diferentes regiões cilíndricas concêntricas que formam a Galáxia. Cada região pode ganhar ou perder gás, dependendo do padrão de velocidades adotado para o mesmo. Os fluxos radiais de gás são inseridos no modelo incluindo-se uma componente de fluxos radiais na equação 4.15:

$$
\frac{d g}{d t}=-\mu g^{n}+a^{\prime} c s_{2}+H^{\prime} c^{2}+f g_{H}+W+f g_{r f}
$$

sendo que o termo responsável pelos fluxos radiais é dado por:

$$
f g_{r f}(k)=F_{2}(k)-F_{1}(k) .
$$

É adotada uma velocidade positiva para o gás que se desloca em direção ao interior da Galáxia (inflow) e negativa para o gás que se desloca na direção externa da Galáxia (outflow). Na equação 4.30, $F_{1}(k)$ e $F_{2}(k)$ são os fluxos de gás que entram/saem da camada $r_{k}$ nas posições $r_{k+1 / 2}$ e $r_{k-1 / 2}$, respectivamente, como pode ser visto na figura 4.1. 


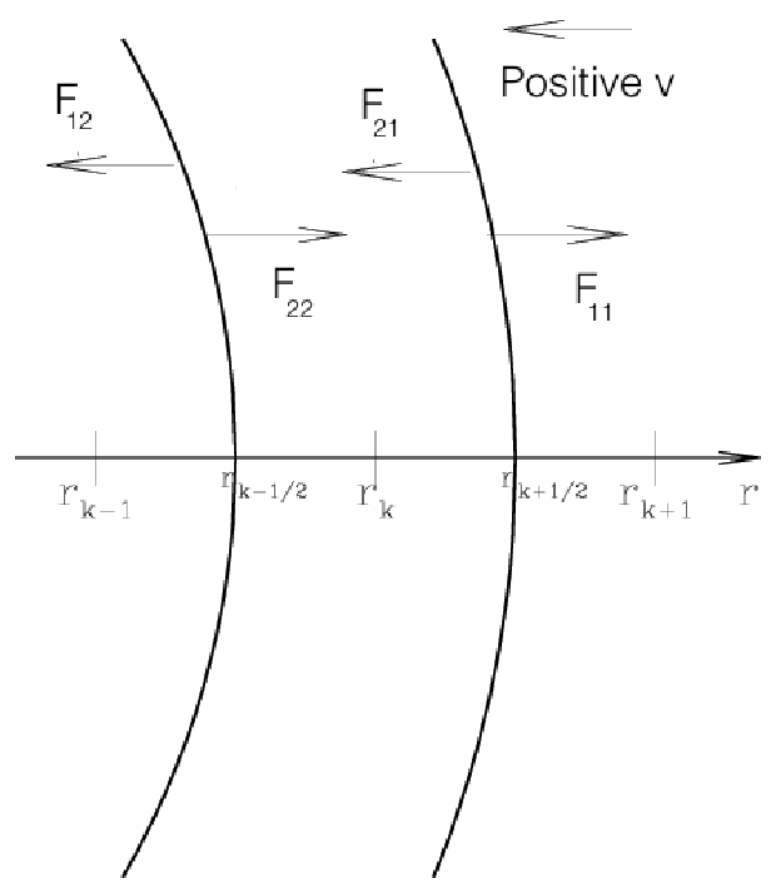

Figura 4.1: Esquema para os fluxos de gás na camada $k$.

Os fluxos $F_{1}$ e $F_{2}$ que entram e saem da camada $k$ podem ser divididos em duas componentes:

$$
F_{2}(k)=F_{21}(k)+F_{22}(k) \quad F_{1}(k)=F_{11}(k)+F_{12}(k) .
$$

Nesta equação, o primeiro índice na função corresponde aos fluxos que entram ou saem da camada k, sendo que 1 refere-se aos fluxos saindo e 2 aos fluxos entrando na camada. O segundo índice corresponde à posição que isto ocorre: 1 para a posição $r_{k+1 / 2}$ e 2 para $r_{k-1 / 2}$. Ou seja:

- Na direção da camada $r_{k}$ a partir das camadas $r_{k+1}\left(F_{21}\right)$ e $r_{k-1}\left(F_{22}\right)$.

- Saindo da camada $r_{k}$ para as camadas $r_{k+1}\left(F_{11}\right)$ e $r_{k-1}\left(F_{12}\right)$.

As funções $F_{i j}$ dependem da velocidade do gás $v(k)$, da densidade do gás $d g(k)$, e de uma função $\chi(x)$ da seguinte maneira:

$$
\begin{gathered}
F_{21}(k)=\frac{2 \pi}{\delta r} v_{k+1 / 2}(k)\left[\chi\left(v_{k+1 / 2}(k)\right) \times g(k+1)\right], \\
F_{22}(k)=-\frac{2 \pi}{\delta r} v_{k-1 / 2}(k)\left[\chi\left(-v_{k-1 / 2}(k)\right) \times g(k-1)\right],
\end{gathered}
$$




$$
\begin{gathered}
F_{11}(k)=-\frac{2 \pi}{\delta r} v_{k+1 / 2}(k)\left[\chi\left(-v_{k+1 / 2}(k)\right) \times g(k)\right], \\
F_{12}(k)=\frac{2 \pi}{\delta r} v_{k-1 / 2}(k)\left[\chi\left(v_{k-1 / 2}(k)\right) \times g(k)\right] .
\end{gathered}
$$

Nestas equações, $v_{k-1 / 2}(k)$ e $v_{k+1 / 2}(k)$ são as velocidades do gás nas posições $r_{k-1 / 2}$ e $r_{k+1 / 2}$, respectivamente, e $\delta r$ é o espaçamento entre as camadas. A função $\chi(x)$ tem os valores:

$$
\chi(x)= \begin{cases}1, & \text { se } x>0 \\ 0, & \text { se } x<0 .\end{cases}
$$

Adicionalmente, os fluxos radiais de gás devem ser incluidos nas derivadas parciais da variação de metalicidades em cada camada. Para uma metalicidade inicial $Z_{0}$ e uma variação de metalicidade $\Delta Z(k)$, a metalicidade final $Z$ é dada por:

$$
Z=Z_{0}+\Delta Z(k)=\frac{Z(k+1)-Z(k)}{d g(k)} \times F_{21}(k)+\frac{Z(k-1)-Z(k)}{d g(k)} \times F_{22}(k) .
$$

Substituindo as funções de fluxos radiais 4.32 e 4.33 na equação acima, tem-se que as derivadas parciais da metalicidade com relação ao gás e a variação de metalicidade:

$$
\begin{gathered}
\frac{\partial Z(k)}{\partial g(k+1)}=\frac{2 \pi}{\delta r} \frac{Z(k+1)-Z(k)}{d g_{c}} \times v_{k+1 / 2}(k)\left[\chi\left(v_{k+1 / 2}(k)\right)\right] \\
\frac{\partial Z(k)}{\partial g(k-1)}=-\frac{2 \pi}{\delta r} \frac{Z(k-1)-Z(k)}{d g_{c}} \times v_{k-1 / 2}(k)\left[\chi\left(-v_{k-1 / 2}(k)\right)\right] \\
\frac{\partial Z(k)}{\partial g(k)}=-\left[\frac{Z(k+1)-Z(k)}{d g_{c}}\right] F_{21}+\left[\frac{Z(k-1)-Z(k)}{d g_{c}^{2}}\right] F_{22} \\
\frac{\partial Z(k)}{\partial Z(k+1)}=\frac{F_{21}}{d g_{c}} \\
\frac{\partial Z(k)}{\partial Z(k-1)}=\frac{F_{22}}{d g_{c}} \\
\frac{\partial Z(k)}{\partial Z(k)}=-\frac{\left(F_{21}+F_{22)}\right.}{d g_{c}}
\end{gathered}
$$

sendo $d g_{c}$ a densidade de gás total do disco. 


\subsection{Resultados}

\subsubsection{Modelo sem fluxos de gás}

Primeiramente são apresentados os resultados do modelo de evolução química sem fluxos de gás. Isto é feito para um melhor entendimento das limitações de um modelo que não considera fluxos de gás para reproduzir os vínculos observacionais da Via Láctea. O modelo considerado nesta seção é o de Mollá e Díaz (2005) com a inclusão de um bojo central, como já descrito anteriormente.

Na figura 4.2 são mostrados os resultados para o perfil radial da densidade superficial de gás . A figura inferior refere-se ao perfil de densidade do gás difuso, enquanto a figura superior ao perfil de densidade do gás molecular para os dados de Williams e McKee (1997) (círculos) e Olling e Merrifield (2001) (quadrados). Na figura 4.2 inferior os dados de HI são de Nakanishi e Sofue (2003). Como se pode ver na figura, o modelo padrão subestima a densidade de HI para $R \lesssim 8 \mathrm{kpc}$ e $R \gtrsim 17 \mathrm{kpc}$. Por outro lado, a densidade de HI é bem reproduzida na vizinhança solar. Para o caso da densidade de $\mathrm{H}_{2}$, mostrada no painel superior da mesma figura, o modelo reproduz bem o perfil de densidade para o disco externo, mas falha em reproduzir o perfil para $R \lesssim 8 \mathrm{kpc}$, subestimando as observações nesta região.

A figura 4.3 mostra o perfil radial da taxa de formação estelar (SFR) atual. O modelo padrão de MD05 é comparado com os dados observacionais de formação estelar retirados de Stahler e Palla (2005). Os dados mostram que existe um máximo de formação estelar no disco em $R \sim 5 \mathrm{kpc}$, enquanto que o modelo de MD05 prevê um máximo na SFR em $R \sim 7$ kpc. O modelo não consegue reproduzir a SFR atual na região interna da Galáxia, porém para $R>7 \mathrm{kpc}$ as observações são bem reproduzidas. Este é um ponto fraco dos modelos estáticos (sem fluxos radiais de gás) de evolução química, onde não conseguem reproduzir a SFR no disco interno da Galáxia (Chiappini et al., 2001; Portinari e Chiosi, 1999, 2000; Fu et al., 2009; Marcon-Uchida et al., 2010).

As figuras 4.4 e 4.5 mostram as previsões do modelo de MD05 para os gradientes radiais de ferro e oxigênio. Os dados para as abundâncias de ferro são de estrelas cefeidas e foram retirados de Andrievsky et al. (2002, a), Andrievsky et al. (2002, b) e Luck e Lambert (2011). 


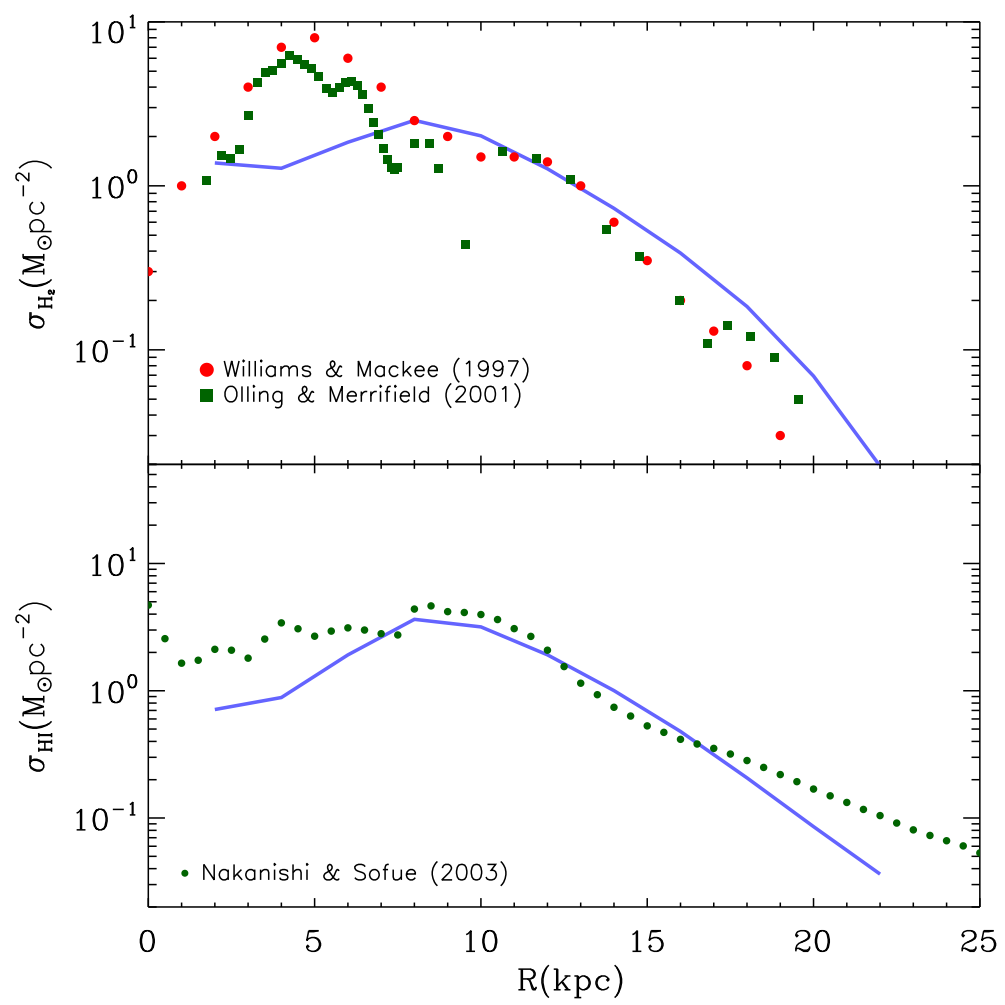

Figura 4.2: Superior: Perfil radial da densidade superficial de gás $\mathrm{H}_{2}$ para o modelo padrão de MD05 sem fluxos radiais de gás. Os dados observacionais para comparação são de Williams e McKee (1997) (círculos) e Olling e Merrifield (2001) (quadrados). Inferior: Perfil radial da densidade superficial de gás HI. Os círculos são dados observacionais de Nakanishi e Sofue (2003). A linha contínua é o modelo padrão de Mollá e Díaz (2005). O quadrado próximo de 0 kpc representa a abundância média das NPs do bojo de CCM10.

O gradiente de ferro é bem ajustado pelo modelo, porém o modelo prevê um gradiente de oxigênio mais inclinado do que as observações nas regiões mais externas do disco. Como as distâncias estatísticas das NPs apresentam uma grande incerteza, é interessante comparar o gradiente de oxigênio do modelo com outras escalas de distância.

Na figura 4.6 é mostrado o gradiente de oxigênio utilizando-se os dados de Henry et al. (2010) de NPs e a escala de distância de Cahn et al. (1992). Neste caso, o gradiente aparenta ser mais inclinado que no caso anterior. De fato, Stanghellini e Haywood (2010) encontram uma inclinação do gradiente de $-0.042 \pm 0.004$ dex $/ \mathrm{kpc}$, enquanto que os dados de Henry et al. (2010) apontam para uma inclinação de $-0.058 \pm 0.006$ dex/kpc. Porém, estes mostram que o verdadeiro gradiente tem inclinação entre -0.04 e -0.06 dex/kpc, mas que não é possível atualmente obter o valor do gradiente com maior precisão, dado os erros na determinação das abundâncias e distâncias das NPs. 


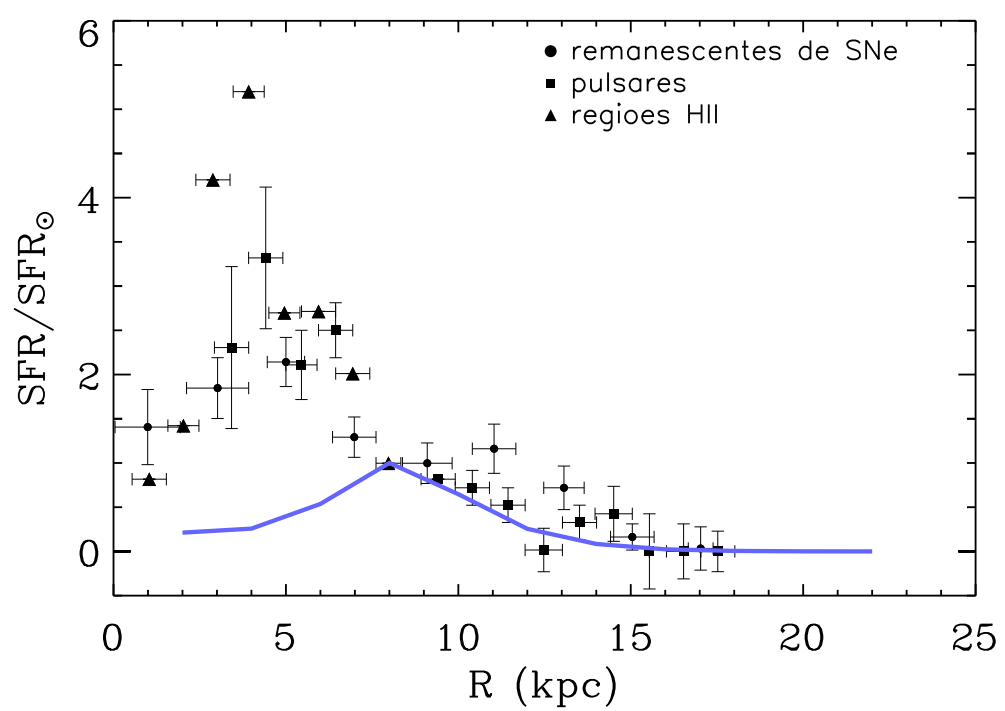

Figura 4.3: Taxa de formação estelar como função da distância galactocêntrica. Os dados observacionais (círculos, quadrados, e triângulos) são de Stahler e Palla (2005). A linha contínua representa o modelo padrão de MD05.

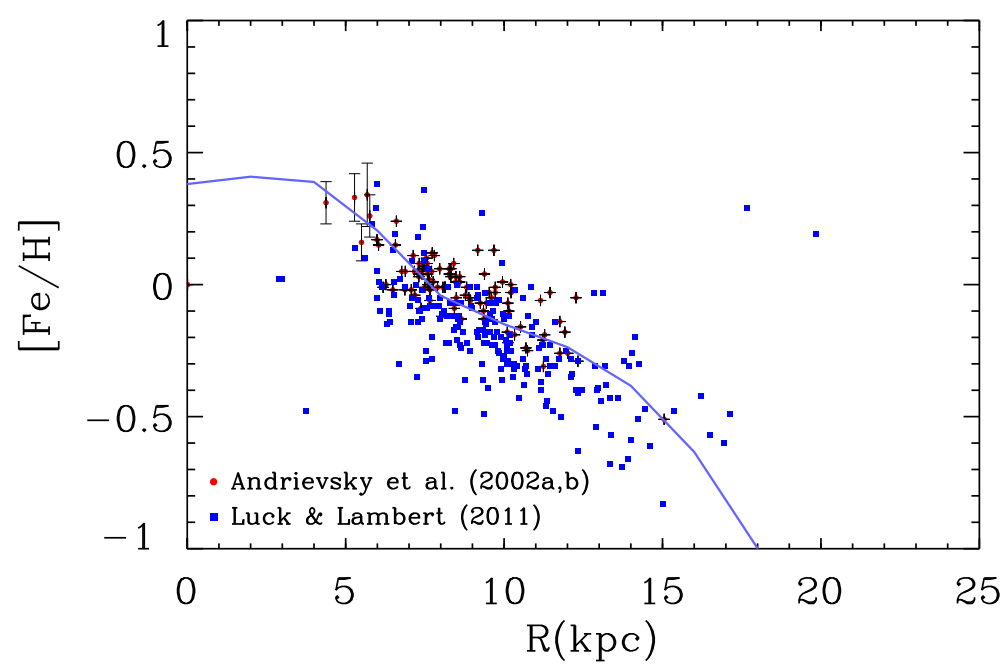

Figura 4.4: Gradiente radial de ferro para estrelas cefeidas de Andrievsky et al. (2002, a), Andrievsky et al. (2002, b) (círculos) e Luck e Lambert (2011) (quadrados) comparados com o modelo de MD05 (linha contínua).

O gradiente encontrado por Henry et al. (2010) está mais em acordo com as observações de regiões HII, que prevêem um gradiente de $-0.078 \pm 0.007$ dex $/ \mathrm{kpc}$ (Afflerbach et al., 1997; Vilchez e Esteban, 1996; Deharveng et al., 2000). Devido a este fato, neste trabalho serão utilizados os dados deste grupo para a comparação com os resultados obtidos do modelo para o gradiente radial de abundâncias de oxigênio do disco.

Na figura 4.7 é mostrada a evolução temporal do gradiente de oxigênio prevista para o 


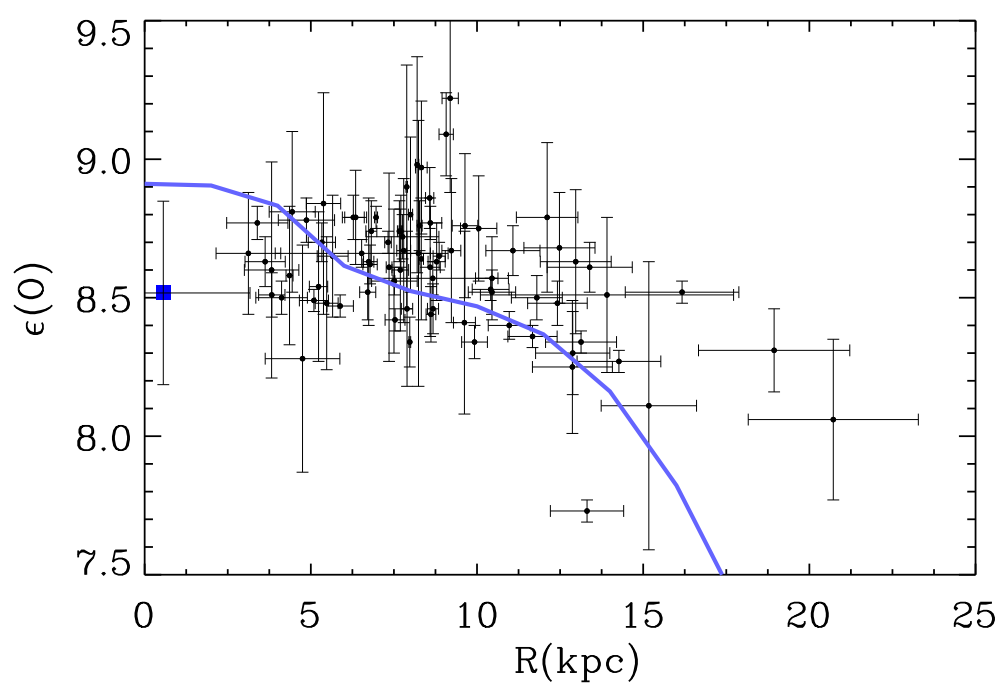

Figura 4.5: Perfil radial da abundância de oxigênio do modelo padrão de MD05 comparado com os resultados observacionais de NPs de Stanghellini e Haywood (2010) (círculos). A abundância média de NPs do bojo para os dados de Cavichia et al. (2010) é representada pelo quadrado próximo a $0 \mathrm{kpc}$. As barras de erro verticais são o desvio padrão para esta última amostra, enquanto que as horizontais representam o desvio padrão esperado para a distribuição de distâncias do bojo.

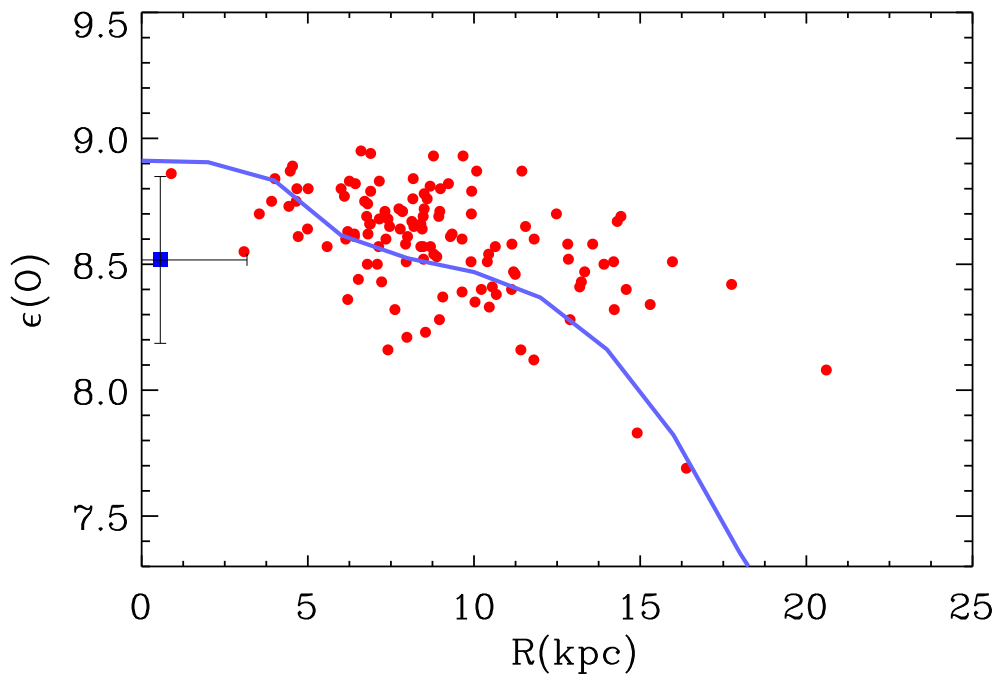

Figura 4.6: Gradiente radial de oxigênio do modelo padrão comparado com os resultados observacionais de NPs de Henry et al. (2010).

modelo de MD05. É possível notar que o modelo prevê um achatamento do gradiente ao longo do tempo. Este resultado é consistente com os resultados de NPs obtidos por Maciel et al. $(2003,2006)$.

O modelo de MD05 na presente versão inclui um bojo galáctico, o que permite a comparação com dados observacionais desta região. Um importante vínculo aos modelos de 


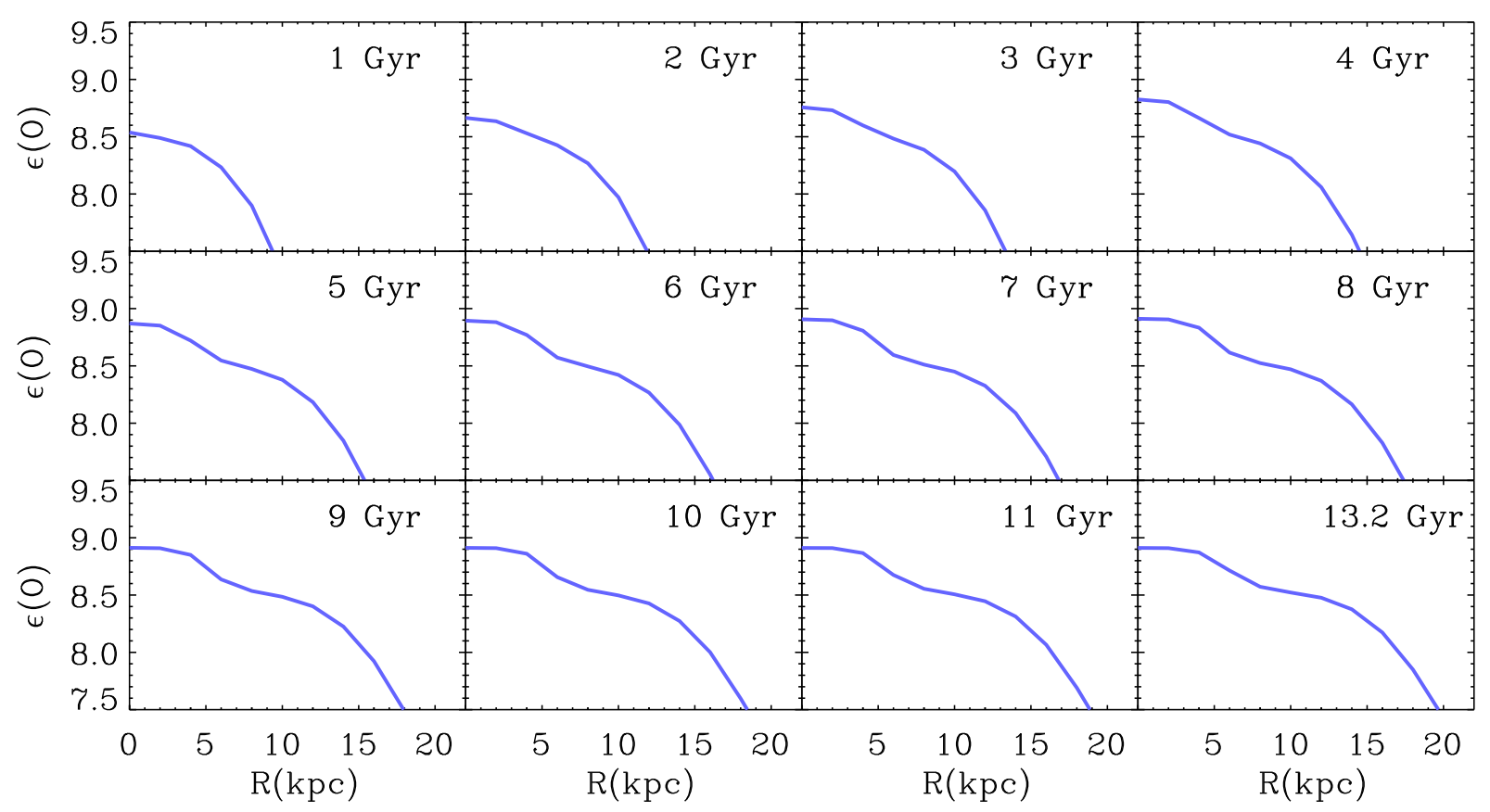

Figura 4.7: Evolução temporal do gradiente radial de oxigênio para o modelo de MD05. No lado superior direito de cada figura é indicada a idade da Galáxia, sendo que 13.2 Gyr é a idade atual.

evolução química que descrevem a formação e evolução do bojo galáctico é a distribuição de metalicidades (MD, em inglês). A MD do bojo é muito sensível à IMF adotada, como mostram Cescutti e Matteucci (2011). Estes autores argumentam que a MD do bojo não pode ser reproduzida por uma IMF de Scalo, esta sendo útil somente para prever a distribuição de abundâncias na vizinhança solar. A questão de uma IMF variável ainda permanece em aberto. Do ponto de vista observacional, as evidências apontam para uma IMF universal, que independe da metalicidade em uma vasta gama de ambientes galácticos (Myers et al., 2011). Portanto, a adoção de uma IMF variável de acordo com o ambiente precisa ser melhor explicada teórica e observacionamente. Dada esta incerteza na variação da IMF, neste trabalho optou-se por uma IMF constante para o bojo e o disco. Como dito anteriormente, neste trabalho é utilizada a IMF de Ferrini et al. (1990), onde não é assumido um equilíbrio linear e tampouco dinâmico para descrever a fragmentação de nuvens moleculares. Neste sistema, a formação estelar ocorre caso seja satisfeito um critério de instabilidade. Levando em conta diferentes critérios de instabilidade quando a massa crítica para a fragmentação é definida, os autores mostraram que, para explicar a IMF na vizinhança solar, é necessário assumir que a massa crítica para a fragmentação é determinada pelo efeito mútuo das forças gravitacional, magnética, e de turbulência. 
A distribuição de ferro do bojo obtida a partir do modelo padrão de MD05 é mostrada na figura 4.8, onde os resultados do modelo são comparados com os dados de estrelas RGB do bojo de Zoccali et al. (2008). O valor original de MD05 para a fração de ferro produzida em SNe Ia prevê uma distribuição de ferro deslocada para menores metalicidades se comparado com os resultados observacionais. Uma fração de 0.049, como mostrado na figura, prevê uma distribuição mais em acordo com as observações. É importante notar que a MD do bojo é razoavelmente bem reproduzida sem a necessidade de se adotar uma IMF para o bojo diferente da IMF do disco, como fazem outros autores (Cescutti e Matteucci, 2011; Ballero et al., 2007, e referências aí contidas).

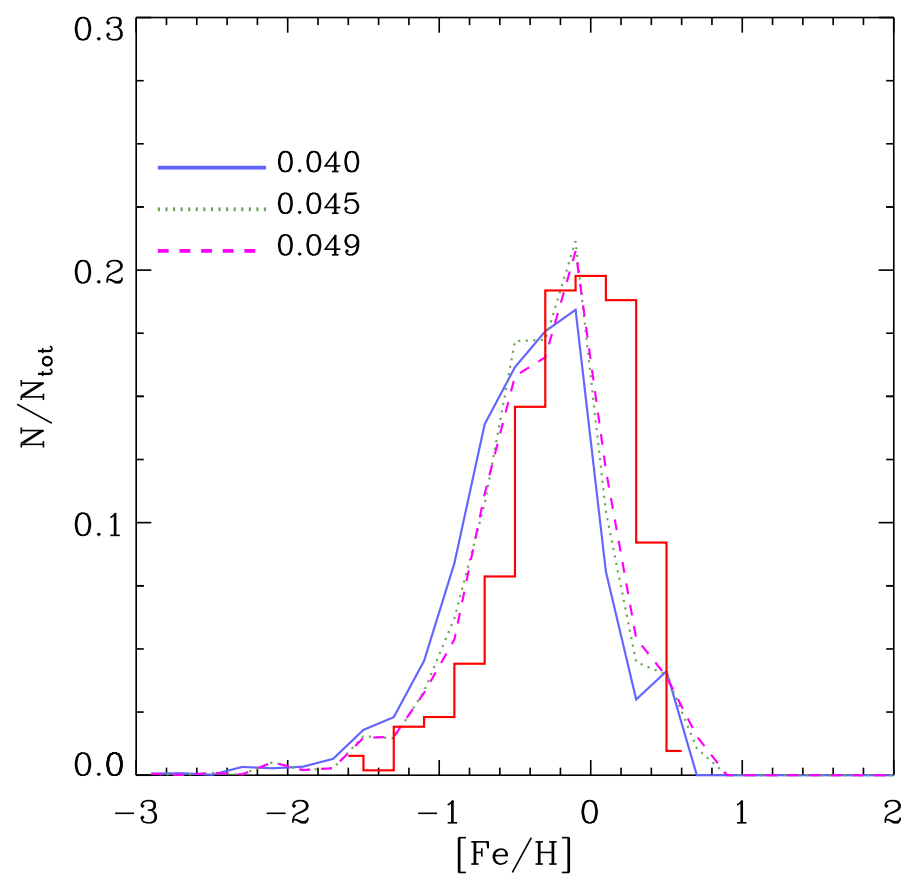

Figura 4.8: Distribuição de ferro (histograma) para 204 estrelas RGB do bojo de Zoccali et al. (2008) comparada com o modelo padrão de MD05 com diferentes frações de ferro provindo de SNe Ia.

Um teste importante para os modelos de evolução química que descrevem a evolução do bojo é a razão $[\alpha / \mathrm{Fe}]$. Este tipo de diagrama é usualmente interpretado com base na diferença de escala de tempo entre o enriquecimento químico das SNe II e Ia (Cescutti e Matteucci, 2011; Ballero et al., 2007; Mollá et al., 2000). Em particular, o longo platô que se estende até a metalicidade solar e os valores supra-solares observados na razão $[\alpha / \mathrm{Fe}]$ nas estrelas do bojo são reproduzidos através de uma formação do bojo muito rápida, como pode ser visto na figura 4.9 . 


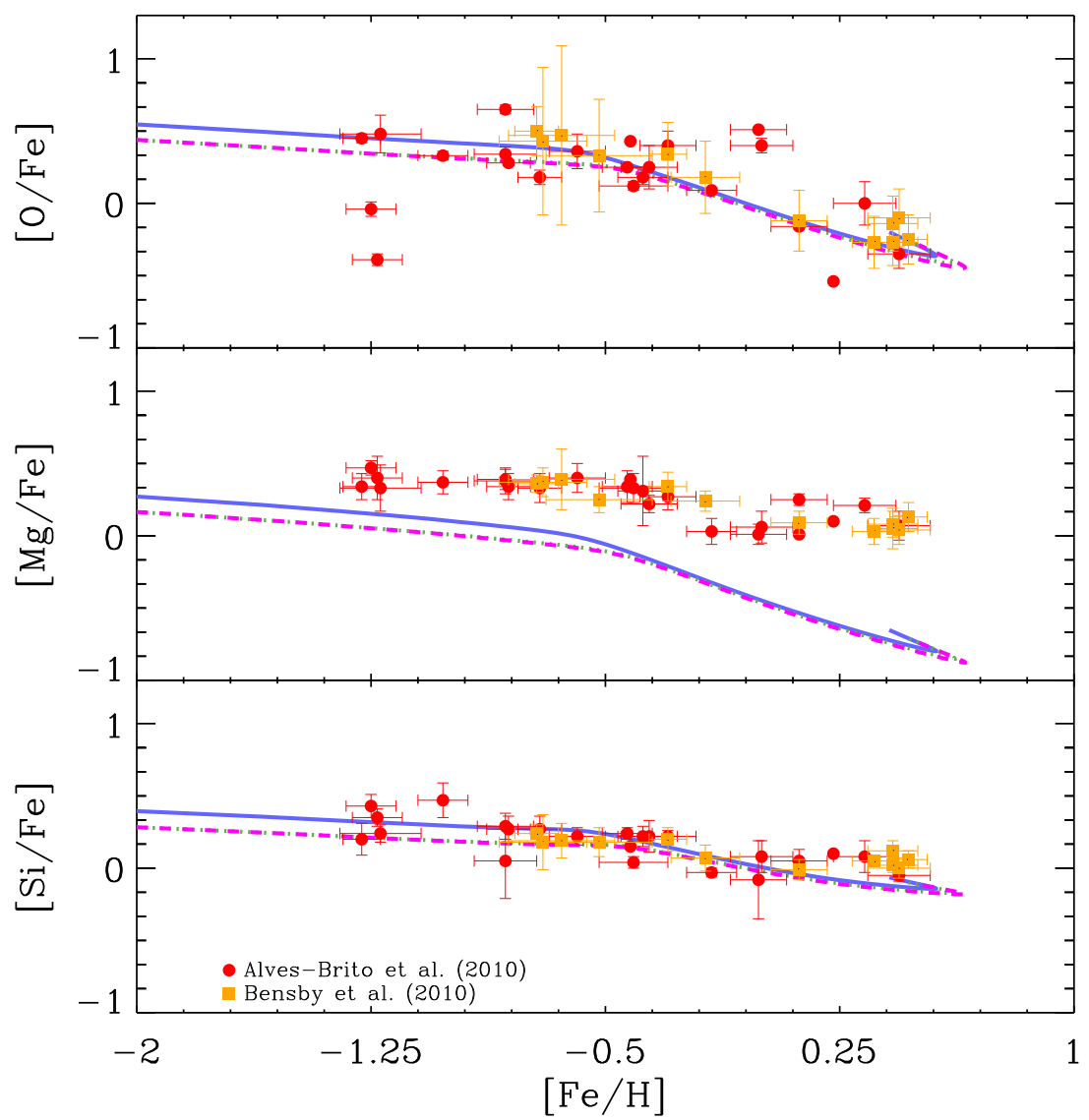

Figura 4.9: Comparação entre as previsões do modelo de MD05 para a razão $[\alpha / \mathrm{Fe}]$ utilizando-se diferentes valores para a fração de SNe Ia que contribuem para a abundância de ferro. Os dados observacionais para o bojo são de Alves-Brito et al. (2010) (círculos) e Bensby et al. (2010) (quadrados). A legenda para as diferentes linhas do modelo é similar à figura 4.8 .

Aumentando-se a fração de ferro que é produzida nas SNe Ia, diminui-se o valor da razão $[\alpha / \mathrm{Fe}]$ na região do platô, como é mostrado na figura 4.9. Porém, ao contrário da MD do bojo, os erros envolvidos na determinação das abundâncias não permitem apontar qual razão é a mais adequada para descrever a evolução do bojo. É importante notar que o modelo de MD05 não é capaz de reproduzir a razão observada de $[\mathrm{Mg} / \mathrm{Fe}]$. Como discutem Mollá et al. (2000), esta subestimativa do modelo é provavelmente relacionada com o modelo de nucleossíntese nas SNe II adotado. Thomas et al. (1998) comparam os modelos de nucleossíntese nas SNe II de Woosley e Weaver (1995) com os modelos de Thielemann et al. (1996) e encontram que estes sobrestimam a razão $[\mathrm{Mg} / \mathrm{Fe}]$ de Woosley e Weaver (1995) em 20\%. Como notam Mollá et al. (2000), para reproduzir a abundância de Mg, é necessária uma nucleossíntese de SNe II duas vezes maior que a prevista pelo 
modelo de Woosley e Weaver (1995).

Pode-se concluir nesta seção que os modelos estáticos de evolução química são adequados para reproduzir o comportamento do gradiente radial de abundâncias na vizinhança solar e nas regiões mais externas do disco. Porém, falham em reproduzir o gás, a taxa de formação estelar e as abundâncias nas regiões mais internas da Galáxia.

Como notado por Portinari e Chiosi (1999), parece impossível os modelos estáticos reproduzirem simultaneamente a densidade de gás, a taxa de formação estelar e o gradiente de metalicidades nesta região interna da Galáxia. Para produzir uma metalicidade mais alta nas regiões mais internas, a formação estelar deve ser mais efetiva nesta região e, consequentemente, os processos que envolvem o consumo do gás disponível devem ser mais eficientes. Porém, como se pode ver nas figuras 4.2, 4.3, e 4.5, maior metalicidade não implica em maiores quantidades de gás ou taxa de formação estelar. Portinari e Chiosi (1999) propõem que uma solução para este problema seria uma IMF voltada para maiores massas nas regiões internas da Galáxia. Contudo, como argumentam os autores e como discutido anteriormente, uma variação sistemática da IMF é controversa do ponto de vista teórico e observacional (Scalo, 1998). Uma outra solução proposta pelos autores é que a formação do anel molecular de gás na região interna da Galáxia envolve processos cinemáticos e dinâmicos não levados em conta por simples modelos químicos estáticos. Como discutido no capítulo introdutório, a formação de anéis em galáxias espirais barradas pode estar ligada aos processos dinâmicos induzidos pela barra dessas galáxias nestas regiões.

Existem alguns modelos de evolução química que levam em conta os fluxos radiais de gás para descrever a evolução química da Via Láctea. O gás que cai no disco possui um momento angular menor do que o gás que está em um movimento circular no disco, e a mistura de ambos os gases induz um inflow de gás no disco. Lacey e Fall (1985) estimam que a velocidade desse fluxo de gás é da ordem de até alguns $\mathrm{km} \mathrm{s}^{-1}$. Goetz e Koeppen (1992) propõem modelos numéricos e analíticos que incluem fluxos radiais de gás. Eles concluem que os fluxos radiais por si só não são suficientes para explicar os gradientes de abundâncias no disco, mas são uma maneira eficiente de amplificar os gradientes já existentes. Koeppen (1994) mostra que os gradientes podem ser gerados por inflow radial de gás quando a velocidade deste aumenta com a distância galactocêntrica. 
Ou, ao contrário, também podem ser gerados por outflows quando a velocidade diminui com o raio. Portinari e Chiosi (2000) incluem fluxos radiais de gás no modelo publicado pelo mesmo grupo em 1999. Eles mostram que os gradientes são explicados por meio dos fluxos radiais, o que seria uma alternativa aos modelos de formação inside-out. O modelo de Portinari e Chiosi (2000) reproduz com sucesso o perfil radial de gás na região interna da Galáxia e ao mesmo tempo o gradiente de metalicidades nesta região. Os autores ainda discutem os possíveis efeitos dinâmicos da barra, e mostram que é possível reproduzir o pico da distribuição de gás ao redor de 4 kpc, porém não estudam a distribuição radial da SFR nesta região. Schönrich e Binney (2009) consideram fluxos de gás e estrelas em um modelo de evolução química sem formação inside-out. Eles são capazes de reproduzir o gradiente de metalicidades do disco, porém não estudam com detalhes as distribuições de gás e SFR no disco. Mais recentemente, Spitoni e Matteucci (2011) estudam os efeitos dos fluxos radiais de gás no gradiente de metalicidades do disco. Os autores conseguem reproduzir o gradiente através de fluxos radiais com velocidades variáveis e concluem que os fluxos radiais de gás podem, em princípio, reproduzir os gradientes ao longo do disco, mas argumentam que um modelo com formação inside-out junto com uma eficiência de formação estelar variável também é capaz de reproduzir os gradientes. Porém, com este modelo não é possível reproduzir o perfil de gás nas regiões internas da Galáxia. Como os autores discutem, isto é devido à não inclusão dos efeitos da barra nesta região mais interna.

\subsubsection{Modelos com fluxos radiais de gás}

Neste trabalho pretende-se utilizar o conhecimento atual sobre fluxos radiais de gás para estudar detalhadamente os efeitos desses fluxos nas distribuições de abundâncias, SFR, e gás nas regiões internas da Via Láctea. Mais especificamente, pela primeira vez é utilizado um modelo de evolução química que inclui fluxos radiais de gás e a evolução química conjunta do disco e bojo da Galáxia. Portanto, é interessante comparar os resultados obtidos com tal modelo com observações de estrelas e nebulosas planetárias do disco e bojo da Galáxia de uma maneira unificada. A seguir são apresentados os resultados dos modelos desenvolvidos. São considerados três casos neste trabalho:

A. Inflow radial de gás; 
B. Outflow radial de gás;

C. Inflow radial de gás no disco e a presença de uma barra na região interna da Galáxia.

No disco, um possível mecanismo de indução de fluxos radiais de gás é a viscosidade das camadas de gás. Lacey e Fall (1985) apontam que uma viscosidade efetiva $\nu$ pode induzir uma velocidade radial dada por:

$$
\left|v_{r}\right| \sim \frac{\nu}{r}
$$

Para um fluido de partículas com caminho livre médio $\ell$, dispersão de velocidade total $\sigma$, e frequência epicíclica $\kappa$, a viscosidade cinemática é dada por (Goldreich e Tremaine, 1978; Fukunaga, 1983):

$$
\nu \approx \frac{\sigma^{3} \ell}{3\left[(\kappa \ell)^{2}+\sigma^{2}\right]}
$$

Esta expressão é válida sejam as partículas gás atômico ou nuvens de gás, mas a viscosidade devida às colisões atômicas é desprezível com relação à viscosidade das colisões entre nuvens. Para as nuvens HI, $\ell \sim 300$ pc e $\sigma \approx 14 \mathrm{~km} \mathrm{~s}^{-1}$, desta forma $\nu \approx 1 \mathrm{~km} \mathrm{~s}^{-1} \mathrm{kpc}$. Para as nuvens gigantes moleculares, $\sigma \approx 6 \mathrm{~km} \mathrm{~s}^{-1}$, sendo assim $\nu \approx 0.1 \mathrm{~km} \mathrm{~s}^{-1} \mathrm{kpc}$. A viscosidade final é uma combinação das outras duas ponderadas pela densidade superficial correspondente:

$$
\nu=\frac{\nu_{H I} \times G_{\mathrm{HI}}+\nu_{\mathrm{GMC}} \times G_{\mathrm{GMC}}}{G_{\mathrm{HI}}+G_{\mathrm{GMC}}} .
$$

Portanto tem-se que:

$$
\left|v_{r}\right| \approx \frac{1 \mathrm{~km} \mathrm{~s}^{-1} \mathrm{kpc}}{r(\mathrm{kpc})} .
$$

Os resultados obtidos com o modelo utilizando fluxos radiais de gás são apresentados agora. Os três casos de fluxos radiais de gás estudados neste trabalho são mostrados na tabela 4.1. Nesta tabela, a coluna 1 indica o nome do modelo, as colunas 2 e 3 o padrão de velocidades adotado e as velocidades, e a coluna 4 o fator de escala do tempo de colapso, conforme a equação 4.2. Em todos os casos, os modelos com fluxos radiais são comparados com o modelo padrão de Mollá e Díaz (2005) para uma melhor visualização dos efeitos dos fluxos radiais de gás nos resultados obtidos. Nos modelos, são variados o padrão de velocidade dos fluxos e o fator de escala do tempo de colapso. O modelo A representa um inflow radial de gás no disco constante no tempo. O modelo B representa um outflow 
Tabela 4.1 - Parâmetros utilizados nos modelos.

\begin{tabular}{lccc}
\hline \hline Modelo & padrão de vel. & $v\left(\mathrm{~km} \mathrm{~s}^{-1}\right)$ & $\lambda$ \\
\hline MD05 & estático & 0.0 & 0.5 \\
A & inflow & +1.0 & 0.5 \\
B & outflow & -1.0 & 0.5 \\
C & variável & fig. 4.10 & 0.8 \\
\hline
\end{tabular}

radial de gás. Em ambos os casos, a velocidade diminui radialmente de acordo com a equação 4.47.

O modelo $\mathrm{C}$ inclui os efeitos da barra além de um inflow de gás no disco e é baseado no caso B de Portinari e Chiosi (2000). Neste modelo, a corrotação (CR) da barra está localizada em $2.5 \mathrm{kpc}$, próxima da extremidade desta, e a ressonância externa de Lindblad da barra (OLR) está localizada em 4.5 kpc. O gás então escoa da CR para a OLR, onde é acumulado, enquanto que o gás das regiões externas escoa em direção ao centro da Galáxia, acumulando-se na ressonância em 4.5 kpc. Este padrão de fluxos deve começar no momento em que a barra é originada. Desta forma, os fluxos de gás que simulam o efeito da barra começam em 8 Gyr após o início da formação da Galáxia, pois não se espera que a barra tenha mais que 5 Gyr de idade (Cole e Weinberg, 2002). O padrão de velocidade para o modelo que inclui a barra é mostrado na figura 4.10. A Galáxia evolui até uma idade de 8 Gyr com uma velocidade de inflow dada pela curva tracejada na figura. A partir de 8 Gyr, a barra começa a atuar modificando os fluxos de gás na região interna da Galáxia. O padrão de velocidade para este caso é representado pela linha pontilhada na figura.

O valor da velocidade máxima para todas as simulações é de $1 \mathrm{~km} \mathrm{~s}^{-1}$ pois não se esperam velocidades muito elevadas para os fluxos de gás no disco galáctico (Lacey e Fall, 1985; Portinari e Chiosi, 2000).

A figura 4.11 mostra os resultados obtidos para o perfil de densidade de gás a partir do modelo de evolução química modificado para a inclusão de fluxos radiais de gás. O modelo padrão de MD05 é mostrado na figura para uma melhor comparação com os outros modelos. Na figura, é possível ver que o modelo A com inflow de gás reproduz bem o perfil de densidade de gás nas regiões externas do disco, mas falha em reproduzir o perfil na região interna do disco, para $R<R_{\odot}$. O modelo $\mathrm{B}$ com outflow de gás também não consegue 


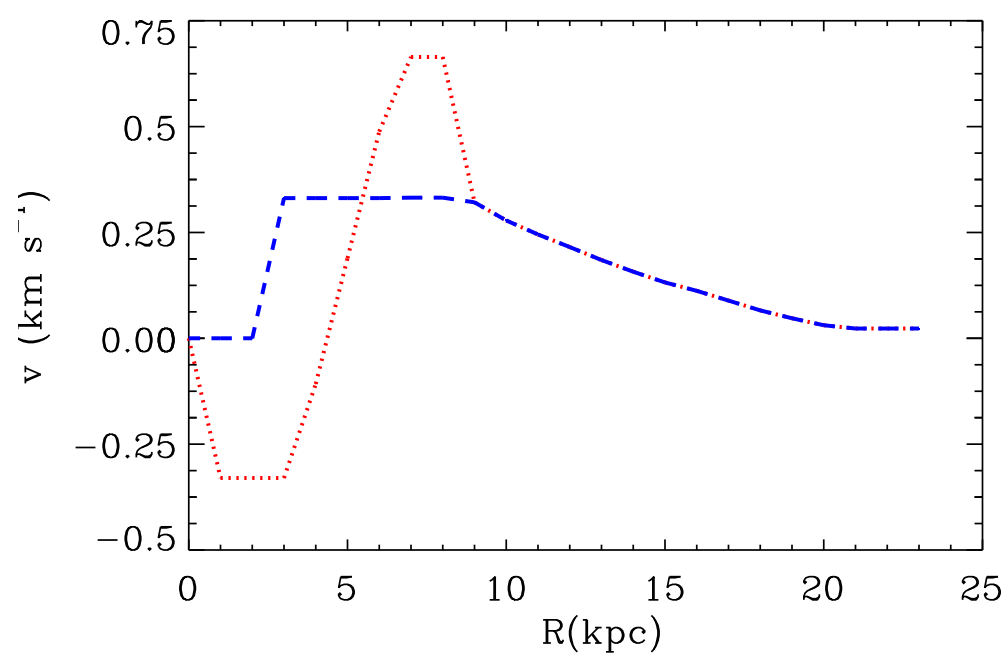

Figura 4.10: Padrão de velocidades adotado para o modelo C. A linha tracejada corresponde ao perfil de velocidade do gás para o modelo com $T<8$ Gyr. A idade da barra é de 5 Gyr neste modelo e a partir de $T=8 \mathrm{Gyr}$ a barra começa a alterar o perfil de velocidade do gás, que corresponde à linha pontilhada.

reproduzir o perfil de densidade para esta região e, além disso, o perfil é sobrestimado na região mais externa do disco. É importante notar que um inflow de gás traz gás da região externa do disco para a interna e, portanto, a densidade de gás é maior na região de 4-5 kpc do disco do que os modelos A e MD05. Porém, apenas um inflow de gás constante não é suficiente para reproduzir o anel de gás nesta região. O modelo $\mathrm{C}$ que inclui os efeitos da barra é o melhor modelo para explicar a formação do anel de gás na região interna do disco. Apesar deste modelo não conseguir reproduzir com perfeição o anel de gás, os resultados indicam que um padrão de velocidades com o gás saindo da corrotação da barra em direção à ressonância OLR produz importantes alterações no perfil de densidade de gás nesta região. Entretanto, o perfil de densidade de gás na região mais externa do disco também é sobrestimado por este modelo.

Contudo, o resultado mais convincente para justificar a inclusão dos efeitos da barra na evolução do disco interno da Galáxia é fornecido pela figura 4.12. Esta figura mostra o perfil radial da taxa de formação estelar (SFR) atual, normalizada para a taxa de formação na vizinhança solar. Os dados observacionais são de Stahler e Palla (2005) e incluem observações de remanescentes de supernova, pulsares, e regiões HII. É interessante notar a existência de um pico na formação estelar ao redor de $5 \mathrm{kpc}$. Os modelos A, B e MD05 não conseguem reproduzir este pico, mesmo após a inclusão dos fluxos radiais de gás. 


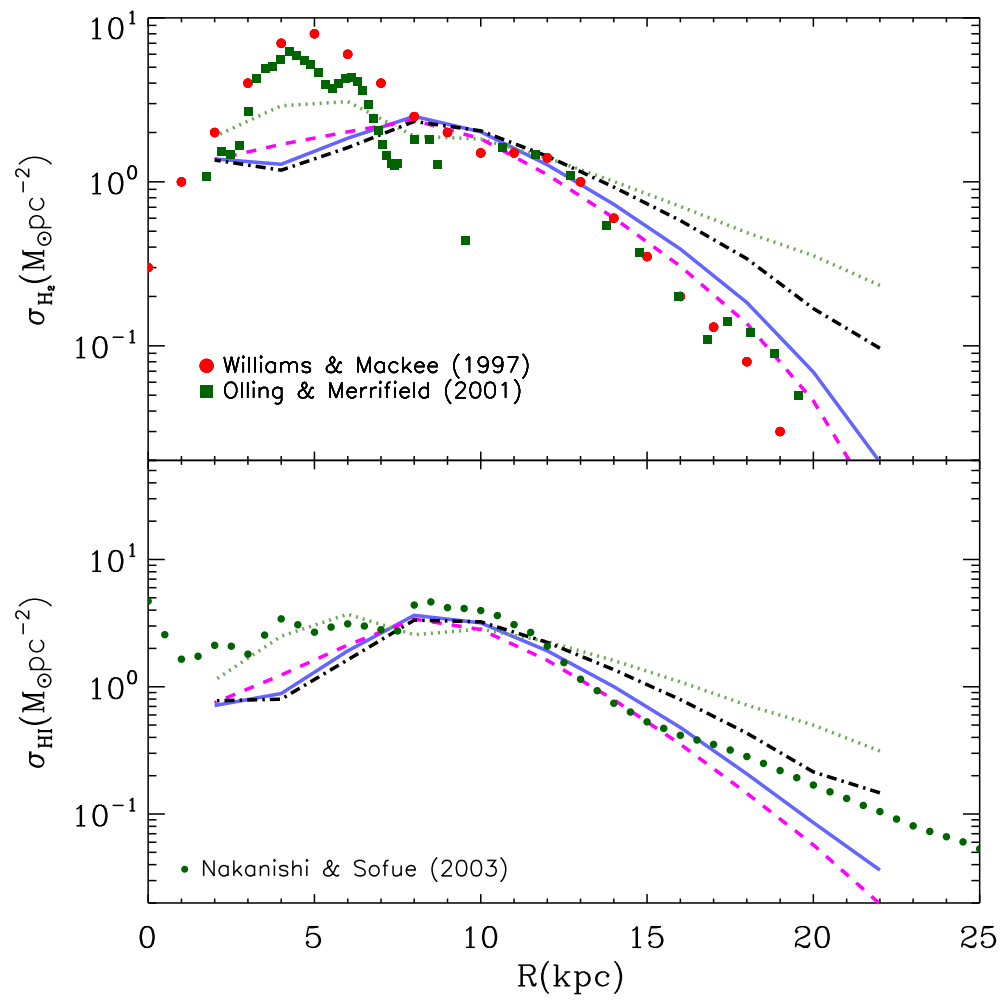

Figura 4.11: Superior: Perfil radial da densidade superficial de gás $\mathrm{H}_{2}$ para o modelo padrão de MD05 (linha contínua) sem fluxos radiais de gás. O modelo A é representado pela linha tracejada, o modelo B pela linha tracejada e pontilhada, e o modelo C pela linha pontilhada. Os dados observacionais para comparação são de Williams e McKee (1997) (círculos) e Olling e Merrifield (2001) (quadrados). Inferior: Perfil radial da densidade superficial de gás HI. Os círculos são dados observacionais de Nakanishi e Sofue (2003). As linhas representam os modelos como no caso do painel superior.

Apenas o modelo C com a barra é capaz de descrever a formação do pico da SFR. Este é um resultado importante, pois pela primeira vez um modelo de evolução química prevê a formação de um anel de gás no disco interno da Galáxia e, ao mesmo tempo, a formação de um pico na taxa de formação estelar nesta mesma região.

Um teste importante para a comparação entre os modelos é o gradiente radial de ferro das estrelas cefeidas. Dada a precisão na determinação das abundâncias destas estrelas, da ordem de 0.1 dex, e das distâncias, da ordem de 13\% (Luck e Lambert, 2011), estes objetos são um importante vínculo aos modelos de evolução química que descrevem a formação do disco. Uma comparação entre os resultados do modelo e o gradiente de ferro das estrelas cefeidas é mostrada na figura 4.13. Os dados observacionais são de Andrievsky et al. (2002, a), Andrievsky et al. (2002, b) e Luck e Lambert (2011). O modelo padrão é capaz de 


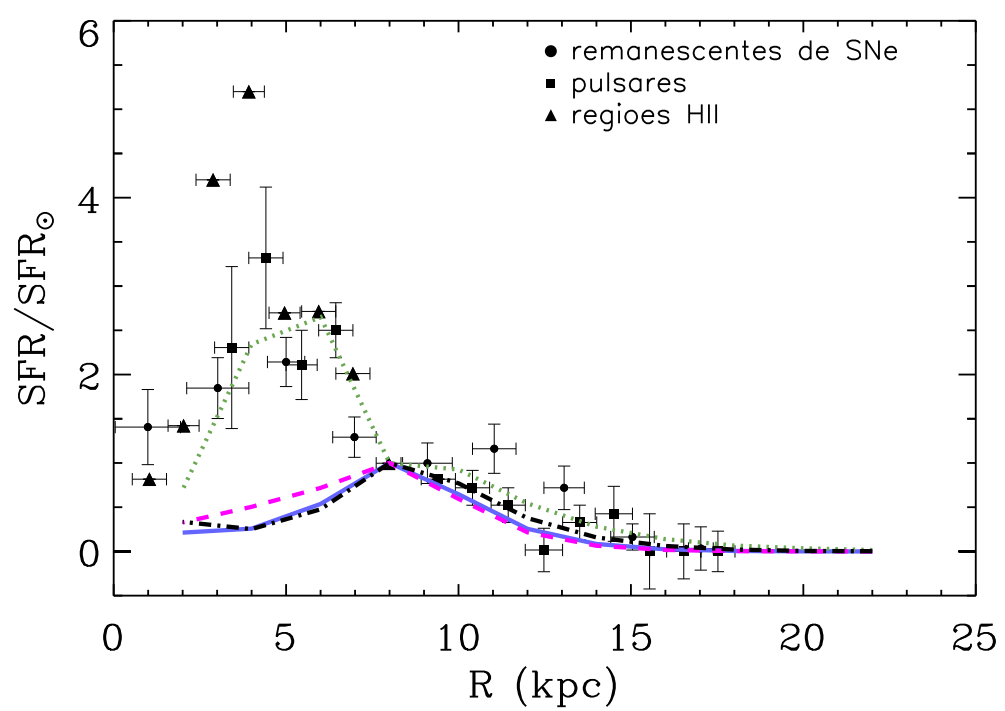

Figura 4.12: Taxa de formação estelar como função da distância galactocêntrica. Os dados observacionais (círculos, quadrados, e triângulos) são de Stahler e Palla (2005). As linhas representam os modelos MD05 (linha contínua), A (linha tracejada), B (linha tracejada e pontilhada), e C (linha pontilhada).

reproduzir com sucesso o gradiente de ferro com os dados de Andrievsky et al. (2002). Porém, os novos dados publicados por Luck e Lambert (2011), apontam para abundâncias de ferro subsolares na vizinhança solar. Mesmo com as cefeidas, ainda é difícil prever o comportamento do gradiente na região externa do disco. O conjunto de objetos mais externos no disco, mesmo que sendo poucos, apontam para um achatamento do gradiente nesta região comparado com a região mais interna. Ainda são necessários mais dados nesta região externa para se obter o comportamento do gradiente nesta parte do disco. Os modelos B e C são os que mais sobrestimam o gradiente para $R>10 \mathrm{kpc}$, como pode ser visto na figura. É interessante notar que os modelos B e C prevêem um decréscimo da abundância de ferro próximo ao centro galáctico, em acordo com os resultados obtidos por Cunha et al. (2007).

A distribuição radial das abundâncias de oxigênio em nebulosas planetárias também é um importante vínculo para os modelos de evolução química. Apesar das distâncias destes objetos não serem tão precisas quanto as das cefeidas, as NPs tem se mostrado uma ferramenta importante para o estudo do gradiente em galáxias (Maciel e Costa, 2010; Henry et al., 2010; Stanghellini e Haywood, 2010; Gutenkunst et al., 2008; Magrini et al., 2004). Em um recente artigo publicado por Stanghellini e Haywood (2010), os autores 


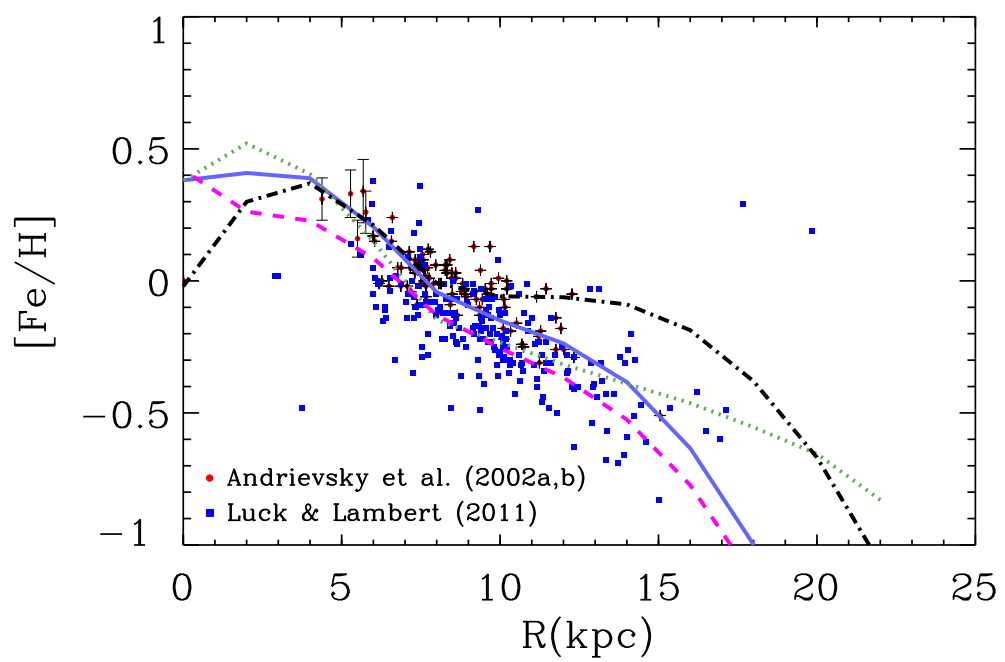

Figura 4.13: Gradiente radial de ferro para estrelas cefeidas de Andrievsky et al. (2002, a), Andrievsky et al. (2002, b) (círculos) e Luck e Lambert (2011) (quadrados). Os símbolos e cores das linhas dos modelos são análogos à figura 4.12.

usam a nova escala de distância publicada por Stanghellini et al. (2008) para estudar o gradiente de metalicidade do disco. Os resultados são apresentados na figura 4.14, onde é mostrado o gradiente obtido por Stanghellini e Haywood (2010) juntamente com os modelos desenvolvidos neste trabalho. Os modelos concordam razoavelmente bem com os dados na região interna da Galáxia, contudo as observações mostram que o gradiente é mais plano na região externa do disco. É importante notar que existem dados de apenas dois objetos para $R>17$ kpc e é necessário interpretar com cautela o gradiente nesta região. Os dados de Stanghellini e Haywood (2010) apontam para um gradiente mais plano do que o obtido por outros grupos. De fato, Henry et al. (2010), utilizando também NPs e a escala de distância de Cahn et al. (1992), mostram que o gradiente do disco é mais inclinado do que o trabalho de Stanghellini e Haywood (2010).

O gradiente de abundâncias de oxigênio obtido por Henry et al. (2010) é mostrado na figura 4.15. Como discutido anteriormente, este gradiente é mais inclinado que o anterior, mostrando que as diferentes escalas de distância influenciam no valor do gradiente. Mas de uma maneira geral, o comportamento dos dois gradientes é similar: os objetos localizados na região mais interna do disco apresentam abundâncias maiores do que os localizados nas regiões mais externas, e indicam a existência de dois platôs de abundâncias. O primeiro platô está localizado na região interna do raio solar, enquanto que o segundo está localizado na região externa do mesmo raio. Lépine et al. (2011) atribuem este fato ao efeito da 


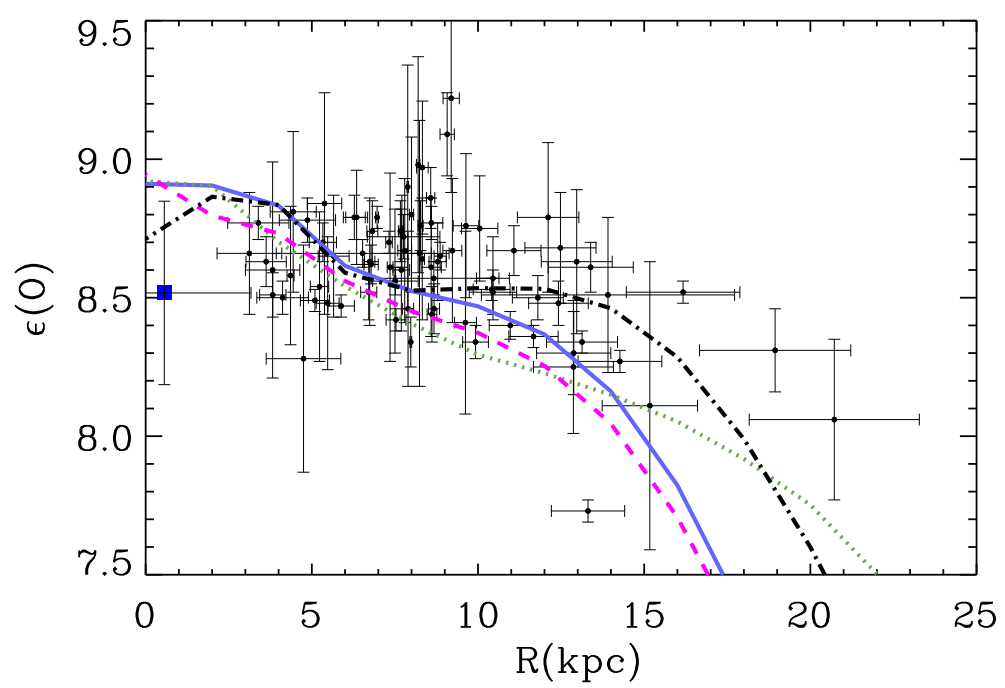

Figura 4.14: Perfil radial da abundância de oxigênio dos diferentes modelos considerados neste trabalho em $T=8 \mathrm{Gyr}$, comparado com os resultados observacionais de NPs de Stanghellini e Haywood (2010). Os símbolos e cores das linhas são análogos à figura 4.12. A abundância média de NPs do bojo para os dados de CCM10 é representada pelo quadrado próximo a 0 kpc. As barras de erros verticais são o desvio padrão para esta última amostra, enquanto que as horizontais representam o desvio padrão esperado para a distribuição de distâncias do bojo.

corrotação do disco próximo à vizinhança solar. É interessante notar que o modelo B que prevê um outflow de gás apresenta um gradiente mais em acordo com as observações. Como a população de NPs do disco é composta em sua maioria por objetos oriundos de estrelas com idade de 5 Gyr ou mais (Maciel et al., 2003), ela não representa o gradiente atual, mas sim o gradiente de 5 Gyr atrás. Deste modo, os efeitos da barra no gradiente destes objetos não pode ser notado.

Para uma melhor comparação entre os diferentes tipos de modelos, são necessários mais dados na região externa do disco galáctico, assim como uma melhor precisão nas distâncias e abundâncias químicas. Com relação às distâncias, a missão Gaia trará grandes progressos neste campo. Como informado no website da ESA (Agência Espacial Européia), o principal objetivo da missão Gaia é realizar o maior e mais preciso mapa tridimensional da Via Láctea, observando-se da ordem de 1\% de sua população de 100 bilhões de estrelas. O lançamento previsto para esta missão será em 2013, sendo que a duração prevista é de 5 anos.

A evolução temporal do gradiente também é de grande interesse para a evolução galáctica, como pode ser visto em Maciel et al. (2006) e referências aí contidas. A fi- 


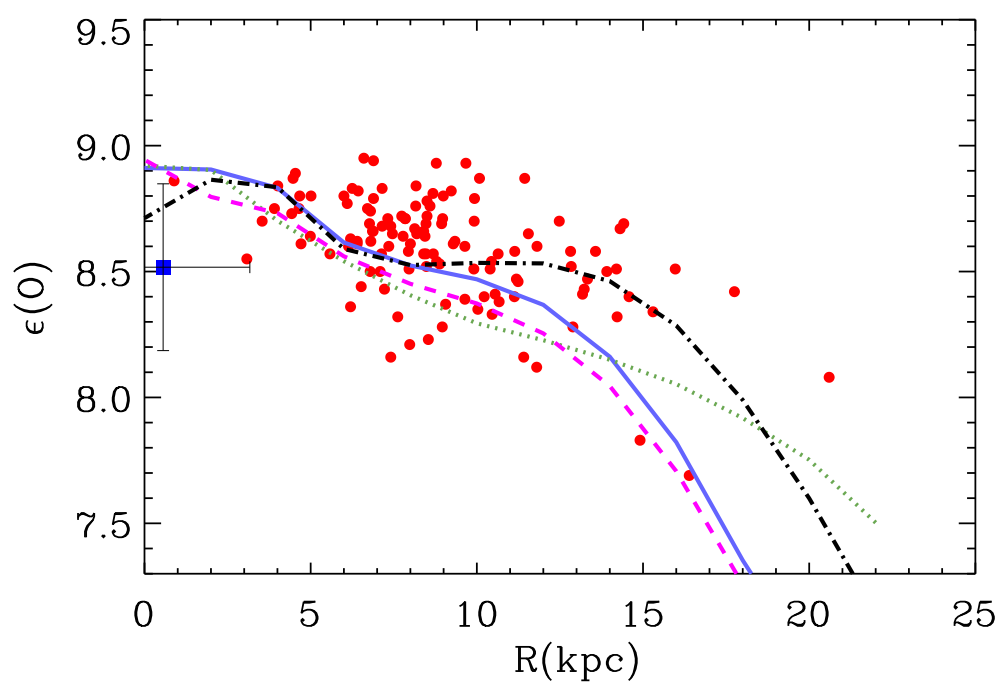

Figura 4.15: Gradiente radial de oxigênio dos modelos deste trabalho em $T=8$ Gyr, comparado com os resultados observacionais de NPs de Henry et al. (2010). Os símbolos e cores das linhas são análogos à figura 4.14.

gura 4.16 mostra a abundância do oxigênio em função da distância galactocêntrica $R$ para diferentes instantes de tempo. No canto direito superior de cada painel está indicada a idade da Galáxia no momento de cada simulação, sendo que 13.2 Gyr é a idade atual da Galáxia. Em todos os modelos, a Galáxia se forma de dentro para fora (inside-out) e, à medida que o tempo evolui, o gradiente vai se tornando mais plano. Para os modelos B e C o achatamento do gradiente ocorre mais rápido se comparado aos demais modelos. No caso do modelo B isto é de se esperar, pois um fluxo maior de gás para as regiões externas transporta os elementos produzidos nas regiões mais internas para as mais externas da Galáxia. Porém para o modelo $\mathrm{C}$ que inclui uma barra este fato é surpreendente. Após o início da atuação da barra em 8 Gyr, a diferença para os modelos MD05 e C é aumentada na região externa do disco. Este fato está em acordo com observações feitas por Martin e Roy $(1994,1995)$, que encontraram uma correlação entre o gradiente de abundâncias e a força da barra em galáxias espirais barradas. Esta correlação mostra que as galáxias espirais com barras mais fortes apresentam um gradiente de metalicidade mais plano.

Pretende-se agora entender a influência dos fluxos de gás na evolução do bojo galáctico. Existem modelos na literatura que consideram o caso dos fluxos radiais no disco, como por exemplo os trabalhos de Goetz e Koeppen (1992), Koeppen (1994), Portinari e Chiosi (2000), Schönrich e Binney (2009), Spitoni e Matteucci (2011), porém nenhum destes mo- 


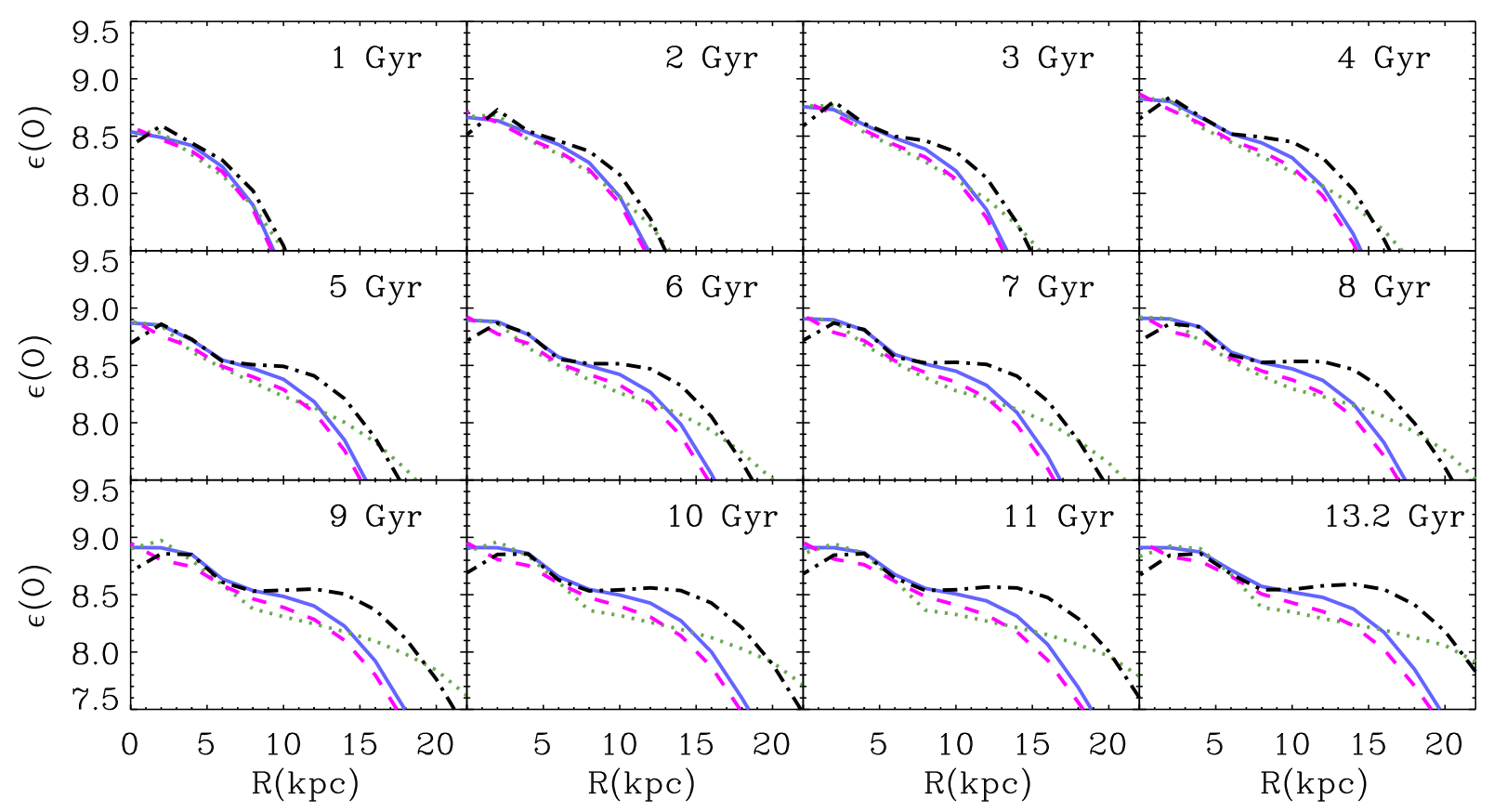

Figura 4.16: Evolução temporal do gradiente radial de oxigênio para os modelos estudados neste trabalho. No lado superior direito de cada figura é indicada a idade da Galáxia, sendo que 13.2 Gyr é a idade atual. Os símbolos e cores das linhas são análogos à figura 4.12.

delos inclui um bojo central. São poucos os trabalhos que buscam estudar a região central da Galáxia de forma conjunta. A grande maioria deles trata as subestruturas da Galáxia de forma independente. Dependendo do cenário de evolução do bojo, esta diferenciação acarreta vários problemas na descrição da evolução química e dinâmica destas estruturas, que estão certamente interceptadas, e é exatamente a interconexão destas estruturas que merece especial atenção, já que nestes pontos deve haver o encontro das características individuais de cada uma. Portanto, faz-se necessário o estudo dos efeitos dos fluxos radiais de gás no estudo da evolução do bojo galáctico.

Primeiramente, são apresentados os resultados para a distribuição de metalicidades do bojo, como pode ser visto na figura 4.17. Existem algumas alterações na distribuição de metalicidades quando são considerados os fluxos radiais de gás no modelo. Em particular, o modelo B com outflow de gás prevê uma distribuição mais estreita do que os dados mostram. Os modelos A e C apresentam poucas alterações na distribuição de metalicidade se comparados ao modelo de MD05. As distribuições destes modelos são levemente diferentes, sendo que o modelo $\mathrm{C}$ apresenta uma distribuição voltada para metalicidades mais altas do que o modelo A. Isto é, o modelo com barra tem uma formação estelar mais alta do que 
os demais modelos com fluxos. Este fato pode ser visualizado na figura 4.18, que mostra a evolução temporal da SFR do bojo.

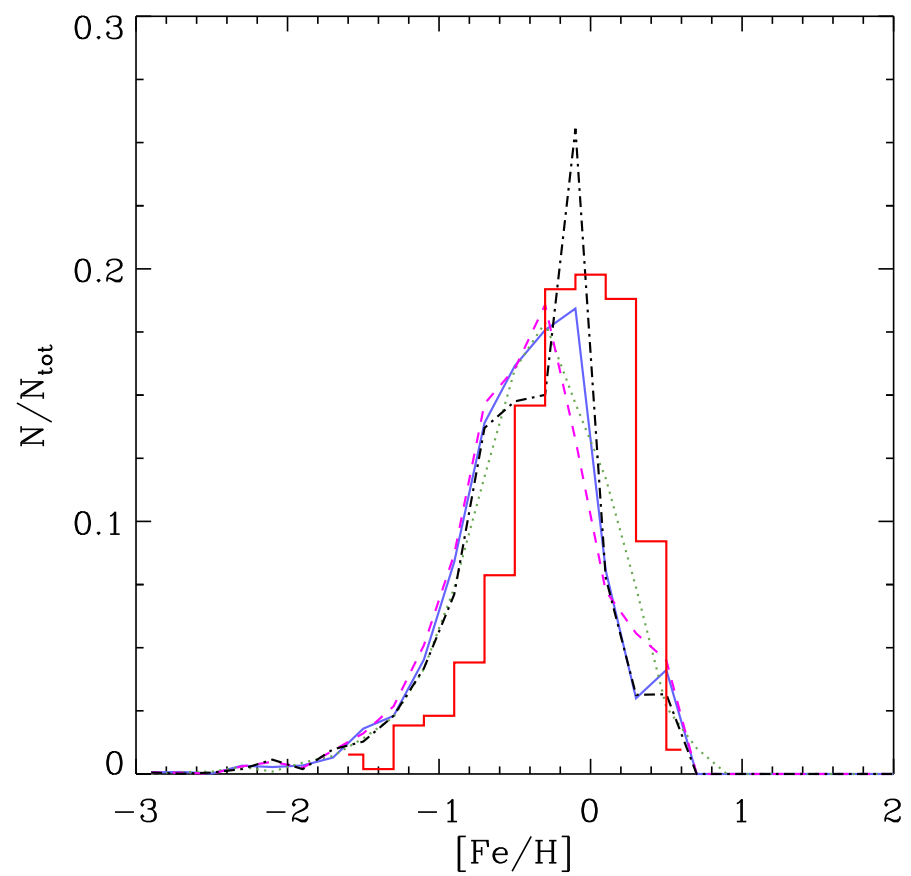

Figura 4.17: Distribuição de ferro (histograma) para 204 estrelas RGB do bojo de Zoccali et al. (2008) comparada com os modelos com fluxos de gás. Os símbolos e cores das linhas são análogos à figura 4.12.

Em geral, os modelos com fluxos de gás apresentam uma SFR mais alta do que o modelo de MD05 sem fluxos. De fato, como a figura mostra, a taxa de formação estelar no bojo é mais intensa por mais tempo para os modelos A, B e C do que o modelo MD05. Este resultado concorda com os resultados obtidos por Ellison et al. (2011) que utilizam uma amostra de galáxias barradas e não barradas para estudar a SFR na região central destas galáxias. Os autores mostram que a SFR central de galáxias classificadas visualmente como barradas com $\mathrm{M}>10^{10} \mathrm{M}_{\odot}$ são maiores que a das galáxias não barradas de mesma massa por $\sim 60 \%$. Estes resultados indicam que a barra e os fluxos de gás exercem um importante papel na formação de estrelas no centro das galáxias espirais barradas.

Uma outra comparação que pode ser feita entre os modelos é a razão $[\alpha / \mathrm{Fe}]$. A figura 4.19 mostra as previsões dos modelos para a razão entre os elementos $\alpha$ e a abundância de ferro. Como se pode ver na figura, não existe diferença apreciável entre os diferentes modelos considerados. Portanto, pode-se concluir que os fluxos radiais de gás não alteram a razão entre as abundâncias dos elementos $\alpha$ e a abundância de ferro. De fato, esta razão 


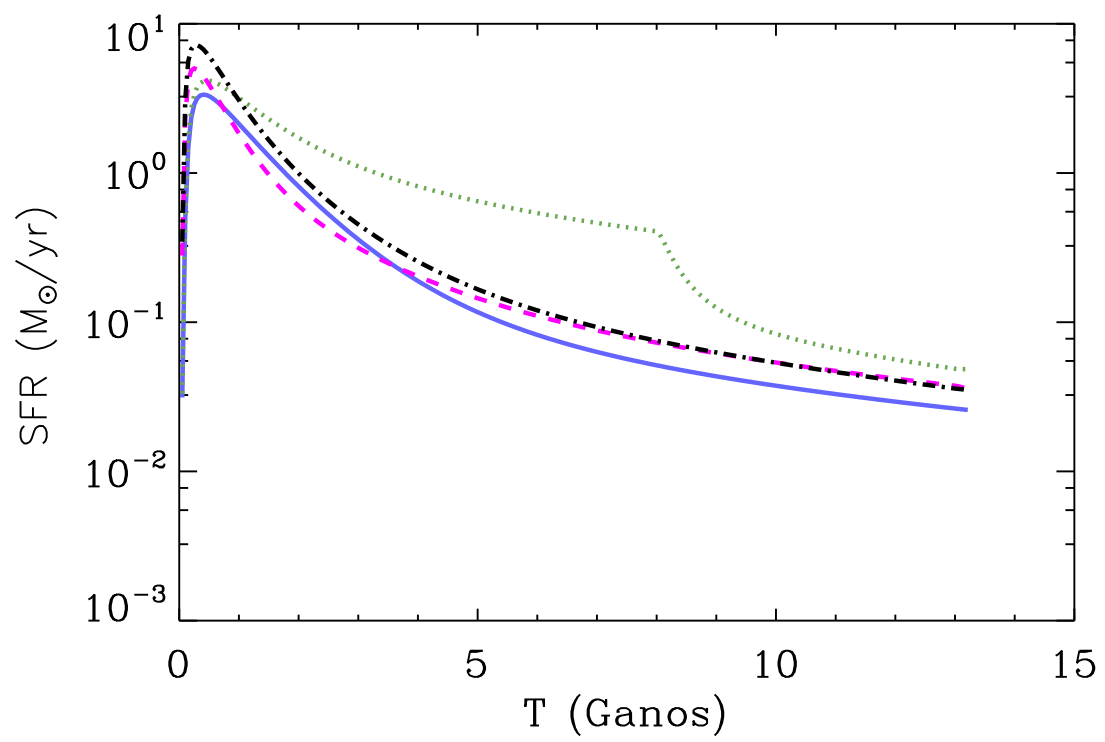

Figura 4.18: Comparação entre as previsões dos modelos deste trabalho para a dependência temporal da taxa de formação estelar no bojo galáctico. Os símbolos e cores das linhas são análogos à figura 4.12 .

depende da fração de estrelas binárias que dão origem às SNe Ia e também da fração da contribuição das SNe II para a abundância de ferro. Como a inclusão dos fluxos de gás não muda nenhum destes parâmetros, a razão $[\alpha / \mathrm{Fe}]$ permanece essencialmente sem nenhuma alteração apreciável.

Recentemente, Bensby et al. (2011) encontraram uma distribuição bimodal para a MD do bojo. Eles se baseiam em observações espectroscópicas de alta resolução e sinal-ruído de estrelas anãs e subgigantes amplificadas por um efeito de microlentes gravitacionais. Os resultados apontam para duas populações coexistindo no bojo: uma rica em metais e outra pobre. A população pobre em metais poderia ser originada nos primórdios do bojo, onde se espera que a maior parte das estrelas sejam velhas e pobres em metais. Já a população rica em metais poderia ser originada por um inflow de gás posterior. Para investigar esta hipótese, foi desenvolvido um modelo para o bojo com um inflow radial de gás provindo do disco galáctico durante toda a evolução deste. Os resultados são mostrados na figura 4.20. Com um fluxo constante com velocidade de $5 \mathrm{~km} \mathrm{~s}^{-1}$ é possível reproduzir a bimodalidade da distribuição de ferro do bojo encontrada por Bensby et al. (2011). Estes resultados mostram que uma interação entre o bojo e o disco da Galáxia via fluxos radiais de gás é importante para se reproduzir algumas propriedades destas regiões. A MD dupla do bojo é explicada por um recente modelo de Tsujimoto e Bekki (2012), onde a 


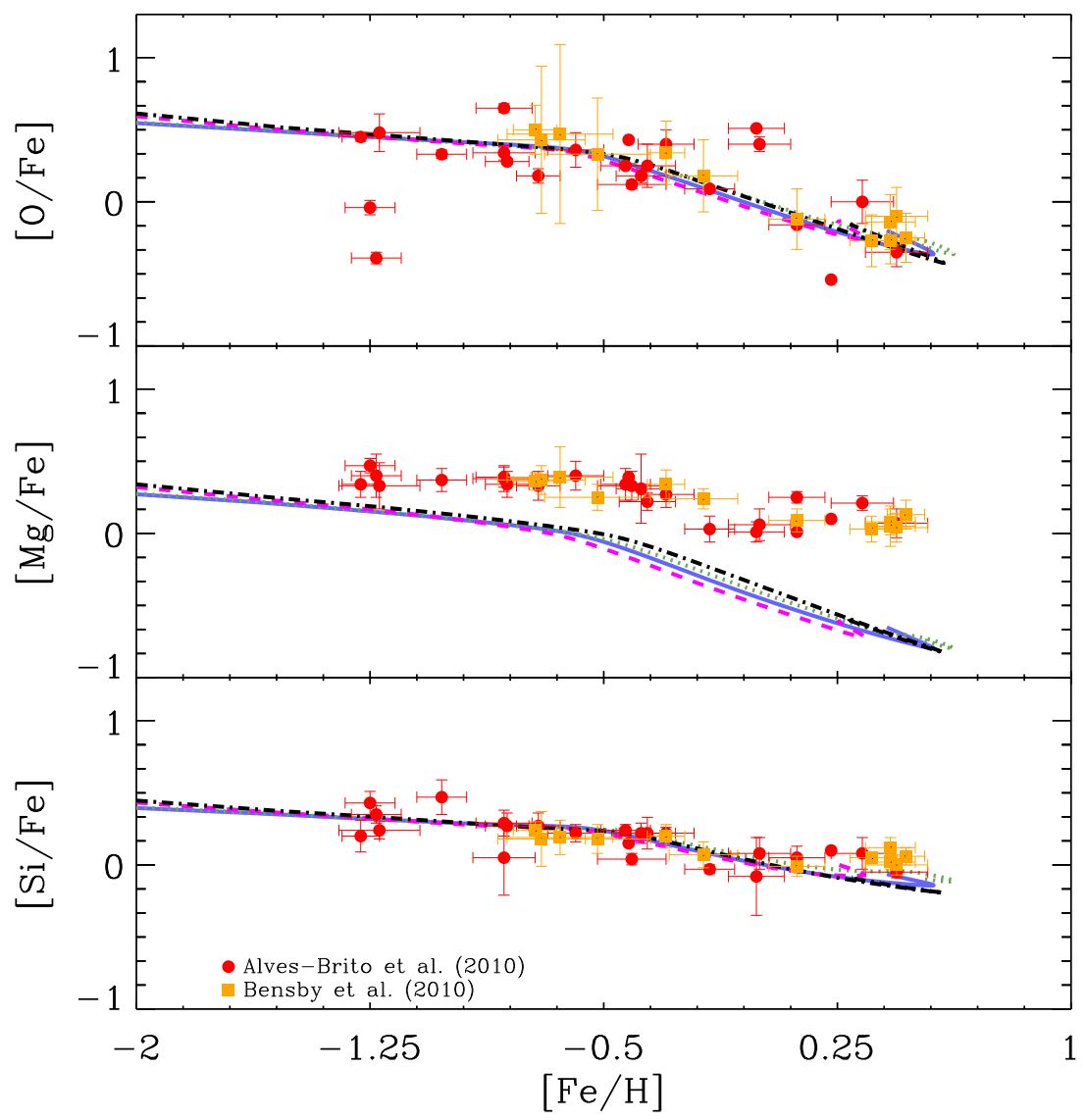

Figura 4.19: Comparação entre as previsões dos models para a razão $[\alpha / \mathrm{Fe}]$, onde $\alpha$ significa O, Mg, Si. Os dados observacionais para o bojo são de Alves-Brito et al. (2010) (círculos) e Bensby et al. (2010) (quadrados). Os símbolos e cores das linhas são análogos à figura 4.12.

formação do bojo é descrita pela formação de uma população pobre em metais com uma escala de tempo curta, e a partir do gás remanescente do bojo mais um inflow de gás do disco interno, uma população rica em metais é formada com uma escala de tempo mais longa. Contudo, os autores argumentam que é necessária uma IMF voltada para maiores massas para reproduzir a distribuição da população mais rica em metais. No caso deste trabalho não é necessária nenhuma modificação na IMF para o modelo conseguir ajustar as distribuições observadas.

A razão para diferentes tipos de estrelas do bojo apresentarem diferentes distribuições de metalicidades permanece não explicada. Bensby et al. (2011) não excluem uma contaminação de estrelas do disco interno em sua amostra, o que poderia explicar a fração de estrelas pobres em metais encontradas. Contudo, dado o pequeno número de estrelas anãs observadas, ainda são necessários mais dados para uma conclusão mais definitiva sobre a 
formação do bojo.

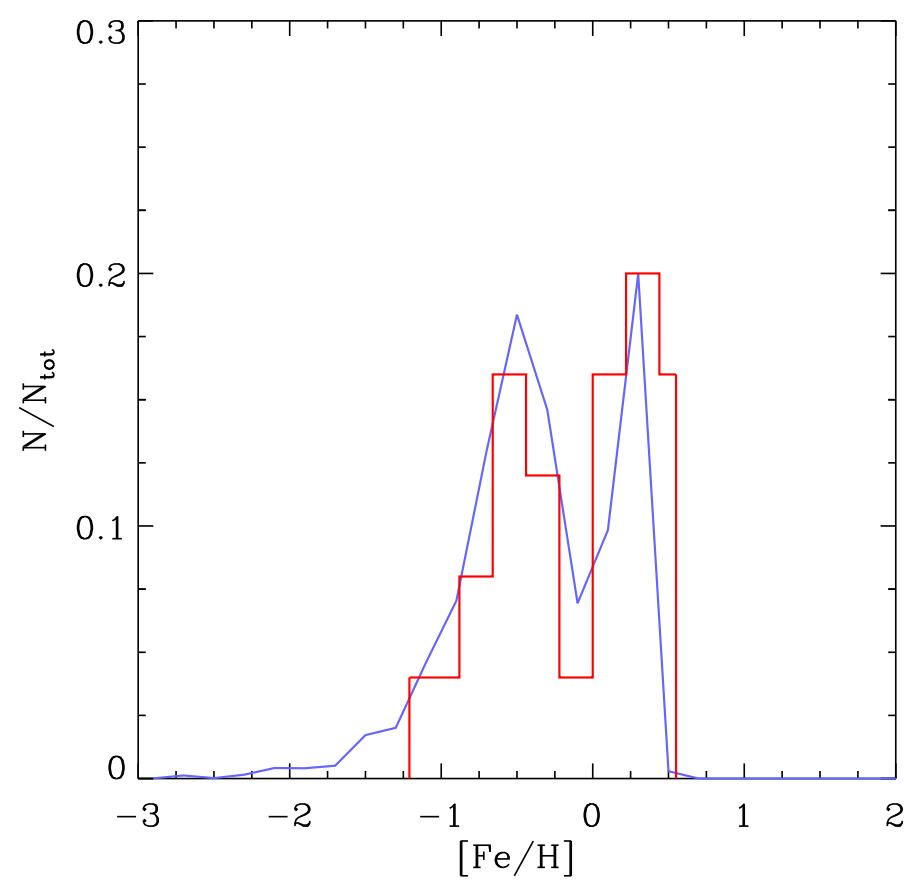

Figura 4.20: Distribuição de ferro (histograma) para as estrelas anãs e subgigantes do bojo de Bensby et al. (2011) comparada com o modelo com fluxos radiais de gás considerando uma velocidade de $5 \mathrm{~km} \mathrm{~s}^{-1}$.

Em resumo, os fluxos radiais de gás podem apresentar importantes alterações nos gradientes de abundâncias químicas da Galáxia. Dentre os modelos utilizados neste trabalho, destaca-se o modelo $\mathrm{C}$, onde foram introduzidos fluxos radiais de gás para simular os efeitos de uma barra na região interna da Galáxia. As simulações mostram que o gradiente de abundâncias do disco é mais plano para o caso da inclusão da barra. Este resultado concorda com os resultados observacionais obtidos por Maciel et al. (2003, 2006), onde o gradiente de oxigênio apresenta um achatamento nos últimos 6 a 8 Gyr. Os resultados deste modelo também concordam com observações de NPs do bojo galáctico obtidas por Cavichia et al. (2010, 2011). Nestes trabalhos, observa-se um decréscimo das abundâncias químicas das NPs do bojo se comparadas com as do disco interno da Galáxia. Os resultados mostram também que as abundâncias químicas das NPs do bojo não seguem o gradiente de abundâncias do disco se projetado na direção do centro galáctico. Por fim, o modelo com fluxos radiais de gás está de acordo com observações de outras galáxias espirais barradas feitas por Martin e Roy (1995), onde se observa que as galáxias com barras mais fortes apresentam os menores gradientes de metalicidades. 
A partir dos resultados deste capítulo está sendo redigido um artigo (Cavichia et al., 2012), cuja versão preliminar pode ser vista no apêndice desta tese. 
Capítulo 5

\section{Conclusões e perspectivas}

\subsection{Abundâncias na conexão bojo-disco}

Esta parte do trabalho descreve um importante resultado relacionando NPs com a evolução química da Galáxia. O mesmo utiliza os dados de Cavichia et al. (2010) que apresenta a derivação e análise das abundâncias químicas para uma amostra de 56 NPs na direção do bojo galáctico, das quais 35 apresentam as abundâncias determinadas pela primeira vez. Esta amostra foi acrescida de outros dados da literatura, resultando em uma amostra final contendo 140 objetos com distâncias e abundâncias determinadas. A amostra foi utilizada para estudar a distribuição de abundâncias no disco interno e no bojo da Via Láctea.

Uma análise estatística foi realizada com o objetivo de encontrar a distância galactocêntrica onde as características do bojo e do disco se interceptam. Duas escalas de distância distintas foram utilizadas: Zhang (1995) (Z95) e Stanghellini et al. (2008) (SSV08). Aplicando-se o teste de Kolmogorov-Smirnov, a primeira resultou em uma distância de 1.5 kpc, enquanto que para a segunda o teste não foi conclusivo. Contudo, as distribuições de abundâncias dos elementos $\alpha$ para as duas escalas mostram que os objetos do bojo não seguem a tendência das abundâncias do disco. Em média, as abundâncias dos objetos do bojo são menores que as dos objetos pertencentes ao disco interno, apesar dessa diferença não ser superior aos erros individuais das abundâncias. Considerando a escala de distância de SSV08, a diferença de abundâncias entre os dois grupos é baseada em 68, 62, 53, e 56 NPs para o grupo I (bojo) para os elementos O, S, Ar, e Ne, respectivamente. Para o grupo II (disco interno), estes números são 16, 15, 14, 12, para os mesmos elementos. Esta diferença para a escala de Z95 é baseada em 72, 66, 50, e 43 NPs do grupo I e 41, 39, 28, 29 
NPs do grupo II para os mesmos elementos. Ademais, os erros combinados para os quatro elementos $\alpha(\mathrm{O}, \mathrm{S}, \mathrm{Ar}, \mathrm{Ne})$ de cada grupo é consideravelmente menor que a diferença de abundâncias médias entre os dois grupos.

Existem outras evidências que apontam para uma transição do disco interno para o bojo com uma distância galactocêntrica similar à encontrada neste trabalho. De fato, observações do bojo no infravermelho, como as realizadas pelo satélite COBE/DIRBE (Weiland et al., 1994), suportam este resultado. A partir da figura 1 daquele trabalho, está claro que o raio nuclear do bojo se localiza entre $10^{\circ}$ e $15^{\circ}$. Para a distância canônica do Sol ao centro da Galáxia de 8 kpc, isto corresponde a uma raio nuclear do bojo entre 1.4 e $2.1 \mathrm{kpc}$.

Do ponto de vista das estrelas, Tiede e Terndrup (1999) realizaram observações fotométricas e espectroscópicas de 503 estrelas em quatro direções do bojo, com coordenadas $(\ell, b):\left(-28.8^{\circ},-6.0^{\circ}\right),\left(-8.7^{\circ}, 6.0^{\circ}\right),\left(8.4^{\circ},-6.0^{\circ}\right)$, e $\left(24.4^{\circ}, 6.1^{\circ}\right)$. De acordo com os resultados, a distribuição de abundâncias na região interna da Galáxia apresenta uma descontinuidade. Esta diferença é maior que qualquer tendência na seleção da amostra ou erros nas abundâncias. Como sugere-se nesta tese, os autores associam esta diferença às diferentes populações na linha de visada.

Smartt et al. (2001) também encontram um decréscimo de abundâncias na região interna da Galáxia. Isto foi obtido observando-se estrelas tipo B localizadas entre 2.5 e $5 \mathrm{kpc}$ do centro galáctico. Devido à natureza jovem destes objetos, as abundâncias fotosféricas refletem as abundâncias atuais do meio interestelar. Contudo, as barras de erro são grandes e somente é possível afirmar que as abundâncias de oxigênio do dos objetos mais próximos do centro da Galáxia não seguem o gradiente de abundâncias do disco. Estes objetos apresentam abundâncias entre 0.3 e 0.4 dex abaixo do gradiente de metalicidades de Rolleston et al. (2000) esperado nesta região.

Em estudos mais recentes, Gutenkunst et al. (2008) apontam para uma descontinuidade do gradiente de abundâncias das NPs na direção central da Galáxia. O mesmo comportamento pode ser visto no trabalho de Stanghellini e Haywood (2010). Considerando as NPs do tipo III como definido por Peimbert (1978), as quais representam a população velha do bojo, é possível notar que as abundâncias de oxigênio são menores para distâncias galactocêntricas menores que $4 \mathrm{kpc}$. 
Mishurov et al. (2002) propuseram um modelo de formação da Galáxia onde os braços espirais são indutores de formação estelar e podem existir somente entre as ressonâncias interna e externa de Lindblad. Como consequência, a SFR diminui acentuadamente fora destes limites, e as abundâncias químicas são reduzidas nestas regiões.

Combinando estas evidências com os resultados encontrados neste trabalho, propõe-se uma distância galactocêntrica $R_{L}=1.5 \mathrm{kpc}$, a qual define a interface bojo-disco baseada na análise de abundâncias químicas da população de massa intermediária do disco interno da Galáxia e do bojo.

\subsection{Abundâncias químicas de NPs na direção central da Via Láctea}

Nesta parte do trabalho, foram observadas com o telescópio SOAR 21 NPs localizadas na direção do centro da Galáxia. O interesse em se observar estes objetos está em suas localizações: bem próximas ao plano galáctico na direção central da Via Láctea. Esta região possui uma alta extinção interestelar pois a luz emitida por estes objetos precisa atravessar todo o disco para ser observada.

Durante este projeto foi desenvolvido um programa utilizando as linguagens IRAF e Python, para a redução de dados espectrofotométricos dos telescópios LNA e SOAR. O pacote do IRAF desenvolvido recebeu o nome de PNePack e realiza a redução dos dados e calibração em comprimento de onda e fluxo (PNeReduc), extração automática ou manual dos fluxos das linhas (PNeFlux), cálculos da extinção interestelar (PNeDeredden), cálculos de parâmetros físicos e abundâncias (PNeCalc). Em particular, o programa PNeCalc inclui as mais recentes emissividades do HeI publicadas por Porter e Ferland (2007), o que garante o cálculo das abundâncias com maior precisão.

As NPs observadas apresentam uma alta extinção interestelar, apresentando uma extinção de 7 magnitudes, mas em alguns casos a extinção no visível pode chegar a 10 magnitudes. Tal extinção inviabilizou a obtenção da temperatura eletrônica a partir das linhas do [OI] e [OIII], restando apenas as linhas do [NII]. Porém, em alguns casos a linha do [NII] $\lambda 5755 \AA$, que é essencial para a obtenção da temperatura, não foi observada por possuir um baixo sinal-ruído $(\mathrm{S} / \mathrm{N})$. Nestes casos, são apresentados três métodos distintos para o cálculo das abundâncias: utilização de uma temperatura de $10^{4} \mathrm{~K}$; utilização do limite do S/N dos espectros como estimativa do fluxos da linha [NII] $\lambda 5755 \AA$; e utilização 
do método estatístico de obtenção de abundâncias em nebulosas. A partir das análises realizadas, pôde-se constatar que as NPs apresentam grandes variações de temperaturas eletrônicas e, mais importante, as abundâncias de oxigênio, enxofre, e argônio dependem das temperaturas adotadas. Como consequência, o segundo método onde a temperatura eletrônica é aproximada por um valor superior é o mais adequado entre os três métodos estudados.

As análises das abundâncias químicas mostraram que as NPs localizadas na direção central da Galáxia apresentam baixas abundâncias de oxigênio comparadas com as NPs do disco interno. Com relação as NPs do bojo de outras regiões, as diferenças não são muito pronunciáveis, porém os resultados indicam que a presente amostra apresenta uma tendência para baixas metalicidades. Uma comparação da amostra observada com uma amostra de NPs do disco mostrou que as abundâncias das NPs deste trabalho não podem ser reproduzidas por uma simples extrapolação do gradiente de abundâncias do disco. De fato, a média de abundâncias para os objetos deste trabalho está 0.63 dex abaixo deste limite. Ainda são necessários mais dados para confirmar este resultado, porém os resultados apontam para que a maior parte da população do bojo foi originada no início de sua formação. Neste cenário espera-se que a maioria da população do bojo seja velha, com uma idade próxima à idade da Galáxia.

A caracterização química da região estudada é importante para a classificação do bojo como sendo clássico ou pseudo-bojo. As evidências observacionais encontradas por este trabalho indicam que o bojo apresenta uma complexa composição de populações estelares. Por um lado, a presença de nebulosas com baixas abundâncias mostra que o bojo pode ter se formado a partir de um disco galáctico antigo através de uma evolução secular (Genzel et al., 2008). Uma evolução secular precoce poderia alimentar a região central da Galáxia com gás e estrelas e, desta forma, construir um disco exponencial e um bojo massivo, mesmo sem a necessidade de fusões. Neste caso, o bojo se formaria simultaneamente com o disco, mas separadamente. Em um outro cenário, o bojo se formaria a partir do disco espesso, como mostram as simulações de Bournaud et al. (2009). Este cenário explicaria as similaridades entre o bojo e o disco espesso. Por outro lado, é interessante notar que existem alguns objetos do bojo para os quais as abundâncias coincidem com o limite do gradiente radial do disco nesta região. Isto poderia ser interpretado como um bojo 
composto por duas ou mais populações: uma originada do disco fino, e outra originada do disco espesso. Bensby et al. (2011) também encontram evidências de que o bojo é composto por uma população rica e outra pobre em metais. Como eles argumentam, estas são evidências para um bojo formado a partir de um disco, como indicam os resultados do survey BRAVA que apontam para um pseudo-bojo (Shen et al., 2010).

\subsection{A evolução química da Via Láctea com fluxos radiais de gás}

Os modelos de evolução química que não consideram troca de gás entre os anéis concêntricos nos quais divide-se o disco galáctico para fins de modelagem não conseguem reproduzir todas a propriedades observadas da Galáxia. A evolução química da região interna da Via Láctea é difícil de ser explicada sem a inclusão de fluxos radiais de gás, como pode ser visto em Portinari e Chiosi $(1999,2000)$. Sendo assim, nesta parte do trabalho foram incluídos fluxos radiais de gás no modelo de evolução química de Mollá e Díaz (2005), permitindo a troca de gás entre os anéis cilíndricos do disco.

As simulações com fluxos radiais de gás mostram que:

- Em geral, os modelos com fluxos de gás apresentam uma SFR mais alta no bojo do que o modelo de MD05 sem fluxos. Este resultado concorda com os resultados obtidos por Ellison et al. (2011) que utilizam uma amostra de galáxias barradas e não barradas para estudar a SFR na região central destas galáxias. Os autores mostram que a SFR central de galáxias classificadas visualmente como barradas com $M>10^{10} M_{\odot}$ são maiores que a das galáxias não barradas de mesma massa por $\sim 60 \%$. Estes resultados indicam que a barra e os fluxos de gás exercem um importante papel na formação de estrelas no centro das galáxias espirais barradas.

- No modelo com barra, a corrotação (CR) da barra está localizada em 2.5 kpc, próxima da extremidade desta, e a ressonância externa de Lindblad da barra (OLR) está localizada em $4.5 \mathrm{kpc}$. O gás então escoa da CR para a OLR, onde é acumulado, enquanto que o gás das regiões externas escoa em direção ao centro da Galáxia, acumulando-se na ressonância em 4.5 kpc. Este padrão de fluxos deve começar no momento em que a barra é originada. A Galáxia evolui até uma idade de 8 Gyr com 
uma velocidade de inflow constante no tempo. A partir de $8 \mathrm{Gyr}$, a barra começa a atuar modificando os fluxos de gás na região interna da Galáxia.

- Os fluxos radiais de gás podem induzir importantes alterações nos gradientes de abundâncias químicas da Galáxia. Dentre os modelos utilizados neste trabalho, destaca-se o modelo $\mathrm{C}$, onde foram introduzidos fluxos radiais de gás para simular os efeitos de uma barra na região interna da Galáxia. As simulações mostram que o gradiente de abundâncias do disco é mais plano para o caso da inclusão da barra. Este resultado concorda com os resultados observacionais obtidos por Maciel et al. (2003, 2006), onde o gradiente de oxigênio apresenta um achatamento nos últimos 6 a 8 Gyr. Os resultados deste modelo também concordam com observações de NPs do bojo galáctico obtidas por Cavichia et al. (2010, 2011). Nestes trabalhos observa-se um decréscimo das abundâncias químicas das NPs do bojo se comparadas com as do disco interno da Galáxia. Os resultados apontam também que as abundâncias químicas das NPs do bojo não seguem o gradiente de abundâncias do disco se projetado na direção do centro galáctico. Por fim, o modelo com fluxos radiais de gás está de acordo com observações de outras galáxias espirais barradas feitas por Martin e Roy (1995), onde se observa que as galáxias com barras mais fortes apresentam os menores gradientes de metalicidades.

- Utilizando um modelo com um fluxo constante com velocidade de $5 \mathrm{~km} \mathrm{~s}^{-1}$ é possível reproduzir a bimodalidade da distribuição de ferro do bojo encontrada por Bensby et al. (2011). Estes resultados mostram que a inclusão nos modelos de uma interação entre o bojo e o disco da Galáxia via fluxos radiais de gás é importante para se reproduzir algumas propriedades destas regiões.

\subsection{Considerações finais}

Os resultados deste trabalho mostram que a visão de um bojo se formando a partir de um cenário monolítico onde a queda de gás acontece em períodos definidos já não explica algumas características observadas como por exemplo a distribuição de metalicidades dupla. Um cenário onde a troca de gás entre o bojo e o disco interno é mais plausível, explicando melhor os recentes dados observacionais. 
Mostrou-se nesta tese que a barra da Via Láctea exerce importantes efeitos nas regiões interna do disco e central da Galáxia. Os modelos cujo objetivo é explicar as observações nestas regiões precisam incluir fluxos de gás induzidos pela barra, caso contrário, ter-se-á apenas uma visão parcial da formação e evolução da Via Láctea nesta região.

Sem dúvida a região central da Via Láctea é uma região muito complexa, com interação entre as diferentes estruturas que a compõem, e diferentes populações estelares co-habitando as mesmas regiões. Com o advento de observações com maior resolução e maior qualidade dos dados, os modelos mais simples de evolução química já estão apresentando dificuldades para explicar algumas características observadas. E isto deve continuar nos próximos anos. A era dos telescópios gigantes está se aproximando e, consequentemente, dados em muito maior quantidade, com maior resolução e qualidade, deverão revelar mais detalhes sobre a estrutura e formação desta região da Galáxia. A missão Gaia também trará grandes benefícios para esta área, pois com seus resultados o problema das distâncias dos objetos desta região será resolvido e, pela primeira vez, será possível obter um mapa tridimensional da Via Láctea. Os novos levantamentos nesta região também estão revelando e ainda revelarão muitos detalhes estruturais, cinemáticos e químicos da mesma. Por exemplo, recentemente Gonzalez et al. (2011), utilizando os dados do levantamento $\mathrm{VVV}^{1}$, encontraram uma segunda estrutura próxima a barra, que é interpretada como uma segunda barra com semi-eixo de $\sim 500$ pc.

Os novos modelos de evolução química da região interna da Galáxia deverão se adaptar para reproduzir as mais recentes observações da estrutura, cinemática, e abundâncias químicas da Via Láctea. Hoje conhecemos detalhes sobre a formação e evolução da Via Láctea jamais imaginados duas décadas atrás e, num futuro próximo, as novas observações prometem revelar outros detalhes ainda não conhecidos atualmente. Estamos caminhando para um visão mais completa da formação da nossa própria galáxia.

\subsection{Perspectivas}

Esta tese abre algumas perspectivas que poderão ser consideradas mais adiante. A seguir são listadas algumas possibilidades para a continuação do trabalho.

\footnotetext{
${ }^{1}$ ESO Vista Variables in the Via Lactea
} 
- Observação de NPs na direção central da Galáxia: a amostra observada de NPs localizada na direção central da Via Láctea ainda é pequena. Os resultados encontrados neste trabalho mostram que é interessante a observação de mais NPs nesta região da Galáxia com o objetivo de se confirmar se esta população difere do restante do bojo em termos das abundâncias químicas. Com a entrada do Brasil para o ESO, as possibilidades de telescópios para a observação destes objetos aumentam muito.

- Novas emissividades para o hélio: com a atualização do código de cálculo de abundâncias com as mais recentes emissividades do hélio, faz-se necessário recalcular as abundâncias químicas do restante da amostra do grupo do IAG/USP. Desta forma, a base de abundâncias químicas deste grupo permanecerá mais precisa e homogênea frente aos outros grupos.

- Observar NPs em outras galáxias barradas: é importante uma comparação dos resultados alcançados neste trabalho com outras galáxias espirais barradas. Como em outras galáxias o problema da alta extinção interestelar é muito menor, a obtenção de abundâncias químicas de NPs próximas ao centro dessas galáxias é, a princípio, mais direta. Estas observações podem ajudar na própria interpretação da formação da Via Láctea.

- Aplicar o modelo a outras galáxias espirais barradas: novamente, a comparação dos resultados obtidos para a Via Láctea com outras galáxias espirais barradas pode auxiliar no estudo da nossa própria galáxia. Além disso, em geral os modelos de evolução química com fluxos radiais de gás ignoram as outras galáxias espirais barradas. Portanto, é interessante utilizar este modelo no estudo da evolução química de outras galáxias.

- Yields estelares mais recentes: utilizando os yields estelares de Woosley e Weaver (1995), o modelo não conseguem reproduzir o correto comportamento de $[\mathrm{Mg} / \mathrm{Fe}] \mathrm{x}$ Fe para o bojo. Faz-se necessária a inclusão de modelos mais atualizados para os yields estelares, como por exemplo os de François et al. (2004) para os yields de O e Fe. 
- Novos fluxos de gás: pode-se utilizar outros padrões de velocidades para os fluxos de gás, como por exemplo o caso A de Portinari e Chiosi (2000). Neste caso, a corrotação da barra está localizada em $3.5 \mathrm{kpc}$, portanto a diminuição de gás entre 1.5 e 3.5 kpc é interpretado como um rápido deslocamento de gás da corrotação para a ressonância interna de Lindblad e o anel nuclear. 


\section{Referências Bibliográficas}

Acker A., Marcout J., Ochsenbein F., Stenholm B., Tylenda R., Strasbourg - ESO catalogue of galactic planetary nebulae. Part 1; Part 2. Garching: European Southern Observatory, 1992

Acker A., Peyaud A. E. J., Parker Q., 400 new Planetary Nebulae in the Galactic Bulge. In Planetary Nebulae in our Galaxy and Beyond , vol. 234 of IAU Symposium, 2006, p. 355

Afflerbach A., Churchwell E., Werner M. W., Galactic Abundance Gradients from Infrared Fine-Structure Lines in Compact H II Regions, ApJ, 1997, vol. 478, p. 190

Aller L. H., Physics of Thermal Gaseous Nebulae. Astrophysics and Space Science Library v. 112, Dordrecht, Holanda, 1984

Alloin D., Collin-Souffrin S., Joly M., Vigroux L., Nitrogen and oxygen abundances in galaxies, A\&A, 1979, vol. 78, p. 200

Alves-Brito A., Meléndez J., Asplund M., Ramírez I., Yong D., Chemical similarities between Galactic bulge and local thick disk red giants: O, Na, Mg, Al, Si, Ca, and Ti, A\&A, 2010, vol. 513, p. A35

Anderson L. D., Zavagno A., Barlow M. J., García-Lario P., Noriega-Crespo A., Distinguishing between HII regions and planetary nebulae with Hi-GAL, WISE, MIPSGAL, and GLIMPSE, A\&A, 2012, vol. 537, p. A1 
Andrievsky S. M., Bersier D., Kovtyukh V. V., Luck R. E., Maciel W. J., Lépine J. R. D., Beletsky Y. V., Using Cepheids to determine the galactic abundance gradient. II. Towards the galactic center, A\&A, 2002, vol. 384, p. 140

Andrievsky S. M., Kovtyukh V. V., Luck R. E., Lépine J. R. D., Bersier D., Maciel W. J., Barbuy B., Klochkova V. G., Panchuk V. E., Karpischek R. U., Using Cepheids to determine the galactic abundance gradient. I. The solar neighbourhood, A\&A, 2002, vol. 381 , p. 32

Andrievsky S. M., Luck R. E., Martin P., Lépine J. R. D., The Galactic abundance gradient from Cepheids. V. Transition zone between 10 and 11 kpc, A\&A, 2004, vol. 413, p. 159

Athanassoula E., The existence and shapes of dust lanes in galactic bars, MNRAS, 1992, vol. 259 , p. 345

Athanassoula E., On the nature of bulges in general and of box/peanut bulges in particular: input from N-body simulations, MNRAS, 2005, vol. 358, p. 1477

Aver E., Olive K. A., Skillman E. D., A new approach to systematic uncertainties and self-consistency in helium abundance determinations, J. Cosmology Astropart. Phys., 2010, vol. 5, p. 3

Babusiaux C., Gilmore G., The structure of the Galactic bar, MNRAS, 2005, vol. 358, p. 1309

Babusiaux C., Gómez A., Hill, V. et al. Insights on the Milky Way bulge formation from the correlations between kinematics and metallicity, A\&A, 2010, vol. 519, p. A77+

Ballero S. K., Matteucci F., Origlia L., Rich R. M., Formation and evolution of the Galactic bulge: constraints from stellar abundances, A\&A, 2007, vol. 467, p. 123

Beaulieu S. F., Freeman K. C., Kalnajs A. J., Saha P., Zhao H., Dynamics of the Galactic Bulge Using Planetary Nebulae, AJ, 2000, vol. 120, p. 855

Bensby T., Adén D., Meléndez J., et al. Chemical evolution of the Galactic bulge as traced by microlensed dwarf and subgiant stars. IV. Two bulge populations, A\&A, 2011, vol. 533, p. A134 
Bensby T., Feltzing S., Johnson J. A., Gould A., Adén D., Asplund M., Meléndez J., Gal-Yam A., Lucatello S., Sana H., Sumi T., Miyake N., Suzuki D., Han C., Bond I., Udalski A., Chemical evolution of the Galactic bulge as traced by microlensed dwarf and subgiant stars. II. Ages, metallicities, detailed elemental abundances, and connections to the Galactic thick disc, A\&A, 2010, vol. 512, p. A41

Bernard-Salas J., Infrared spectroscopy of planetary nebulae, including Spitzer. In Planetary Nebulae in our Galaxy and Beyond, vol. 234 of IAU Symposium, 2006, p. 181

Binney J., On the rotation of elliptical galaxies, MNRAS, 1978, vol. 183, p. 501

Binney J., The Bulge-disc connection in the Milky Way. In The Galaxy Disk in Cosmological Context, vol. 254 of IAU Symposium, 2009, p. 145

Bissantz N., Gerhard O., Spiral arms, bar shape and bulge microlensing in the Milky Way, MNRAS, 2002, vol. 330, p. 591

Boumis P., Akras S., Xilouris E. M., Mavromatakis F., Kapakos E., Papamastorakis J., Goudis C. D., New planetary nebulae in the Galactic bulge region with $l>0 \mathrm{deg}-\mathrm{II}$, MNRAS, 2006, vol. 367, p. 1551

Bournaud F., Elmegreen B. G., Martig M., The Thick Disks of Spiral Galaxies as Relics from Gas-rich, Turbulent, Clumpy Disks at High Redshift, ApJ, 2009, vol. 707, p. L1

Burkert A., Hensler G., Chemodynamical models of galactic evolution. In Nuclear Astrophysics , vol. 287 of Lecture Notes in Physics, Berlin Springer Verlag, 1987, p. 159

Cabrera-Lavers A., Hammersley P. L., González-Fernández C., López-Corredoira M., Garzón F., Mahoney T. J., Tracing the long bar with red-clump giants, A\&A, 2007, vol. 465 , p. 825

Cahn J. H., Kaler J. B., Stanghellini L., A catalogue of absolute fluxes and distances of planetary nebulae, A\&AS, 1992, vol. 94, p. 399

Cardelli J. A., Clayton G. C., Mathis J. S., The relationship between infrared, optical, and ultraviolet extinction, ApJ, 1989, vol. 345, p. 245 
Carigi L., Peimbert M., Esteban C., García-Rojas J., Carbon, Nitrogen, and Oxygen Galactic Gradients: A Solution to the Carbon Enrichment Problem, ApJ, 2005, vol. 623, p. 213

Cavichia O., Costa R. D. D., Maciel W. J., Planetary nebulae in the inner Milky Way: new abundances, RMxAA, 2010, vol. 46, p. 159

Cavichia O., Costa R. D. D., Maciel W. J., Planetary nebulae in the inner Milky Way II: the bulge-disk transition, RMxAA, 2011, vol. 47, p. 49

Cavichia O., Mollá M., Costa R. D. D., Maciel W. J., The chemical evolution of the Milky Way galaxy with radial gas flows, MNRAS, 2012

Cescutti G., Matteucci F., Galactic astroarchaeology: reconstructing the bulge history by means of the newest data, A\&A, 2011, vol. 525, p. A126

Chen L., Hou J. L., Wang J. J., On the Galactic Disk Metallicity Distribution from Open Clusters. I. New Catalogs and Abundance Gradient, AJ, 2003, vol. 125, p. 1397

Chiappini C., Górny S. K., Stasińska G., Barbuy B., Abundances in the Galactic bulge: results from planetary nebulae and giant stars, A\&A, 2009, vol. 494, p. 591

Chiappini C., Matteucci F., Gratton R., The Chemical Evolution of the Galaxy: The TwoInfall Model, ApJ, 1997, vol. 477, p. 765

Chiappini C., Matteucci F., Romano D., Abundance Gradients and the Formation of the Milky Way, ApJ, 2001, vol. 554, p. 1044

Colavitti E., Cescutti G., Matteucci F., Murante G., The origin of abundance gradients in the Milky Way: the predictions of different models, A\&A, 2009, vol. 496, p. 429

Colavitti E., Matteucci F., Murante G., The chemical evolution of a Milky Way-like galaxy: the importance of a cosmologically motivated infall law, A\&A, 2008, vol. 483, p. 401

Cole A. A., Weinberg M. D., An Upper Limit to the Age of the Galactic Bar, ApJ, 2002, vol. 574, p. L43 
Combes F., Sanders R. H., Formation and properties of persisting stellar bars, A\&A, 1981, vol. 96 , p. 164

Conselice C. J., Bershady M. A., Dickinson M., Papovich C., A Direct Measurement of Major Galaxy Mergers at z lower than 3, AJ, 2003, vol. 126, p. 1183

Costa R. D. D., Escudero A. V., Maciel W. J., Planetary Nebulae and the Chemical Evolution of the Galactic Bulge. In Planetary Nebulae as Astronomical Tools, vol. 804 of American Institute of Physics Conference Series, 2005, p. 252

Costa R. D. D., Maciel W. J., Planetary nebulae as probes for galactic chemical evolution. In Planetary Nebulae in our Galaxy and Beyond , vol. 234 of IAU Symposium, 2006, p. 243

Costa R. D. D., Maciel W. J., Escudero A. V., Chemical Evolution of the Galactic Bulge: Single and Double Infall Models, Baltic Astronomy, 2008, vol. 17, p. 321

Costa R. D. D., Uchida M. M. M., Maciel W. J., Chemical abundances of planetary nebulae towards the Galactic anticenter, A\&A, 2004, vol. 423, p. 199

Cuisinier F., Maciel W. J., Köppen J., Acker A., Stenholm B., Observations of planetary nebulae in the Galactic Bulge, A\&A, 2000, vol. 353, p. 543

Cunha K., Sellgren K., Smith V. V., Ramirez S. V., Blum R. D., Terndrup D. M., Chemical Abundances of Luminous Cool Stars in the Galactic Center from High-Resolution Infrared Spectroscopy, ApJ, 2007, vol. 669, p. 1011

Cunha K., Smith V. V., Chemical Evolution of the Galactic Bulge as Derived from HighResolution Infrared Spectroscopy of $K$ and $M$ Red Giants, ApJ, 2006, vol. 651, p. 491

Daflon S., Cunha K., Galactic Metallicity Gradients Derived from a Sample of OB Stars, ApJ, 2004, vol. 617, p. 1115

de Freitas Pacheco J. A., Maciel W. J., Costa R. D. D., Chemical abundances of disk planetary nebulae, A\&A, 1992, vol. 261, p. 579

Deharveng L., Peña M., Caplan J., Costero R., Oxygen and helium abundances in Galactic Hii regions - II. Abundance gradients, MNRAS, 2000, vol. 311, p. 329 
Drilling J. S., Schoenberner D., On the progenitors of white dwarfs, A\&A, 1985, vol. 146, p. L23

Dwek E., Arendt R. G., Hauser M. G., Kelsall T., Lisse C. M., Moseley S. H., Silverberg R. F., Sodroski T. J., Weiland J. L., Morphology, near-infrared luminosity, and mass of the Galactic bulge from COBE DIRBE observations, ApJ, 1995, vol. 445, p. 716

Eggen O. J., Lynden-Bell D., Sandage A. R., Evidence from the motions of old stars that the Galaxy collapsed., ApJ, 1962, vol. 136, p. 748

Ellison S. L., Nair P., Patton D. R., Scudder J. M., Mendel J. T., Simard L., The impact of gas inflows on star formation rates and metallicities in barred galaxies, MNRAS, 2011, vol. 416 , p. 2182

Elmegreen B. G., What triggers star formation in galaxies?, ArXiv e-prints, 2012

Elmegreen B. G., Bournaud F., Elmegreen D. M., Bulge Formation by the Coalescence of Giant Clumps in Primordial Disk Galaxies, ApJ, 2008, vol. 688, p. 67

Elmegreen B. G., Galliano E., Alloin D., Massive Clusters in the Inner Regions of NGC 1365: Cluster Formation and Gas Dynamics in Galactic Bars, ApJ, 2009, vol. 703, p. 1297

Erwin P., The coexistence of classical bulges and disky pseudobulges in early-type disk galaxies. In IAU Symposium, vol. 245 of IAU Symposium, 2008, p. 113

Escudero A. V., Propriedades químicas e evolução da população de massa intermediária do bojo galáctico, São Paulo: Universidade de São Paulo, 2005, Tese de Doutorado, 142 p.

Escudero A. V., Costa R. D. D., Abundances of recently discovered planetary nebulae towards the galactic bulge, A\&A, 2001, vol. 380, p. 300

Escudero A. V., Costa R. D. D., Maciel W. J., New abundances of planetary nebulae in the Galactic Bulge, A\&A, 2004, vol. 414, p. 211

Escudero A. V., Costa R. D. D., Maciel W. J., Chemical evolution of the Galactic Bulge using planetary nebulae and stars, MNRAS, 2007 
Esteban C., García-Rojas J., Peimbert M., Peimbert A., Ruiz M. T., Rodríguez M., Carigi L., Carbon and Oxygen Galactic Gradients: Observational Values from H II Region Recombination Lines, ApJ, 2005, vol. 618, p. L95

Exter K. M., Barlow M. J., Walton N. A., The abundance distributions of Galactic bulge and disc planetary nebulae, MNRAS, 2004, vol. 349, p. 1291

Faundez-Abans M., Maciel W. J., Neon, argon, and chlorine abundance gradients from type II planetary nebulae, Ap\&SS, 1987, vol. 129, p. 353

Ferland G. J., Korista K. T., Verner D. A., Ferguson J. W., Kingdon J. B., Verner E. M., CLOUDY 90: Numerical Simulation of Plasmas and Their Spectra, PASP, 1998, vol. 110, p. 761

Ferrini F., Matteucci F., Pardi C., Penco U., Evolution of spiral galaxies. I - Halo-disk connection for the evolution of the solar neighborhood, ApJ, 1992, vol. 387, p. 138

Ferrini F., Molla M., Pardi M. C., Diaz A. I., Evolution of spiral galaxies. 3: Application of the multiphase model to the galactic disk, ApJ, 1994, vol. 427, p. 745

Ferrini F., Penco U., Palla F., Bimodality versus multimodality - Do fragmentation theories support a bimodal IMF?, A\&A, 1990, vol. 231, p. 391

Fitzpatrick E. L., Correcting for the Effects of Interstellar Extinction, PASP, 1999, vol. 111, p. 63

François P., Matteucci F., Cayrel R., Spite M., Spite F., Chiappini C., The evolution of the Milky Way from its earliest phases: Constraints on stellar nucleosynthesis, A\&A, 2004, vol. 421, p. 613

Friedli D., Benz W., Kennicutt R., On the influence of bars and star formation on galactic abundance gradients, ApJ, 1994, vol. 430, p. L105

Friel E. D., Janes K. A., Tavarez M., Scott J., Katsanis R., Lotz J., Hong L., Miller N., Metallicities of Old Open Clusters, AJ, 2002, vol. 124, p. 2693

Fu J., Hou J. L., Yin J., Chang R. X., Origin and Evolution of the Abundance Gradient Along the Milky Way Disk, ApJ, 2009, vol. 696, p. 668 
Fukunaga M., Radial distribution of giant molecular clouds - Consequences of viscous torque in the system of giant molecular clouds, PASJ, 1983, vol. 35, p. 173

Fulbright J. P., McWilliam A., Rich R. M., Abundances of Baade's Window Giants from Keck HIRES Spectra. I. Stellar Parameters and [Fe/H] Values, ApJ, 2006, vol. 636, p. 821

Fulbright J. P., McWilliam A., Rich R. M., Abundances of Baade's Window Giants from Keck HIRES Spectra. II. The Alpha and Light Odd Elements, ApJ, 2007, vol. 661, p. 1152

Gavilán M., Buell J. F., Mollá M., Low and intermediate mass star yields: The evolution of carbon abundances, A\&A, 2005, vol. 432, p. 861

Genzel R., Burkert A., Bouché N., et al. From Rings to Bulges: Evidence for Rapid Secular Galaxy Evolution at z 2 from Integral Field Spectroscopy in the SINS Survey, ApJ, 2008, vol. 687, p. 59

Gillessen S., Eisenhauer F., Trippe S., Alexander T., Genzel R., Martins F., Ott T., Monitoring Stellar Orbits Around the Massive Black Hole in the Galactic Center, ApJ, 2009, vol. 692, p. 1075

Goetz M., Koeppen J., On abundance gradients in spiral galaxies, A\&A, 1992, vol. 262, p. 455

Goldreich P., Tremaine S., The excitation and evolution of density waves, ApJ, 1978, vol. 222 , p. 850

Gonzalez O. A., Rejkuba M., Minniti D., Zoccali M., Valenti E., Saito R. K., The inner Galactic bar traced by the VVV survey, A\&A, 2011, vol. 534, p. L14

Górny S. K., Stasińska G., Escudero A. V., Costa R. D. D., The populations of planetary nebulae in the direction of the Galactic bulge. Chemical abundances and Wolf-Rayet central stars, A\&A, 2004, vol. 427, p. 231

Gutenkunst S., Bernard-Salas J., Pottasch S. R., Sloan G. C., Houck J. R., Chemical Abundances and Dust in Planetary Nebulae in the Galactic Bulge, ApJ, 2008, vol. 680, p. 1206 
Henry R. B. C., Kwitter K. B., Balick B., Sulfur, Chlorine, and Argon Abundances in Planetary Nebulae. IV. Synthesis and the Sulfur Anomaly, AJ, 2004, vol. 127, p. 2284

Henry R. B. C., Kwitter K. B., Jaskot A. E., Balick B., Morrison M. A., Milingo J. B., Abundances of Galactic Anticenter Planetary Nebulae and the Oxygen Abundance Gradient in the Galactic Disk, ApJ, 2010, vol. 724, p. 748

Henry R. B. C., Speck A., Karakas A. I., Ferland G. J., Maguire M., The Curious Conundrum Regarding Sulfur Abundances In Planetary Nebulae, ArXiv e-prints, 2012

Hou J. L., Prantzos N., Boissier S., Abundance gradients and their evolution in the Milky Way disk, A\&A, 2000, vol. 362, p. 921

Howard C. D., Rich R. M., Clarkson W., Mallery R., Kormendy J., De Propris R., Robin A. C., Fux R., Reitzel D. B., Zhao H. S., Kuijken K., Koch A., Kinematics at the Edge of the Galactic Bulge: Evidence for Cylindrical Rotation, ApJ, 2009, vol. 702, p. L153

Iben Jr. I., Nomoto K., Tornambe A., Tutukov A. V., On interacting helium star-white dwarf pairs as supernova precursors, ApJ, 1987, vol. 317, p. 717

Iwamoto K., Brachwitz F., Nomoto K., Kishimoto N., Umeda H., Hix W. R., Thielemann F.-K., Nucleosynthesis in Chandrasekhar Mass Models for Type IA Supernovae and Constraints on Progenitor Systems and Burning-Front Propagation, ApJS, 1999, vol. 125 , p. 439

Jablonka P., Martin P., Arimoto N., The Luminosity-Metallicity Relation for Bulges of Spiral Galaxies, AJ, 1996, vol. 112, p. 1415

Jacoby G. H., Van de Steene G., Planetary nebulae near the Galactic center: Identifications, A\&A, 2004, vol. 419, p. 563

Jarvis B. J., Freeman K. C., A dynamical model for galactic bulges, ApJ, 1985a, vol. 295, p. 314

Jarvis B. J., Freeman K. C., The dynamics of galactic bulges - NGC 7814 and NGC 4594, ApJ, 1985b, vol. 295, p. 324 
Kent S. M., Galactic structure from the spacelab infrared telescope. III - A dynamical model for the Milky Way bulge, ApJ, 1992, vol. 387, p. 181

Kingdon J., Ferland G. J., Collisional effects in He I: an observational analysis, ApJ, 1995, vol. 442 , p. 714

Kingsburgh R. L., Barlow M. J., Elemental abundances for a sample of southern galctic planetary nebulae., MNRAS, 1994, vol. 271, p. 257

Koeppen J., The evolution of abundance gradients in spiral galaxies, A\&A, 1994, vol. 281, p. 26

Köppen J., Acker A., Stenholm B., Spectrophotometric survey of southern planetary nebulae. II - Chemical compositions, A\&A, 1991, vol. 248, p. 197

Kormendy J., Rotation of the bulge components of barred galaxies, ApJ, 1982, vol. 257, p. 75

Kormendy J., Illingworth G., Rotation of the bulge components of disk galaxies, ApJ, 1982, vol. 256 , p. 460

Kormendy J., Kennicutt Jr. R. C., Secular Evolution and the Formation of Pseudobulges in Disk Galaxies, ARA\&A, 2004, vol. 42, p. 603

Kwok S., From red giants to planetary nebulae, ApJ, 1982, vol. 258, p. 280

Kwok S., The Origin and Evolution of Planetary Nebulae. Cambridge ; New York, Cambridge University Press (Cambridge astrophysics series ; 31), 2000

Kwok S., Purton C. R., Fitzgerald P. M., On the origin of planetary nebulae, ApJ, 1978, vol. 219, p. L125

Lacey C. G., Fall S. M., Chemical evolution of the galactic disk with radial gas flows, ApJ, 1985, vol. 290, p. 154

Lecureur A., Hill V., Zoccali M., Barbuy B., Gómez A., Minniti D., Ortolani S., Renzini A., Oxygen, sodium, magnesium, and aluminium as tracers of the galactic bulge formation, A\&A, 2007, vol. 465, p. 799 
Lépine J. R. D., Cruz P., Scarano Jr. S., Barros D. A., Dias W. S., Pompéia L., Andrievsky S. M., Carraro G., Famaey B., Overlapping abundance gradients and azimuthal gradients related to the spiral structure of the Galaxy, MNRAS, 2011, vol. 417, p. 698

Liu X.-W., Luo S.-G., Barlow M. J., Danziger I. J., Storey P. J., Chemical abundances of planetary nebulae from optical recombination lines - III. The Galactic bulge PN M 1-42 and M 2-36, MNRAS, 2001, vol. 327, p. 141

Luck R. E., Lambert D. L., The Distribution of the Elements in the Galactic Disk. III. A Reconsideration of Cepheids from l $=30$ to 250 degrees, AJ, 2011, vol. 142, p. 136

Maciel W. J., A catalogue of distances of planetary nebulae, A\&AS, 1984, vol. 55, p. 253

Maciel W. J., Metallicity distribution of bulge planetary nebulae and the $[\mathrm{O} / \mathrm{Fe}] x[\mathrm{Fe} / \mathrm{H}]$ relation, A\&A, 1999, vol. 351, p. L49

Maciel W. J., Some aspects of the chemical evolution of He in the Galaxy (Invited Paper). In The Light Elements and their Evolution , vol. 198 of IAU Symposium, 2000, p. 204

Maciel W. J., Astrofísica do Meio Interestelar. Edusp, São Paulo, 2002

Maciel W. J., Costa R. D. D., Metallicity gradients in the Milky Way. In IAU Symposium , vol. 265 of IAU Symposium, 2010, p. 317

Maciel W. J., Costa R. D. D., Escudero A. V., The evolution of the Galactic bulge from planetary nebulae. In IAU Symposium, vol. 245 of IAU Symposium, 2008, p. 365

Maciel W. J., Costa R. D. D., Uchida M. M. M., An estimate of the time variation of the O/H radial gradient from planetary nebulae, A\&A, 2003, vol. 397, p. 667

Maciel W. J., Lago L. G., Costa R. D. D., An estimate of the time variation of the abundance gradient from planetary nebulae. II. Comparison with open clusters, cepheids and young objects, A\&A, 2005, vol. 433, p. 127

Maciel W. J., Lago L. G., Costa R. D. D., An estimate of the time variation of the abundance gradient from planetary nebulae. III. O, S, Ar, and Ne: a comparison of PN samples, A\&A, 2006, vol. 453, p. 587 
Maciel W. J., Pottasch S. R., Distances of planetary nebulae, A\&A, 1980, vol. 88, p. 1

Magrini L., Perinotto M., Mampaso A., Corradi R. L. M., Chemical abundances of Planetary Nebulae in M 33, A\&A, 2004, vol. 426, p. 779

Malkin Z., The current best estimate of the Galactocentric distance of the Sun based on comparison of different statistical techniques, ArXiv e-prints, 2012

Maraston C., Greggio L., Renzini A., Ortolani S., Saglia R. P., Puzia T. H., KisslerPatig M., Integrated spectroscopy of bulge globular clusters and fields. II. Implications for population synthesis models and elliptical galaxies, A\&A, 2003, vol. 400, p. 823

Marcon-Uchida M. M., Matteucci F., Costa R. D. D., Chemical evolution models for spiral disks: the Milky Way, M 31, and M 33, A\&A, 2010, vol. 520, p. A35

Marigo P., Chemical yields from low-and intermediate-mass stars: Model predictions and basic observational constraints, A\&A, 2001, vol. 370, p. 194

Martin P., Element Distributions in Barred Galaxies. In Abundance Profiles: Diagnostic Tools for Galaxy History, vol. 147 of Astronomical Society of the Pacific Conference Series, 1998, p. 68

Martin P., Roy J., The oxygen distribution in NGC 3359 or a disk galaxy in the early phase of bar formation, ApJ, 1995, vol. 445, p. 161

Martin P., Roy J.-R., The influence of bars on the chemical composition of spiral galaxies, ApJ, 1994, vol. 424, p. 599

Martinet L., Friedli D., Bar strength and star formation activity in late-type barred galaxies., A\&A, 1997, vol. 323, p. 363

Matteucci F., Francois P., Galactic chemical evolution - Abundance gradients of individual elements, MNRAS, 1989, vol. 239, p. 885

Matteucci F., Greggio L., Relative roles of type I and II supernovae in the chemical enrichment of the interstellar gas, A\&A, 1986, vol. 154, p. 279 
Matteucci F., Tornambe A., Chemical evolution of elliptical galaxies, A\&A, 1987, vol. 185, p. 51

McWilliam A., Rich R. M., The first detailed abundance analysis of Galactic bulge K giants in Baade's window, ApJS, 1994, vol. 91, p. 749

McWilliam A., Rich R. M., Smecker-Hane T. A., Constraints on the Origin of Manganese from the Composition of the Sagittarius Dwarf Spheroidal Galaxy and the Galactic Bulge, ApJ, 2003, vol. 592, p. L21

Merrifield M. R., The Galactic Bar. In Milky Way Surveys: The Structure and Evolution of our Galaxy, vol. 317 of Astronomical Society of the Pacific Conference Series, 2004, p. 289

Milingo J. B., Kwitter K. B., Henry R. B. C., Souza S. P., Alpha Element Abundances in a Large Sample of Galactic Planetary Nebulae, ApJ, 2010, vol. 711, p. 619

Minniti D., Zoccali M., The Galactic bulge: a review. In IAU Symposium, vol. 245 of IAU Symposium, 2008, p. 323

Mishurov Y. N., Lépine J. R. D., Acharova I. A., Corotation: Its Influence on the Chemical Abundance Pattern of the Galaxy, ApJ, 2002, vol. 571, p. L113

Miszalski B., Parker Q. A., Acker A., Birkby J. L., Frew D. J., Kovacevic A., MASH-II:

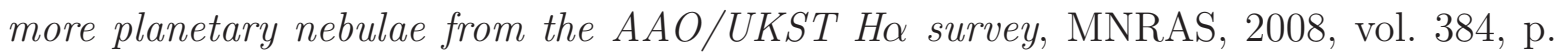
525

Mollá M., Díaz A. I., A grid of chemical evolution models as a tool to interpret spiral and irregular galaxies data, MNRAS, 2005, vol. 358, p. 521

Molla M., Ferrini F., Evolution of Spiral Galaxies. V. The Galactic Bulge, ApJ, 1995, vol. 454, p. 726

Mollá M., Ferrini F., Diaz A. I., Evolution of Spiral Galaxies. VI. Radial Distributions of Abundances in External Galaxies, ApJ, 1996, vol. 466, p. 668

Mollá M., Ferrini F., Gozzi G., Galactic bulges, MNRAS, 2000, vol. 316, p. 345 
Mollá M., Roy J. R., Modeling the Radial Abundance Distribution of the Transition Galaxy NGC 1313, ApJ, 1999, vol. 514, p. 781

Myers A. T., Krumholz M. R., Klein R. I., McKee C. F., Metallicity and the Universality of the Initial Mass Function, ApJ, 2011, vol. 735, p. 49

Naab T., Ostriker J. P., A simple model for the evolution of disc galaxies: the Milky Way, MNRAS, 2006, vol. 366, p. 899

Nakanishi H., Sofue Y., Three-Dimensional Distribution of the ISM in the Milky Way Galaxy: I. The H I Disk, PASJ, 2003, vol. 55, p. 191

Nishiyama S., Nagata T., Sato S., Kato D., Nagayama T., Kusakabe N., Matsunaga N., Naoi T., Sugitani K., Tamura M., The Distance to the Galactic Center Derived from Infrared Photometry of Bulge Red Clump Stars, ApJ, 2006, vol. 647, p. 1093

Nomoto K., Thielemann F.-K., Yokoi K., Accreting white dwarf models of Type I supernovae. III - Carbon deflagration supernovae, ApJ, 1984, vol. 286, p. 644

Olling R. P., Merrifield M. R., Luminous and dark matter in the Milky Way, MNRAS, 2001, vol. 326, p. 164

Ortolani S., Renzini A., Gilmozzi R., Marconi G., Barbuy B., Bica E., Rich R. M., Near Coeval Formation of the Galactic Bulge and Halo Inferred from Globular Cluster Ages, Nature, 1995, vol. 377, p. 701

Osterbrock D. E., Astrophysics of gaseous nebulae and active galactic nuclei. University Science Books, Mill Valley, California, 1989, 422 p., 1989

Osterbrock D. E., Ferland G. J., Astrophysics of gaseous nebulae and active galactic nuclei, 2006

Pagel B. E. J., Edmunds M. G., Blackwell D. E., Chun M. S., Smith G., On the composition of $H$ II regions in southern galaxies. I - NGC 300 and 1365, MNRAS, 1979, vol. 189, p. 95

Parker Q. A., Acker A., Frew et al. The Macquarie/AAO/Strasbourg Halpha Planetary Nebula Catalogue: MASH, MNRAS, 2006, vol. 373, p. 79 
Pasquali A., Perinotto M., Chemical behavior of planetary nebulae and galactic abundance gradients, A\&A, 1993, vol. 280, p. 581

Peimbert M., Chemical abundances in planetary nebulae. In Planetary Nebulae, vol. 76 of IAU Symposium, 1978, p. 215

Peimbert M., Luridiana V., Torres-Peimbert S., Temperature fluctuations and the chemical composition of planetary nebulae of Type I., Rev. Mexicana Astron. Astrofis., 1995, vol. 31 , p. 147

Peletier R. F., Falcón-Barroso J., Bacon R., Cappellari M., Davies R. L., de Zeeuw P. T., Emsellem E., Ganda K., Krajnović D., Kuntschner H., McDermid R. M., Sarzi M., van de Ven G., The SAURON project - XI. Stellar populations from absorption-line strength maps of 24 early-type spirals, MNRAS, 2007, vol. 379, p. 445

Perinotto M., Morbidelli L., The chemical gradient of oxygen in the Galaxy from planetary nebulae, MNRAS, 2006, vol. 372, p. 45

Perinotto M., Morbidelli L., Scatarzi A., A reanalysis of chemical abundances in galactic PNe and comparison with theoretical predictions, MNRAS, 2004, vol. 349, p. 793

Persic M., Salucci P., Stel F., The universal rotation curve of spiral galaxies - I. The dark matter connection, MNRAS, 1996, vol. 281, p. 27

Pettini M., Pagel B. E. J., [OIII]/[NII] as an abundance indicator at high redshift, MNRAS, 2004, vol. 348, p. L59

Peyaud A. E. J., Boily C., Acker A., Parker Q., Kinematics and Dynamics of the Galactic Bulge through Planetary Nebulae. In Planetary Nebulae in our Galaxy and Beyond, vol. 234 of IAU Symposium, 2006, p. 485

Porter R. L., Bauman R. P., Ferland G. J., MacAdam K. B., Theoretical He I Emissivities in the Case B Approximation, ApJ, 2005, vol. 622, p. L73

Porter R. L., Ferland G. J., Revisiting He-like X-Ray Emission-Line Plasma Diagnostics, ApJ, 2007, vol. 664, p. 586 
Portinari L., Chiosi C., On star formation and chemical evolution in the Galactic disc, A\&A, 1999, vol. 350, p. 827

Portinari L., Chiosi C., On radial gas flows, the Galactic Bar and chemical evolution in the Galactic Disc, A\&A, 2000, vol. 355, p. 929

Pottasch S. R., Bernard-Salas J., Planetary nebulae abundances and stellar evolution, A\&A, 2006, vol. 457, p. 189

Prugniel P., Maubon G., Simien F., The formation of galaxy bulges: Spectrophotometric constraints, A\&A, 2001, vol. 366, p. 68

Ratag M. A., Pottasch S. R., Dennefeld M., Menzies J., Abundances in planetary nebulae near the galactic centre. I. Abundance determinations, A\&AS, 1997, vol. 126, p. 297

Ratag M. A., Pottasch S. R., Dennefeld M., Menzies J. W., Abundances in planetary nebulae near the galactic center. II - Abundance distributions, A\&A, 1992, vol. 255, p. 255

Rattenbury N. J., Mao S., Sumi T., Smith M. C., Modelling the Galactic bar using OGLE-II red clump giant stars, MNRAS, 2007, vol. 378, p. 1064

Rich R. M., Spectroscopy and abundances of 88 K giants in Baade's Window, AJ, 1988, vol. 95 , p. 828

Rich R. M., Origlia L., The First Detailed Abundances for M Giants in Baade's Window from Infrared Spectroscopy, ApJ, 2005, vol. 634, p. 1293

Rich R. M., Origlia L., Valenti E., The First Detailed Abundances for $M$ Giants in the Inner Bulge from Infrared Spectroscopy, ApJ, 2007, vol. 665, p. L119

Rolleston W. R. J., Smartt S. J., Dufton P. L., Ryans R. S. I., The Galactic metallicity gradient, A\&A, 2000, vol. 363, p. 537

Rudolph A. L., Fich M., Bell G. R., Norsen T., Simpson J. P., Haas M. R., Erickson E. F., Abundance Gradients in the Galaxy, ApJS, 2006, vol. 162, p. 346 
Ruffle P. M. E., Zijlstra A. A., Walsh J. R., Gray M. D., Gesicki K., Minniti D., Comeron F., Angular diameters, fluxes and extinction of compact planetary nebulae: further evidence for steeper extinction towards the bulge, MNRAS, 2004, vol. 353, p. 796

Saha P., A Method for Comparing Discrete Kinematic Data and N-Body Simulations, AJ, 1998, vol. 115, p. 1206

Samland M., Gerhard O. E., The formation of a disk galaxy within a growing dark halo, A\&A, 2003, vol. 399, p. 961

Samland M., Köppen J., Acker A., Stenholm B., Spectrophotometric survey of southern planetary nebulae. III - Automatic ionization modelling, A\&A, 1992, vol. 264, p. 184

Scalo J., The IMF Revisited: A Case for Variations. In The Stellar Initial Mass Function (38th Herstmonceux Conference), vol. 142 of Astronomical Society of the Pacific Conference Series, 1998, p. 201

Scalo J. M., Struck-Marcell C., A physical mechanism for bursts of star formation, ApJ, 1986, vol. 301, p. 77

Schönrich R., Binney J., Chemical evolution with radial mixing, MNRAS, 2009, vol. 396, p. 203

Searle L., Zinn R., Compositions of halo clusters and the formation of the galactic halo, ApJ, 1978, vol. 225, p. 357

Sevenster M. N., Chapman J. M., Habing H. J., Killeen N. E. B., Lindqvist M., The ATCA/VLA OH 1612 MHz survey. I. Observations of the galactic bulge Region, A\&AS, 1997, vol. 122 , p. 79

Shaw R. A., Lee T.-H., Stanghellini L., Davies J. E., García-Hernández D. A., García-Lario P., Perea-Calderón J. V., Villaver E., Manchado A., Palen S., Balick B., A Detailed look at Chemical Abundances in Magellanic Cloud Planetary Nebulae. I. The Small Magellanic Cloud, ApJ, 2010, vol. 717, p. 562

Shen J., Rich R. M., Kormendy J., Howard C. D., De Propris R., Kunder A., Our Milky Way as a Pure-disk Galaxy - A Challenge for Galaxy Formation, ApJ, 2010, vol. 720, p. L72 
Sheth K., Elmegreen D. M., Elmegreen B. G., Capak P., Abraham R. G., Athanassoula E., Ellis R. S., Mobasher B., Salvato M., Schinnerer E., Scoville N. Z., Spalsbury L., Strubbe L., Carollo M., Rich M., West A. A., Evolution of the Bar Fraction in COSMOS: Quantifying the Assembly of the Hubble Sequence, ApJ, 2008, vol. 675, p. 1141

Shklovsky I. S., , Sov. Astron. J., 1956

Smartt S. J., Venn K. A., Dufton P. L., Lennon D. J., Rolleston W. R. J., Keenan F. P., Chemical abundances in the inner 5 kpc of the Galactic disk, A\&A, 2001, vol. 367, p. 86

Soto M., Rich R. M., Kuijken K., Evidence of a Metal-rich Galactic Bar from the Vertex Deviation of the Velocity Ellipsoid, ApJ, 2007, vol. 665, p. L31

Spitoni E., Matteucci F., Effects of the radial flows on the chemical evolution of the Milky Way disk, A\&A, 2011, vol. 531, p. A72

Stahler S. W., Palla F., The Formation of Stars, 2005

Stanek K. Z., Udalski A., Szymanski M., Kaluzny J., Kubiak M., Mateo M., Krzeminski W., Modeling the Galactic Bar Using Red Clump Giants, ApJ, 1997, vol. 477, p. 163

Stanghellini L., Haywood M., The Galactic Structure and Chemical Evolution Traced by the Population of Planetary Nebulae, ApJ, 2010, vol. 714, p. 1096

Stanghellini L., Shaw R. A., Villaver E., The Magellanic Cloud Calibration of the Galactic Planetary Nebula Distance Scale, ApJ, 2008, vol. 689, p. 194

Stasińska G., [Ar III]/[O III] and [S III]/[O III]: well-behaved oxygen abundance indicators for HII regions and star forming galaxies, A\&A, 2006, vol. 454, p. L127

Stasińska G., Richer M. G., McCall M. L., The planetary nebulae populations in five galaxies: abundance patterns and evolution, A\&A, 1998, vol. 336, p. 667

Talbot Jr. R. J., Arnett W. D., The Evolution of Galaxies. II. Chemical Evolution Coefficients, ApJ, 1973, vol. 186, p. 51

Thielemann F.-K., Nomoto K., Hashimoto M.-A., Core-Collapse Supernovae and Their Ejecta, ApJ, 1996, vol. 460, p. 408 
Thomas D., Greggio L., Bender R., Stellar Yields and Chemical Evolution - I. Abundance Ratios and Delayed Mixing in the Solar Neighbourhood, MNRAS, 1998, vol. 296, p. 119

Tiede G. P., Terndrup D. M., Kinematics, Metallicities, and Stellar Distributions in the Inner Disk and Bulge of the Milky Way, AJ, 1999, vol. 118, p. 895

Tinsley B. M., Evolution of the Stars and Gas in Galaxies, Fund. Cosmic Phys., 1980, vol. 5 , p. 287

Tinsley B. M., Larson R. B., Chemical evolution and the formation of galactic disks, ApJ, 1978, vol. 221 , p. 554

Toomre A., Mergers and Some Consequences. In Evolution of Galaxies and Stellar Populations , 1977, p. 401

Torres-Peimbert S., Peimbert M., Photoelectric photometry and physical conditions of planetary nebulae., Rev. Mexicana Astron. Astrofis., 1977, vol. 2, p. 181

Tsujimoto T., Bekki K., Two-component Galactic Bulge Probed with Renewed Galactic Chemical Evolution Model, ApJ, 2012, vol. 747, p. 125

Tylenda R., Siódmiak N., Górny S. K., Corradi R. L. M., Schwarz H. E., Angular dimensions of planetary nebulae, A\&A, 2003, vol. 405, p. 627

van den Bergh S., McClure R. D., Evans R., The supernova rate in Shapley-Ames galaxies, ApJ, 1987, vol. 323, p. 44

van den Hoek L. B., Groenewegen M. A. T., New theoretical yields of intermediate mass stars, A\&AS, 1997, vol. 123, p. 305

van Loon J. T., Gilmore G. F., Omont A., Blommaert J. A. D. L., Glass I. S., Messineo M., Schuller F., Schultheis M., Yamamura I., Zhao H. S., Infrared stellar populations in the central parts of the Milky Way galaxy, MNRAS, 2003, vol. 338, p. 857

Vilchez J. M., Esteban C., The chemical composition of HII regions in the outer Galaxy, MNRAS, 1996, vol. 280, p. 720 
Weiland J. L., Arendt R. G., Berriman G. B., Dwek E., Freudenreich H. T., Hauser M. G., Kelsall T., Lisse C. M., Mitra M., Moseley S. H., Odegard N. P., Silverberg R. F., Sodroski T. J., Spiesman W. J., Stemwedel S. W., COBE diffuse infrared background experiment observations of the galactic bulge, ApJ, 1994, vol. 425, p. L81

Whelan J., Iben Jr. I., Binaries and Supernovae of Type I, ApJ, 1973, vol. 186, p. 1007

Williams J. P., McKee C. F., The Galactic Distribution of OB Associations in Molecular Clouds, ApJ, 1997, vol. 476, p. 166

Woosley S. E., Weaver T. A., The Evolution and Explosion of Massive Stars. II. Explosive Hydrodynamics and Nucleosynthesis, ApJS, 1995, vol. 101, p. 181

Wyse R. F. G., Phase-space density constraints on the formation of bulges from discs, MNRAS, 1998, vol. 293, p. 429

Wyse R. F. G., Gilmore G., Formation and evolution of the Galactic bulge and spheroid Where did the spheroid gas go?, AJ, 1992, vol. 104, p. 144

Zhang C. Y., A statistical distance scale for Galactic planetary nebulae, ApJS, 1995, vol. 98, p. 659

Zoccali M., Hill V., Lecureur A., Barbuy B., Renzini A., Minniti D., Gómez A., Ortolani S., The metal content of bulge field stars from FLAMES-GIRAFFE spectra. I. Stellar parameters and iron abundances, A\&A, 2008, vol. 486, p. 177

Zoccali M., Lecureur A., Barbuy B., Hill V., Renzini A., Minniti D., Momany Y., Gómez A., Ortolani S., Oxygen abundances in the Galactic bulge: evidence for fast chemical enrichment, A\&A, 2006, vol. 457, p. L1

Zoccali M., Lecureur A., Barbuy B., Hill V., Renzini A., Minniti D., Momany Y., Gómez A., Ortolani S., Abundances in the Galactic Bulge: evidence for fast chemical enrichment. In IAU Symposium , vol. 241 of IAU Symposium, 2007, p. 73

Zoccali M., Renzini A., Ortolani S., Greggio L., Saviane I., Cassisi S., Rejkuba M., Barbuy B., Rich R. M., Bica E., Age and metallicity distribution of the Galactic bulge from extensive optical and near-IR stellar photometry, A\&A, 2003, vol. 399, p. 931 
Apêndice 



\title{
PLANETARY NEBULAE IN THE INNER MILKY WAY: NEW ABUNDANCES
}

\author{
O. Cavichia, R. D. D. Costa, and W. J. Maciel \\ Instituto de Astronomia, Geofísica e Ciências Atmosféricas \\ Universidade de São Paulo, Brazil
}

Received 2009 November 19; accepted 2010 February 8

\section{RESUMEN}

El estudio de las nebulosas planetarias del disco interior y del bulbo galáctico proporciona importante información sobre las abundancias químicas de elementos como He, N, O, Ar, Ne y sobre la evolución de estas abundancias, la cual está asociada a la evolución de las estrellas de masa intermedia y a la evolución química de la Galaxia.

Presentamos abundancias precisas de los elementos He, N, S, O, Ar, y Ne para una muestra de 54 nebulosas planetarias localizadas en la dirección del bulbo galáctico, para 33 de las cuales se presentan abundancias aquí por primera vez. Las abundancias se derivan a partir de observaciones en la región óptica hechas en el Laboratorio Nacional de Astrofísica (LNA), Brasil. Los datos muestran una buena concordancia con otros resultados en la literatura, en el sentido de que la distribución de abundancias es similar a la obtenida en otros trabajos.
\end{abstract}

\section{ABSTRACT}

The study of planetary nebulae in the inner-disk and bulge gives important information on the chemical abundances of elements such as He, N, O, Ar, Ne, and on the evolution of these abundances, which is associated with the evolution of intermediate-mass stars and the chemical evolution of the Galaxy.

We present accurate abundances of the elements $\mathrm{He}, \mathrm{N}, \mathrm{S}, \mathrm{O}, \mathrm{Ar}$, and $\mathrm{Ne}$ for a sample of 54 planetary nebulae located towards the bulge of the Galaxy, for 33 of which the abundances are derived here for the first time. The abundances are obtained based on observations in the optical domain made at the National Laboratory for Astrophysics (LNA, Brazil). The data show a good agreement with other results in the literature, in the sense that the distribution of the abundances is similar to that of those works.

Key Words: Galaxy: abundances - Galaxy: evolution — planetary nebulae: general — techniques: spectroscopic

\section{INTRODUCTION}

The bulge of the Galaxy shows a large metallicity dispersion. The study of the metallicity distribution from K giants, as done by Rich (1988), shows values from 0.1 to $10 Z_{\odot}$. More recently, Rich \& Origlia (2005) find an $\alpha$-enhancement at the level of +0.3 dex relative to the solar composition stars for $14 \mathrm{M}$ giants and within a narrow metallicity range around $[\mathrm{Fe} / \mathrm{H}]=-0.2$. Zoccali et al. (2006) and Lecureur et al. (2007) find that bulge stars have larger values of $[\mathrm{O} / \mathrm{Fe}]$ and $[\mathrm{Mg} / \mathrm{Fe}]$ when compared to thin and thick disk stars. This is the signature of a chemical enrichment by massive stars, progenitors of type II supernovae, with little or no contribution from type Ia supernovae, showing a shorter formation timescale for the bulge than for both the thin and thick disks.

In this context, planetary nebulae $(\mathrm{PNe})$ are an important tool for the study of the chemical evolution of galaxies. The understanding of this stage of stellar evolution allows us to grasp how the Galaxy originated and developed. As an intermediate mass star evolution product, $\mathrm{PNe}$ offer the possibility of studying elements produced in both low and intermediate mass stars, such as helium and nitrogen, and 
also elements which result from the nucleosynthesis of large mass stars, such as oxygen, sulfur and neon, which are present in the interstellar medium at the formation epoch of the PNe stellar progenitor.

Regardless of the fact that the chemical abundances obtained from $\mathrm{PNe}$ are relatively accurate, their distances are subject to discussion even nowadays. Excluding a few PNe whose distances are determined from direct methods such as trigonometric parallax, or those cases where there is a binary companion in the main sequence, most $\mathrm{PNe}$ have their distances derived from nebular properties (see e.g., Maciel \& Pottasch 1980; Cahn, Kaler, \& Stanghellini 1992; Stanghellini, Shaw, \& Villaver 2008). These uncertainties in the distances of PNe make the study of the chemical properties as a function of galactocentric distance a difficult task. In spite of the uncertainties, statistical distance scales are still the best tool to study the chemical abundance patterns in the Galaxy from the point of view of PNe, as e.g., done by Maciel \& Quireza (1999), Maciel, Lago, \& Costa (2006), Perinotto \& Morbidelli (2006), and Gutenkunst et al. (2008).

Since the bulge and the disk may have different evolution histories, described for example by the disk inside-out formation model (Chiappini, Matteucci, \& Romano 2001) or by the multiple infalls scenario (Costa, Escudero, \& Maciel 2005; Costa, Maciel, \& Escudero 2008), we should expect these differences to be reflected on the chemical properties of each component. Indeed, bulge and disk display different chemical abundance patterns, like the radial abundance gradients found in the disk (Carigi et al. 2005; Daflon \& Cunha 2004; Andrievsky et al. 2004; Maciel, Lago, \& Costa 2005, 2006), or the large abundance distribution found in the bulge (Rich 1988; Zoccali et al. 2003, 2006).

On the other hand, Chiappini et al. (2009) made a comparison between abundances from PNe located in the bulge, the inner-disk and the Large Magellanic Cloud. Their results do not show any clear difference between bulge and inner-disk objects. Some other previous studies of the Galactic bulge based on abundances of PNe such as Ratag et al. (1992), Cuisinier et al. (2000), Escudero \& Costa (2001), Escudero, Costa, \& Maciel (2004), and Exter, Barlow, \& Walton (2004), find that bulge PNe have an abundance distribution similar to disk $\mathrm{PNe}$, showing that He, $\mathrm{O}, \mathrm{Si}, \mathrm{Ar}$, and $\mathrm{Ca}$ have a normal abundance pattern, favoring therefore a Galactic evolution slower than that indicated by stars. In conclusion, the study of chemical abundances in the inner region of the
Galaxy is still an open question, especially regarding the bulge-disk connection.

The goal of this paper is to report new spectrophotometric observations for a sample of PNe located in the inner-disk and bulge of the Milky Way galaxy, aiming to derive their nebular physical parameters and chemical abundances, as has been done by our group (see e.g., Costa et al. 1996; Costa, de Freitas, \& Idiart 2000; Escudero \& Costa 2001; Escudero et al. 2004, and references therein), as part of a long-term program to derive a large sample of chemical abundances of southern PNe. As a result, our database has become one of the largest in the literature, with a very homogeneous observational setup, reduction and analysis procedures, which are necessary to perform large-scale statistical studies. In this work, 33 objects have their abundances derived for the first time. Additionally, objects in common with other samples are used to compare our data with previous data already published. The comparison of the final abundances with those obtained in other multi-object studies allow us to assess the accuracy of the new abundances.

This paper is organized as follows: in $\S 2$ the details of the observations and data reduction procedures are presented. In $\S 3$ we describe the process of determination of chemical abundances, and the new abundances are listed. In $\S 4$, a comparison is made between the abundances obtained in this work and those taken from the literature. Finally, in $\S 5$ the main conclusions are presented.

\section{OBSERVATIONS AND DATA REDUCTION}

\subsection{Observations}

The observations were made at the $1.60 \mathrm{~m}$ telescope of the National Laboratory for Astrophysics (LNA, Brazil) during 2006 and 2007, according to the log of observations shown in Table 1 . In this table, Column 1 displays the PN G designation, Column 2 the usual name, Columns 3 and 4 the equatorial coordinates for epoch 2000, Column 5 the date of observation, and Column 6 the exposure time in seconds. A Cassegrain Boller \& Chivens spectrograph was used with a $300 \mathrm{l} / \mathrm{mm}$ grid, which provides a reciprocal dispersion of $0.2 \mathrm{~nm} /$ pixel. For all program objects, a long slit of 1.5 arcsec width was used. Each night at least three spectrophotometric standard stars were observed in order to improve the flux calibration. These stars were observed with a long slit of 7.5 arcsec width, allowing a more precise flux calibration.

The sample was selected from the Strasbourg ESO catalogue of Galactic planetary nebulae (Acker 
PLANETARY NEBULAE IN THE INNER MILKY WAY

TABLE 1

LOG OF THE OBSERVATIONS

\begin{tabular}{|c|c|c|c|c|c|}
\hline PN G & Name & RA (J2000) & DEC (J2000) & Date of Obs. & Exp. Time (s) \\
\hline $000.7-02.7$ & M 2-21 & $1758 \quad 09.57$ & -294420.10 & Jun 24,07 & $2 \times 1200$ \\
\hline $000.9-04.8$ & M 3-23 & $\begin{array}{lll}18 & 07 & 06.15\end{array}$ & -303417.00 & Jun 21,07 & $3 \times 1200$ \\
\hline $004.0-11.1$ & M 3-29 & 183925.77 & -304036.70 & Jun 24,06 & $2 \times 1200$ \\
\hline $004.2-04.3$ & H 1-60 & $1812 \quad 25.16$ & -272913.00 & Jun 21,07 & $2 \times 1200$ \\
\hline $004.2-05.9$ & M 2-37 & 181838.35 & -280801.00 & Jun 24,07 & $1 \times 1200$ \\
\hline $005.2-18.6$ & StWr 2-21 & 191423.33 & -323416.70 & Jun 21,06 & $3 \times 900$ \\
\hline $005.5-2.5$ & M 3-24 & 180753.91 & -252402.71 & Jun 24,07 & $3 \times 900$ \\
\hline $006.4-04.6$ & Pe $2-13$ & $1818 \quad 13.36$ & -253808.90 & Jun $22 / 23,07$ & $2 \times 1800$ \\
\hline $006.8-03.4$ & H 2-45 & 181428.84 & -244338.30 & Jun 23, 07 & $2 \times 900$ \\
\hline $007.0+06.3$ & M 1-24 & 173811.59 & -193737.60 & Jun 24,07 & $2 \times 1200$ \\
\hline $010.7+07.4$ & Sa $2-230$ & 174202.01 & -155607.50 & Jun 24,06 & $2 \times 1800$ \\
\hline $011.0-05.1$ & M 1-47 & 182911.15 & -214653.40 & Jun 21,07 & $2 \times 900$ \\
\hline $011.3+02.8$ & Th 4-11 & 180008.82 & -174043.30 & Jun 24,06 & $3 \times 600$ \\
\hline $011.7-06.6$ & M 1-55 & 183642.55 & -214859.10 & Jun 23,06 & $2 \times 1200$ \\
\hline $012.6-02.6$ & M 1-45 & 182307.98 & -191705.30 & Jun 21,07 & $2 \times 1200$ \\
\hline $013.8-07.9$ & Pc 21 & $1845 \quad 35.22$ & -203458.30 & Jun 21,06 & $2 \times 1200$ \\
\hline $015.9+03.3$ & M 1-39 & 180730.70 & -132847.60 & Jun 23,06 & $3 \times 600$ \\
\hline $016.4-01.9$ & M 1-46 & 182756.34 & -153254.40 & Jun 23,07 & $3 \times 600$ \\
\hline $019.7-04.5$ & M 1-60 & 184338.11 & -134448.60 & Jun 23,07 & $3 \times 600$ \\
\hline $021.8-00.4$ & M 3-28 & 183241.29 & -100550.00 & Jun 22,07 & $2 \times 1200$ \\
\hline $023.0+04.3$ & MA 3 & $\begin{array}{lll}18 & 17 & 49.38\end{array}$ & -064821.50 & Jun 24,06 & $3 \times 1200$ \\
\hline $023.3-07.6$ & $\mathrm{MaC} 1-16$ & 190121.77 & -115820.00 & Jun 21, 06 & $3 \times 1200$ \\
\hline $023.8-01.7$ & K $3-11$ & $\begin{array}{lll}18 & 41 & 07.31\end{array}$ & -085559.00 & Jun 22,07 & $2 \times 1800$ \\
\hline $024.1+03.8$ & M 2-40 & 182123.85 & -060155.80 & Jun 24,06 & $2 \times 1200$ \\
\hline $025.9-02.1$ & Pe $1-15$ & 184624.48 & -071434.60 & Jun 22,07 & $2 \times 1200$ \\
\hline $335.4-01.1$ & He $2-169$ & 163413.33 & -492113.20 & Jun 23,07 & $2 \times 1200$ \\
\hline $335.9-03.6$ & Mewe 1-7 & 164757.07 & -504248.30 & Jun 21, 06 & $3 \times 1200$ \\
\hline $336.2+01.9$ & Pe 1-6 & 162354.31 & -464215.30 & Jun 22,07 & $2 \times 1200$ \\
\hline $336.3-05.6$ & He $2-186$ & 165936.06 & -514206.50 & Jun 25,07 & $3 \times 600$ \\
\hline $336.9+08.3$ & StWr 4-10 & 160213.04 & -413335.90 & Jun 23,06 & $2 \times 1200$ \\
\hline $338.8+05.6$ & He $2-155$ & 161923.10 & -421536.00 & Jun 21,07 & $3 \times 900$ \\
\hline $340.9-04.6$ & Sa $1-5$ & 171127.37 & -472501.60 & Jun 23, 06 & $2 \times 900$ \\
\hline $342.9-04.9$ & He 2-207 & 171932.97 & -455316.70 & Jun 23,06 & $3 \times 900$ \\
\hline $343.0-01.7$ & Vd 1-9 & 170538.30 & -435618.00 & Jun 21, 06 & $2 \times 1200$ \\
\hline $344.2-01.2$ & H 1-6 & 170658.87 & -424109.75 & Jun 23,07 & $2 \times 1800$ \\
\hline $344.4+02.8$ & Vd 1-5 & 165133.57 & -400256.00 & Jun 21,06 & $2 \times 1200$ \\
\hline $344.8+03.4$ & Vd 1-3 & 164932.87 & -392108.90 & Jun 23,06 & $2 \times 1800$ \\
\hline $345.0+03.4$ & Vd 1-4 & 165025.32 & -390818.90 & Jun 24,06 & $3 \times 900$ \\
\hline $346.2-08.2$ & IC 4663 & $1745 \quad 28.37$ & -445415.90 & Jun 25,07 & $2 \times 900$ \\
\hline $347.7+02.0$ & Vd 1-8 & 170433.77 & -375314.90 & Jun 24,06 & $2 \times 1200$ \\
\hline $348.0-13.8$ & IC 4699 & 181832.02 & -455901.70 & Jun 23, 06 & $3 \times 900$ \\
\hline $350.5-05.0$ & H 1-28 & 174254.07 & -393624.00 & Jun 24,07 & $2 \times 1800$ \\
\hline $350.9+04.4$ & H 2-1 & 170436.26 & -335918.80 & Jun 21,07 & $4 \times 240,1 \times 120$ \\
\hline $351.6-06.2$ & H $1-37$ & 175044.57 & -391726.00 & Jun 24,07 & $2 \times 900$ \\
\hline $352.6+03.0$ & H 1-8 & 171442.90 & -332447.20 & Jun 24,07 & $2 \times 1200$ \\
\hline $355.4-04.0$ & Hf $2-1$ & 175112.15 & -345524.30 & Jun 25,07 & $2 \times 900$ \\
\hline $355.9+03.6$ & H 1-9 & 172131.90 & -302048.35 & Jun 22,07 & $3 \times 500$ \\
\hline $356.3-06.2$ & M 3-49 & $\begin{array}{lll}18 & 02 & 32.11\end{array}$ & -351314.70 & Jun 23,07 & $2 \times 1800$ \\
\hline $356.8-05.4$ & H 2-35 & 180018.26 & -342739.30 & Jun 21,07 & $2 \times 1800$ \\
\hline $357.4-04.6$ & M 2-22 & 175832.63 & -332836.60 & Jun 22,07 & $2 \times 1200$ \\
\hline $358.2+03.5$ & H 2-10 & 172732.85 & -283106.90 & Jun 21,07 & $2 \times 1200$ \\
\hline $358.3+03.0$ & H $1-17$ & 172940.59 & -284022.10 & Jun 23,07 & $3 \times 900$ \\
\hline $358.7+05.2$ & M 3-40 & $\begin{array}{lll}17 & 22 & 28.27\end{array}$ & -270842.40 & Jun 23,07 & $2 \times 1200$ \\
\hline $358.8+03.0$ & Th 3-26 & 173109.30 & -281450.40 & Jun 24,07 & $2 \times 1800$ \\
\hline $359.8+03.7$ & Th 3-25 & 173046.72 & -270559.10 & Jun 22,07 & $2 \times 1200$ \\
\hline
\end{tabular}

et al. 1992), based on three criteria: galactic coordinates within the range $|\ell| \leq 25^{\circ}$ and $|b| \leq 10^{\circ}, 5 \mathrm{GHz}$ flux below $100 \mathrm{mJy}$, and optical diameter lower than 12 arcsec. The galactic coordinates were used to take into account only the $\mathrm{PNe}$ which are in the galactic center direction. The combination of the other two criteria leads to the rejection of about $90-95 \%$ of the $\mathrm{PNe}$ which are in the galactic center direction, but have heliocentric distances lower than $4 \mathrm{kpc}$ (cf. Stasińska, Richer, \& McCall 1998). These criteria 


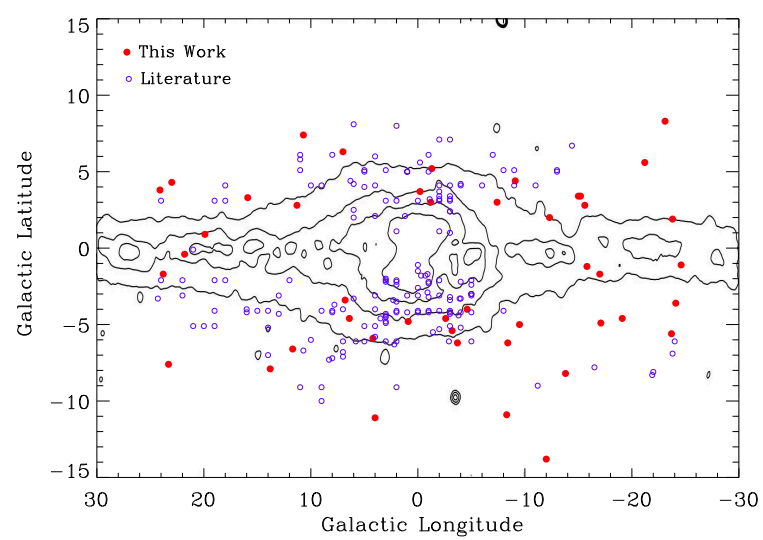

Fig. 1. PNe distribution compared to the galactic bulge for this work (filled circles) and data from the literature (open circles).

are commonly used by other authors to select bulge PNe (e.g. Exter et al. 2004 and Chiappini et al. 2009). Hence, most of the objects selected in this work should be in or near the bulge.

Figure 1 displays the distribution of the sample with respect to the galactic bulge. The figure also shows the distribution for the objects selected from the literature (see $\S 4$ for more details). As can be seen, the selected objects are located in the direction of the galactic bulge, whose contours are displayed using the image from the $2.2 \mu \mathrm{m}$ COBE/DIRBE satellite plot (Weiland et al. 1994). Furthermore, the sample objects spread over the entire region of the galactic bulge, avoiding tendencies in the chemical abundances analysis introduced by partial coverage of the bulge, as found by Escudero \& Costa (2001). They showed that objects located in a region with galactic latitude larger than 5 degrees display lower abundances when compared with other works in the literature such as Ratag et al. (1997), Cuisinier et al. (2000), and Stasińska et al. (1998), whose samples are located elsewhere.

Data reduction was performed using the IRAF package, following the standard procedure for long slit spectra: correction of bias, flat-field, extraction, wavelength and flux calibration. Atmospheric extinction was corrected through mean coefficients derived for the LNA observatory. Table 2 displays the line fluxes in a scale where $\mathrm{F}(\mathrm{H} \beta)=100$, with reddening correction. A typical spectrum can be seen in Figure 2, for the planetary nebula Pe 1-15.

\subsection{Interstellar extinction}

As pointed out by Escudero et al. (2004), the application of the extinction curve of Fitzpatrick

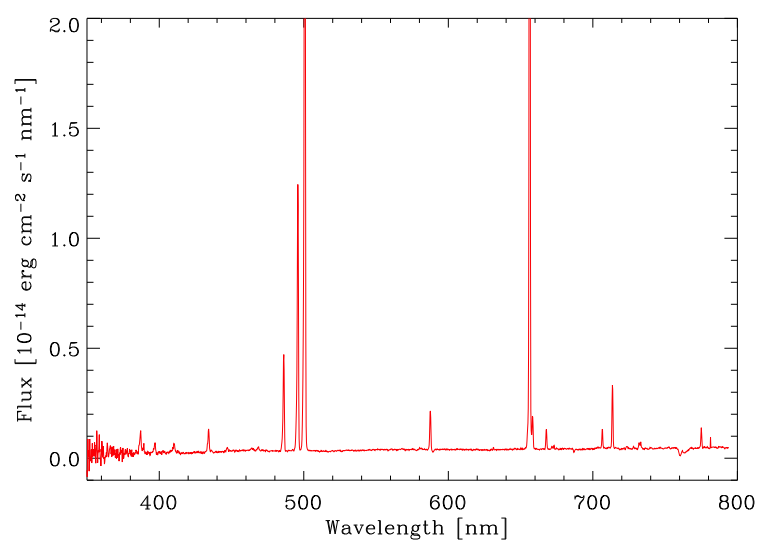

Fig. 2. Typical spectrum from our sample for the object $\mathrm{Pe} 1-15$. The [O III] $500.7 \mathrm{~nm}$ and $\mathrm{H} \alpha$ lines are saturated to allow a better view of other lines.

(1999) has produced better results than the curve of Cardelli, Clayton, \& Mathis (1989) for the interstellar extinction correction. Therefore we chose the former to correct the interstellar extinction, deriving $\mathrm{E}(\mathrm{B}-\mathrm{V})$ from the observed Balmer ratio $\mathrm{H} \alpha / \mathrm{H} \beta$ and adopting the theoretical value $\mathrm{H} \alpha / \mathrm{H} \beta=2.85$, with $\mathrm{R}_{\mathrm{V}}=3.1$. This extinction curve is given by a seven-degree polynomial equation as follows:

$$
\begin{aligned}
{\left[\frac{\mathrm{A}_{\lambda}}{E(B-V)}\right] } & =0.00001+0.22707 x+1.95243 x^{2} \\
& -2.67596 x^{3}+2.6507 x^{4}-1.26812 x^{5} \\
& +0.27549 x^{6}-0.02212 x^{7}
\end{aligned}
$$

with $x=1 / \lambda\left[\mu \mathrm{m}^{-1}\right]$.

\section{DETERMINATION OF CHEMICAL ABUNDANCES}

\subsection{Physical parameters}

The physical parameters - electron densities and electron temperatures- were derived from optical emission lines. The electron density was determined from the sulfur line ratio $[\mathrm{S} \mathrm{II}] \lambda 671.6 / \lambda 673.1 \mathrm{~nm}$. For the electron temperature we used both [O III] $\lambda 436.3 / \lambda 500.7 \mathrm{~nm}$, and [N II] $\lambda 575.5 / \lambda 654.8 \mathrm{~nm}$ line ratios, which give two temperature zones: one for the low potential lines and the other for high potential lines.

Table 3 shows the physical parameters obtained for the observed PNe. Column 1 lists the PN $\mathrm{G}$ number, Columns 2 and 3 the interstellar extinction $E(B-V)$ with uncertainties (described in $\S 3.3)$, Columns $4-5$ the electron density from [S II] in $10^{3} \mathrm{~cm}^{-3}$, and Columns 6-7 and 8-9 the electron 
PLANETARY NEBULAE IN THE INNER MILKY WAY

TABLE 2

REDDENING-CORRECTED LINE FLUXES IN UNITS OF F(H $\beta=100)$

\begin{tabular}{|c|c|c|c|c|c|c|c|c|}
\hline & $000.7-02.7$ & $000.9-04.8$ & $004.0-11.1$ & $004.2-04.3$ & $004.2-05.9$ & $005.2-18.6$ & $005.5-2.5$ & 006.4-04.6 \\
\hline$[\mathrm{OII}] \lambda 372.8$ & 13.0 & 15.3 & - & 5.0 & 43.6 & - & 35.4 & 13.6 \\
\hline$[\mathrm{NeIII}] \lambda 386.9$ & 57.7 & 143.3 & 107.0 & 82.1 & 103.4 & 97.9 & 84.1 & 83.9 \\
\hline H8 $\lambda 388.9$ & 18.1 & 8.4 & 37.1 & 16.2 & 30.7 & 21.9 & 17.7 & 8.3 \\
\hline$[\mathrm{NeIII}] \lambda 396.7$ & 24.6 & 51.2 & 53.7 & 34.7 & 37.2 & 56.4 & 44.4 & 19.5 \\
\hline H7 7397.0 & - & - & - & - & - & - & - & 4.9 \\
\hline $\mathrm{H} 6 \lambda 410.2$ & 14.1 & 33.1 & 34.5 & 27.6 & 27.2 & 30.8 & 24.8 & 28.2 \\
\hline $\mathrm{H} \gamma \lambda 434.0$ & 39.1 & 53.3 & 46.0 & 47.0 & 50.0 & 50.1 & 44.5 & 61.4 \\
\hline [OIII] $\lambda 436.3$ & 16.5 & 20.0 & 4.1 & 7.6 & 13.8 & 12.6 & 4.0 & 23.4 \\
\hline $\operatorname{HeI} \lambda 447.1$ & 5.7 & 2.8 & 5.8 & 7.6 & 17.4 & 4.3 & 6.7 & 21.8 \\
\hline HeII $\lambda 468.6$ & 24.1 & 105.7 & - & 6.2 & - & 41.3 & 22.3 & 99.9 \\
\hline$[\mathrm{ArIV}] \lambda 471.1$ & 3.9 & 22.3 & - & 3.9 & 1.4 & 4.7 & 4.0 & 16.4 \\
\hline$[\mathrm{ArIV}] \lambda 474.0$ & 4.3 & 17.7 & - & 2.3 & 2.0 & 3.8 & 2.7 & 14.2 \\
\hline $\mathrm{H} \beta \lambda 486.1$ & 100.0 & 100.0 & 100.0 & 100.0 & 100.0 & 100.0 & 100.0 & 100.0 \\
\hline [OIII] $\lambda 495.9$ & 442.6 & 387.4 & 189.6 & 317.0 & 43.7 & 359.1 & 220.7 & 393.8 \\
\hline [OIII] $\lambda 500.7$ & 1294.3 & 1106.4 & 546.9 & 924.6 & 108.2 & 1066.2 & 650.9 & 1139.8 \\
\hline$[\mathrm{NI}] \lambda 519.9$ & 1.0 & - & - & - & 3.8 & 0.6 & 1.0 & - \\
\hline$[\mathrm{CaV}] \lambda 530.9$ & - & - & - & 1.8 & - & - & - & - \\
\hline HeII $\lambda 541.1$ & 2.2 & 7.3 & - & 1.0 & - & 3.9 & 2.4 & 19.8 \\
\hline$[\mathrm{NII}] \lambda 575.5$ & 1.0 & 0.6 & 0.8 & - & 1.7 & 0.4 & 2.1 & - \\
\hline HeI $\lambda 587.6$ & 15.2 & 4.1 & 12.6 & 15.6 & 21.5 & 10.7 & 19.6 & 16.8 \\
\hline$[\mathrm{OI}] \lambda 630.0$ & 5.1 & 0.3 & 0.4 & 0.7 & 1.2 & 2.3 & 1.9 & 12.5 \\
\hline [SIII] $\lambda 631.2$ & 4.5 & 3.6 & 0.7 & 0.6 & 1.8 & 1.7 & 1.1 & 4.5 \\
\hline$[\mathrm{OI}] \lambda 636.4$ & 1.9 & 0.3 & 0.6 & 0.2 & - & 0.9 & 1.1 & - \\
\hline$[\mathrm{ArV}] \lambda 643.5$ & - & 2.7 & 0.2 & 0.5 & - & 0.2 & - & 5.7 \\
\hline$[\mathrm{NII}] \lambda 654.8$ & 8.1 & 4.3 & 22.0 & 1.7 & 30.4 & 15.1 & 31.7 & 8.3 \\
\hline H5 $\lambda 656.3$ & 285.0 & 285.0 & 285.0 & 202.9 & 285.0 & 284.6 & 285.0 & 285.0 \\
\hline$[\mathrm{NII}] \lambda 658.3$ & 24.4 & 12.8 & 66.5 & 5.3 & 54.7 & 18.6 & 75.8 & 25.1 \\
\hline HeI $\lambda 667.8$ & 5.4 & 3.0 & 4.1 & 5.0 & 7.0 & 3.3 & 5.5 & 8.3 \\
\hline$[\mathrm{SII}] \lambda 671.6+3.1$ & 2.0 & 3.7 & 7.8 & 0.8 & 5.9 & 6.4 & 6.4 & 9.3 \\
\hline$[\mathrm{SII}] \lambda 671.6 / 3.1$ & 0.6 & 0.9 & 0.9 & 0.3 & 1.1 & 0.7 & 0.7 & 0.8 \\
\hline$[\mathrm{ArV}] \lambda 700.6$ & 1.3 & 7.1 & - & - & - & 0.5 & - & 11.7 \\
\hline HeI $\lambda 706.5$ & 8.4 & 1.3 & 3.1 & 5.2 & 4.0 & 3.3 & 3.9 & 14.4 \\
\hline$[$ ArIII] $] 713.6$ & 8.7 & 23.4 & 9.8 & 8.0 & 5.3 & 12.6 & 18.0 & 32.4 \\
\hline$[\mathrm{ArIV}] \lambda 717.0$ & 0.3 & 2.5 & - & - & - & - & 0.7 & 3.0 \\
\hline HeII $\lambda 717.7$ & 0.5 & - & - & - & - & 0.7 & - & 5.3 \\
\hline$[\mathrm{ArIV}] \lambda 723.8$ & 1.0 & 1.8 & - & 2.0 & 2.2 & 0.8 & 1.9 & - \\
\hline$[$ ArIV] $] \lambda 726.3$ & - & 1.2 & - & - & - & 0.3 & 0.3 & - \\
\hline$[\mathrm{OII}] \lambda 732.5$ & 11.2 & 2.2 & 3.0 & 3.5 & 4.7 & 3.9 & 5.2 & 17.1 \\
\hline \multirow[t]{2}{*}[\text{ArIII}]{$\lambda 775.1$} & 2.4 & 7.2 & 6.8 & 3.9 & 3.3 & 4.9 & 3.8 & 16.6 \\
\hline & 006.8-03.4 & $007.0+06.3$ & $010.7+07.4$ & 011.0-05.1 & $011.3+02.8$ & 011.7-06.6 & 012.6-02.6 & $013.8-07.9$ \\
\hline$[\mathrm{OII}] \lambda 372.8$ & - & 31.4 & - & 9.5 & - & - & 87.4 & - \\
\hline$[\mathrm{NeIII}] \lambda 386.9$ & 94.4 & 54.0 & 104.6 & 113.2 & 67.0 & - & - & 76.4 \\
\hline H8 $\lambda 388.9$ & 20.9 & 27.1 & 22.6 & 18.5 & 35.0 & 11.8 & 31.0 & 14.2 \\
\hline$[\mathrm{NeIII}] \lambda 396.7$ & 26.9 & 37.3 & 56.6 & 39.9 & 45.5 & 19.0 & 25.1 & 40.4 \\
\hline H7 7397.0 & - & - & - & - & - & - & - & - \\
\hline $\mathrm{H} 6 \lambda 410.2$ & 26.9 & 33.8 & 45.2 & 26.4 & 44.0 & 24.6 & 37.3 & 31.7 \\
\hline $\mathrm{H} \gamma \lambda 434.0$ & 49.7 & 49.5 & 55.5 & 45.2 & 52.3 & 50.1 & 53.5 & 47.5 \\
\hline$[\mathrm{OIII}] \lambda 436.3$ & 11.8 & 4.3 & 12.0 & 11.5 & 29.7 & - & 3.9 & 12.8 \\
\hline $\operatorname{HeI} \lambda 447.1$ & 11.1 & 6.8 & 5.7 & 6.5 & 6.6 & - & 4.5 & 3.7 \\
\hline $\operatorname{HeII} \lambda 468.6$ & - & - & 115.4 & 4.1 & 8.4 & - & 3.2 & 102.4 \\
\hline$[\mathrm{ArIV}] \lambda 471.1$ & 3.1 & - & 12.7 & 3.5 & 2.2 & 2.0 & - & 13.5 \\
\hline$[\mathrm{ArIV}] \lambda 474.0$ & 2.9 & - & 9.7 & 2.5 & 1.3 & - & - & 10.2 \\
\hline $\mathrm{H} \beta \lambda 486.1$ & 100.0 & 100.0 & 100.0 & 100.0 & 100.0 & 100.0 & 100.0 & 100.0 \\
\hline$[\mathrm{OIII}] \lambda 495.9$ & 328.2 & 166.0 & 295.5 & 399.3 & 29.2 & - & 1.3 & 242.6 \\
\hline$[\mathrm{OIII}] \lambda 500.7$ & 948.7 & 482.0 & 879.8 & 1184.4 & 81.8 & 1.2 & 2.0 & 735.8 \\
\hline$[\mathrm{NI}] \lambda 519.9$ & - & - & 0.4 & - & 0.7 & 1.6 & 1.6 & 0.6 \\
\hline$[\mathrm{CaV}] \lambda 530.9$ & - & - & - & - & 0.9 & - & - & - \\
\hline HeII $\lambda 541.1$ & 0.6 & 0.3 & 9.7 & - & 0.9 & - & - & 9.5 \\
\hline$[\mathrm{NII}] \lambda 575.5$ & - & 0.9 & 0.9 & 0.2 & 0.7 & 1.4 & 1.3 & 0.3 \\
\hline HeI $\lambda 587.6$ & 15.1 & 8.8 & 8.4 & 13.8 & 18.1 & 0.8 & 2.4 & 6.2 \\
\hline$[\mathrm{OI}] \lambda 630.0$ & 1.1 & 0.6 & - & - & 0.8 & 2.3 & 1.5 & 0.7 \\
\hline [SIII] $\lambda 631.2$ & 0.9 & 0.9 & 3.3 & 0.6 & 0.6 & - & 0.2 & 2.1 \\
\hline$[\mathrm{OI}] \lambda 636.4$ & 0.5 & 0.6 & 0.5 & - & 0.7 & 0.9 & 0.6 & 0.3 \\
\hline$[\mathrm{ArV}] \lambda 643.5$ & 0.3 & 0.9 & 1.2 & - & 0.2 & - & 0.1 & 2.2 \\
\hline$[\mathrm{NII}] \lambda 654.8$ & 2.2 & 19.0 & 5.1 & - & 4.7 & 73.5 & 80.2 & 2.7 \\
\hline H5 $\lambda 656.3$ & 285.0 & 285.0 & 285.0 & 285.0 & 285.0 & 285.0 & 285.0 & 284.7 \\
\hline$[\mathrm{NII}] \lambda 658.3$ & 6.4 & 31.8 & 15.4 & - & 14.1 & 191.4 & 222.6 & 8.2 \\
\hline HeI 6667.8 & 3.5 & 4.9 & 2.7 & 4.8 & 3.9 & 0.2 & 1.1 & 2.6 \\
\hline$[\mathrm{SII}] \lambda 671.6+3.1$ & 0.5 & 2.0 & 7.6 & 0.3 & 1.6 & 30.9 & 8.0 & 3.9 \\
\hline$[\mathrm{SII}] \lambda 671.6 / 3.1$ & 0.6 & 0.6 & 1.0 & 0.8 & 0.8 & 0.5 & 0.5 & 1.0 \\
\hline
\end{tabular}


TABLE 2 (CONTINUED)

\begin{tabular}{|c|c|c|c|c|c|c|c|c|}
\hline & $006.8-03.4$ & $007.0+06.3$ & $010.7+07.4$ & $011.0-05.1$ & $011.3+02.8$ & $011.7-06.6$ & 012.6-02.6 & $013.8-07.9$ \\
\hline$[\mathrm{ArV}] \lambda 700.6$ & - & 0.2 & 2.2 & - & 0.4 & 0.2 & 0.2 & 4.8 \\
\hline HeI $\lambda 706.5$ & 4.4 & 4.8 & 0.9 & 5.1 & 12.1 & 0.3 & 0.7 & 1.2 \\
\hline$[\mathrm{ArIII}] \lambda 713.6$ & 5.2 & 16.0 & 20.0 & 5.7 & 1.3 & 0.5 & 0.7 & 12.3 \\
\hline$[$ ArIV $] \lambda 717.0$ & - & - & - & - & 0.3 & - & - & 0.7 \\
\hline HeII $\lambda 717.7$ & - & - & 1.3 & - & - & - & - & 1.9 \\
\hline$[\mathrm{ArIV}] \lambda 723.8$ & 0.2 & 0.5 & 0.6 & 2.2 & 0.3 & - & 0.8 & 0.5 \\
\hline$[$ ArIV] $] \lambda 726.3$ & - & - & - & - & 0.2 & - & - & 0.5 \\
\hline$[\mathrm{OII}] \lambda 732.5$ & 1.9 & 3.6 & 3.7 & 1.0 & 0.9 & 4.9 & 1.7 & 3.4 \\
\hline \multirow[t]{2}{*}[\text{ArIII}]{$\lambda 775.1$} & 1.2 & 4.8 & 5.8 & 2.0 & 0.3 & - & - & 5.1 \\
\hline & $015.9+03.3$ & 016.4-01.9 & $019.7-04.5$ & 021.8-00.4 & $023.0+04.3$ & 023.3-07.6 & $023.8-01.7$ & 025.9-02.1 \\
\hline$[\mathrm{OII}] \lambda 372.8$ & - & 203.5 & 47.7 & 108.3 & - & - & 133.3 & 9.7 \\
\hline$[\mathrm{NeIII}] \lambda 386.9$ & - & 2.0 & 141.0 & 116.1 & 74.2 & 118.2 & 66.1 & 64.9 \\
\hline H8 $\lambda 388.9$ & 32.1 & 26.4 & 18.0 & - & 39.3 & 26.3 & 68.6 & 14.4 \\
\hline$[\mathrm{NeIII}] \lambda 396.7$ & 38.3 & - & 43.6 & 55.1 & 44.0 & 47.9 & 18.5 & 24.8 \\
\hline H $7 \lambda 397.0$ & - & 7.7 & - & - & - & - & - & - \\
\hline $\mathrm{H} 6 \lambda 410.2$ & 34.9 & 30.5 & 36.6 & 40.2 & 36.5 & 29.4 & 193.0 & 28.1 \\
\hline $\mathrm{H} \gamma \lambda 434.0$ & 57.6 & 49.6 & 58.5 & 51.6 & 53.3 & 45.2 & 61.8 & 42.0 \\
\hline$[\mathrm{OIII}] \lambda 436.3$ & - & 2.9 & 8.0 & 18.0 & 5.9 & 5.9 & 13.8 & 3.3 \\
\hline $\mathrm{HeI} \lambda 447.1$ & 7.2 & 3.1 & 9.9 & 11.3 & 4.8 & 6.0 & - & 7.0 \\
\hline HeII $\lambda 468.6$ & 3.3 & 4.9 & - & 18.8 & - & 17.0 & 2.7 & 6.1 \\
\hline$[\mathrm{ArIV}] \lambda 471.1$ & - & - & 3.4 & 13.5 & 5.3 & 2.3 & - & 2.1 \\
\hline$[\mathrm{ArIV}] \lambda 474.0$ & - & - & 2.6 & 10.4 & 3.3 & 1.3 & - & 2.4 \\
\hline $\mathrm{H} \beta \lambda 486.1$ & 100.0 & 100.0 & 100.0 & 100.0 & 100.0 & 100.0 & 100.0 & 100.0 \\
\hline$[\mathrm{OIII}] \lambda 495.9$ & 17.1 & 29.1 & 360.9 & 418.0 & 191.9 & 257.0 & 2.9 & 250.1 \\
\hline$[\mathrm{OIII}] \lambda 500.7$ & 51.3 & 71.2 & 983.9 & 1236.0 & 540.8 & 776.1 & 2.1 & 734.7 \\
\hline$[\mathrm{NI}] \lambda 519.9$ & 1.7 & 1.2 & 1.4 & 4.8 & - & 11.2 & - & 0.8 \\
\hline$[\mathrm{CaV}] \lambda 530.9$ & - & - & - & - & - & 1.9 & - & - \\
\hline HeII $\lambda 541.1$ & 0.4 & - & 0.7 & 2.4 & - & 1.8 & - & - \\
\hline$[\mathrm{NII}] \lambda 575.5$ & 3.0 & 1.4 & 3.9 & 10.9 & 0.6 & 8.5 & 1.9 & 0.7 \\
\hline $\mathrm{HeI} \lambda 587.6$ & 13.4 & 26.6 & 20.4 & 17.6 & 12.7 & 22.2 & 1.2 & 18.2 \\
\hline$[\mathrm{OI}] \lambda 630.0$ & 2.2 & - & 5.6 & 19.0 & 0.6 & 37.5 & 1.6 & 0.3 \\
\hline$[\mathrm{SIII}] \lambda 631.2$ & 0.8 & 2.1 & 2.3 & 1.7 & 0.8 & 2.2 & 0.3 & 0.6 \\
\hline$[\mathrm{OI}] \lambda 636.4$ & 0.8 & 0.8 & 2.1 & 6.3 & - & 12.9 & 0.8 & - \\
\hline$[\mathrm{ArV}] \lambda 643.5$ & 0.1 & - & 0.1 & - & - & - & - & - \\
\hline$[\mathrm{NII}] \lambda 654.8$ & 114.7 & 61.0 & 56.0 & 191.3 & 3.0 & 226.8 & 67.6 & 3.8 \\
\hline H5 $\lambda 656.3$ & 285.0 & 359.5 & 285.0 & 285.0 & 285.0 & 284.9 & 285.0 & 285.0 \\
\hline$[\mathrm{NII}] \lambda 658.3$ & 313.3 & 150.7 & 152.7 & 556.6 & 9.0 & 680.8 & 186.5 & 11.3 \\
\hline $\mathrm{HeI} \lambda 667.8$ & 3.4 & 8.9 & 5.1 & 5.5 & 4.0 & 7.0 & 0.7 & 5.5 \\
\hline$[\mathrm{SII}] \lambda 671.6+3.1$ & 14.5 & 10.7 & 4.1 & 7.1 & 1.6 & 137.7 & 9.9 & 0.9 \\
\hline$[\mathrm{SII}] \lambda 671.6 / 3.1$ & 0.5 & 0.8 & 0.5 & 0.7 & 0.8 & 1.0 & 0.5 & 0.8 \\
\hline$[\mathrm{ArV}] \lambda 700.6$ & - & 3.9 & - & 1.4 & - & - & 0.5 & - \\
\hline HeI $\lambda 706.5$ & 4.5 & 11.2 & 7.6 & 7.3 & 4.1 & 5.0 & 0.8 & 3.7 \\
\hline$[$ ArIII] $] \lambda 713.6$ & 10.5 & 19.7 & 20.4 & 34.5 & 9.8 & 27.6 & - & 14.0 \\
\hline$[\mathrm{ArIV}] \lambda 717.0$ & - & - & 0.1 & - & - & - & - & - \\
\hline $\operatorname{HeII} \lambda 717.7$ & - & - & 0.1 & - & - & - & - & - \\
\hline$[$ ArIV] $] \lambda 723.8$ & 0.6 & - & 0.6 & 2.5 & - & - & - & 0.9 \\
\hline$[$ ArIV] $] \lambda 726.3$ & - & - & - & - & - & - & 1.2 & - \\
\hline$[\mathrm{OII}] \lambda 732.5$ & 7.2 & 18.6 & 7.5 & 21.4 & 2.4 & 18.1 & 4.2 & 2.8 \\
\hline \multirow[t]{2}{*}[\text{ArIII}]{$\lambda 775.1$} & 2.5 & 13.3 & 6.1 & 10.4 & 2.7 & 12.3 & - & 3.2 \\
\hline & $335.4-01.1$ & 335.9-03.6 & $336.2+01.9$ & $336.2+01.9$ & 336.3-05.6 & $336.9+08.3$ & $338.8+05.6$ & 340.9-04.6 \\
\hline$[\mathrm{OII}] \lambda 372.8$ & - & - & - & 56.1 & 111.2 & - & 61.0 & - \\
\hline$[\mathrm{NeIII}] \lambda 386.9$ & 255.0 & 20.7 & 88.2 & 142.3 & 157.7 & 86.2 & 111.3 & 108.1 \\
\hline H8 $\lambda 388.9$ & - & 40.6 & 46.9 & - & 11.9 & 20.6 & 18.9 & 12.4 \\
\hline$[\mathrm{NeIII}] \lambda 396.7$ & - & 784.3 & 63.3 & 54.9 & 61.1 & 39.7 & 46.4 & 46.6 \\
\hline H7 7397.0 & - & 68.1 & - & - & - & - & - & 40.1 \\
\hline $\mathrm{H} 6 \lambda 410.2$ & - & 42.6 & 40.9 & 49.6 & 27.8 & 25.6 & 26.7 & 30.6 \\
\hline $\mathrm{H} \gamma \lambda 434.0$ & 257.9 & 64.4 & 58.8 & 54.4 & 49.5 & 48.5 & 46.2 & 51.3 \\
\hline$[\mathrm{OIII}] \lambda 436.3$ & 44.4 & 11.2 & 14.9 & 10.6 & 23.4 & 10.1 & 6.8 & 11.9 \\
\hline HeI $\lambda 447.1$ & - & 5.1 & 10.2 & 12.5 & 5.1 & 6.7 & 5.0 & 6.0 \\
\hline HeII $\lambda 468.6$ & 142.3 & 61.1 & 32.2 & 34.4 & 58.9 & - & 6.6 & 2.6 \\
\hline$[\mathrm{ArIV}] \lambda 471.1$ & 94.1 & 5.3 & 9.3 & 6.0 & 10.8 & - & 3.1 & 3.6 \\
\hline$[\mathrm{ArIV}] \lambda 474.0$ & 56.2 & 3.7 & 4.5 & 5.5 & 8.5 & - & 2.4 & 3.6 \\
\hline $\mathrm{H} \beta \lambda 486.1$ & 100.0 & 100.0 & 100.0 & 100.0 & 100.0 & 100.0 & 100.0 & 100.0 \\
\hline [OIII] $\lambda 495.9$ & 370.0 & 206.6 & 248.4 & 250.4 & 537.8 & 283.2 & 343.1 & 387.6 \\
\hline$[\mathrm{OIII}] \lambda 500.7$ & 1089.1 & 614.8 & 771.3 & 736.4 & 1557.7 & 851.0 & 996.3 & 1113.2 \\
\hline$[\mathrm{NI}] \lambda 519.9$ & 48.1 & 1.0 & - & 2.0 & 3.6 & - & 0.7 & - \\
\hline$[\mathrm{CaV}] \lambda 530.9$ & - & - & - & - & - & - & 0.2 & - \\
\hline HeII $\lambda 541.1$ & 19.6 & 5.7 & 2.8 & 4.1 & 4.6 & - & 0.8 & - \\
\hline$[\mathrm{NII}] \lambda 575.5$ & 35.8 & 0.8 & 1.6 & 3.0 & 6.0 & - & 0.7 & 0.7 \\
\hline HeI $\lambda 587.6$ & 18.8 & 13.6 & 9.6 & 20.7 & 12.6 & 15.2 & 17.7 & 16.8 \\
\hline$[\mathrm{OI}] \lambda 630.0$ & 47.2 & 1.8 & 0.2 & 1.3 & 19.8 & - & 1.6 & 2.0 \\
\hline$[$ SIII] $\lambda 631.2$ & 9.1 & 0.8 & 0.5 & 0.7 & 4.2 & 0.6 & 1.2 & 1.4 \\
\hline
\end{tabular}


PLANETARY NEBULAE IN THE INNER MILKY WAY

TABLE 2 (CONTINUED)

\begin{tabular}{|c|c|c|c|c|c|c|c|c|}
\hline & $335.4-01.1$ & $335.9-03.6$ & $336.2+01.9$ & $336.2+01.9$ & 336.3-05.6 & $336.9+08.3$ & $338.8+05.6$ & $340.9-04.6$ \\
\hline$[\mathrm{OI}] \lambda 636.4$ & 16.4 & 0.9 & - & 0.8 & 7.0 & - & 0.6 & 0.7 \\
\hline$[\mathrm{ArV}] \lambda 643.5$ & 5.3 & 0.1 & - & 0.5 & 2.8 & - & - & - \\
\hline$[\mathrm{NII}] \lambda 654.8$ & 449.7 & 2.0 & 6.0 & 6.8 & 95.7 & - & 23.1 & 5.9 \\
\hline H5 $\lambda 656.3$ & 285.0 & 285.2 & 285.0 & 285.0 & 285.0 & 285.0 & 285.0 & 285.0 \\
\hline$[\mathrm{NII}] \lambda 658.3$ & 1328.7 & 6.1 & 18.2 & 20.0 & 271.4 & - & 39.5 & 17.8 \\
\hline HeI $\lambda 667.8$ & 6.6 & 4.6 & 3.5 & 6.2 & 4.7 & 3.6 & 4.9 & 4.0 \\
\hline$[\mathrm{SII}] \lambda 671.6+3.1$ & 67.8 & 3.2 & 3.6 & 2.6 & 15.3 & - & 4.3 & 4.2 \\
\hline$[\mathrm{SII}] \lambda 671.6 / 3.1$ & 0.8 & 1.3 & 0.7 & 0.8 & 0.6 & - & 0.8 & 0.6 \\
\hline$[\mathrm{ArV}] \lambda 700.6$ & 10.3 & 1.5 & - & - & 4.9 & - & - & - \\
\hline HeI $\lambda 706.5$ & 6.5 & 2.0 & 2.2 & 3.9 & 6.5 & 3.8 & 3.5 & 5.3 \\
\hline$[$ ArIII] $\lambda 713.6$ & 49.6 & 11.3 & 16.5 & 16.6 & 26.7 & 7.3 & 12.3 & 9.4 \\
\hline$[$ ArIV] $] \lambda 717.0$ & 1.9 & 1.9 & - & - & 1.7 & - & - & - \\
\hline HeII $\lambda 717.7$ & 2.4 & 0.6 & - & - & 0.8 & - & - & - \\
\hline$[$ ArIV] $] \lambda 723.8$ & 0.7 & 4.5 & 1.6 & 2.6 & 0.6 & - & 0.6 & - \\
\hline$[$ ArIV] $] \lambda 726.3$ & - & - & - & - & 0.6 & - & - & - \\
\hline$[\mathrm{OII}] \lambda 732.5$ & 21.1 & 4.2 & 3.5 & 5.8 & 25.6 & - & 2.9 & 4.2 \\
\hline \multirow[t]{2}{*}[\mathrm{ArIII}]{$\lambda 775.1$} & 15.2 & 8.6 & 3.2 & 4.4 & 9.4 & 2.1 & 3.9 & 2.6 \\
\hline & 342.9-04.9 & $343.0-01.7$ & $344.2-01.2$ & $344.4+02.8$ & $344.8+03.4$ & $345.0+03.4$ & $346.2-08.2$ & $347.7+02.0$ \\
\hline$[\mathrm{OII}] \lambda 372.8$ & - & - & - & - & - & - & 57.2 & - \\
\hline$[\mathrm{NeIII}] \lambda 386.9$ & 128.0 & 121.5 & 130.9 & 87.1 & - & 132.0 & 128.2 & 188.8 \\
\hline H8 $\lambda 388.9$ & 21.5 & 56.2 & 25.4 & 20.9 & 19.0 & 20.4 & 16.9 & 125.6 \\
\hline$[\mathrm{NeIII}] \lambda 396.7$ & 60.8 & - & 98.9 & 70.9 & - & 43.8 & 49.7 & 73.4 \\
\hline H7 $\lambda 397.0$ & - & - & - & - & - & - & - & - \\
\hline $\mathrm{H} 6 \lambda 410.2$ & 27.1 & - & 11.4 & 32.1 & 28.9 & 31.5 & 37.5 & 33.1 \\
\hline $\mathrm{H} \gamma \lambda 434.0$ & 49.4 & 49.5 & 42.7 & 46.2 & 51.6 & 52.0 & 58.1 & 85.0 \\
\hline$[\mathrm{OIII}] \lambda 436.3$ & 20.7 & 7.6 & 19.9 & 17.3 & - & 17.1 & 10.1 & 47.4 \\
\hline $\operatorname{HeI} \lambda 447.1$ & 4.3 & 11.2 & 23.1 & 4.2 & 6.0 & 6.6 & 5.1 & 27.2 \\
\hline HeII $\lambda 468.6$ & 67.0 & 4.5 & 26.2 & 39.7 & - & 4.8 & 91.0 & 15.0 \\
\hline$[\mathrm{ArIV}] \lambda 471.1$ & 10.8 & 10.6 & - & 8.8 & - & 2.0 & 11.6 & 10.1 \\
\hline$[\mathrm{ArIV}] \lambda 474.0$ & 7.5 & 2.8 & - & 8.3 & - & 2.2 & 7.7 & 14.0 \\
\hline $\mathrm{H} \beta \lambda 486.1$ & 100.0 & 100.0 & 100.0 & 100.0 & 100.0 & 100.0 & 100.0 & 100.0 \\
\hline$[\mathrm{OIII}] \lambda 495.9$ & 505.2 & 297.1 & 243.8 & 439.7 & 36.2 & 384.8 & 347.2 & 526.2 \\
\hline$[\mathrm{OIII}] \lambda 500.7$ & 1531.0 & 829.3 & 768.2 & 1316.0 & 110.2 & 1125.7 & 1028.4 & 1526.4 \\
\hline$[\mathrm{NI}] \lambda 519.9$ & 5.0 & 0.7 & 8.7 & 0.4 & 0.5 & 0.7 & - & 1.4 \\
\hline$[\mathrm{CaV}] \lambda 530.9$ & - & - & - & 0.3 & - & - & - & - \\
\hline HeII $\lambda 541.1$ & 5.9 & 0.3 & 4.6 & 3.8 & - & 0.5 & 5.5 & 2.3 \\
\hline$[\mathrm{NII}] \lambda 575.5$ & 6.7 & 1.3 & 14.1 & 0.2 & 1.2 & 2.1 & 0.9 & 2.5 \\
\hline HeI $\lambda 587.6$ & 11.5 & 18.8 & 28.5 & 11.1 & 13.6 & 18.3 & 6.4 & 18.5 \\
\hline$[\mathrm{OI}] \lambda 630.0$ & 15.4 & 2.7 & 33.3 & 0.3 & 5.0 & 9.4 & - & 6.6 \\
\hline [SIII] 7631.2 & 7.4 & 1.2 & 4.5 & 0.8 & - & 1.4 & 2.6 & 2.1 \\
\hline$[\mathrm{OI}] \lambda 636.4$ & 5.5 & 1.1 & 13.8 & 0.1 & 1.7 & 3.2 & - & 2.1 \\
\hline$[\mathrm{ArV}] \lambda 643.5$ & 1.0 & - & - & 0.6 & - & - & 0.5 & 0.4 \\
\hline$[\mathrm{NII}] \lambda 654.8$ & 138.3 & 26.0 & 275.3 & 1.8 & 50.4 & 23.5 & 19.7 & 13.1 \\
\hline H5 $\lambda 656.3$ & 285.0 & 286.0 & 285.0 & 285.0 & 285.0 & 285.0 & 285.0 & 285.0 \\
\hline$[\mathrm{NII}] \lambda 658.3$ & 395.6 & 26.9 & 811.5 & 5.2 & 139.5 & 51.5 & 31.3 & 39.7 \\
\hline $\mathrm{HeI} \lambda 667.8$ & 3.9 & 4.7 & 10.0 & 3.2 & 3.8 & 4.3 & 3.2 & 3.8 \\
\hline$[\mathrm{SII}] \lambda 671.6+3.1$ & 104.4 & 4.7 & 71.0 & 1.8 & 48.8 & 5.0 & 5.4 & 6.6 \\
\hline$[\mathrm{SII}] \lambda 671.6 / 3.1$ & 1.0 & 0.6 & 0.9 & 0.9 & 1.0 & 0.5 & 0.8 & 0.5 \\
\hline$[\mathrm{ArV}] \lambda 700.6$ & 2.0 & - & 2.3 & 0.7 & - & - & 1.1 & 0.6 \\
\hline HeI $\lambda 706.5$ & 3.0 & 7.7 & 8.1 & 2.7 & 2.1 & 9.8 & 1.4 & 6.4 \\
\hline$[$ ArIII] $] \lambda 713.6$ & 48.5 & 13.6 & 57.8 & 10.2 & 8.3 & 11.0 & 28.7 & 12.8 \\
\hline$[$ ArIV $] \lambda 717.0$ & - & - & - & 0.8 & - & 0.2 & 1.2 & 0.4 \\
\hline HeII $\lambda 717.7$ & 1.4 & - & - & 0.7 & - & - & - & - \\
\hline$[\mathrm{ArIV}] \lambda 723.8$ & 2.0 & 0.6 & 1.3 & - & - & 1.1 & 1.1 & 0.3 \\
\hline$[\mathrm{ArIV}] \lambda 726.3$ & - & - & - & 0.4 & - & - & - & 0.3 \\
\hline$[\mathrm{OII}] \lambda 732.5$ & 11.5 & 7.7 & 18.9 & 1.4 & 6.6 & 17.6 & 2.8 & 9.9 \\
\hline \multirow[t]{2}{*}[\text{ArIII}]{$\lambda 775.1$} & 16.8 & 3.3 & 11.6 & 3.0 & 3.0 & 2.9 & 6.1 & 2.9 \\
\hline & $348.0-13.8$ & $350.5-05.0$ & $350.9+04.4$ & $351.6-06.2$ & $352.6+03.0$ & $355.4-04.0$ & $355.9+03.6$ & $356.3-06.2$ \\
\hline$[\mathrm{OII}] \lambda 372.8$ & - & 148.9 & 133.1 & 135.7 & - & 52.3 & 100.0 & 226.1 \\
\hline$[\mathrm{NeIII}] \lambda 386.9$ & 125.0 & 81.6 & 7.2 & 125.7 & 99.1 & 130.6 & 8.1 & 56.6 \\
\hline H8 $\lambda 388.9$ & 19.0 & 29.6 & 16.5 & 19.6 & 40.8 & 33.2 & 23.7 & 17.8 \\
\hline$[\mathrm{NeIII}] \lambda 396.7$ & 50.9 & 37.5 & 15.8 & 46.3 & 44.9 & 57.5 & 16.0 & 34.7 \\
\hline $\mathrm{H} 7 \lambda 397.0$ & - & - & - & - & - & - & - & - \\
\hline $\mathrm{H} 6 \lambda 410.2$ & 27.0 & 41.2 & 23.5 & 32.6 & 48.7 & 31.9 & 30.7 & 30.2 \\
\hline $\mathrm{H} \gamma \lambda 434.0$ & 47.2 & 55.2 & 42.6 & 46.8 & 48.4 & 49.8 & 48.8 & 54.1 \\
\hline$[\mathrm{OIII}] \lambda 436.3$ & 16.3 & 5.0 & 2.3 & 10.1 & 10.1 & 17.3 & 3.4 & 7.4 \\
\hline HeI $\lambda 447.1$ & 5.3 & 10.7 & 3.2 & 5.6 & 12.9 & 1.9 & 4.7 & 13.8 \\
\hline HeII $\lambda 468.6$ & 29.7 & 16.7 & 0.1 & 83.4 & 5.8 & 97.5 & - & 23.2 \\
\hline$[\mathrm{ArIV}] \lambda 471.1$ & 5.2 & 2.0 & - & 16.0 & 1.9 & 17.2 & 2.8 & - \\
\hline$[\mathrm{ArIV}] \lambda 474.0$ & 4.6 & 1.4 & - & 10.0 & 5.2 & 10.2 & - & - \\
\hline $\mathrm{H} \beta \lambda 486.1$ & 100.0 & 100.0 & 100.0 & 100.0 & 100.0 & 100.0 & 100.0 & 100.0 \\
\hline$[\mathrm{OIII}] \lambda 495.9$ & 401.7 & 158.3 & 27.5 & 271.3 & 214.6 & 449.6 & 55.6 & 176.9 \\
\hline
\end{tabular}


TABLE 2 (CONTINUED)

\begin{tabular}{|c|c|c|c|c|c|c|c|c|}
\hline & $348.0-13.8$ & $350.5-05.0$ & $350.9+04.4$ & $351.6-06.2$ & $352.6+03.0$ & $355.4-04.0$ & $355.9+03.6$ & $356.3-06.2$ \\
\hline$[\mathrm{OIII}] \lambda 500.7$ & 1188.0 & 465.3 & 82.7 & 756.1 & 575.7 & 1333.3 & 153.1 & 522.0 \\
\hline$[\mathrm{NI}] \lambda 519.9$ & - & 4.9 & 0.5 & 4.0 & 7.1 & 0.9 & 1.2 & 8.4 \\
\hline$[\mathrm{CaV}] \lambda 530.9$ & - & - & - & - & - & - & - & - \\
\hline HeII $\lambda 541.1$ & 2.2 & 1.4 & - & 7.4 & 1.2 & 6.5 & 1.0 & 3.5 \\
\hline$[\mathrm{NII}] \lambda 575.5$ & - & 4.6 & 2.9 & 4.0 & 2.3 & 2.0 & 5.5 & 4.4 \\
\hline HeI $\lambda 587.6$ & 8.4 & 24.6 & 9.5 & 12.1 & 8.0 & 6.5 & 13.3 & 14.0 \\
\hline$[\mathrm{OI}] \lambda 630.0$ & 0.3 & 8.5 & 2.0 & 7.9 & 5.1 & 3.3 & 2.6 & 14.1 \\
\hline$[\mathrm{SIII}] \lambda 631.2$ & 0.4 & 1.2 & 1.6 & 3.7 & 1.6 & 4.0 & 2.7 & - \\
\hline$[\mathrm{OI}] \lambda 636.4$ & - & 3.6 & 0.9 & 2.7 & 2.0 & 2.0 & 1.0 & 6.4 \\
\hline$[\mathrm{ArV}] \lambda 643.5$ & 0.3 & 1.0 & 0.2 & 1.6 & - & 1.2 & - & - \\
\hline [NII] 7654.8 & - & 149.1 & 32.2 & 84.3 & 92.4 & 35.8 & 31.6 & 121.6 \\
\hline H5 $\lambda 656.3$ & 285.0 & 285.0 & 285.0 & 285.0 & 285.0 & 285.0 & 285.0 & 285.0 \\
\hline$[\mathrm{NII}] \lambda 658.3$ & - & 427.4 & 94.5 & 233.1 & 280.2 & 70.3 & 89.8 & 367.0 \\
\hline $\mathrm{HeI} \lambda 667.8$ & 3.4 & 6.1 & 2.8 & 4.6 & 8.0 & 3.3 & 3.8 & 7.3 \\
\hline$[\mathrm{SII}] \lambda 671.6+3.1$ & 1.1 & 33.2 & 2.3 & 20.9 & 8.5 & 13.7 & 0.9 & 44.6 \\
\hline$[\mathrm{SII}] \lambda 671.6 / 3.1$ & 1.1 & 0.9 & 0.6 & 0.8 & 0.5 & 1.0 & 0.5 & 1.2 \\
\hline$[\mathrm{ArV}] \lambda 700.6$ & - & - & 0.6 & 3.8 & 0.4 & 2.2 & 0.8 & - \\
\hline HeI $\lambda 706.5$ & 2.1 & 4.0 & 5.7 & 3.2 & 11.8 & 1.7 & 9.5 & 4.9 \\
\hline$[$ ArIII $] \lambda 713.6$ & 4.1 & 22.3 & 6.0 & 26.8 & 34.5 & 35.7 & 9.0 & 19.9 \\
\hline$[\mathrm{ArIV}] \lambda 717.0$ & 1.2 & 0.3 & - & - & 0.6 & 1.7 & - & - \\
\hline HeII $\lambda 717.7$ & - & 0.7 & - & 0.7 & 0.4 & - & - & - \\
\hline$[$ ArIV] $] \lambda 723.8$ & - & 1.8 & 0.4 & 1.5 & 2.1 & 0.9 & - & 6.2 \\
\hline$[$ ArIV] $] 726.3$ & - & - & - & - & 0.2 & - & - & 3.3 \\
\hline$[\mathrm{OII}] \lambda 732.5$ & 1.3 & 7.4 & 37.0 & 4.4 & 8.3 & 3.2 & 87.4 & 4.4 \\
\hline \multirow[t]{2}{*}{ ArIII] $\lambda 775.1$} & 4.8 & 6.4 & 1.8 & 7.9 & 9.5 & 8.2 & 2.2 & 6.1 \\
\hline & $356.8-05.4$ & 357.4-04.6 & $358.2+03.5$ & $358.3+03.0$ & $358.7+05.2$ & $358.8+03.0$ & $359.8+03.7$ & \\
\hline$[\mathrm{OII}] \lambda 372.8$ & 76.6 & 42.6 & 41.1 & 39.7 & - & 54.1 & 82.8 & \\
\hline$[\mathrm{NeIII}] \lambda 386.9$ & 91.2 & 104.1 & 178.7 & 120.8 & 83.9 & 135.0 & 53.6 & \\
\hline H8 $\lambda 388.9$ & - & 23.3 & 31.8 & 26.2 & - & - & 34.6 & \\
\hline$[\mathrm{NeIII}] \lambda 396.7$ & 48.8 & 42.2 & 43.1 & 63.2 & 23.5 & 58.2 & 21.1 & \\
\hline H7 $\lambda 397.0$ & - & - & - & - & - & - & 11.6 & \\
\hline $\mathrm{H} 6 \lambda 410.2$ & 31.3 & 36.0 & 39.0 & 36.1 & 40.8 & 27.0 & 42.4 & \\
\hline $\mathrm{H} \gamma \lambda 434.0$ & 48.3 & 58.2 & 53.7 & 50.8 & 55.2 & 73.8 & 52.6 & \\
\hline [OIII] $\lambda 436.3$ & 7.8 & 9.0 & 13.1 & 23.8 & 11.2 & 20.7 & 9.6 & \\
\hline $\operatorname{HeI} \lambda 447.1$ & 7.9 & 9.0 & 8.3 & 11.2 & - & - & 10.8 & \\
\hline HeII $\lambda 468.6$ & 29.2 & 33.6 & 1.7 & 7.1 & - & 92.4 & - & \\
\hline$[\mathrm{ArIV}] \lambda 471.1$ & - & 7.0 & 2.8 & 5.7 & - & 28.5 & 1.7 & \\
\hline$[\mathrm{ArIV}] \lambda 474.0$ & - & 5.7 & 2.5 & 8.2 & - & 17.6 & 1.3 & \\
\hline $\mathrm{H} \beta \lambda 486.1$ & 100.0 & 100.0 & 100.0 & 100.0 & 100.0 & 100.0 & 100.0 & \\
\hline$[\mathrm{OIII}] \lambda 495.9$ & 247.3 & 267.2 & 345.8 & 496.3 & - & 337.0 & 166.1 & \\
\hline$[\mathrm{OIII}] \lambda 500.7$ & 725.6 & 770.2 & 949.4 & 1458.7 & - & 961.6 & 438.4 & \\
\hline$[\mathrm{NI}] \lambda 519.9$ & 0.5 & 3.7 & - & - & - & 3.7 & - & \\
\hline$[\mathrm{CaV}] \lambda 530.9$ & 1.2 & - & - & - & - & - & 0.5 & \\
\hline HeII $\lambda 541.1$ & 2.1 & 4.0 & 0.3 & 2.2 & - & 7.7 & - & \\
\hline$[\mathrm{NII}] \lambda 575.5$ & 1.4 & 4.6 & 0.6 & 6.4 & 1.3 & 2.9 & 1.4 & \\
\hline HeI $\lambda 587.6$ & 10.6 & 13.1 & 17.4 & 23.1 & 3.1 & 6.9 & 15.9 & \\
\hline$[\mathrm{OI}] \lambda 630.0$ & 1.5 & 4.8 & 1.8 & 13.5 & 1.9 & 5.9 & 1.7 & \\
\hline$[\mathrm{SIII}] \lambda 631.2$ & 0.9 & 1.3 & 1.1 & 4.7 & 0.6 & 7.9 & 1.1 & \\
\hline$[\mathrm{OI}] \lambda 636.4$ & 0.5 & 1.6 & 0.6 & 4.6 & 1.0 & - & 0.5 & \\
\hline$[\mathrm{ArV}] \lambda 643.5$ & - & 0.6 & 0.1 & 0.4 & 0.3 & 3.1 & 0.2 & \\
\hline$[\mathrm{NII}] \lambda 654.8$ & 43.8 & 66.6 & 7.4 & 40.0 & 81.3 & 48.6 & 18.3 & \\
\hline H5 $\lambda 656.3$ & 285.0 & 285.0 & 285.0 & 285.0 & 285.0 & 285.0 & 285.0 & \\
\hline$[\mathrm{NII}] \lambda 658.3$ & 115.5 & 176.4 & 12.1 & 100.2 & 214.7 & 103.2 & 41.6 & \\
\hline HeI $\lambda 667.8$ & 5.0 & 6.4 & 3.7 & 6.2 & 1.2 & 4.4 & 4.0 & \\
\hline$[\mathrm{SII}] \lambda 671.6+3.1$ & 18.1 & 12.7 & 1.0 & 3.0 & 10.4 & 10.1 & 1.8 & \\
\hline$[\mathrm{SII}] \lambda 671.6 / 3.1$ & 1.2 & 0.7 & 0.5 & 0.5 & 0.5 & 0.7 & 0.6 & \\
\hline$[\mathrm{ArV}] \lambda 700.6$ & - & 1.0 & - & 0.7 & 0.8 & 5.0 & - & \\
\hline HeI $\lambda 706.5$ & 2.5 & 4.7 & 3.5 & 14.8 & 1.5 & 3.7 & 6.0 & \\
\hline$[$ ArIII] $] \lambda 713.6$ & 20.6 & 19.6 & 7.7 & 30.2 & 0.9 & 20.5 & 8.7 & \\
\hline$[$ ArIV] $] \lambda 717.0$ & - & 1.0 & - & 0.9 & - & 4.1 & - & \\
\hline HeII $\lambda 717.7$ & - & - & - & - & - & 0.4 & - & \\
\hline$[\operatorname{ArIV}] \lambda 723.8$ & 1.0 & 2.7 & 0.3 & 0.7 & 0.5 & 2.6 & 0.6 & \\
\hline$[$ ArIV] $] \lambda 726.3$ & - & - & 0.3 & 0.5 & 0.5 & 0.9 & - & \\
\hline$[\mathrm{OII}] \lambda 732.5$ & - & 4.9 & 4.5 & 25.8 & 2.3 & 6.6 & 10.7 & \\
\hline$[$ ArIII] $\lambda 775.1$ & 7.2 & 7.0 & 1.7 & 8.3 & 0.7 & 7.5 & 2.1 & \\
\hline
\end{tabular}

temperatures from [N II] and [O III], respectively, in units of $10^{4} \mathrm{~K}$, with uncertainties. Column 10 refers to the method used to obtain the electronic temperatures (see $\S 3.3$ for more details).
For PN G004.2-0.59 the [O III] flux ratio resulted in a very high electron temperature, not typical for a planetary nebula. However, it is interesting to note that this ratio is very similar to that derived from 
PLANETARY NEBULAE IN THE INNER MILKY WAY

TABLE 3

PHYSICAL PARAMETERS FOR THE OBSERVED OBJECTS ${ }^{\mathrm{a}}$

\begin{tabular}{|c|c|c|c|c|c|c|c|c|c|c|}
\hline PN G & $E(B-V)$ & $\sigma_{E(B-V)}$ & $c(\mathrm{H} \beta)$ & $\mathrm{n}_{\mathrm{e}}([\mathrm{S} \mathrm{II}])$ & $\sigma_{\mathrm{n}_{\mathrm{e}}}([\mathrm{S} \mathrm{II}])$ & $\mathrm{T}([\mathrm{N} \mathrm{II}])$ & $\sigma_{\mathrm{T}([\mathrm{N} I \mathrm{II}])}$ & $\mathrm{T}([\mathrm{O} \mathrm{III}])$ & $\left.\left.\sigma_{\mathrm{T}([\mathrm{O}} \mathrm{III}\right]\right)$ & Notes \\
\hline $000.7-02.7$ & 0.23 & 0.04 & 0.33 & 5.84 & - & 1.41 & 0.19 & 1.28 & 0.07 & \\
\hline $000.9-04.8$ & 0.87 & 0.02 & 1.26 & 0.90 & 0.1 & 1.62 & 0.23 & 1.44 & 0.08 & \\
\hline $004.0-11.1$ & 0.11 & 0.06 & 0.16 & 0.76 & 0.07 & 0.87 & 0.05 & 1.05 & 0.05 & \\
\hline $004.2-04.3$ & 0.26 & - & 0.38 & 5.00 & - & 1.07 & 0.06 & 1.07 & 0.06 & \\
\hline $005.2-18.6$ & 0.17 & 0.03 & 0.25 & 1.90 & 0.1 & 1.10 & 0.10 & 1.23 & 0.05 & \\
\hline $005.5-2.5$ & 0.86 & 0.02 & 1.24 & 2.20 & 0.2 & 1.25 & 0.10 & 0.99 & 0.05 & \\
\hline $006.4-04.6$ & 0.12 & - & 0.17 & 3.10 & 2.7 & 1.30 & 0.10 & 1.67 & 0.12 & 1 \\
\hline $006.8-03.4$ & 1.18 & 0.01 & 1.71 & 6 & 3 & 1.24 & 0.08 & 1.24 & 0.08 & \\
\hline $007.0+06.3$ & 0.86 & 0.04 & 1.24 & 5 & 4 & 1.15 & 0.11 & 1.09 & 0.06 & \\
\hline $010.7+07.4$ & 0.70 & 0.10 & 1.01 & 0.70 & 0.2 & 2.02 & 0.39 & 1.30 & 0.08 & \\
\hline $011.0-05.1$ & 0.30 & 0.01 & 0.43 & 3 & 3 & 1.14 & 0.04 & 1.14 & 0.04 & \\
\hline $011.3+02.8$ & 1.55 & 0.02 & 2.24 & 1.30 & 0.6 & 1.78 & 0.21 & 1.78 & 0.21 & \\
\hline $011.7-06.6$ & 0.12 & 0.05 & 0.17 & 10 & 1 & 0.72 & 0.04 & 0.72 & 0.04 & \\
\hline $012.6-02.6$ & 1.33 & - & 1.92 & 8 & 2 & 0.67 & 0.04 & 0.67 & 0.04 & \\
\hline $013.8-07.9$ & 0.38 & - & 0.55 & 0.79 & 0.07 & 1.49 & 0.20 & 1.44 & 0.07 & \\
\hline $015.9+03.3$ & 1.66 & 0.02 & 2.40 & 34 & 30 & 0.76 & 0.04 & 0.76 & 0.04 & \\
\hline $016.4-01.9$ & 0.19 & 0.06 & 0.27 & 2.00 & 0.4 & 0.81 & 0.04 & 2.16 & 0.22 & \\
\hline $019.7-04.5$ & 1.21 & 0.01 & 1.75 & 6.90 & 0.8 & 1.16 & 0.07 & 1.06 & 0.04 & \\
\hline $021.8-00.4$ & 1.21 & 0.04 & 1.75 & 1.90 & 0.3 & 1.06 & 0.07 & 1.32 & 0.10 & \\
\hline $023.0+04.3$ & 1.21 & 0.05 & 1.75 & 1.10 & 0.7 & 2.45 & 0.56 & 1.18 & 0.09 & \\
\hline $023.3-07.6$ & 0.20 & 0.03 & 0.29 & 0.57 & 0.02 & 0.90 & 0.05 & 1.06 & 0.05 & \\
\hline $023.8-01.7$ & 1.89 & 0.06 & 2.73 & 9 & 6 & 0.81 & 0.06 & 0.81 & 0.06 & \\
\hline $024.1+03.8$ & 0.80 & 0.60 & 1.16 & 5.04 & - & 0.86 & 0.13 & 1.16 & 0.17 & \\
\hline $025.9-02.1$ & 0.89 & 0.03 & 1.29 & 1.60 & 0.9 & 2.17 & 0.41 & 0.90 & 0.04 & \\
\hline $335.4-01.1$ & 2.00 & 0.10 & 2.89 & 1.24 & 0.03 & 1.24 & 0.10 & 2.49 & 0.39 & \\
\hline $335.9-03.6$ & 0.92 & - & 1.33 & 0.20 & 0.2 & 1.40 & 0.60 & 1.47 & 0.12 & 1 \\
\hline $336.2+01.9$ & 1.50 & 0.50 & 2.17 & 1.00 & 0.1 & 2.82 & 1.17 & 1.51 & 0.26 & \\
\hline $336.3-05.6$ & 0.52 & 0.05 & 0.75 & 3.52 & 0.03 & 1.10 & 0.07 & 1.33 & 0.06 & \\
\hline $336.9+08.3$ & 0.66 & 0.07 & 0.95 & 5 & - & 1.23 & 0.06 & 1.23 & 0.06 & \\
\hline $338.8+05.6$ & 0.56 & 0.02 & 0.81 & 1.20 & 0.3 & 1.01 & 0.06 & 1.01 & 0.04 & \\
\hline $340.9-04.6$ & 0.95 & 0.01 & 1.37 & 3.60 & 0.3 & 1.45 & 0.17 & 1.18 & 0.06 & \\
\hline $342.9-04.9$ & 0.29 & 0.01 & 0.42 & 0.53 & 0.05 & 1.02 & 0.06 & 1.30 & 0.06 & \\
\hline $343.0-01.7$ & 1.92 & - & 2.78 & 5.5 & 0.3 & 1.72 & 0.27 & 1.13 & 0.08 & \\
\hline $344.2-01.2$ & 1.00 & 0.10 & 1.45 & 0.80 & 0.2 & 1.03 & 0.09 & 1.74 & 0.19 & \\
\hline $344.4+02.8$ & 1.07 & 0.01 & 1.55 & 0.8 & 0.3 & 1.74 & 0.30 & 1.28 & 0.07 & \\
\hline $344.8+03.4$ & 0.82 & 0.06 & 1.19 & 0.71 & 0.08 & 0.81 & 0.05 & 0.81 & 0.05 & \\
\hline $345.0+03.4$ & 0.83 & 0.07 & 1.20 & 7.50 & 0.9 & 1.48 & 0.16 & 1.34 & 0.07 & \\
\hline $346.2-08.2$ & 0.40 & 0.10 & 0.58 & 3.81 & - & 1.28 & 0.11 & 1.15 & 0.06 & \\
\hline $347.7+02.0$ & 1.84 & 0.01 & 2.66 & 10 & 2 & 2.00 & 0.32 & 1.88 & 0.15 & \\
\hline $348.0-13.8$ & 0.20 & 0.20 & 0.29 & 1.39 & - & 1.27 & 0.07 & 1.27 & 0.07 & \\
\hline $350.5-05.0$ & 0.67 & 0.02 & 0.97 & 0.70 & 0.2 & 0.86 & 0.04 & 1.19 & 0.06 & \\
\hline $350.9+04.4$ & 0.49 & 0.05 & 0.71 & 5 & 3 & 1.30 & 0.07 & 1.83 & 0.11 & \\
\hline $351.6-06.2$ & 0.48 & 0.03 & 0.69 & 1.22 & - & 1.01 & 0.06 & 1.28 & 0.06 & \\
\hline $352.6+03.0$ & 1.42 & - & 2.05 & 7.00 & 0.8 & 0.74 & 0.05 & 1.40 & 0.11 & \\
\hline $355.4-04.0$ & 0.53 & 0.01 & 0.77 & 0.6 & 0.1 & 1.29 & 0.11 & 1.28 & 0.06 & \\
\hline $355.9+03.6$ & 1.00 & 0.10 & 1.45 & 13 & 9 & 1.94 & 0.28 & 1.58 & 0.13 & \\
\hline $356.3-06.2$ & 0.35 & 0.06 & 0.51 & 0.24 & 0.03 & 0.90 & 0.06 & 1.33 & 0.09 & \\
\hline $356.8-05.4$ & 0.63 & 0.02 & 0.91 & 0.24 & 0.06 & 0.91 & 0.07 & 1.19 & 0.07 & \\
\hline $357.4-04.6$ & 0.69 & 0.05 & 1.00 & 1.69 & - & 1.23 & 0.10 & 1.22 & 0.07 & \\
\hline $358.2+03.5$ & 1.57 & 0.01 & 2.27 & 7 & 3 & 1.74 & 0.24 & 1.28 & 0.07 & \\
\hline $358.3+03.0$ & 1.39 & 0.07 & 2.01 & 19 & 6 & 1.98 & 0.29 & 1.40 & 0.09 & \\
\hline $358.7+05.2$ & 1.53 & 0.04 & 2.21 & 8.99 & 0.08 & 0.68 & 0.04 & 0.68 & 0.04 & \\
\hline $358.8+03.0$ & 1.12 & - & 1.62 & 2 & 2 & 1.31 & 0.14 & 1.58 & 0.13 & \\
\hline $359.8+03.7$ & 1.60 & 0.06 & 2.31 & 5.21 & 0.08 & 1.31 & 0.13 & 1.55 & 0.14 & \\
\hline
\end{tabular}

${ }^{a}$ Densities are listed in units of $10^{3} \mathrm{~cm}^{-3}$ and temperatures in units of $10^{4} \mathrm{~K}$.

${ }^{1} \mathrm{~T}([\mathrm{~N} \mathrm{II}])$ and $\sigma_{\mathrm{T}([\mathrm{N} \mathrm{II}])}$ were obtained from the mean of individual measures for each object.

the data of Exter et al. (2004), what indicates that intrinsic properties of this nebula, such as large density variations or the presence of shocked material, could lead to an unusual flux ratio of the [OIII] lines, making them inappropriate to derive electron temperatures. Additionally, this object does not have 


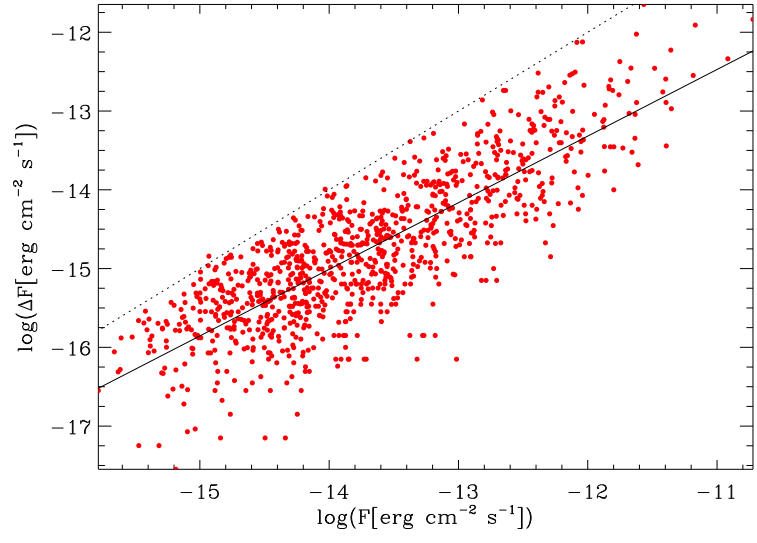

Fig. 3. Errors in line fluxes as a function of the fluxes. The dotted line represents $\Delta \mathrm{F}=\mathrm{F}$, and the continuous line is the linear fit to the data.

the [NII]5755 line, which makes it impossible to obtain $\mathrm{T}([\mathrm{NII}])$. Spectra with better $\mathrm{S} / \mathrm{N}$ as well as high quality, high resolution direct pictures of this object would be helpful to establish its nature. In view of this situation, we decided to keep the fluxes for this object but, since we cannot derive electron temperature, it is not included in the abundance analysis.

\subsection{Ionic and elemental abundances}

Ionic abundances were calculated from the fits by Alexander \& Balick (1997), who provide convenient empirical relations for the determination of ionic abundances obtained from numerical simulations. Ionic abundances for $\mathrm{He}^{+}$and $\mathrm{He}^{++}$were derived using the recombination coefficients from Pequignot, Petitjean, \& Boisson (1991). The $\mathrm{He}^{+}$ abundance was also corrected for collisional effects using the correction terms from Kingdon \& Ferland (1995). For the derivation of the $\mathrm{O}^{+}$abundance we chose the red pair of lines $\lambda 731.9+2.9 \mathrm{~nm}$, since they have better signal-to-noise in our spectra than the blue pair $\lambda 372.7+2.9 \mathrm{~nm}$ counterpart, due to the greater efficiency of the instrumental setup in the red region. Besides that, as discussed by Escudero et al. (2004), there is a small difference between both determinations, with a tendency for smaller abundances when the blue lines are used. However, such difference is not larger than the errors involved in the determination of the abundances, so that we expect no measurable differences in the final oxygen abundance when using the red lines instead of the blue ones.

For those objects where $\mathrm{S}^{++}$lines were not available we adopted the same technique used by Kingsburgh \& Barlow (1994) and Escudero et al. (2004) to calculate the sulfur abundance. This technique consists of deriving the $\mathrm{S}^{++}$abundance through a relation between the ratios $\mathrm{S}^{++} / \mathrm{S}^{+}$and $\mathrm{O}^{++} / \mathrm{O}^{+}$. In this work we adopted the same relation used by Escudero et al. (2004). The derived ionic abundances can be seen in Table 4, where the errors for the ionic abundances obtained from a Monte Carlo simulation are also shown.

Chemical abundances were calculated by means of ionization correction factors (ICFs), to account for unobserved ions of each element. The ICFs used were the same as those adopted by Escudero et al. (2004), and were obtained from Kingsburgh \& Barlow (1994) for the nitrogen, sulfur, and neon abundances; from Torres-Peimbert \& Peimbert (1977) for the oxygen abundance; and from de Freitas Pacheco et al. (1993) for argon.

For helium, in particular, we have the abundances of the ions $\mathrm{He}^{+}$and $\mathrm{He}^{++}$. In agreement with the criterion defined by Torres-Peimbert \& Peimbert (1977) there is no essential contribution from neutral helium in the total helium abundance when

$$
\log \mathrm{O}^{+} / \mathrm{O}<-0.4
$$

and therefore this component can be neglected. In this case, the helium total abundance can be written as

$$
\frac{\mathrm{He}}{\mathrm{H}}=\frac{\mathrm{He}^{+}}{\mathrm{H}^{+}}+\frac{\mathrm{He}^{++}}{\mathrm{H}^{+}} .
$$

Table 5 shows the chemical abundances and uncertainties obtained in this work in the notation $\epsilon(\mathrm{X})=\log (\mathrm{X} / \mathrm{H})+12$, where $\mathrm{X}$ denotes $\mathrm{N}, \mathrm{S}, \mathrm{O}, \mathrm{Ar}$, and $\mathrm{Ne}$. For $\mathrm{He}$, the $\mathrm{He} / \mathrm{H}$ is given instead. When the condition expressed by equation 2 is not satisfied, an asterisk is displayed after the $\mathrm{PN} \mathrm{G}$ number. In these cases, the helium abundances are lower limits for the total helium abundances and must be considered carefully. In some cases, the method used to calculate the errors and mean abundances (see $\S 3.3$ ) did not converge, and the abundances and errors were replaced by the mean and the standard deviation obtained from the independent measures for each object. These abundances are indicated with two asterisks in Table 5.

\subsection{Errors}

In order to determine errors in the physical parameters and abundances, Gaussian noise was added to the observed spectra by means of a Monte Carlo simulation, where each line flux was varied randomly 500 times within its respective error interval. These error intervals were estimated from a relation between the errors in the fluxes and the fluxes obtained 
TABLE 4

IONIC ABUNDANCES RELATIVE TO HYDROGEN

\begin{tabular}{|c|c|c|c|c|c|c|c|c|c|c|c|c|c|c|c|c|c|c|}
\hline PN G & $\mathrm{He}^{+}$ & $\sigma_{\mathrm{He}^{+}}$ & $\mathrm{He}^{++}$ & $\sigma_{\mathrm{He}^{+}+}$ & $\begin{array}{c}\mathrm{N}^{+} \\
\times 10^{6}\end{array}$ & $\begin{array}{l}\sigma_{\mathrm{N}}^{+} \\
\times 10^{6}\end{array}$ & $\begin{array}{c}\mathrm{S}^{+} \\
\times 10^{7}\end{array}$ & $\begin{array}{l}\sigma_{\mathrm{SS}}^{+} \\
\times 10^{7}\end{array}$ & $\begin{array}{l}\mathrm{S}^{++} \\
\times 10^{6}\end{array}$ & $\begin{array}{c}\sigma_{\mathrm{S}++}+{ }^{6} \\
\times 10^{6}\end{array}$ & $\begin{array}{c}\mathrm{O}^{+} \\
\times 10^{5}\end{array}$ & $\begin{array}{l}\sigma \mathrm{O}^{+} \\
\times 10^{5}\end{array}$ & $\begin{array}{l}\mathrm{O}^{++} \\
\times 10^{4}\end{array}$ & $\begin{array}{c}\sigma_{\mathrm{O}++}^{++} \\
\times 10^{4}\end{array}$ & $\begin{array}{c}\mathrm{Ar}^{++} \\
\times 10^{6}\end{array}$ & $\underset{\times 10^{6}}{\sigma}$ & $\begin{array}{l}\mathrm{Ne}^{++} \\
\times 10^{5}\end{array}$ & $\begin{array}{c}\sigma_{\mathrm{Ne}+}++ \\
\times 10^{5}\end{array}$ \\
\hline $000.7-02.7$ & 0.090 & 0.016 & 0.020 & 0.003 & 2.08 & 0.63 & 0.86 & 0.47 & 3.23 & 0.89 & 1.73 & 1.04 & 2.25 & 0.44 & 0.47 & 0.10 & 1.80 & 0.42 \\
\hline $000.9-04.8$ & 0.029 & 0.005 & 0.089 & 0.011 & 0.87 & 0.26 & 0.73 & 0.18 & 2.30 & 0.55 & 0.28 & 0.16 & 1.45 & 0.27 & 1.02 & 0.17 & 3.31 & 0.69 \\
\hline $004.0-11.1$ & 0.088 & 0.012 & 0005 & - & $\begin{array}{r}13.73 \\
075\end{array}$ & 3.64 & 2.67 & 0.74 & 1.22 & 0.33 & $\begin{array}{r}10.85 \\
.17\end{array}$ & 5.92 & 1.72 & 0.30 & 0.80 & 0.16 & 7.40 & 1.45 \\
\hline $\begin{array}{l}004.2-04.3 \\
005.2-18.6\end{array}$ & $\begin{array}{l}0.101 \\
0.073\end{array}$ & $\begin{array}{l}0.020 \\
0.010\end{array}$ & $\begin{array}{l}0.005 \\
0.034\end{array}$ & 0.004 & $\begin{array}{l}0.75 \\
3.66\end{array}$ & $\begin{array}{l}0.16 \\
0.94\end{array}$ & $\begin{array}{l}0.46 \\
1.49\end{array}$ & $\begin{array}{l}0.08 \\
0.53\end{array}$ & $\begin{array}{l}1.01 \\
1.74\end{array}$ & $\begin{array}{l}0.36 \\
0.40\end{array}$ & $\begin{array}{l}2.17 \\
2.43\end{array}$ & $\begin{array}{l}0.26 \\
1.31\end{array}$ & $\begin{array}{l}2.85 \\
2.05\end{array}$ & $\begin{array}{l}0.85 \\
0.35\end{array}$ & $\begin{array}{l}0.66 \\
0.74\end{array}$ & $\begin{array}{l}0.10 \\
0.12\end{array}$ & $\begin{array}{l}5.48 \\
3.72\end{array}$ & 1.34 \\
\hline $005.5-2.5$ & 0.132 & 0.019 & 0.018 & 0.001 & $\begin{array}{l}8.00 \\
8.80\end{array}$ & $\begin{array}{l}1.97 \\
1.97\end{array}$ & $\begin{array}{l}1.49 \\
2.78\end{array}$ & $\begin{array}{l}0.53 \\
0.79\end{array}$ & $\begin{array}{l}1.74 \\
2.64\end{array}$ & $\begin{array}{l}0.40 \\
0.75\end{array}$ & $\begin{array}{l}2.43 \\
1.61\end{array}$ & $\begin{array}{l}1.31 \\
0.69\end{array}$ & $\begin{array}{l}2.05 \\
2.50\end{array}$ & $\begin{array}{l}0.35 \\
0.54\end{array}$ & $\begin{array}{l}0.74 \\
1.72\end{array}$ & $\begin{array}{l}0.12 \\
0.31\end{array}$ & $\begin{array}{l}3.72 \\
7.39\end{array}$ & $\begin{array}{l}0.68 \\
1.78\end{array}$ \\
\hline $006.4-04.6$ & 0.056 & 0.020 & 0.086 & 0.014 & 0.48 & 0.14 & 0.97 & 0.28 & 2.82 & 0.76 & 0.19 & 0.07 & $\begin{array}{l}2.50 \\
1.01\end{array}$ & $\begin{array}{l}0.54 \\
0.22\end{array}$ & 1.16 & $\begin{array}{l}0.31 \\
0.24\end{array}$ & $\begin{array}{l}.39 \\
1.52 \\
\end{array}$ & $\begin{array}{l}1.78 \\
0.37\end{array}$ \\
\hline $006.8-03.4$ & 0.096 & 0.014 & - & - & 0.71 & 0.13 & 0.30 & 0.12 & 0.79 & 0.22 & 0.51 & 0.21 & 1.82 & 0.37 & 0.30 & 0.06 & 3.57 & 0.88 \\
\hline $007.0+06.3$ & 0.056 & 0.008 & & & 5.03 & 1.40 & 1.34 & 0.58 & 1.33 & 0.38 & 1.47 & 0.84 & 1.32 & 0.30 & 1.21 & 0.25 & 3.23 & 0.78 \\
\hline $010.7+07.4$ & 0.056 & 0.013 & 0.096 & 0.013 & 0.56 & 0.24 & 0.51 & 0.19 & 2.88 & 0.99 & 0.23 & 0.16 & 1.47 & 0.31 & 1.08 & 0.33 & 3.32 & 0.74 \\
\hline $011.0-05.1$ & 0.095 & 0.011 & 0.003 & & & & 0.14 & 0.03 & 0.78 & 0.16 & 0.51 & 0.19 & 2.81 & 0.42 & 0.38 & 0.05 & 5.50 & 0.92 \\
\hline $\begin{array}{l}011.3+02.8 \\
011.7-06.6\end{array}$ & 0.111 & $\begin{array}{l}0.018 \\
0.001\end{array}$ & 0.007 & 0.001 & $\begin{array}{r}0.62 \\
100.14\end{array}$ & $\begin{array}{r}0.14 \\
0583\end{array}$ & 0.14 & 0.04 & 0.21 & 0.07 & 0.07 & $\begin{array}{r}0.03 \\
23.47\end{array}$ & 0.07 & 0.02 & 0.04 & 0.01 & 0.88 & 0.26 \\
\hline $\begin{array}{l}011.7-06.6 \\
012.6-02.6\end{array}$ & $\begin{array}{l}0.005 \\
0.015\end{array}$ & $\begin{array}{l}0.001 \\
0.003\end{array}$ & - & - & $\begin{array}{l}100.14 \\
144.76\end{array}$ & $\begin{array}{l}22.83 \\
35.43\end{array}$ & $\begin{array}{l}41.91 \\
34.63\end{array}$ & $\begin{array}{l}27.63 \\
15.82\end{array}$ & 3.69 & 1.50 & $\begin{array}{l}42.87 \\
26.93\end{array}$ & $\begin{array}{l}23.47 \\
13.69\end{array}$ & $\begin{array}{l}0.01 \\
0.05\end{array}$ & $\begin{array}{l}0.00 \\
0.02\end{array}$ & $\begin{array}{l}0.12 \\
0.22\end{array}$ & $\begin{array}{l}0.04 \\
0.06\end{array}$ & - & - \\
\hline $013.8-07.9$ & 0.044 & 0.007 & 0.086 & 0.009 & 0.64 & 0.19 & $\begin{array}{r}3.03 \\
0.40\end{array}$ & $\begin{array}{r}15.02 \\
0.11\end{array}$ & $\begin{array}{l}.09 \\
1.27\end{array}$ & $\begin{array}{l}.50 \\
0.29\end{array}$ & $\begin{array}{r}20.95 \\
0.63\end{array}$ & $\begin{array}{r}0.09 \\
0.36\end{array}$ & 0.95 & 0.15 & 0.54 & $\begin{array}{l}0.00 \\
0.09\end{array}$ & 1.79 & 0.33 \\
\hline $015.9+03.3$ & 0.087 & 0.012 & 0.002 & - & 136.70 & 37.17 & 27.17 & 33.28 & 8.27 & 5.20 & 41.15 & 27.18 & 0.66 & 0.35 & 2.42 & 1.04 & & \\
\hline $016.4-01.9$ & 0.100 & 0.013 & 0.005 & - & 54.01 & 13.02 & 13.36 & 3.71 & 0.46 & 0.13 & 88.74 & 41.64 & 0.04 & 0.01 & 0.49 & 0.10 & 0.02 & 0.00 \\
\hline $019.7-04.5$ & 0.129 & 0.013 & & $000 ?$ & 19.44 & 3.60 & 3.67 & 1.57 & 3.94 & 0.74 & 2.55 & 0.83 & 3.05 & 0.49 & 1.65 & 0.21 & 9.32 & 1.68 \\
\hline $\begin{array}{l}021.8-00.4 \\
023.0+04.3\end{array}$ & $\begin{array}{l}0.122 \\
0.069\end{array}$ & $\begin{array}{l}0.021 \\
0.022\end{array}$ & 0.015 & 0.002 & $\begin{array}{r}89.34 \\
0.26\end{array}$ & $\begin{array}{r}21.72 \\
0.10\end{array}$ & $\begin{array}{l}4.20 \\
0.09\end{array}$ & 1.36 & $\begin{array}{l}1.32 \\
0.82\end{array}$ & 0.41 & 16.94 & 8.06 & $\begin{array}{l}1.99 \\
1.18\end{array}$ & 0.45 & 1.78 & 0.38 & 3.53 & 0.90 \\
\hline $\begin{array}{l}023.0+04.3 \\
023.3-07.6\end{array}$ & $\begin{array}{l}0.069 \\
0.157\end{array}$ & $\begin{array}{l}0.022 \\
0.022\end{array}$ & 0.014 & 0.002 & $\begin{array}{r}0.26 \\
170.57\end{array}$ & $\begin{array}{r}0.10 \\
36.57\end{array}$ & $\begin{array}{r}0.09 \\
41.89\end{array}$ & $\begin{array}{l}0.03 \\
8.49\end{array}$ & $\begin{array}{l}0.82 \\
4.02\end{array}$ & $\begin{array}{l}0.27 \\
1.11\end{array}$ & $\begin{array}{l}0.07 \\
54.63\end{array}$ & $\begin{array}{r}0.05 \\
22.50\end{array}$ & $\begin{array}{l}1.18 \\
2.37\end{array}$ & 0.31 & $\begin{array}{l}0.62 \\
2.24\end{array}$ & 0.14 & 3.21 & 0.95 \\
\hline $023.8-01.7$ & 0.007 & $\begin{array}{l}0.022 \\
0.001\end{array}$ & 0.014 & 0.002 & 63.48 & $\begin{array}{l}17.88 \\
17.88\end{array}$ & $\begin{array}{l}41.89 \\
22.68\end{array}$ & $\begin{array}{r}8.49 \\
11.82\end{array}$ & $\begin{array}{l}4.02 \\
1.90\end{array}$ & $\begin{array}{l}1.11 \\
0.92\end{array}$ & $\begin{array}{l}54.63 \\
14.89\end{array}$ & $\begin{array}{r}22.30 \\
8.30\end{array}$ & 0.03 & $\begin{array}{l}0.4 r \\
0.01\end{array}$ & 2.24 & 0.46 & $\begin{array}{r}7.73 \\
15.51\end{array}$ & $\begin{array}{l}1.74 \\
6.72\end{array}$ \\
\hline $024.1+03.8$ & 0.143 & 0.089 & - & - & 68.34 & 91.73 & 6.66 & 9.81 & 1.56 & 2.07 & 32.99 & 72.20 & 0.56 & 0.32 & 2.24 & 3.13 & & 0.12 \\
\hline $025.9-02.1$ & 0.102 & 0.024 & 0.005 & 0.001 & 0.51 & 0.16 & 0.14 & 0.05 & 2.32 & 0.68 & 0.12 & 0.07 & 3.93 & 0.89 & 1.69 & 0.33 & 8.26 & 2.07 \\
\hline $335.4-01.1$ & 0.128 & 0.030 & 0.131 & 0.026 & 146.10 & 47.89 & 23.99 & 8.04 & 1.53 & 0.64 & 7.88 & 4.91 & 0.50 & & 1.05 & 0.36 & 2.11 & 0.67 \\
\hline $335.9-03.6$ & 0.055 & 0.061 & 0.051 & 0.008 & 0.12 & 0.04 & 0.09 & 0.04 & 0.42 & 0.14 & 0.08 & 0.05 & 0.74 & 0.17 & 0.48 & 0.10 & 0.44 & 0.13 \\
\hline $\begin{array}{l}336.2+01.9 \\
336.3-05.6\end{array}$ & 0.034 & $\begin{array}{l}0.029 \\
0.012\end{array}$ & 0.028 & 0.006 & $\begin{array}{r}0.40 \\
3951\end{array}$ & 0.45 & 0.19 & 0.23 & 0.26 & 0.29 & 0.05 & 0.09 & 0.86 & 0.41 & 0.60 & 0.68 & 1.57 & 0.44 \\
\hline $\begin{array}{l}336.3-05.6 \\
336.9+08.3\end{array}$ & $\begin{array}{l}0.087 \\
0.096\end{array}$ & $\begin{array}{l}0.012 \\
0.014\end{array}$ & 0.049 & 0.005 & 39.51 & 7.94 & 11.04 & 3.44 & $\begin{array}{l}3.34 \\
0.70\end{array}$ & $\begin{array}{l}0.65 \\
0.20\end{array}$ & 12.79 & 4.67 & $\begin{array}{l}2.45 \\
1.64\end{array}$ & $\begin{array}{l}0.36 \\
0.29\end{array}$ & $\begin{array}{l}1.35 \\
0.44\end{array}$ & $\begin{array}{l}0.22 \\
0.10\end{array}$ & $\begin{array}{l}4.46 \\
3.29\end{array}$ & $\begin{array}{l}0.73 \\
0.66\end{array}$ \\
\hline $338.8+05.6$ & 0.125 & 0.013 & 0.005 & - & 8.66 & 1.77 & 2.43 & 0.48 & 2.69 & 0.55 & 3.65 & 1.50 & 3.56 & 0.53 & 1.10 & 0.15 & 8.71 & 1.67 \\
\hline 340.9-04.6 & 0.102 & 0.018 & 0.002 & - & 1.06 & 0.29 & 0.64 & 0.26 & 1.63 & 0.40 & 0.55 & 0.26 & 2.45 & 0.45 & 0.6 & 0.11 & 4.87 & 1.13 \\
\hline $342.9-04.9$ & 0.083 & 0.012 & 0.056 & 0.007 & 71.14 & 14.06 & 22.87 & 4.24 & 6.26 & 1.39 & 16.66 & 6.88 & 2.50 & 0. & 2.5 & 0.35 & 4.04 & 0.70 \\
\hline $343.0-01.7$ & 0.100 & 0.021 & 0.004 & 0.001 & $\begin{array}{r}2.41 \\
127.32\end{array}$ & $\begin{array}{r}0.73 \\
53.70\end{array}$ & 0.63 & 0.31 & 1.69 & 0.58 & 0.69 & 0.42 & 2.10 & 0. & 0.8 & 0.21 & 6.71 & 2.43 \\
\hline $\begin{array}{l}344.2-01.2 \\
344.4+02.8\end{array}$ & 0.202 & $\begin{array}{l}0.043 \\
0.016\end{array}$ & 0.022 & 0.005 & $\begin{array}{r}137.33 \\
0.31\end{array}$ & 53.79 & 32.06 & 12.37 & 1.71 & 0.76 & 22.33 & 15.77 & 0.64 & & & 0.73 & 1.80 & 0.58 \\
\hline $\begin{array}{l}344.4+02.8 \\
344.8+03.4\end{array}$ & $\begin{array}{l}0.072 \\
0.094\end{array}$ & $\begin{array}{l}0.016 \\
0.016\end{array}$ & 0.033 & 0.005 & $\begin{array}{r}0.31 \\
49.22\end{array}$ & $\begin{array}{r}0.10 \\
14.96\end{array}$ & $\begin{array}{r}0.15 \\
20.62\end{array}$ & $\begin{array}{l}0.06 \\
5.91\end{array}$ & 0.70 & 0.19 & $\begin{array}{r}0.51 \\
41.18\end{array}$ & $\begin{array}{r}0.34 \\
24.15\end{array}$ & $\begin{array}{l}2.29 \\
0.88\end{array}$ & $\begin{array}{l}0.46 \\
0.27\end{array}$ & $\begin{array}{l}0.56 \\
1.33\end{array}$ & 0.11 & 2.93 & 0.69 \\
\hline $345.0+03.4$ & 0.104 & 0.018 & 0.004 & - & $\begin{array}{r}4.22 \\
4.26\end{array}$ & $\begin{array}{r}1.96 \\
1.30\end{array}$ & $\begin{array}{r}0.02 \\
0.92\end{array}$ & $\begin{array}{l}.91 \\
0.48\end{array}$ & 1.06 & 0.29 & $\begin{array}{r}41.18 \\
1.89\end{array}$ & $\begin{array}{r}24.15 \\
0.96\end{array}$ & $\begin{array}{l}0.88 \\
1.74\end{array}$ & $\begin{array}{l}0.27 \\
0.32\end{array}$ & $\begin{array}{l}1.33 \\
0.55\end{array}$ & $\begin{array}{l}.55 \\
0.11\end{array}$ & 3.89 & 0.76 \\
\hline $346.2-08.2$ & 0.0 & 0.0 & 0.074 & 0.008 & 3.94 & 1.40 & 1.91 & 0.70 & 3.39 & 1.19 & 0.89 & 0.55 & 2.39 & 0.4 & & 0.6 & 6.17 & 1.05 \\
\hline $347.7+02.0$ & 0.085 & 0.019 & 0.013 & 0.003 & 1.44 & 0.39 & 0.77 & 0.37 & 0.62 & 0.16 & 0.3 & 0.17 & & & 0. & & 2.27 & 0.58 \\
\hline & 0.055 & & 0.025 & 0.003 & & & 0.05 & 0.0 & 0.5 & $0.2>>$ & 0.6 & 0.41 & 2.0 & 0. & 0. & $0.8 \quad>\quad>$ & 4 & 0.69 \\
\hline $350.5-05.0$ & 0.169 & 0.025 & 0.013 & 0.002 & 124.70 & 25.65 & 24.32 & $4.6>3$ & 1.3 & 0.39 & 30.4 & 12.83 & 0.9 & 0 & 1. & & & 0.77 \\
\hline $350.9+04.4$ & 0.059 & 0.006 & & & 9.27 & 1.60 & 1.26 & 0.3 & $0.4>>3$ & 0.10 & 7.6 & 2.3 & 0.0 & $0.8>>$ & 0.1 & & 0.09 & 0.02 \\
\hline-06.2 & 0.084 & 0.012 & 0.069 & 0.008 & 43.55 & 9.86 & 11.97 & 2.84 & 3.33 & 0.75 & & 2.27 & 1.35 & 0.25 & $1.4 \mathrm{Y}-\mathrm{s}$ & 0.24 & 4.21 & 0.85 \\
\hline 352. & 0.0 & & 0.004 & 0.001 & 125.01 & 31.92 & 23.51 & 10.80 & 1.09 & 0.32 & 58.87 & 28.77 & 0.82 & 0.20 & 1.62 & 0.30 & 2.20 & 0.59 \\
\hline $4-04.0$ & 0.0 & & 0.081 & 0.010 & 8.15 & 1.75 & 3.68 & 0.77 & 3.53 & 0.72 & 1.17 & 0.50 & 2.3 & 0. & 1.5 & 0.2 & 4.34 & 0.74 \\
\hline 355. & 0.0 & & & & 4.6 & 1. & 0. & 0.2 & 1.19 & 0.44 & 3.75 & 2.53 & 0. & 0. & 0. & 0.13 & 0.16 & 0.04 \\
\hline $356.3-06.2$ & 0.100 & 0.01 & 0.019 & 0.004 & 93.51 & 24.10 & 23.92 & 6.0 & & & 16.03 & 8.94 & 0. & 0. & 1.0 & 0. & 1.65 & 0.47 \\
\hline $356.8-05.4$ & 0.074 & 0.012 & 0.023 & 0.004 & 29.19 & 7.79 & 9.29 & 2.34 & 1.05 & 0.32 & & & & & & 0.27 & 3.95 & 0.97 \\
\hline $\begin{array}{l}357.4-04.6 \\
358.2+03.5\end{array}$ & 0.089 & 0.015 & 0.028 & 0.004 & $\begin{array}{r}20.69 \\
0.85\end{array}$ & 5.22 & 5.26 & 1.64 & 1.29 & 0.39 & 1.80 & 0.84 & 1.51 & 0.32 & 1.19 & 0.24 & 4.01 & 0.98 \\
\hline $\begin{array}{l}358.2+03.5 \\
358.3+03.0\end{array}$ & $\begin{array}{l}0.090 \\
0.107\end{array}$ & $\begin{array}{l}0.014 \\
0.020\end{array}$ & 0.006 & $0 . \overline{0} 1$ & $\begin{array}{l}0.85 \\
5.35\end{array}$ & $\begin{array}{l}0.23 \\
1.55\end{array}$ & $\begin{array}{l}0.39 \\
1.32\end{array}$ & $\begin{array}{l}0.18 \\
0.79\end{array}$ & $\begin{array}{l}0.92 \\
3.13\end{array}$ & $\begin{array}{l}0.22 \\
0.86\end{array}$ & $\begin{array}{l}0.27 \\
0.98\end{array}$ & $\begin{array}{l}0.13 \\
0.48\end{array}$ & $\begin{array}{l}1.67 \\
2.06\end{array}$ & $\begin{array}{l}0.31 \\
0.44\end{array}$ & $\begin{array}{l}0.42 \\
1.46\end{array}$ & $\begin{array}{l}0.07 \\
0.35\end{array}$ & $\begin{array}{l}6.01 \\
3.22\end{array}$ & $\begin{array}{l}1.36 \\
0.78\end{array}$ \\
\hline $\begin{array}{l}530.0+03.0 \\
358.7+05.2\end{array}$ & 0.020 & 0.004 & 0.000 & & $\begin{array}{r}0.00 \\
137.87\end{array}$ & $\begin{array}{l}1.50 \\
43.56\end{array}$ & $\begin{array}{l}1.32 \\
43.95\end{array}$ & 20.69 & $\begin{array}{l}.13 \\
10.30\end{array}$ & $\begin{array}{l}4.80 \\
4.89\end{array}$ & $\begin{array}{r}0.98 \\
33.52\end{array}$ & $\begin{array}{l}0.48 \\
20.19\end{array}$ & 2.00 & 0.44 & $\begin{array}{l}1.40 \\
0.25\end{array}$ & $\begin{array}{l}.030 \\
0.09\end{array}$ & $\begin{array}{l}3.22 \\
48.77\end{array}$ & 21.48 \\
\hline $358.8+03.0$ & 0.046 & 0.010 & 0.080 & 0.014 & 11.38 & 3.15 & 4.08 & 1.37 & 3.53 & 1.07 & 1.61 & 0.93 & 1.00 & 0.24 & 0.75 & 0.15 & 2.62 & 0.74 \\
\hline $359.8+03.7$ & 0.097 & 0.018 & - & - & 4.32 & 1.28 & 1.01 & 0.54 & 0.52 & 0.17 & 2.09 & 1.13 & 0.49 & 0.12 & 0.34 & 0.09 & 1.01 & 0.29 \\
\hline
\end{tabular}




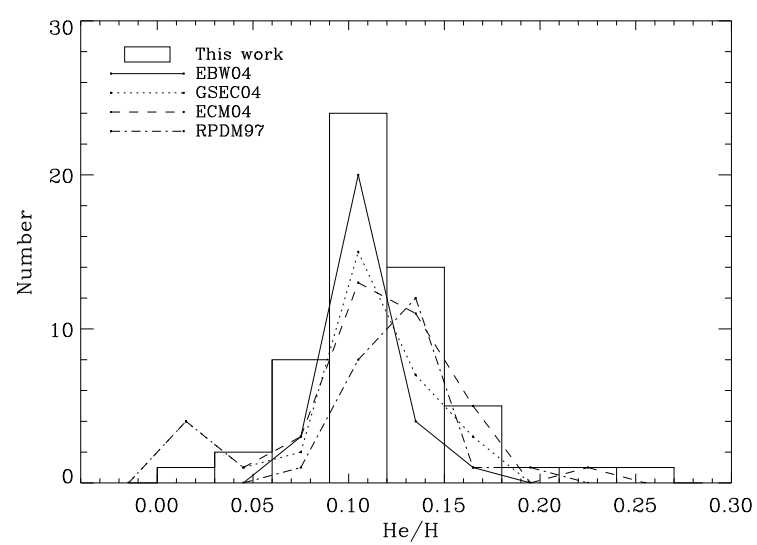

Fig. 4. Comparison between distribution of helium abundances derived in this work (boxed histogram) and the abundances taken from the literature (lines).

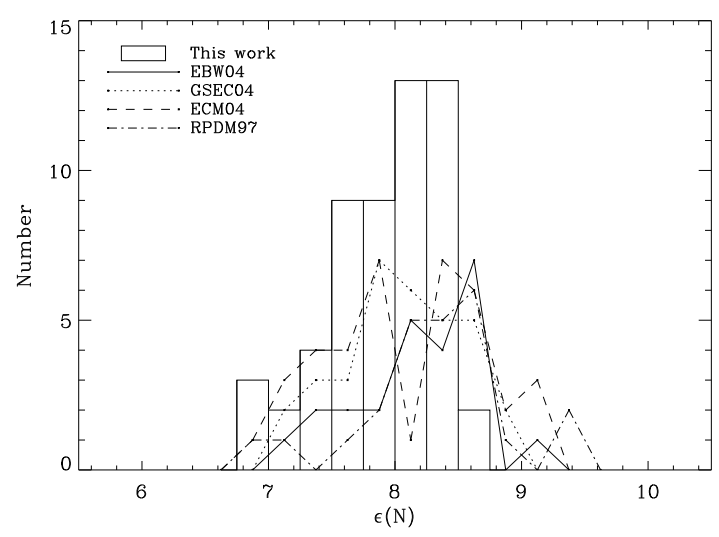

Fig. 5. The same as Figure 4 for nitrogen.

from a linear fit in the data as shown in Figure 3. In this figure, the horizontal axis shows the mean reddened fluxes for each line of each object and the vertical axis shows the errors in the line fluxes, which are the standard deviations calculated from the independent line flux measurements for each object.

The linear fit gives:

$$
\log (\Delta \mathrm{F})=(-3.2 \pm 0.2)+(0.85 \pm 0.02) \log (\mathrm{F})
$$

The color excesses were also varied randomly within their error intervals, which were estimated from the standard deviation calculated for each measure. Final abundances and electron temperatures were adopted as the peak of a Gaussian fit to the histogram of the 500 random generated values, and the errors were adopted as half of the FWHM of the Gaussian profile fitted to each histogram, except for the densities, whose value distribution is not Gaussian. Densities and errors were estimated from the mean and standard deviation calculated for the different measurements of each object, respectively.

Average errors for the whole sample of abundances are shown in Table 6, where the columns indicate the chemical element and the error associated with it. These errors were obtained from the mean of the standard deviations of the chemical abundances for each element. We have to stress the fact that these errors take into account only the influence of line flux uncertainties in the chemical abundances. The major source of errors in our determination of chemical abundances is due to uncertainties in the ICFs; hence, the errors derived here only measure the dispersion of the observational data.

\section{RESULTS}

In order to check the consistency of the data presented in this work, as given in Table 5, we analysed some statistical properties of the sample and compared them with chemical abundances taken from the literature. We searched for chemical abundances of PNe located in the bulge and inner-disk of the Galaxy in the following works: Ratag et al. (1997, hereafter RPDM97); Exter et al. (2004, hereafter EBW04); Górny et al. (2004, hereafter GSEC04); and Escudero et al. (2004, hereafter ECM04). All these works deal with the same region of interest and besides they contain significant and homogeneous samples.

RPDM97 derived abundances for a sample of 45 bulge PNe based on theoretical photoionization models used to account for individual ICF for each PN. They also reanalysed the data for 50 bulge PNe previously published.

EBW04 published chemical abundances for 45 bulge PNe using the empirical method, as in this work. They use ICFs from Kingsburgh \& Barlow (1994).

ECM04 observed 57 bulge PNe using the empirical method to derive the abundances. They adopted the blue line pair to derive the $\mathrm{O}^{+}$abundance. The ICFs used by them are as in the present work.

GSEC04 observed 44 PNe towards the bulge and the abundances were derived using the empirical method. They used the [N II] temperature for the ions of low ionization level and the [O III] temperature for those of high ionization level to derive the abundances. They adopted as $\mathrm{O}^{+}$abundance the mean between the abundances obtained from the [O II] $\lambda 372.7$ and [O II] $\lambda 732.0,733.0 \mathrm{~nm}$ lines.

\subsection{Abundance distributions}

Figures 4 to 9 show the distribution of the chemical abundances obtained in this work (boxed his- 
PLANETARY NEBULAE IN THE INNER MILKY WAY

TABLE 5

NEW CHEMICAL ABUNDANCES AND ERRORS IN THE USUAL NOTATION

\begin{tabular}{|c|c|c|c|c|c|c|c|c|c|c|c|c|}
\hline PN G & $\mathrm{He} / \mathrm{H}$ & $\sigma_{\mathrm{He} / \mathrm{H}}$ & $\epsilon(\mathrm{N})$ & $\sigma_{\epsilon(\mathrm{N})}$ & $\epsilon(\mathrm{S})$ & $\sigma_{\epsilon(\mathrm{S})}$ & $\epsilon(\mathrm{O})$ & $\sigma_{\epsilon(\mathrm{O})}$ & $\epsilon(\mathrm{Ar})$ & $\sigma_{\epsilon(\mathrm{Ar})}$ & $\epsilon(\mathrm{Ne})$ & $\sigma_{\epsilon(\mathrm{Ne})}$ \\
\hline $000.7-02.7$ & 0.110 & 0.017 & 7.55 & 0.15 & 6.79 & 0.14 & 8.47 & 0.08 & 5.92 & 0.09 & 7.38 & 0.10 \\
\hline $000.9-04.8$ & 0.118 & 0.013 & 8.27 & 0.18 & 6.99 & 0.14 & 8.79 & 0.10 & 6.76 & 0.09 & 8.14 & 0.10 \\
\hline $004.0-11.1$ & 0.088 & 0.012 & 7.56 & 0.08 & 6.22 & 0.11 & 8.45 & 0.11 & 6.24 & 0.14 & 8.08 & 0.11 \\
\hline $004.2-04.3$ & 0.106 & 0.021 & $8.02^{* *}$ & - & $6.66^{* *}$ & - & $8.45^{* *}$ & - & 5.99 & 0.06 & 7.79 & 0.10 \\
\hline $005.2-18.6$ & 0.106 & 0.012 & 7.71 & 0.13 & 6.51 & 0.13 & 8.54 & 0.07 & 6.22 & 0.08 & 7.79 & 0.08 \\
\hline $005.5-2.5$ & 0.149 & 0.021 & 8.22 & 0.14 & 6.74 & 0.14 & 8.48 & 0.09 & 6.45 & 0.08 & 7.96 & 0.10 \\
\hline $006.4-04.6$ & 0.145 & 0.028 & 7.80 & 0.20 & 7.00 & 0.16 & 8.40 & 0.13 & 6.59 & 0.13 & 7.58 & 0.14 \\
\hline $006.8-03.4$ & 0.096 & 0.014 & 7.40 & 0.12 & 6.28 & 0.12 & 8.27 & 0.09 & 5.62 & 0.08 & 7.57 & 0.11 \\
\hline $007.0+06.3$ & 0.051 & 0.012 & 7.70 & 0.13 & 6.37 & 0.14 & 8.17 & 0.09 & 6.26 & 0.09 & 7.56 & 0.11 \\
\hline $010.7+07.4$ & 0.151 & 0.020 & 8.02 & 0.20 & 7.07 & 0.16 & 8.62 & 0.10 & 6.61 & 0.13 & 7.97 & 0.13 \\
\hline $011.0-05.1$ & 0.098 & 0.012 & - & - & 6.34 & 0.09 & 8.47 & 0.07 & 5.73 & 0.07 & 7.76 & 0.07 \\
\hline $011.3+02.8$ & 0.118 & 0.019 & 6.83 & 0.10 & 5.55 & 0.13 & 6.89 & 0.11 & 4.83 & 0.09 & 7.02 & 0.13 \\
\hline $011.7-06.6^{*}$ & - & - & 8.00 & 0.11 & 7.38 & 0.28 & 8.63 & 0.23 & 7.74 & 0.22 & - & - \\
\hline $012.6-02.6^{*}$ & - & - & 8.23 & 0.10 & 6.86 & 0.18 & 8.51 & 0.22 & 7.28 & 0.22 & - & - \\
\hline $013.8-07.9$ & 0.131 & 0.013 & 7.46 & 0.17 & 6.51 & 0.13 & 8.48 & 0.08 & 6.37 & 0.08 & 7.76 & 0.09 \\
\hline $015.9+03.3^{*}$ & 0.089 & 0.012 & 8.21 & 0.10 & 7.03 & 0.31 & 8.70 & 0.29 & 7.38 & 0.24 & - & - \\
\hline $016.4-01.9^{*}$ & 0.104 & 0.013 & 7.75 & 0.10 & 6.26 & 0.10 & 8.97 & 0.20 & 8.15 & 0.22 & 7.62 & 0.21 \\
\hline $019.7-04.5$ & 0.129 & 0.013 & 8.39 & 0.09 & 6.86 & 0.09 & 8.52 & 0.07 & 6.38 & 0.06 & 8.01 & 0.09 \\
\hline $021.8-00.4^{*}$ & 0.138 & 0.023 & 8.35 & 0.09 & 6.29 & 0.12 & 8.63 & 0.12 & 6.70 & 0.12 & 7.87 & 0.12 \\
\hline $023.0+04.3$ & 0.063 & 0.028 & 7.62 & 0.20 & 6.50 & 0.19 & 8.08 & 0.11 & 5.92 & 0.10 & 7.51 & 0.12 \\
\hline $023.3-07.6^{*}$ & 0.171 & 0.022 & 8.43 & 0.06 & 6.92 & 0.08 & 8.93 & 0.13 & 7.03 & 0.14 & 8.45 & 0.13 \\
\hline $023.8-01.7^{*}$ & - & - & 7.92 & 0.12 & 6.62 & 0.21 & 8.29 & 0.24 & - & - & 9.97 & 0.26 \\
\hline $024.1+03.8^{*}$ & 0.136 & 0.098 & 7.88 & 0.43 & 6.37 & 0.59 & 8.55 & 0.85 & 7.28 & 1.22 & - & - \\
\hline 025.9-02.1 & 0.107 & 0.025 & 8.25 & 0.17 & 7.06 & 0.17 & 8.62 & 0.10 & 6.38 & 0.08 & 7.94 & 0.11 \\
\hline $335.4-01.1$ & 0.261 & 0.044 & 8.70 & 0.10 & 6.66 & 0.13 & 8.43 & 0.17 & 6.88 & 0.22 & 8.05 & 0.16 \\
\hline $335.9-03.6$ & 0.118 & 0.050 & 7.29 & 0.30 & 6.21 & 0.21 & 8.13 & 0.16 & 6.07 & 0.16 & 6.91 & 0.18 \\
\hline $336.2+01.9$ & $0.165^{* *}$ & 0.014 & 8.07 & 0.27 & 6.12 & 0.29 & 8.20 & 0.12 & 6.15 & 0.34 & 7.43 & 0.20 \\
\hline $336.3-05.6$ & 0.136 & 0.015 & 8.26 & 0.07 & 6.75 & 0.09 & 8.77 & 0.08 & 6.64 & 0.09 & 8.03 & 0.08 \\
\hline $336.9+08.3$ & 0.096 & 0.014 & - & - & 5.84 & 0.13 & 8.22 & 0.08 & 5.77 & 0.10 & 7.52 & 0.09 \\
\hline $338.8+05.6$ & 0.130 & 0.013 & 7.98 & 0.11 & 6.67 & 0.10 & 8.61 & 0.06 & 6.23 & 0.06 & 8.00 & 0.08 \\
\hline $340.9-04.6$ & 0.104 & 0.017 & 7.69 & 0.14 & 6.63 & 0.14 & 8.41 & 0.08 & 5.96 & 0.08 & 7.70 & 0.10 \\
\hline $342.9-04.9$ & 0.139 & 0.016 & 8.49 & 0.07 & 7.02 & 0.08 & 8.85 & 0.08 & 6.99 & 0.09 & 8.06 & 0.09 \\
\hline $343.0-01.7$ & 0.103 & 0.022 & 7.88 & 0.19 & 6.60 & 0.18 & 8.36 & 0.12 & 6.14 & 0.09 & 7.86 & 0.16 \\
\hline $344.2-01.2^{*}$ & 0.225 & 0.046 & 8.30 & 0.12 & 6.70 & 0.16 & 8.51 & 0.24 & 7.10 & 0.32 & 7.95 & 0.21 \\
\hline $344.4+02.8$ & 0.106 & 0.017 & 7.31 & 0.19 & 6.30 & 0.16 & 8.54 & 0.09 & 6.05 & 0.08 & 7.64 & 0.11 \\
\hline $344.8+03.4^{*}$ & 0.094 & 0.016 & 7.78 & 0.12 & 7.11 & 0.12 & 8.70 & 0.23 & 7.00 & 0.22 & - & - \\
\hline $345.0+03.4$ & 0.107 & 0.019 & 7.64 & 0.13 & 6.27 & 0.13 & 8.30 & 0.08 & 5.93 & 0.10 & 7.65 & 0.08 \\
\hline $346.2-08.2$ & 0.118 & 0.012 & 8.49 & 0.16 & 7.03 & 0.12 & 8.84 & 0.07 & 6.87 & 0.12 & 8.25 & 0.09 \\
\hline $347.7+02.0$ & 0.099 & 0.020 & 7.70 & 0.14 & 6.23 & 0.15 & 8.13 & 0.09 & 5.80 & 0.09 & 7.44 & 0.11 \\
\hline $348.0-13.8$ & 0.079 & 0.012 & - & - & 6.15 & 0.13 & 8.50 & 0.08 & 5.62 & 0.15 & 7.78 & 0.08 \\
\hline $350.5-05.0^{*}$ & 0.183 & 0.026 & 8.26 & 0.06 & 6.58 & 0.07 & 8.64 & 0.14 & 6.92 & 0.14 & 8.19 & 0.14 \\
\hline $350.9+04.4^{*}$ & 0.059 & 0.007 & 7.00 & 0.07 & 5.79 & 0.09 & 7.92 & 0.12 & 6.52 & 0.15 & 7.08 & 0.13 \\
\hline $351.6-06.2$ & 0.154 & 0.017 & 8.46 & 0.09 & 6.80 & 0.09 & 8.54 & 0.08 & 6.70 & 0.09 & 8.04 & 0.10 \\
\hline $352.6+03.0^{*}$ & $0.073^{* *}$ & - & 8.19 & 0.09 & 6.55 & 0.15 & 8.86 & 0.19 & 7.28 & 0.18 & 8.29 & 0.20 \\
\hline $355.4-04.0$ & 0.127 & 0.014 & 8.66 & 0.14 & 7.02 & 0.11 & 8.83 & 0.09 & 6.88 & 0.08 & 8.10 & 0.09 \\
\hline $355.9+03.6^{*}$ & 0.063 & 0.014 & 6.82 & 0.10 & 6.11 & 0.16 & 7.73 & 0.23 & 6.19 & 0.31 & 6.71 & 0.18 \\
\hline $356.3-06.2^{*}$ & 0.119 & 0.019 & 8.24 & 0.08 & 7.20 & 0.09 & 8.46 & 0.17 & 6.68 & 0.18 & 7.77 & 0.18 \\
\hline $356.8-05.4$ & 0.098 & 0.013 & - & - & 6.31 & 0.10 & 8.31 & 0.10 & 6.36 & 0.09 & 7.72 & 0.11 \\
\hline $357.4-04.6$ & 0.117 & 0.016 & 8.42 & 0.13 & 6.49 & 0.12 & 8.35 & 0.09 & 6.37 & 0.09 & 7.78 & 0.10 \\
\hline $358.2+03.5$ & 0.091 & 0.015 & 7.72 & 0.14 & 6.42 & 0.14 & 8.24 & 0.09 & 5.77 & 0.08 & 7.79 & 0.10 \\
\hline $358.3+03.0$ & 0.113 & 0.021 & 8.08 & 0.12 & 6.82 & 0.13 & 8.36 & 0.09 & 6.34 & 0.11 & 7.55 & 0.11 \\
\hline $358.7+05.2^{*}$ & $0.020^{* *}$ & - & 8.14 & 0.14 & 7.17 & 0.20 & 8.52 & 0.26 & - & - & - & - \\
\hline $358.8+03.0$ & 0.126 & 0.019 & 8.35 & 0.17 & 6.88 & 0.16 & 8.51 & 0.11 & 6.51 & 0.10 & 7.92 & 0.12 \\
\hline $359.8+03.7$ & 0.097 & 0.018 & 7.14 & 0.10 & 5.87 & 0.14 & 7.86 & 0.11 & 5.83 & 0.13 & 7.17 & 0.12 \\
\hline
\end{tabular}

* There is a substantial contribution of neutral helium not taken into account.

**Abundances were calculated from the mean of each measure of the same object.

togram) compared with data from the literature (lines). Each line is taken from a different work as indicated at the top left in each figure.
Since helium and nitrogen abundances are modified by the evolution of intermediate mass stars (IMS), the histograms in Figures 4 and 5 show the 
TABLE 6

MEAN ERRORS FOR THE ABUNDANCES IN DEX. FOR HELIUM. THE UNCERTAINTY IN THE HE/H RATIO IS GIVEN

\begin{tabular}{ccccccc}
\hline Element & $\mathrm{He}$ & $\mathrm{N}$ & $\mathrm{S}$ & $\mathrm{O}$ & $\mathrm{Ar}$ & $\mathrm{Ne}$ \\
\hline \multirow{2}{*}{ Error } & \pm 0.021 & \pm 0.14 & \pm 0.15 & \pm 0.14 & \pm 0.16 & \pm 0.13 \\
\hline
\end{tabular}

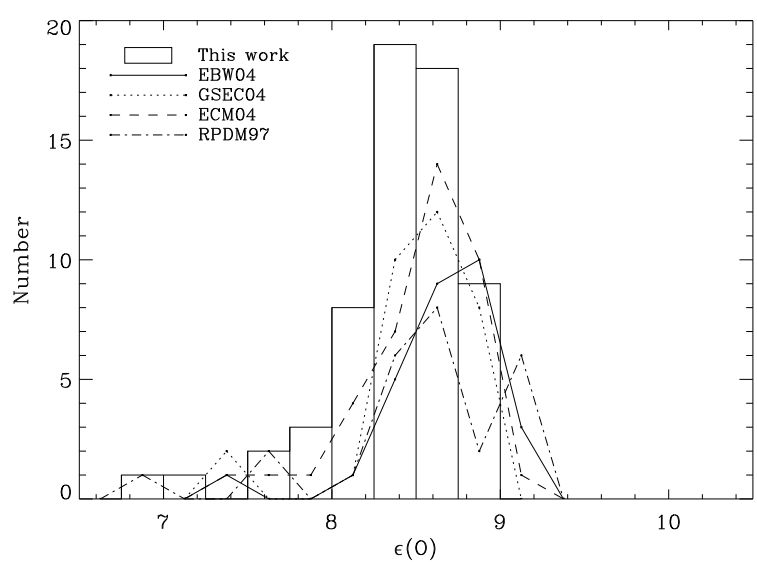

Fig. 6. The same as Figure 4 for oxygen.

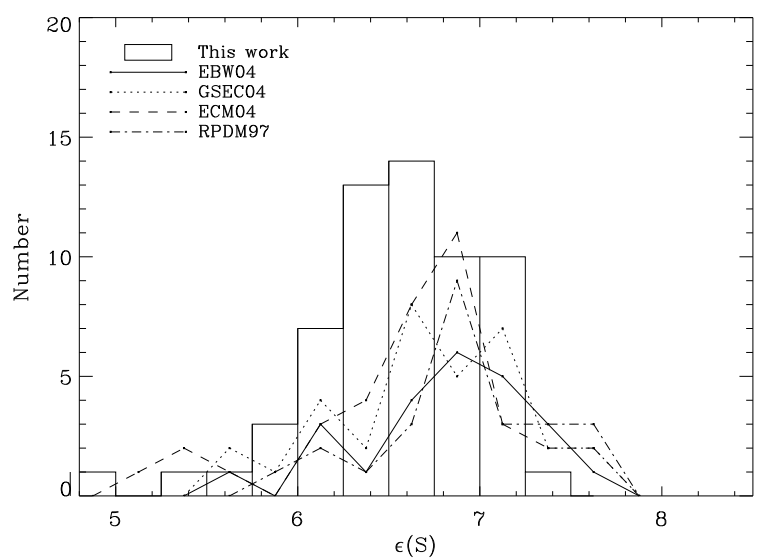

Fig. 7. The same as Figure 4 for sulfur.

results of this evolution coupled to the chemical evolution of the Galaxy. For helium in particular, the histogram shows a wide distribution, which results from the mass and age ranges of the progenitor stars that originate the PNe. This behavior is seen both in our data as well as in data from the literature. It is important to note the good agreement between the data from different authors and the present work as shown by these histograms.

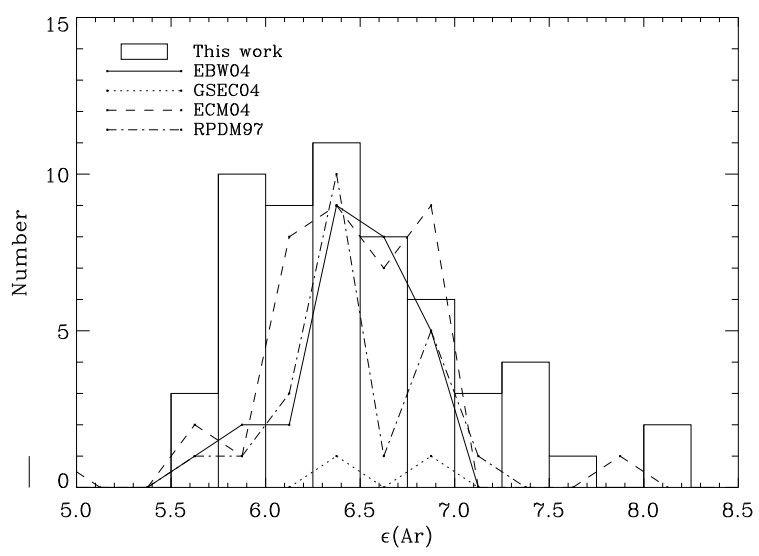

Fig. 8. The same as Figure 4 for argon.

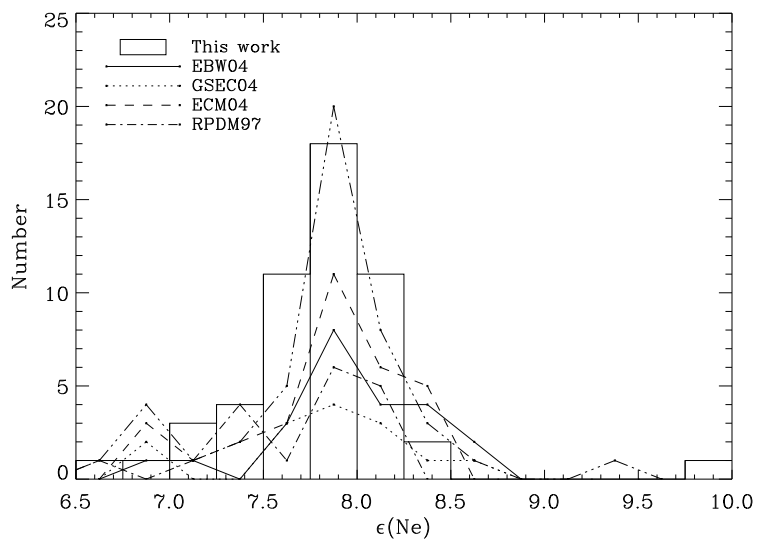

Fig. 9. The same as Figure 4 for neon.

In agreement with theories of stellar evolution and nucleosynthesis (Lattanzio \& Forestini 1999), we do not expect significant changes in the abundances of the $\alpha$-elements $(\mathrm{O}, \mathrm{S}, \mathrm{Ar}, \mathrm{Ne})$, so that these abundances should reflect the abundances of the interstellar medium at the progenitor formation epoch, indicating the chemical evolution of the Galaxy.

The histograms for oxygen, sulfur, argon, and neon, are displayed in Figures 6, 7, 8, and 9, respectively. In Figure 6, oxygen shows a systematic 


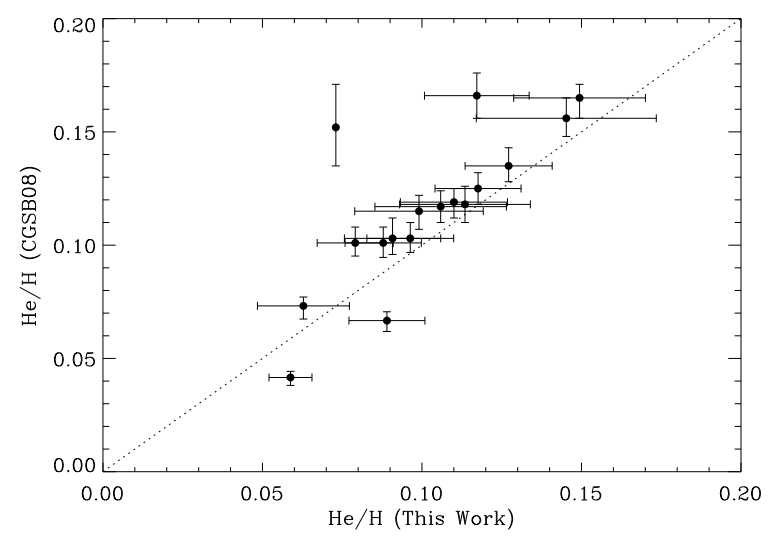

Fig. 10. Comparison between abundances from this work and CGSB09 for helium, with error bars. The dashed line represents the equality between the data.

lower abundance than the data from the literature by approximately 0.2 dex, which is larger than the expected errors for the oxygen abundance obtained in this work. However, the bulge is formed by different populations, mostly by stars with ages $10 \pm 2.5$ Gyr (Zoccali et al. 2003). On the other hand, there are evidences for a younger population formed by $\mathrm{OH} / \mathrm{IR}$ stars, AGB variables, etc, that appear to be located in the galactic plane (van Loon et al. 2003). Such an age distribution results in a wide abundance distribution for oxygen and $\alpha$-elements in general. It can be seen that there is a significant number of $\mathrm{PNe}$ in the range 8 to 9 dex, showing that the progenitor stars of the bulge PNe were formed in different epochs, suggesting a scenario where the bulge was formed in a diversity of epochs, as discussed by Costa \& Maciel (2006).

For sulfur, argon and neon (Figures 7, 8 and 9 , respectively) the distributions of the abundances are very similar to the data from the literature, in the sense that they are very wide, and the peaks of the distributions match each other. It is worth to note that the distributions of argon are bimodal for RPDM97 and ECM04 data.

\subsection{Comparison of individual abundances}

In this work, 21 out of 54 objects have abundances already published in the literature. The remaining 33 objects have abundances published here for the first time. Table 7 shows a comparison between our data (left column for each element) and data from the literature (right column for each element). The references are shown in the last column, where the abbreviations are as follows: CAK96 (Cuisinier, Acker, \& Köppen 1996), CMKAS00

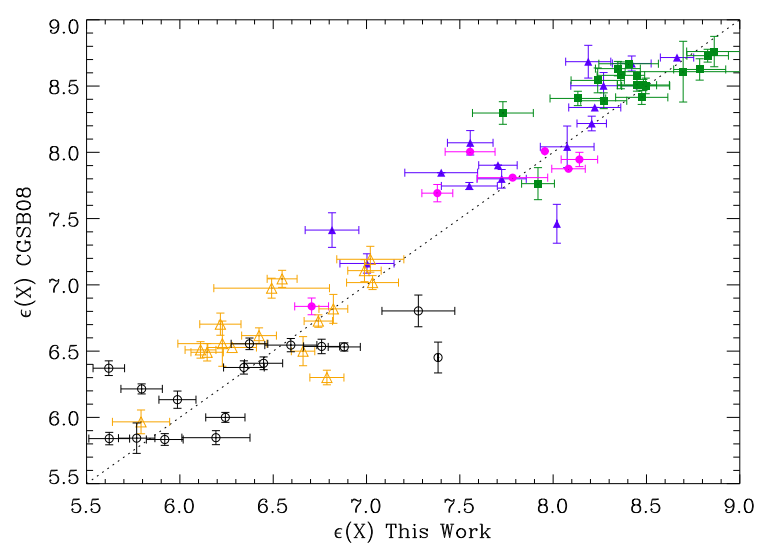

Fig. 11. The same as Figure 10 but for other elements. The abundances are in units of $\log (\mathrm{X} / \mathrm{H})$ where $\mathrm{X}$ stands for nitrogen (filled triangles), oxygen (filled squares), neon (filled circles), sulfur (open triangles), argon (open circles).

(Cuisinier et al. 2000), GKA07 (Girard, Köppen, \& Acker 2007), P91 (Perinotto 1991), CGSB09 (Chiappini et al. 2009), PMS04 (Perinotto, Morbidelli, \& Scatarzi 2004), WL07 (Wang \& Liu 2007). P91 compiled a catalogue of chemical abundances for 209 $\mathrm{PNe}$, taken from the literature. CAK96 gives chemical abundances for 62 PNe derived by the same empirical method as used in this work but the ICFs are from their own model, except for N, S and Ne, whose ICFs are from Kingsburgh \& Barlow (1994), as in this work. GKA07 analyze chemical properties for $48 \mathrm{PNe}$ around central stars of spectral types [WC], [WO]. The ICFs are from Aller (1984) which, except for argon, are the same we used. Recently CGSB09 published chemical abundances for 245 objects belonging to the bulge and inner disk of the Galaxy, from which 90 PNe were observed with $4 \mathrm{~m}$ class telescopes by Górny et al. (2009), and the others have chemical abundances recalculated from an empirical method described in Górny et al. (2009). The advantage over our observations is the size of the telescope, but the disadvantage is the fact that some spectra were dereddened by using the ratio $\mathrm{H} \alpha / \mathrm{H} \gamma$ instead of the usual ratio $\mathrm{H} \alpha / \mathrm{H} \beta$. This can introduce errors in the dereddened fluxes, which are propagated to the chemical abundances. PMS04 did a reanalysis of all chemical abundances published so far in a very homogeneous way. The ICFs used are as in the present work, but the extinction curve used is from Mathis (1990), while here we made use of those from Fitzpatrick (1999). Finally, WL07 give chemical abundances for 25 galactic bulge PNe and 6 from the Galactic disk determined from both collisional 
TABLE 7

COMPARISON BETWEEN ABUNDANCES FROM THIS WORK (LEFT COLUMN FOR EACH ELEMENT) AND ABUNDANCES FROM THE LITERATURE (RIGHT COLUMN), FOR PNE WITH PREVIOUSLY PUBLISHED ABUNDANCES

\begin{tabular}{|c|c|c|c|c|c|c|c|c|c|c|c|c|c|}
\hline \multirow[b]{2}{*}{ Name } & \multicolumn{2}{|c|}{$\mathrm{He} / \mathrm{H}$} & \multicolumn{2}{|c|}{$\epsilon(\mathrm{N})$} & \multicolumn{2}{|c|}{$\epsilon(\mathrm{S})$} & \multicolumn{2}{|c|}{$\epsilon(\mathrm{O})$} & \multicolumn{2}{|c|}{$\epsilon(\mathrm{Ar})$} & \multicolumn{2}{|c|}{$\epsilon(\mathrm{Ne})$} & \multirow[b]{2}{*}{ Reference } \\
\hline & Our & Lit. & Our & Lit. & Our & Lit. & Our & Lit. & Our & Lit. & Our & Lit. & \\
\hline H $1-8$ & 0.073 & 0.152 & 8.19 & 8.68 & 6.55 & 7.04 & 8.86 & 8.76 & 7.28 & 6.80 & 8.29 & - & CGSB09 \\
\hline H 1-9 & 0.063 & 0.073 & 6.82 & 7.41 & 6.11 & 6.51 & 7.73 & 8.30 & 6.19 & 5.85 & 6.71 & 6.84 & CGSB09 \\
\hline H 1-17 & 0.112 & $\begin{array}{l}0.100 \\
0.083 \\
0.086 \\
0.118\end{array}$ & 8.07 & $\begin{array}{l}8.32 \\
8.08 \\
7.73 \\
8.04\end{array}$ & 6.81 & $\begin{array}{l}6.78 \\
6.62 \\
6.52 \\
6.82\end{array}$ & 8.36 & $\begin{array}{l}8.61 \\
8.32 \\
8.35 \\
8.58\end{array}$ & 6.34 & $\begin{array}{l}6.42 \\
6.09 \\
6.34 \\
6.38 \\
\end{array}$ & $7 . \overline{5} 5$ & $\begin{array}{l}7.90 \\
8.00\end{array}$ & $\begin{array}{c}\text { RPDM97 } \\
\text { CMKAS00 } \\
\text { EBW04 } \\
\text { CGSB09 }\end{array}$ \\
\hline H 1-60 & 0.114 & $\begin{array}{l}0.098 \\
0.117\end{array}$ & 8.02 & $\begin{array}{c}- \\
7.46\end{array}$ & 6.66 & $\begin{array}{l}6.93 \\
6.50\end{array}$ & 8.45 & $\begin{array}{l}8.56 \\
8.58\end{array}$ & 6.00 & $\begin{array}{l}6.41 \\
6.13\end{array}$ & 7.80 & $\begin{array}{c}7.90 \\
-\end{array}$ & $\begin{array}{l}\text { RPDM97 } \\
\text { CGSB09 }\end{array}$ \\
\hline H $2-1$ & 0.059 & $\begin{array}{l}0.038 \\
0.041\end{array}$ & 7.00 & $\begin{array}{l}6.73 \\
7.16\end{array}$ & 5.79 & $\begin{array}{l}6.06 \\
5.97\end{array}$ & 7.92 & $\begin{array}{l}7.71 \\
7.76\end{array}$ & 6.52 & $\begin{array}{l}5.35 \\
5.42\end{array}$ & 7.08 & $\begin{array}{l}- \\
-\end{array}$ & $\begin{array}{c}\text { PMS04 } \\
\text { CGSB09 }\end{array}$ \\
\hline H 2-10 & 0.090 & $\begin{array}{l}0.089 \\
0.103\end{array}$ & 7.72 & $\begin{array}{l}7.87 \\
7.80\end{array}$ & 6.42 & $\begin{array}{l}6.74 \\
6.62\end{array}$ & 8.24 & $\begin{array}{l}8.62 \\
8.54\end{array}$ & 5.76 & $\begin{array}{l}5.78 \\
5.84\end{array}$ & 7.79 & $\begin{array}{l}- \\
-\end{array}$ & $\begin{array}{c}\text { CMKAS00 } \\
\text { CGSB09 }\end{array}$ \\
\hline H 2-45 & 0.096 & 0.103 & 7.40 & 7.85 & 6.28 & 6.53 & 8.27 & 8.39 & 5.62 & 5.84 & 7.57 & - & CGSB09 \\
\hline Hf $2-1$ & 0.127 & 0.135 & 8.66 & 8.71 & 7.02 & 7.19 & 8.83 & 8.73 & 6.88 & 6.53 & 8.10 & - & CGSB09 \\
\hline IC4699 & 0.079 & $\begin{array}{l}0.098 \\
0.101\end{array}$ & - & $\begin{array}{l}7.34 \\
7.69\end{array}$ & 6.15 & $\begin{array}{l}6.34 \\
6.49\end{array}$ & 8.50 & $\begin{array}{l}8.49 \\
8.50\end{array}$ & 5.62 & $\begin{array}{l}6.28 \\
6.37\end{array}$ & 7.78 & $\begin{array}{l}7.79 \\
7.81\end{array}$ & $\begin{array}{c}\text { WL07 } \\
\text { CGSB09 }\end{array}$ \\
\hline M 1-39 & 0.089 & 0.067 & 8.21 & 8.22 & 7.03 & 7.02 & 8.70 & 8.61 & 7.38 & 6.45 & - & - & CGSB09 \\
\hline M 1-45 & 0.017 & $\begin{array}{c}- \\
0.112\end{array}$ & 8.23 & $\begin{array}{l}8.41 \\
8.30\end{array}$ & 6.85 & $\begin{array}{l}6.82 \\
6.96\end{array}$ & 8.49 & $\begin{array}{l}8.68 \\
8.73\end{array}$ & 6.89 & $\begin{array}{l}- \\
-\end{array}$ & - & - & $\begin{array}{c}\text { CAK96 } \\
\text { RPDM97 }\end{array}$ \\
\hline M 1-46 & 0.104 & 0.080 & 7.75 & 7.95 & 6.26 & 7.13 & 8.97 & 8.87 & 8.15 & 6.53 & 7.62 & - & GKA07 \\
\hline M 1-47 & 0.096 & 0.112 & - & 8.15 & 6.34 & - & 8.47 & 8.51 & 5.73 & 5.85 & 7.76 & - & CAK96 \\
\hline M 1-60 & 0.127 & $\begin{array}{l}0.117 \\
0.117\end{array}$ & 8.50 & $\begin{array}{l}8.73 \\
8.96\end{array}$ & 6.86 & $\begin{array}{c}7.4 \\
7.21\end{array}$ & 8.52 & $\begin{array}{l}9.06 \\
8.78\end{array}$ & 6.38 & $\begin{array}{l}6.74 \\
6.67\end{array}$ & 8.00 & $\begin{array}{c}- \\
8.22\end{array}$ & $\begin{array}{l}\text { CAK96 } \\
\text { GKA07 }\end{array}$ \\
\hline M 2-21 & 0.110 & $\begin{array}{l}0.120 \\
0.119\end{array}$ & 7.55 & $\begin{array}{l}7.95 \\
7.75\end{array}$ & 6.78 & $\begin{array}{c}- \\
6.30\end{array}$ & 8.47 & $\begin{array}{l}8.49 \\
8.41\end{array}$ & 5.92 & $\begin{array}{c}- \\
5.83\end{array}$ & 7.38 & $\begin{array}{l}7.77 \\
7.69\end{array}$ & $\begin{array}{c}\text { P91 } \\
\text { CGSB09 }\end{array}$ \\
\hline M 2-22 & 0.147 & $\begin{array}{l}0.140 \\
0.148 \\
0.166\end{array}$ & 8.95 & $\begin{array}{l}8.48 \\
8.45 \\
8.67\end{array}$ & 6.75 & $\begin{array}{c}- \\
7.03 \\
6.97\end{array}$ & 8.27 & $\begin{array}{l}8.53 \\
8.59 \\
8.63\end{array}$ & 6.37 & $\begin{array}{c}- \\
6.66 \\
6.56\end{array}$ & 7.84 & $\begin{array}{c}- \\
8.30 \\
-\end{array}$ & $\begin{array}{c}\text { P91 } \\
\text { RPDM97 } \\
\text { CGSB09 }\end{array}$ \\
\hline M 3-23 & 0.118 & $\begin{array}{l}0.122 \\
0.125\end{array}$ & 8.27 & $\begin{array}{c}- \\
8.50\end{array}$ & 6.99 & $\begin{array}{c}- \\
7.11\end{array}$ & 8.79 & $\begin{array}{l}8.64 \\
8.63\end{array}$ & 6.76 & $\begin{array}{c}- \\
6.54\end{array}$ & 8.14 & $\begin{array}{l}7.92 \\
7.95\end{array}$ & $\begin{array}{c}\text { EBW04 } \\
\text { CGSB09 }\end{array}$ \\
\hline M 3-24 & 0.149 & 0.165 & 8.22 & 8.34 & 6.74 & 6.73 & 8.48 & 8.51 & 6.45 & 6.41 & 7.96 & 8.01 & CGSB09 \\
\hline M 3-29 & 0.088 & $\begin{array}{l}0.100 \\
0.101\end{array}$ & 7.56 & $\begin{array}{l}7.98 \\
8.07\end{array}$ & 6.22 & $\begin{array}{l}6.70 \\
6.70\end{array}$ & 8.45 & $\begin{array}{l}8.51 \\
8.51\end{array}$ & 6.24 & $\begin{array}{l}5.89 \\
6.00\end{array}$ & 8.08 & $\begin{array}{l}7.85 \\
7.88\end{array}$ & $\begin{array}{c}\text { WL07 } \\
\text { CGSB09 }\end{array}$ \\
\hline Pe $2-13$ & 0.145 & 0.156 & 7.80 & - & 7.00 & - & 8.40 & 8.67 & 6.59 & 6.55 & 7.58 & - & CGSB09 \\
\hline $\mathrm{Vd} 1-8$ & 0.099 & 0.115 & 7.70 & 7.90 & 6.23 & 6.56 & 8.13 & 8.41 & 5.80 & 6.21 & 7.44 & - & CGSB09 \\
\hline
\end{tabular}

excitation lines and optical recombination lines, by solving level populations of the emitting ions. The ICFs are the same as adopted in Wesson, Liu, \& Barlow (2005), which for S and Ne are the same as used in this work.
In order to verify the dispersion of the results, we computed the difference between the abundances obtained in this work and those from the literature. The helium abundances from this work differ of the abundances from the literature by 0.01 , which is 


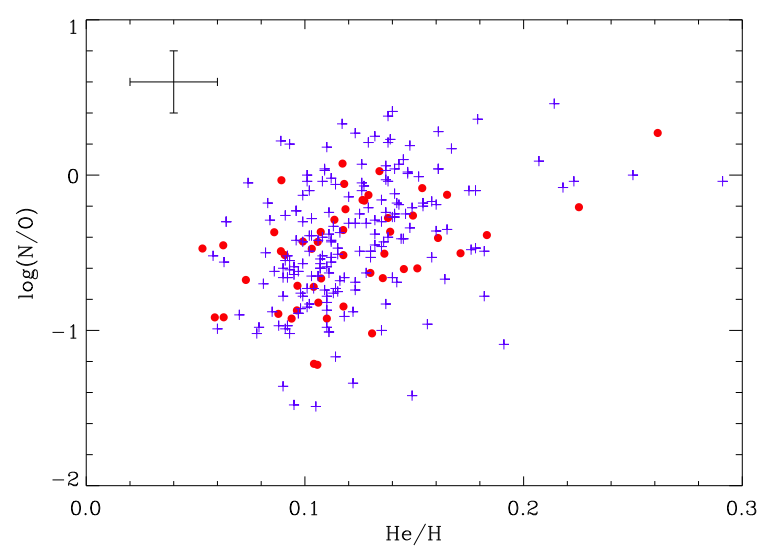

Fig. 12. $\log (\mathrm{N} / \mathrm{O})$ as a function of $\mathrm{He} / \mathrm{H}$. Crosses are data from the literature and filled circles are our data. The error bar at the upper left corner indicates the mean errors for the abundances.

lower than our error estimate for the helium abundances of this work. For the other elements, the differences are $0.16,0.21,0.14,0.24$, and 0.21 dex, for $\mathrm{N}, \mathrm{S}, \mathrm{O}, \mathrm{Ar}$, and Ne, respectively. These differences are similar to the errors estimated for these abundances, and are the result of the differences between the methods employed to obtain the chemical abundances, such as ICFs, as well as of the errors associated to different observation and reduction processes. In particular, we can compare our data with those from CGSB09 directly, since there are enough objects in common between the two samples. Figures 10 and 11 show a comparison between abundances from this work and CGSB09 for helium. Abundances from CGBS09 display a systematic tendency to higher values compared to our data. Nonetheless, the difference is not larger than the expected errors for the abundances.

\subsection{Abundance correlations}

Correlations between the chemical abundances for the different elements are an important tool to understand the evolution of the central stars of PN (CSPN). In particular, the correlations between elements not produced by the progenitor stars give important information about the nucleosynthesis of massive stars and the formation and evolution of the Galaxy, as described by Ballero et al. (2007).

In Figure 12 we show the correlation between $\log (\mathrm{N} / \mathrm{O})$ and $\mathrm{He} / \mathrm{H}$ for our data and for the works previously mentioned. As discussed earlier, helium and nitrogen abundances are modified during the evolution of the progenitor star, and $\mathrm{PNe}$ with high abundances of helium and nitrogen are originated

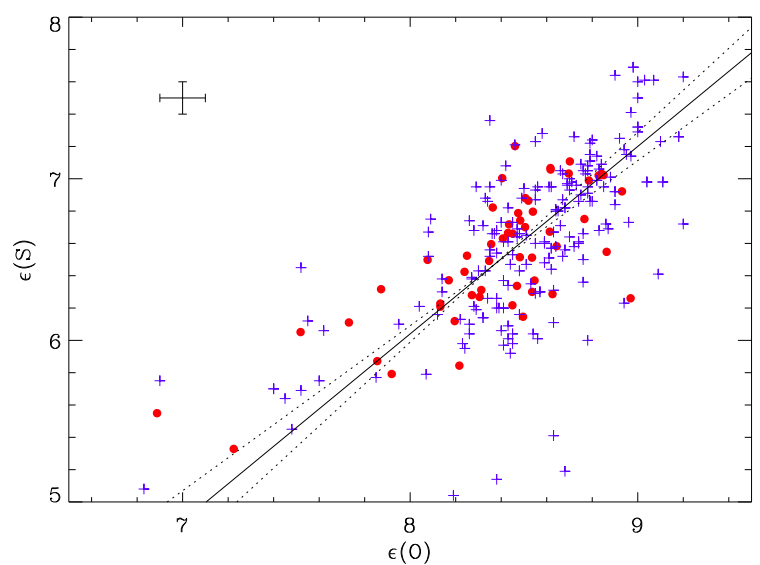

Fig. 13. Correlation between sulfur and oxygen abundances from our results (filled circles) and from the literature (crosses). Mean errors are shown at the upper left corner. The continuous line is a linear bisector fit to the data, while dashed lines are the one-sigma confidence levels obtained from the uncertainties in the fit parameters.

from massive stars, so that the correlation between these elements must be positive. From Figure 12 it can be seen that the correlation between $\log (\mathrm{N} / \mathrm{O})$ and helium is positive, although there is no tight correlation between these quantities. Indeed, excluding helium abundances lower than 0.050, which are not realistic and probably indicate the presence of neutral helium in these nebulae, the linear Pearson correlation coefficient of our data is 0.47 , showing a small correlation. The whole sample, which consists of literature and our data, shows a correlation coefficient $23 \%$ lower compared with our data. It is important to note that both ours and literature data show a large spread in this correlation, which is probably related to distinct efficiencies in the mixing episodes occurring along the evolution for stars with different masses. It is expected that nitrogen enhancement would not be high in non-type I PNe, which represent $80 \%$ of the $\mathrm{PNe}$ population in the Galaxy (Peimbert \& Serrano 1980). In Figure 12 it is possible to see that most objects show a low $\mathrm{N} / \mathrm{O}$ ratio, except for a small number of $\mathrm{PNe}$ with a $\log (\mathrm{N} / \mathrm{O})$ ratio close to 0.5 . These $\mathrm{PNe}$ could have originated from massive stars, pointing to recent star formation. Cuisinier et al. (2000) showed that bulge $\mathrm{PNe}$ have lower $\mathrm{N} / \mathrm{O}$ ratio compared with disk PNe. Therefore, those $\mathrm{PNe}$ with high $\mathrm{N} / \mathrm{O}$ ratio could be located in the transition between the disk and the bulge.

Figures 13, 14, and 15 show the correlations between S, Ar and Ne with O. The symbols are as 


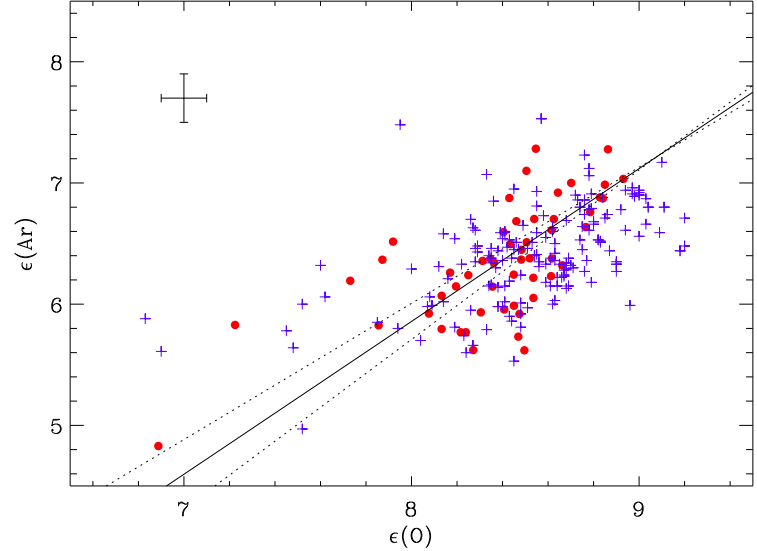

Fig. 14. The same as Figure 13 for argon and oxygen.

in Figure 12. Since these elements are produced by the same process and their abundances do not change significantly in IMS, a positive correlation is expected between the sulfur, argon, neon and oxygen abundances in PNe. In these figures positive correlations are observed, with linear correlation coefficients of $0.60,0.68$, and 0.78 for sulfur, argon, and neon, respectively. These correlations indicate a medium to large correlation. Concerning our data and excluding the helium abundances lower than 0.050 since they are not realistic, as discussed before, the slope and the $y$-intercept of a bisector method for the correlation between sulfur, argon, and neon with oxygen are, in this order, $1.2 \pm 0.2$ and $(-0.3 \pm 0.1) \times 10,1.3 \pm 0.2$ and $(-0.4 \pm 0.1) \times 10$, $0.9 \pm 0.1$ and $(-0.0 \pm 0.1) \times 10$. These slopes differ from the whole sample by $-4 \%, 20 \%$, and $-15 \%$ for sulfur, argon, and neon, respectively. From these results we can see that a linear correlation between the $\alpha$-elements with oxygen with a slope close to unity is a good approximation. The linear correlations between $\alpha$-elements and oxygen found throughout this section suggest that these elements are in lockstep in $\mathrm{PNe}$, so that modifications (if any) during the evolution of the progenitor star are small. Again, there is a generally good agreement between our new abundances and those from the literature.

\section{SUMMARY AND CONCLUSION}

In summary, this work reports an important result concerning $\mathrm{PNe}$ and the chemical evolution of the Galaxy.

We present the analysis of the chemical abundances of a PNe sample located towards the Galactic bulge. New chemical abundances were derived through spectrophotometric observations made at

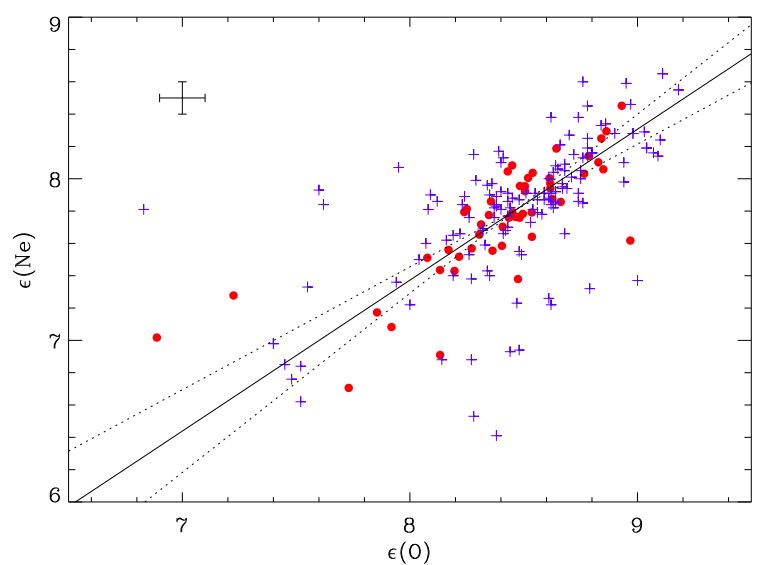

Fig. 15. The same as Figure 13 for neon and oxygen.

the $1.60 \mathrm{~m}$ telescope of the LNA-Brazil, comprising the elements $\mathrm{He}, \mathrm{N}, \mathrm{S}, \mathrm{O}, \mathrm{Ar}$, and Ne. $54 \mathrm{PNe}$ were considered; for 33 objects abundances were derived here for the first time. A comparison between the chemical abundances from this work and abundances obtained from the literature was performed. The analysis shows that the distributions of abundances are similar but not identical. Some objects of this work are listed in other investigations and a direct comparison between these abundances shows that the differences are of the order of 0.2 dex, indicating that the distinct methods used to derive the abundances are the main source of this difference. With the present results, we intend to enlarge the number of planetary nebulae with accurate chemical abundances, providing a large and homogeneous set of chemical abundances, and contributing to the understanding of this stage of star evolution as well as the study of the chemical evolution of the inner Galaxy.

Part of this work was supported by the Brazilian agencies FAPESP and CNPq. O.C. would like to acknowledge FAPESP for his graduate fellowship (processes 05/03194-4 and 07/07704-2).

\section{REFERENCES}

Acker, A., Marcout, J., Ochsenbein, F., Stenholm, B., \& Tylenda, R. 1992, Strasbourg-ESO Catalogue of Galactic Planetary Nebulae (Part 1 and 2; Garching: ESO)

Alexander, J., \& Balick, B. 1997, AJ, 114, 713

Aller, L. H. 1984, Physics of Thermal Gaseous Nebulae (Astrophysics and Space Science Library, vol. 112; Reidel, Dordrecht)

Andrievsky, S. M., Luck, R. E., Martin, P., \& Lépine, J. R. D. 2004, A\&A, 413, 159 
Ballero, S. K., Matteucci, F., Origlia, L., \& Rich, R. M. 2007, A\&A, 467, 123

Cahn, J. H., Kaler, J. B., \& Stanghellini, L. 1992, A\&AS, 94, 399

Carigi, L., Peimbert, M., Esteban, C., \& García-Rojas, J. 2005, ApJ, 623, 213

Cardelli, J. A., Clayton, G. C., \& Mathis, J. S. 1989, ApJ, 345, 245

Chiappini, C., Górny, S., Stasińska, G., \& Barbuy, B. 2009, A\&A, 494, 591 (CGSB09)

Chiappini, C., Matteucci, F., \& Romano, D. 2001, ApJ, 554,1044

Costa, R. D. D., Chiappini, C., Maciel, W. J., \& de Freitas Pacheco, J. A. 1996, A\&AS, 116, 249

Costa, R. D. D., de Freitas Pacheco, J. A., \& Idiart, T. P. 2000, A\&AS, 145, 467

Costa, R. D. D., Escudero, A. V., \& Maciel, W. J. 2005, in AIP Conf. Proc. 804, Planetary Nebulae as Astronomical Tools, ed. R. Szczerba, G. Stasińska, \& S. K. Górny (Melville: AIP), 252

Costa, R. D. D., \& Maciel, W. J. 2006, in IAU Symp. 234, Planetary Nebulae in our Galaxy and Beyond, ed. M. J. Barlow \& R. H. Méndez (Cambridge: Cambridge Univ. Press), 243

Costa, R. D. D., Maciel, W. J., \& Escudero, A. V. 2008, Baltic Astron., 17, 321

Cuisinier, F., Acker, A., \& Köppen, J. 1996, A\&A, 307, 215 (CAK96)

Cuisinier, F., Maciel, W. J., Köppen, J., Acker, A., \& Stenholm, B. 2000, A\&A, 353, 543 (CMKAS00)

Daflon, S., \& Cunha, K. 2004, ApJ, 617, 1115

de Freitas-Pacheco, J. A., Barbuy, B., Costa, R. D. D., \& Idiart, T. E. P. 1993, A\&A, 271, 429

Escudero, A. V., \& Costa, R. D. D. 2001, A\&A, 380, 300

Escudero, A. V., Costa, R. D. D., \& Maciel, W. J. 2004, A\&A, 414, 211 (ECM04)

Exter, K. M., Barlow, M. J., \& Walton, N. A. 2004, MNRAS, 349, 1291 (EBW04)

Fitzpatrick, E. L. 1999, PASP, 111, 63

Girard, P., Köppen, J., \& Acker, A. 2007, A\&A, 463, 265 (GKA07)

Górny, S. K., Stasińska, G., Escudero, A. V., \& Costa, R. D. D. 2004, A\&A, 427, 231 (GSEC04)
Gorny, S. K., Chiappini, C., Stasińska, G., \& Cuisinier, F. 2009, A\&A, 500, 1089

Gutenkunst, S., Bernard-Salas, J., Pottasch, S. R., Sloan, G. C., \& Houck, J. R. 2008, ApJ, 680, 1206

Kingdon, J., \& Ferland, G. J. 1995, ApJ, 442, 714

Kingsburgh, R. L., \& Barlow, M. J. 1994, MNRAS, 271, 257

Lattanzio, J.,\& Forestini, M. 1999, in IAU Symp. 191, Asymptotic Giant Branch Stars, ed. T. Le Bertre, A. Lèbre, \& C. Waelkens, (San Francisco: ASP), 31

Lecureur, A., et al. 2007, A\&A, 465, 799

Maciel, W. J., Lago, L. G., \& Costa, R. D. D. 2005, A\&A, 433,127 2006, A\&A, 453, 587

Maciel, W. J., \& Pottasch, S. R. 1980, A\&A, 88, 1

Maciel, W. J., \& Quireza, C. 1999, A\&A, 345, 629

Mathis, J. S. 1990, ARA\&A, 28, 37

Peimbert, M., \& Serrano, A. 1980, RevMexAA, 5, 9

Pequignot, D., Petitjean, P., \& Boisson, C. 1991, A\&A, 251, 680

Perinotto, M. 1991, ApJS, 76, 687 (P91)

Perinotto, M., \& Morbidelli, L. 2006, MNRAS, 372, 45

Perinotto, M., Morbidelli, L., \& Scatarzi, A. 2004, MNRAS, 349, 793 (PMS04)

Ratag, M. A., Pottasch, S. R., Dennefeld, M., \& Menzies, J. W. 1992, A\&A, 255, 255 1997, A\&AS, 126, 297 (RPDM97)

Rich, R. M. 1988, AJ, 95, 828

Rich, R. M., \& Origlia, L. 2005, ApJ, 634, 1293

Stanghellini, L., Shaw, R. A., \& Villaver, E. 2008, ApJ, 689,194

Stasińska, G., Richer, M. G., \& McCall, M. L. 1998, A\&A, 336, 667

Torres-Peimbert, S., \& Peimbert, M. 1977, RevMexAA, 2,181

van Loon, J. T., et al. 2003, MNRAS, 338, 857

Wang, W., \& Liu, X.-W. 2007, MNRAS, 381, 669 (WL07)

Weiland, J. L., et al. 1994, ApJ, 425, L81

Wesson, R., Liu, X.-W., \& Barlow, M. J. 2005, MNRAS, 362,424

Zoccali, M., et al. 2006, A\&A, 457, L1

Zoccali, M., et al. 2003, A\&A, 399, 931

O. Cavichia, R. D. D. Costa, and W. J. Maciel: Departamento de Astronomia, Instituto de Astronomia, Geofísica e Ciências Atmosféricas, Universidade de São Paulo, Rua do Matão, 1226, Cidade Universitária, 05508-900 São Paulo-SP, Brazil (cavichia, roberto, maciel@astro.iag.usp.br). 


\title{
PLANETARY NEBULAE IN THE INNER MILKY WAY II: THE BULGE-DISK TRANSITION
}

\author{
O. Cavichia, R. D. D. Costa, and W. J. Maciel \\ Instituto de Astronomia, Geofísica e Ciências Atmosféricas \\ Universidade de São Paulo, Brazil
}

Received 2010 November 29; accepted 2011 January 14

\section{RESUMEN}

En este trabajo se usa una muestra de nebulosas planetarias localizadas en el disco interno y en el bulbo de la Galaxia con objeto de encontrar la distancia galactocéntrica que mejor separa estas dos poblaciones desde el punto de vista de las abundancias. Se utilizan escalas de distancias estadísticas para estudiar la distribución de abundancias en la interfase disco-bulbo. Mediante una prueba de Kolmogorov-Smirnov se encuentra la distancia a la cual las propiedades químicas de estas regiones mejor se separan.

El resultado del análisis estadístico indica que, en promedio, la población interior tiene menores abundancias que la exterior. Además, la población interior no sigue el gradiente radial del disco hacia el centro galáctico. Basados en nuestros resultados, sugerimos que la interfase disco-bulbo está situada a $1.5 \mathrm{kpc}$ del centro, y marca la transición entre la población del bulbo y la del disco interno, definida como la población de masas intermedias.

\begin{abstract}
In this work, a sample of planetary nebulae located in the inner-disk and bulge of the Galaxy is used in order to find the galactocentric distance which better separates these two populations, from the point of view of abundances. Statistical distance scales are used to study the distribution of abundances across the diskbulge interface. A Kolmogorov-Smirnov test is used to find the distance at which the chemical properties of these regions better separate.

The results of the statistical analysis indicate that, on the average, the inner population has lower abundances than the outer. Additionally, for the $\alpha$-element abundances, the inner population does not follow the disk radial gradient towards the galactic center. Based on our results, we suggest a bulge-disk interface at $1.5 \mathrm{kpc}$, marking the transition between the bulge and inner-disk of the Galaxy as defined by the intermediate mass population.
\end{abstract}

Key Words: Galaxy: abundances — Galaxy: evolution — planetary nebulae: general — techniques: spectroscopic

\section{INTRODUCTION}

Chemical abundances of Planetary Nebulae $(\mathrm{PNe})$ are an important tool to investigate the chemical evolution of the Galaxy. As a final stage of evolution of low and intermediate-mass stars $\left(\sim 1-8 M_{\odot}\right)$, the abundances of $\alpha$-elements found in PNe usually are not modified by the evolution of the progenitor star. In this sense, chemical abundances of PNe can be used to study the chemical evolution of galaxies as done by Maciel, Lago, \& Costa (2005, 2006), Fu et al. (2009), Stanghellini \& Haywood (2010).

The chemical abundances obtained from PNe are relatively accurate and the nebulae can be observed at large distances in the Galaxy, even in regions obscured by the dust in the galactic disk, since they have bright emission lines, such as [O III] $\lambda 500.7 \mathrm{~nm}$ and $\mathrm{H} \alpha$. Therefore PNe are useful to study the pattern of abundances in the inner-disk and bulge of the 
Galaxy, where the extinction in the optical range is very severe (see for example Escudero \& Costa 2001; Escudero, Costa, \& Maciel 2004; Chiappini et al. 2009; Cavichia, Costa, \& Maciel 2010). On the other hand, PNe distances are still subject to discussion. Only in a few cases can the distances be determined by a direct method, such as for nearby PNe, which have the distances determined by trigonometric parallax, or in cases where there is a main sequence binary companion. In the cases were accurate individual distances cannot be determined, alternative methods have been developed in order to obtain reliable distances. In these cases, distances are derived from nebular properties (see e.g., Maciel \& Pottasch 1980; Cahn, Kaler, \& Stanghellini 1992; Stanghellini, Shaw, \& Villaver 2008). These methods are called statistical methods and the distances so obtained are called statistical distances. In spite of the uncertainties, statistical distance scales are still the best tool to study the chemical abundance patterns in the Galaxy from the point of view of PNe, as done by Maciel \& Quireza (1999), Maciel et al. (2006), Perinotto \& Morbidelli (2006), and recently by Gutenkunst et al. (2008), Stanghellini \& Haywood (2010), Henry et al. (2010).

From the point of view of the chemical evolution of the Galaxy, the bulge and the disk display different chemical abundance patterns such as the radial abundance gradients in the disk (Carigi et al. 2005; Daflon \& Cunha 2004; Andrievsky et al. 2004; Maciel et al. 2005, 2006), or the wide abundance distribution in the bulge (Rich 1988; Zoccali et al. 2003, 2006). Also, the bulge and the disk may have different evolution histories, as described for example by the multiple infall scenario (Costa, Escudero, \& Maciel 2005; Costa, Maciel, \& Escudero 2008) or by the inside out formation model (Chiappini, Matteucci, \& Romano 2001), respectively. As a consequence, we expect these differences to be reflected on the chemical properties of each component.

Additionally, the gas density, and consequently the star formation rate (SFR), also decrease in the inner Galaxy as found by Portinari \& Chiosi (1999). They attribute this result to the influence of the galactic bar in the first $3 \mathrm{kpc}$ of the Galaxy (see for example Gerhard 2002; Binney 2009). The decrease of the SFR is reflected on the $\alpha$-element abundances in PNe, since a lower SFR limits the total mass ejected by the progenitor star, and consequently the chemical enrichment of the ISM decreases throughout the succeeding stellar generations. The galactic evolution models also point to a severe decrease in the SFR and chemical abundances at radii smaller than 3 kpc (Portinari \& Chiosi 2000). Other chemical evolution models also predict a flatter abundance gradient in the inner-disk, such as those by Hou, Prantzos, \& Boissier (2000) and Mollá \& Díaz (2005).

Some recent work seems to support this scenario, based on the fact that towards the galactic center, stars do not follow the chemical abundance gradient found in the disk (Cunha et al. 2007). Davies et al. (2009) studying the chemical abundance patterns of the Scutum red supergiant clusters, located at the end of the galactic bar, find that there is a minimum in the abundances in this region, compared to other azimuthal angles.

From the point of view of $\mathrm{PNe}$, the results of Gutenkunst et al. (2008) also point to a discontinuity in the abundance gradient towards the galactic center, in the sense that the abundances of bulge PNe do not follow the trend of those from the disk, as can be seen in their Figure 4. Górny et al. (2004) also notice that the oxygen gradient of the PNe population in the galactic disk flattens in the most internal parts of the Galaxy, and may even change sign. On the other hand, Chiappini et al. (2009) compared the abundances of PNe located in the bulge, inner-disk and Large Magellanic Cloud. Their results do not show any clear difference between bulge and inner-disk objects.

Other previous studies of the galactic bulge based on abundances of PNe such as Ratag et al. (1992), Cuisinier et al. (2000), Escudero \& Costa (2001), Escudero et al. (2004), Exter, Barlow, \& Walton (2004), find that bulge PNe have an abundance distribution similar to disk $\mathrm{PNe}$, showing that $\mathrm{He}, \mathrm{O}, \mathrm{Si}$, Ar, and Ca have a normal abundance pattern, and favoring therefore a slower galactic evolution than that indicated by stars. In conclusion, the distribution of chemical abundances in the inner region of the Galaxy is still an open question, especially regarding the bulge-disk connection. On the other hand, a detailed comparison of the bulge and inner-disk populations is important in order to characterize the galactic bulge as a "pseudobulge", as suggested by photometric and kinematic evidences (Howard et al. 2009; Shen et al. 2010), in opposition to a classical bulge as suggested by Binney (2009).

Both from modelling and from observational results, we expect a galactocentric distance to exist which better separates the populations of the bulge and inner-disk from the point of view of chemical abundances. However, such transition is still to be determined from the point of view of chemical abundances. The goal of this paper is to perform a 
statistical analysis using the new data provided by Cavichia et al. (2010, hereafter Paper I), and additional data from the literature, in order to characterize the interface between the bulge and inner-disk of the Galaxy, as defined by the PNe population. Taking into account both the abundance distributions and the individual distances for a sample of $\mathrm{PNe}$, we are able to characterize the interface by establishing at which galactocentric distance bulge and disk characteristics better separate.

This paper is organized as follows: in $\S 2$ the details of the sample and the new distances to our objects are presented. In $\S 3$ the method used in order to characterize the bulge-disk transition is described. In $\S 4$ we discuss the results and compare them with other results in the literature. Finally, in $\S 5$ the main conclusions are presented.

\section{THE SAMPLE AND NEW DISTANCES}

\subsection{The Sample}

An extensive number of statistical scales have been proposed in the literature, and two of them have been adopted in order to study the chemical abundance distribution in the inner Galaxy: the Stanghellini et al. (2008, hereafter SSV08), and the Zhang (1995, hereafter Z95), distance scales. These scales are based on the Shklovsky method but with the introduction of a relationship between the ionized mass and the radius of the nebula, as proposed by Maciel \& Pottasch (1980). SSV08 is a recent revision of the Cahn et al. (1992, hereafter CKS92), scale based on the physical properties of the $\mathrm{PNe}$ in the Magellanic Clouds, whose distances are accurately known. As the authors argue, this new distance scale is the most reliable to date.

The selection criteria applied to search for objects in the two catalogues (SSV08 and Z95) were the following: we selected those PNe which had $5 \mathrm{GHz}$ fluxes lower than $100 \mathrm{mJy}$, optical diameters smaller than 12 arcsec, and galactic coordinates within the range $|\ell| \leq 10^{\circ}$ and $|b| \leq 10^{\circ}$. The galactic coordinates were used to take into account only the $\mathrm{PNe}$ which are in the galactic center direction. The combination of the other two criteria leads to the rejection of about $90-95 \%$ of the $\mathrm{PNe}$ which are in the galactic center direction, but have heliocentric distances of less than 4 kpc (cf. Stasińska, Richer, \& McCall 1998). These criteria are commonly used by other authors to select bulge PNe (e.g., Exter et al. 2004 and Chiappini et al. 2009), so that most of the objects considered in this work should be at or near the bulge.
In order to study the chemical abundance distribution in the inner Galaxy, we have made use of the data published by our group (Cavichia et al. 2010; Escudero et al. 2004; Escudero \& Costa 2001). We also searched for chemical abundances of PNe located in the bulge and inner-disk of the Galaxy in the following works: Ratag et al. (1997), Exter et al. (2004), Górny et al. (2004), Perinotto, Morbidelli, \& Scatarzi (2004), de Freitas Pacheco, Maciel, \& Costa (1992), Köppen, Acker, \& Stenholm (1991), Samland et al. (1992), Cuisinier et al. (2000). All these works deal with the same region of interest, and, besides that, they contain significant and homogeneous samples, which is very important in multi-object study, as we propose in this work. For more details on these works see Paper I. Adding these objects to our original sample in Paper I, our database contains 140 objects, as given in Table 1 . In this table, the columns give the PN G number, the name of the nebula, the galactocentric distance in kpc for the SSV08 and the Z95 distance scales, respectively. An asterisk marks those PNe whose distances were derived in the present work. The galactocentric distances of the objects located beyond the galactic bulge are given with a negative sign in Table 1 . The extinction in this region is very high, and the uncertainties in the distances are large, reaching $30 \%$ in some cases. For example, an object with a heliocentric distance of $8 \mathrm{kpc}$ in this direction according to both scales will have a true heliocentric distance between 5.6 and 10.4. Therefore, it is unlikely that these objects are really located far beyond the galactic bulge, so that we assume that they actually belong to the bulge population. The implications of this assumption will be further discussed in $\S 3.3$. More details on the new distances and the determination of the galactocentric distances are given in $\S 2.2$.

\subsection{New distances to the Planetary Nebulae}

Several of the objects for which the chemical abundances were determined in Paper I, do not have distances published by SSV08. In order to include these PNe in our analysis, their distances were estimated from equations (8a) and (8b) of SSV08. In cases where the $5 \mathrm{GHz}$ flux was not available, their equivalent $5 \mathrm{GHz}$ flux from $\mathrm{H} \beta$ flux was derived using equation (6) in CKS92. The optical thickness parameter was derived from equation (2) in SSV08. Angular radii were obtained from the literature, most of them from Acker et al. (1992), and some from more recent works such as Tylenda et al. (2003) and Ruffle et al. (2004). The objects with new distances are marked with an asterisk in Table 1, and the data 
TABLE 1

GALACTOCENTRIC DISTANCES OF PNE IN THE SAMPLE

\begin{tabular}{|c|c|c|c|c|c|c|c|}
\hline $\mathrm{PN} G$ & Name & $R_{S S V 08}(\mathrm{kpc})$ & $R_{Z 95}(\mathrm{kpc})$ & $\mathrm{PN} \mathrm{G}$ & Name & $R_{S S V 08}(\mathrm{kpc})$ & $R_{Z 95}(\mathrm{kpc})$ \\
\hline $000.1-01.1$ & M3-43 & - & 1.81 & $009.4-09.8$ & M3-32 & 1.85 & 1.57 \\
\hline $000.2-01.9$ & M2-19 & -0.30 & 0.63 & $009.6-10.6$ & M3-33 & -1.45 & - \\
\hline $000.3-04.6$ & M2-28 & - & -0.70 & $009.8-04.6$ & H1-67 & 0.64 & 0.80 \\
\hline $000.4-02.9$ & M3-19 & 0.31 & -0.73 & $010.4+04.5$ & M2-17 & - & 0.85 \\
\hline $000.7-02.7$ & M2-21 & -2.20 & - & $010.7-06.4$ & IC4732 & 1.51 & 3.22 \\
\hline $000.7-03.7$ & M3-22 & 0.50 & -0.63 & $010.7-06.7$ & Pe1-13 & -1.37 & - \\
\hline $000.7+03.2$ & Hen $2-250$ & - & 1.07 & $010.7+07.4^{*}$ & $\mathrm{Sa} 2-230$ & 1.41 & - \\
\hline $000.9-04.8$ & M3-23 & 3.78 & 3.45 & $010.8-01.8$ & NGC 6578 & 4.42 & - \\
\hline $001.0+01.9$ & $\mathrm{~K} 1-4$ & 6.06 & - & $011.0+05.8$ & NGC 6439 & 1.89 & - \\
\hline $001.2-03.0$ & H1-47 & - & -2.07 & $350.5-05.0^{*}$ & H1-28 & -1.93 & - \\
\hline $001.2+02.1$ & Hen 2-262 & -1.57 & 1.39 & $350.9+04.4$ & $\mathrm{H} 2-1$ & 2.45 & - \\
\hline $001.4+05.3$ & H1-15 & -1.29 & 0.73 & $351.1+04.8$ & M1-19 & -2.75 & 0.71 \\
\hline $001.7-04.6$ & H1-56 & - & -3.06 & $351.2+05.2$ & M2-5 & - & 0.80 \\
\hline $001.7+05.7$ & H1-14 & 1.73 & 2.24 & $351.6-06.2^{*}$ & H1-37 & -1.81 & - \\
\hline $002.0-02.0^{*}$ & $\mathrm{H} 1-45$ & -7.12 & -0.36 & $352.0-04.6$ & H1-30 & - & 2.88 \\
\hline $002.0-06.2$ & M2-33 & -1.09 & -1.02 & $352.1+05.1$ & M2-8 & -1.39 & 1.05 \\
\hline $002.1-02.2$ & M3-20 & 0.44 & 2.71 & $352.6+03.0$ & H1-8 & -0.91 & - \\
\hline $002.1-04.2$ & H1-54 & -4.39 & -0.57 & $353.7+06.3$ & M2-7 & 1.19 & -1.00 \\
\hline $002.2-02.7$ & M2-23 & 3.75 & -0.51 & $354.2+04.3$ & M2-10 & - & -2.73 \\
\hline $002.2-09.4$ & Cn1-5 & 2.83 & 3.70 & $355.1-02.9$ & H1-31 & - & -3.78 \\
\hline $002.4+05.8$ & NGC 6369 & 6.92 & - & $355.1-06.9$ & M3-21 & - & 2.55 \\
\hline $002.6-03.4$ & M1-37 & - & -0.62 & $355.4-02.4$ & M3-14 & 2.33 & 1.58 \\
\hline $002.6+08.1$ & H1-11 & 1.19 & 1.30 & $355.4-04.0$ & Hf2-1 & 1.92 & - \\
\hline $002.7-04.8$ & M1-42 & 2.53 & 3.15 & $355.7-03.0$ & H1-33 & -4.05 & -1.23 \\
\hline $002.7+01.6$ & $\mathrm{H} 2-20$ & - & 0.53 & $355.7-03.4^{*}$ & H1-35 & 2.15 & 2.03 \\
\hline $002.8-02.2$ & $\mathrm{Pe} 2-12$ & - & -4.12 & $355.9-04.2$ & M1-30 & - & 2.18 \\
\hline $003.1+02.9$ & $\mathrm{Hb} 4$ & 2.98 & - & $355.9+03.6^{*}$ & H1-9 & 2.19 & - \\
\hline $003.1+03.4$ & $\mathrm{H} 2-17$ & - & -0.98 & $356.2-04.4$ & Cn2-1 & -0.56 & 1.91 \\
\hline $003.2-06.1$ & M2-36 & 2.03 & 1.29 & $356.3-06.2^{*}$ & M3-49 & -5.33 & - \\
\hline $003.3-04.6$ & Ap1-12 & 3.42 & - & $356.5-02.3$ & M1-27 & 3.41 & 4.27 \\
\hline $003.4-04.8$ & H2-43 & - & 3.03 & $356.5-03.9$ & H1-39 & -7.28 & -2.08 \\
\hline $003.5-04.6$ & NGC 6565 & 3.37 & 3.68 & $356.7-04.8$ & H1-41 & 2.37 & 1.51 \\
\hline $003.6-02.3$ & M2-26 & -0.40 & -1.46 & $356.8-05.4^{*}$ & $\mathrm{H} 2-35$ & 1.86 & - \\
\hline $003.7-04.6$ & M2-30 & -1.55 & -0.68 & $356.9-05.8$ & M2-24 & -1.52 & -3.86 \\
\hline $003.8-04.3$ & H1-59 & -1.53 & -3.18 & $356.9+04.4$ & M3-38 & -6.07 & -0.65 \\
\hline $003.8-04.5$ & $\mathrm{H} 2-41$ & -0.85 & -6.23 & $356.9+04.5$ & M2-11 & - & 1.08 \\
\hline $003.8+05.3$ & H2-15 & -7.40 & -8.96 & $357.1-04.7$ & $\mathrm{H} 1-43$ & -5.33 & -3.59 \\
\hline $003.9-02.3$ & M1-35 & 1.93 & 3.38 & $357.1+03.6$ & M3-7 & 1.73 & 2.62 \\
\hline 004.0-03.0 & M2-29 & -0.75 & -2.01 & $357.2-04.5$ & H1-42 & 1.94 & 3.22 \\
\hline $004.0-05.8$ & Pe1-12 & 1.66 & -2.33 & $357.2+07.4$ & M4-3 & - & -0.37 \\
\hline $004.1-04.3$ & H1-60 & -2.24 & -0.82 & $357.3+03.3$ & M3-41 & - & 3.87 \\
\hline $004.6+06.0$ & H1-24 & - & 0.89 & $357.3+04.0$ & $\mathrm{H} 2-7$ & - & -1.32 \\
\hline $004.8-05.0$ & M3-26 & 0.82 & -0.82 & $357.4-03.2$ & M2-16 & 1.05 & 2.18 \\
\hline $004.8+02.0$ & $\mathrm{H} 2-25$ & -3.45 & -4.22 & $357.4-03.5$ & M2-18 & -7.74 & -1.48 \\
\hline $004.9+04.9$ & M1-25 & 1.50 & 3.11 & $357.4-04.6$ & M2-22 & -0.79 & -1.97 \\
\hline $005.0+04.4$ & $\mathrm{H} 1-27$ & 0.65 & -2.94 & $357.5+03.2$ & M3-42 & 1.17 & -1.78 \\
\hline $005.2+05.6$ & M3-12 & - & 1.24 & $357.6+01.7$ & H1-23 & -1.74 & 1.89 \\
\hline $005.5-02.5^{*}$ & M3-24 & 1.34 & - & $357.6+02.6$ & H1-18 & - & 0.72 \\
\hline $005.7-05.3$ & M2-38 & 1.24 & -1.01 & $357.9-05.1$ & M1-34 & - & 2.15 \\
\hline $005.8-06.1$ & NGC 6620 & -1.19 & 1.61 & $358.2+03.5$ & $\mathrm{H} 2-10$ & -5.35 & -0.50 \\
\hline $005.8+05.1$ & H2-16 & 2.81 & - & $358.2+03.6$ & M3-10 & -1.40 & 1.72 \\
\hline $006.0-03.6$ & M2-31 & - & 3.14 & $358.2+04.2$ & M3-8 & 0.96 & 0.78 \\
\hline $006.1+08.3^{*}$ & M1-20 & -1.12 & 2.34 & $358.3-02.5$ & M4-7 & 1.66 & 2.81 \\
\hline $006.4-04.6^{*}$ & $\mathrm{Pe} 2-13$ & 1.92 & - & $358.3+03.0^{*}$ & $\mathrm{H} 1-17$ & 0.42 & -0.59 \\
\hline $006.4+02.0$ & M1-31 & 2.94 & 4.10 & $358.5-04.2^{*}$ & H1-46 & -0.75 & 1.04 \\
\hline 006.8-03.4* & $\mathrm{H} 2-45$ & 1.89 & - & $358.6+01.8$ & M4-6 & - & 1.76 \\
\hline $006.8+04.1$ & M3-15 & - & 3.94 & $358.6+07.8$ & M3-36 & - & -6.05 \\
\hline $007.0-06.8$ & VY2-1 & 0.86 & 2.57 & $358.7-05.2 *$ & H1-50 & -3.03 & 0.79 \\
\hline $007.0+06.3^{*}$ & M1-24 & -1.00 & - & $358.8+03.0$ & Th3-26 & 0.66 & - \\
\hline $007.1-06.0$ & H1-66 & - & -1.70 & $358.9+03.2$ & H1-20 & 0.64 & 2.91 \\
\hline $007.2+01.8^{*}$ & Hb6 & 3.78 & - & $358.9+03.3^{*}$ & H1-19 & -2.95 & -0.51 \\
\hline $007.5+07.4$ & M1-22 & - & -4.02 & 359.1-01.7 & M1-29 & - & 4.70 \\
\hline 007.8-04.4 & H1-65 & - & -2.25 & $359.1-02.3$ & M3-16 & 1.30 & 1.50 \\
\hline $008.0+03.9$ & NGC 6445 & 6.64 & - & $359.3-03.1$ & M3-17 & -3.60 & -1.10 \\
\hline $008.1-04.7$ & M2-39 & -4.02 & -2.21 & $359.4-03.4$ & $\mathrm{H} 2-33$ & 0.54 & -1.78 \\
\hline $008.2-04.8$ & M2-42 & -1.48 & 0.66 & $359.7-02.6$ & $\mathrm{H} 1-40$ & 0.84 & 0.36 \\
\hline $008.2+06.8^{*}$ & Hen $2-260$ & -12.23 & -3.62 & $359.8+03.7$ & Th3-25 & -6.52 & - \\
\hline 008.3-07.3* & NGC 6644 & 2.18 & 4.01 & $359.8+06.9$ & M3-37 & -8.69 & -5.50 \\
\hline $009.0+04.1$ & Th4-5 & - & 1.69 & $359.9-04.5$ & M2-27 & -4.45 & 2.68 \\
\hline $009.4-05.0$ & NGC 6629 & 5.67 & - & $359.9+05.1$ & M3-9 & 4.70 & - \\
\hline
\end{tabular}


TABLE 2

\section{NEW DISTANCES}

\begin{tabular}{cccccr}
\hline PN G & Name & $\theta(\operatorname{arcsec})$ & $F(\mathrm{mJy})$ & $\tau$ & $d(\mathrm{kpc})$ \\
\hline $002.0-02.0$ & H1-45 & 0.8 & 20 & 2 & 15.1 \\
$005.5-02.5$ & M3-24 & 5.1 & 4.9 & 4.3 & 6.7 \\
$006.1+08.3$ & M1-20 & 0.8 & 50 & 1.7 & 8.1 \\
$006.4-04.6$ & Pe2-13 & 6.6 & 3.4 & 4.7 & 6.2 \\
$006.8-03.4$ & H2-45 & 4.6 & 9.7 & 3.9 & 6.2 \\
$007.0+06.3$ & M1-24 & 3.2 & 6.2 & 3.8 & 8.5 \\
$007.2+01.8$ & Hb6 & 2.5 & 240 & 2 & 4.3 \\
$008.2+06.8$ & Hen 2-260 & 0.5 & 10 & 1.9 & 20.4 \\
$008.3-07.3$ & NGC6644 & 1.3 & 100 & 1.8 & 6.1 \\
$010.7+07.4$ & Sa2-230 & 5 & 4 & 4.4 & 7.1 \\
$350.5-05.0$ & H1-28 & 3.9 & 1.5 & 4.6 & 9.9 \\
$351.6-06.2$ & H1-37 & 4.3 & 1.3 & 4.7 & 9.7 \\
$355.7-03.4$ & H1-35 & 1 & 90 & 1.7 & 5.9 \\
$355.9+03.6$ & H1-9 & 3.5 & 30 & 3.2 & 5.9 \\
$356.3-06.2$ & M3-49 & 4.9 & 0.2 & 5.7 & 13.2 \\
$356.8-05.4$ & H2-35 & 5.4 & 0.9 & 5.1 & 9.1 \\
$358.3+03.0$ & H1-17 & 0.5 & 40 & 1.4 & 7.9 \\
$358.5-04.2$ & H1-46 & 0.6 & 40 & 1.5 & 8.5 \\
$358.7-05.2$ & H1-50 & 0.7 & 30 & 1.8 & 10.9 \\
$358.9+03.3$ & H1-19 & 0.7 & 30 & 1.9 & 10.9 \\
\hline
\end{tabular}

used in the determination are shown in Table 2. In this table, Column 1 gives the PN G number, Column 2, the name, Column 3, the angular diameter, Column 4, the $5 \mathrm{GHz}$ flux, Column 5, the optical thickness parameter, and Column 6 lists the new distances derived for these objects.

\subsection{Galactocentric distances and distribution}

Heliocentric distances were converted into galactocentric distances using equation 1 , where $d$ is the heliocentric distance, $b$ and $\ell$ the galactic latitude and longitude, respectively, and $R_{0}$ the solar distance to the galactic center. In this work we adopted $R_{0}=8 \mathrm{kpc}$, as suggested by recent studies (Gillessen et al. 2009; Nishiyama et al. 2006).

$$
R=\sqrt{R_{0}^{2}+(d \cos b)^{2}-2 R_{0} d \cos b \cos \ell},
$$

In order to check the distribution of distances for the $\mathrm{PNe}$ in our database, Figure 1 shows the distribution of the $\mathrm{PNe}$ with respect to the galactocentric distance for both distance scales used in this work, Z95 (left) and SSV08 (right), including the new distances derived in this work. The figure also shows a Gaussian fit to each histogram. The mean and standard deviation are $(0.6 \pm 0.3) \mathrm{kpc}$ and $(2.6 \pm 0.3) \mathrm{kpc}$ for the SSV08 scale, and $(0.6 \pm 0.2) \mathrm{kpc}$ and $(2.5 \pm 0.2) \mathrm{kpc}$ for the Z95 scale. For both scales, the mean is consistent with the most recent determinations of the solar distance to the galactic center, which are all near $8 \mathrm{kpc}$, while the widths are larger than the standard deviation expected of $1.2 \mathrm{kpc}$ for the bulge. As discussed by Z95, this dispersion is a convolution of the probably real Gaussian distribution of the bulge, with the extra spread introduced by the mass-radius relationship.

\section{DETERMINATION OF THE BULGE-DISK INTERFACE}

\subsection{Abundance differences between bulge and inner-disk $P N e$}

In order to study the chemical abundance distribution in the inner Galaxy and to determine the bulge-disk interface, we made use of a method similar to that suggested by Maciel et al. (2006). First, a galactocentric distance $\left(R_{L}\right)$ is chosen, which defines a limit for the sample. Then the sample is divided into two groups: Group I is composed by $\mathrm{PNe}$ with galactocentric distances smaller than the limit previously settled, and Group II, is composed by $\mathrm{PNe}$ with galactocentric distances larger than this limit. For each group, the average abundances and the standard error of the mean are calculated for the available elements, namely $\mathrm{He}, \mathrm{O}, \mathrm{N}, \mathrm{S}$, and Ne. Then, the limiting radius $R_{L}$ is varied, considering distances in the interval from 0.1 to $3.6 \mathrm{kpc}$, in $0.7 \mathrm{kpc}$ steps for each distance scale.

The results are shown in Figures 2 and 3 for the SSV08 and Z95 distance scales, respectively. In each figure, Group I is represented by filled circles joined by continuous lines and Group II by squares joined by dashed lines. Each pair of circle/square points in each plot represents the average abundance for that element adopting a given limit for the bulge-disk interface, as a function of the limiting distance. Therefore, each plot shows how the differences between the groups evolve adopting distinct limits to define them. Considering elements heavier than He, it can be seen that, on average, abundances of Group I are lower than those of Group II objects for both distance scales. That is, in most cases the objects of Group I, which are closer to the galactic center, have systematically lower abundances compared with the objects of Group II, for all chosen values of the limiting radius $\left(R_{L}\right)$. The main exceptions are the helium abundances for both distance scales and argon for the Z95 scale, which present similar distributions for both groups. In the case of helium, these results are not surprising, as (a) this element is equally contaminated by the PN progenitor stars, both in the bulge 


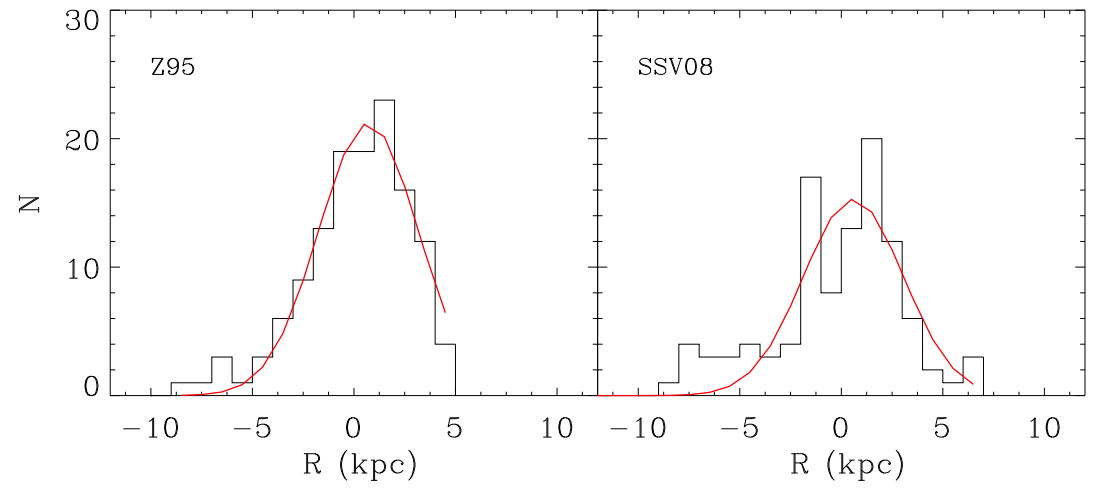

Fig. 1. Galactocentric distance distribution for the Z95 distance scale (left) and for the SSV08 distance scale (right). For each histogram a Gaussian fit is shown (see the text for more details).
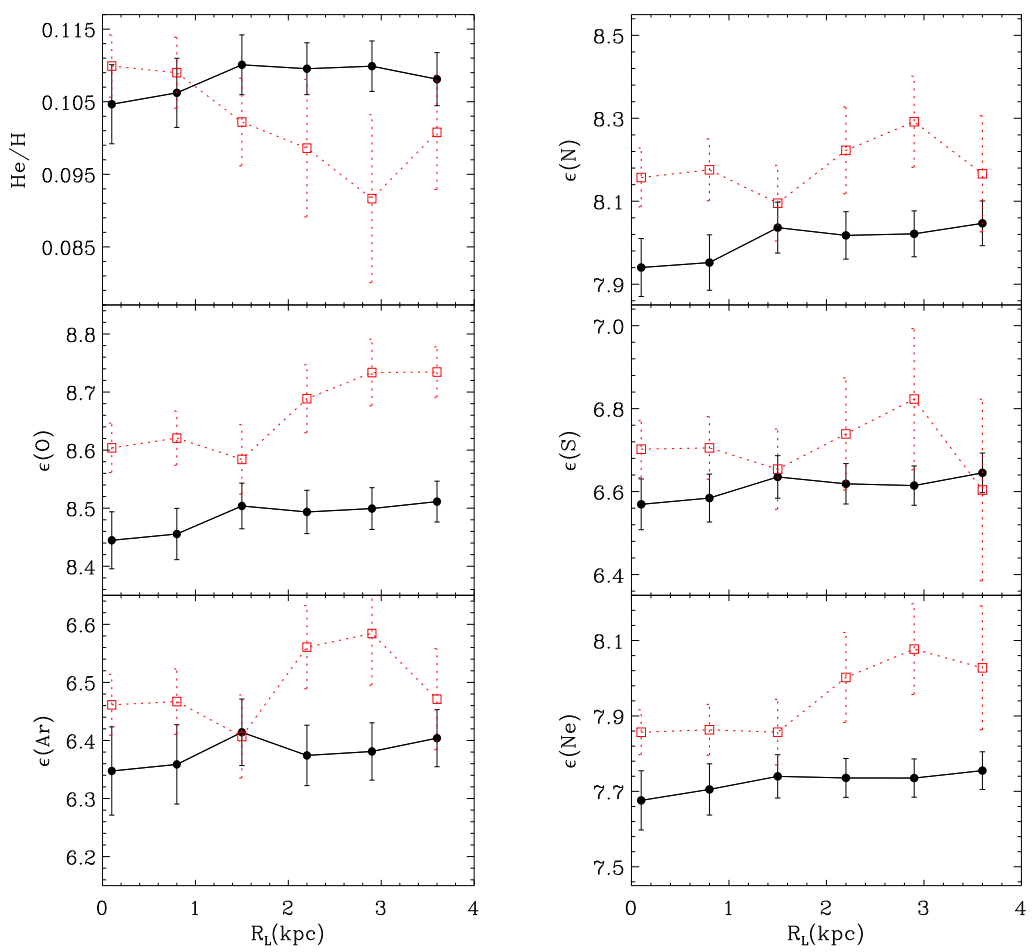

Fig. 2. Average abundances of PNe of Group I (circles joined by continuous lines) and Group II (squares joined by dashed lines) for the SSV08 distance scale. The abscissa gives the limiting galactocentric distance $R_{L}$, considered to be in the range $0-4 \mathrm{kpc}$. Error bars indicate the standard error of the mean for each subsample.

and in the galactic disk, and (b) helium does not show any measurable radial abundance gradient, in contrast with the remaining elements considered in this paper. (See a detailed discussion of the helium gradient in Maciel 2000).

Examining Figure 2 we see that for the $\alpha$ elements oxygen, sulfur and argon the differences between both samples reach a minimum between 1.5 and $2.5 \mathrm{kpc}$, where it is of the order of 0.1 dex or lower. In Figure 3, examining now the $\alpha$-elements, we see that a minimum difference appears around 1.5 or $2 \mathrm{kpc}$. For neon, the abundance difference between the groups is of the order of $0.2 \mathrm{dex}$, while for the other elements this difference is of the order 

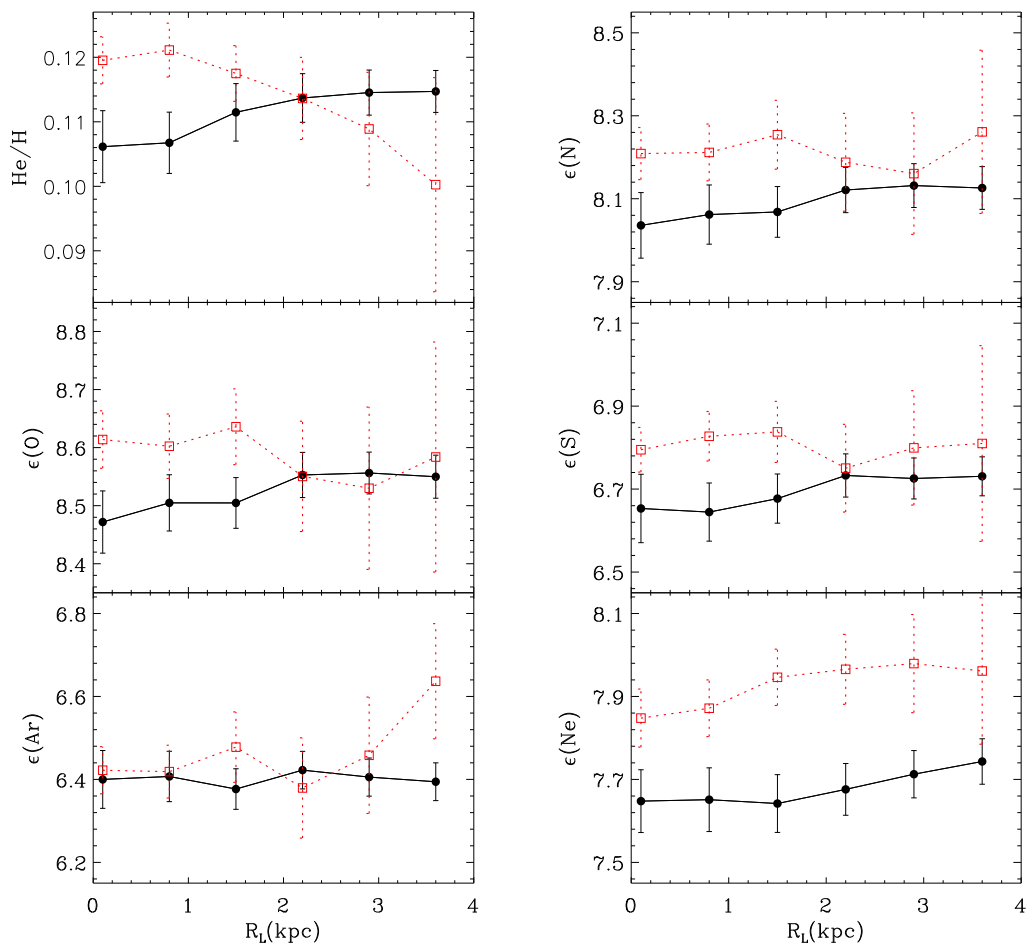

Fig. 3. The same as Figure 2 for the Z95 scale.

of 0.15 dex. For argon this difference is not clear, which is already expected since the ionization correction factor used to derive its abundance can lead to uncertainties larger than those for other elements.

\subsection{Kolmogorov-Smirnov test}

Our goal in this section is to find the distance that best characterizes the separation of the two groups, in the sense that the populations of each group should be as distinct as possible. In this case, we will be able to ascertain a value for the galactocentric distance of the bulge-disk interface based on the intermediate mass population represented by the PNe sample. In order to find such distance, we performed a Kolmogorov-Smirnov test for Groups I and II at each step of the procedure described above. The test returns the probabilities that the two groups are drawn from the same distribution. Small probabilities show that the cumulative distribution function of Group I is significantly different from Group II. The results are displayed in Figure 4. For each element the probability is shown as function of the limiting distance $R_{L}$. For each distance step, the left filled bar represents the SSV08 scale and the right empty bar the Z95 scale. Since we are looking for small probabilities, we can see from the figure that the lowest probabilities are achieved at $1.5 \mathrm{kpc}$ for the Z95 distance scale for the elements $\mathrm{O}, \mathrm{S}, \mathrm{Ar}$, and Ne. The probabilities for each element and distance are listed in Table 3 and the lowest values are highlighted in black. Again, it is clear that for the Z95 distance scale the lowest probabilities are achieved at $1.5 \mathrm{kpc}$ for all the $\alpha$-elements. On the other hand, SSV08 does not show a unique distance for the lowest probabilities. Indeed, considering only the $\alpha$-elements, no distances are alike. Nevertheless, examining Figure 2 in detail, we can see that there is a step in the abundance radial distributions for the $\alpha$-elements concerning the distance of $2.2 \mathrm{kpc}$. So that the safest conclusion we can draw is that $R_{L}<2.9 \mathrm{kpc}$ based on the SSV08 distance scale.

\subsection{Resulting abundance distributions}

Adopting the separation distances obtained for each element and distance scale, namely $1.5 \mathrm{kpc}$ for Z95 and $2.2 \mathrm{kpc}$ for SSV08, the distribution of the abundances for each group are shown in Figures 5 and 6 for the Z95 and SSV08 distance scales, respectively. Empty histograms represent Group I objects, while filled histograms represent Group II objects. The number of objects used is also given for each plot. 


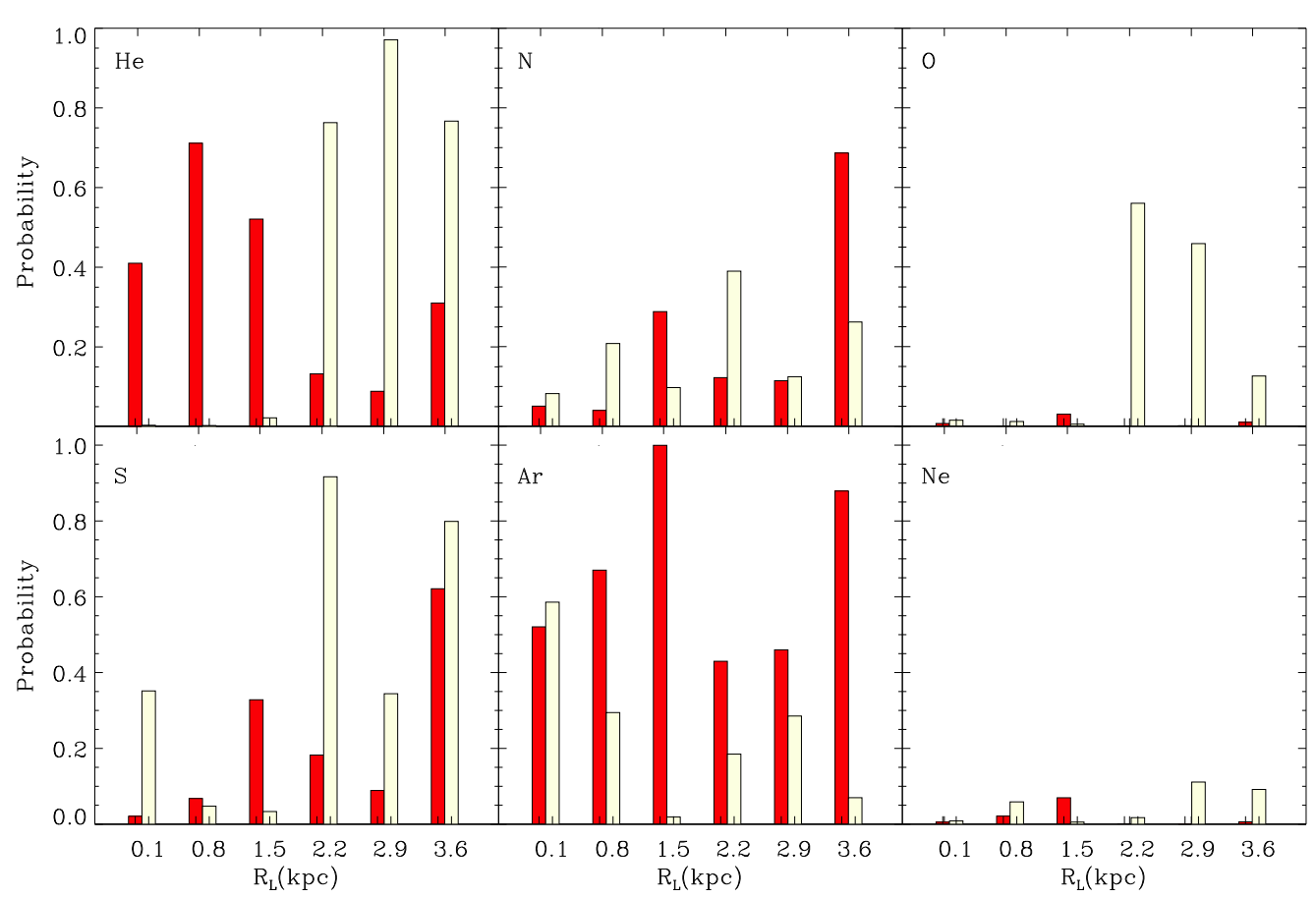

Fig. 4. Kolmogorov-Smirnov probability bar plot for each element as a function of the limiting radius of Groups I and II. Left filled bars correspond to the SSV08 scale and empty right bars to the Z95 scale.

TABLE 3

KOLMOGOROV-SMIRNOV PROBABILITIES

\begin{tabular}{|c|c|c|c|c|c|c|c|c|c|c|c|c|}
\hline \multirow[b]{2}{*}{$R_{L}(\mathrm{kpc})$} & \multicolumn{6}{|c|}{$P\left(R_{L}\right)$ SSV08 } & \multicolumn{6}{|c|}{$P\left(R_{L}\right) \mathrm{Z} 95$} \\
\hline & 0.1 & 0.8 & 1.5 & 2.2 & 2.9 & 3.6 & 0.1 & 0.8 & 1.5 & 2.2 & 2.9 & 3.6 \\
\hline $\mathrm{He}$ & 0.574 & 0.865 & 0.379 & 0.118 & 0.080 & 0.293 & 0.003 & 0.0026 & 0.022 & 0.763 & 0.971 & 0.767 \\
\hline $\mathrm{N}$ & 0.053 & 0.075 & 0.335 & 0.103 & 0.099 & 0.647 & 0.0819 & 0.208 & 0.097 & 0.390 & 0.124 & 0.262 \\
\hline $\mathrm{O}$ & 0.014 & 0.001 & 0.058 & 0.001 & 0.001 & 0.008 & 0.015 & 0.012 & 0.0051 & 0.560 & 0.459 & 0.126 \\
\hline S & 0.022 & 0.074 & 0.370 & 0.154 & 0.077 & 0.583 & 0.352 & 0.047 & 0.0334 & 0.917 & 0.344 & 0.799 \\
\hline Ar & 0.720 & 0.864 & 0.989 & 0.394 & 0.508 & 0.845 & 0.586 & 0.295 & 0.0188 & 0.185 & 0.285 & 0.070 \\
\hline $\mathrm{Ne}$ & 0.014 & 0.046 & 0.128 & 0.001 & 0.000 & 0.007 & 0.009 & 0.059 & 0.0056 & 0.017 & 0.111 & 0.092 \\
\hline
\end{tabular}

In Figure 5 the oxygen distribution for Group I is wider than that for Group II, while most objects from Group II have abundances centered at 8.5 dex. The other $\alpha$-elements also show this pattern according to which Group II objects favor higher abundances than those from Group I. However, these differences are not larger than the individual errors in abundances. Among the $\alpha$-elements, neon displays the largest difference between the two distributions. Nevertheless, some caution must be taken here. In a recent study by Milingo et al. (2010), there are some evidences that neon enhancement is present in a significant portion of PNe. This enhancement could be explained considering the charge exchange reaction $\mathrm{O}^{++}+\mathrm{H}^{0} \rightarrow \mathrm{O}^{+}+\mathrm{H}^{+}$(see Peimbert, Luridiana, \& Torres-Peimbert 1995, and references therein). Since the neon ICF depends inversely on the $\mathrm{O}^{++}$abundance, the charge exchange reaction could increase the neon elemental abundance. If the neon enhancement is real, it does not represent the abundance of the interstellar medium at the time of the formation of the progenitor star. Thus, the neon distribution in Figure 5 must be interpreted carefully.

In Figure 6, showing the distribution of the abundances for the SSV08 scale, the oxygen distribution for Group I objects is wider than for Group II and the 

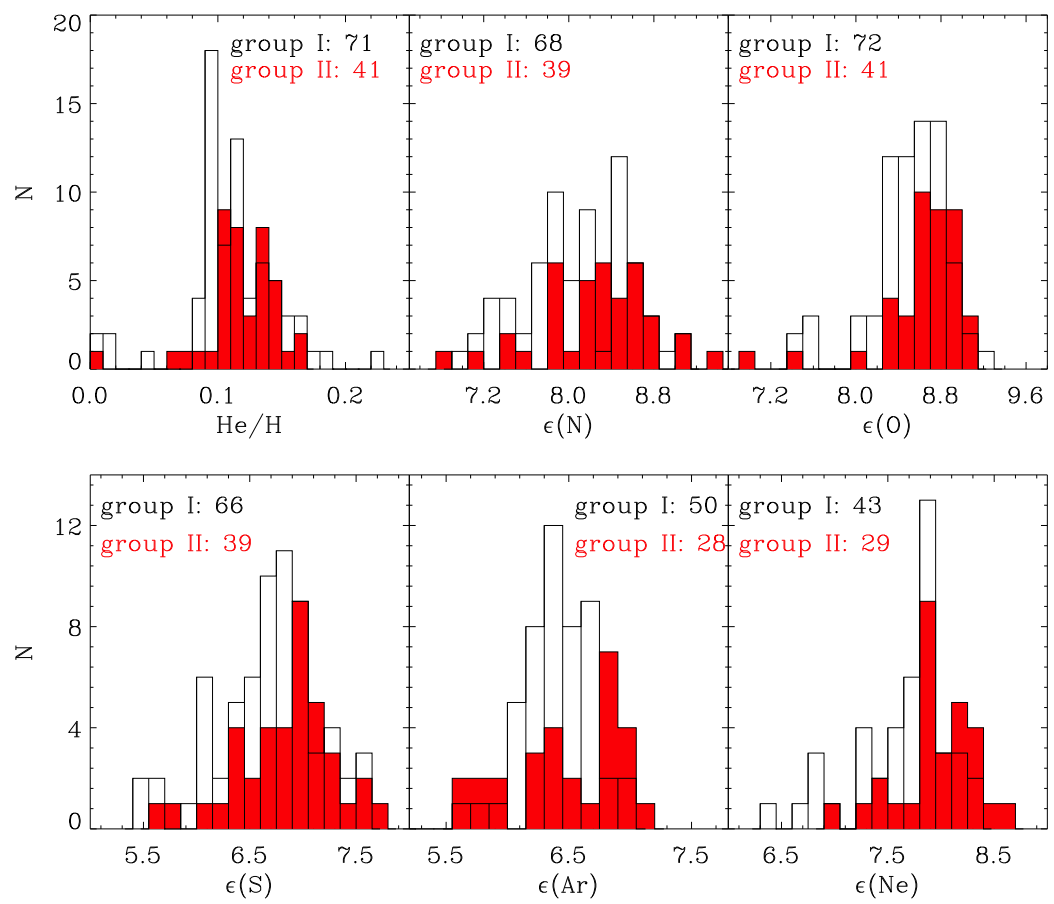

Fig. 5. Abundance distributions for Groups I and II using the Z95 distance scale. Unfilled histograms represent Group I objects and filled histograms are for Group II. The number of objects in each distribution is shown at the top.
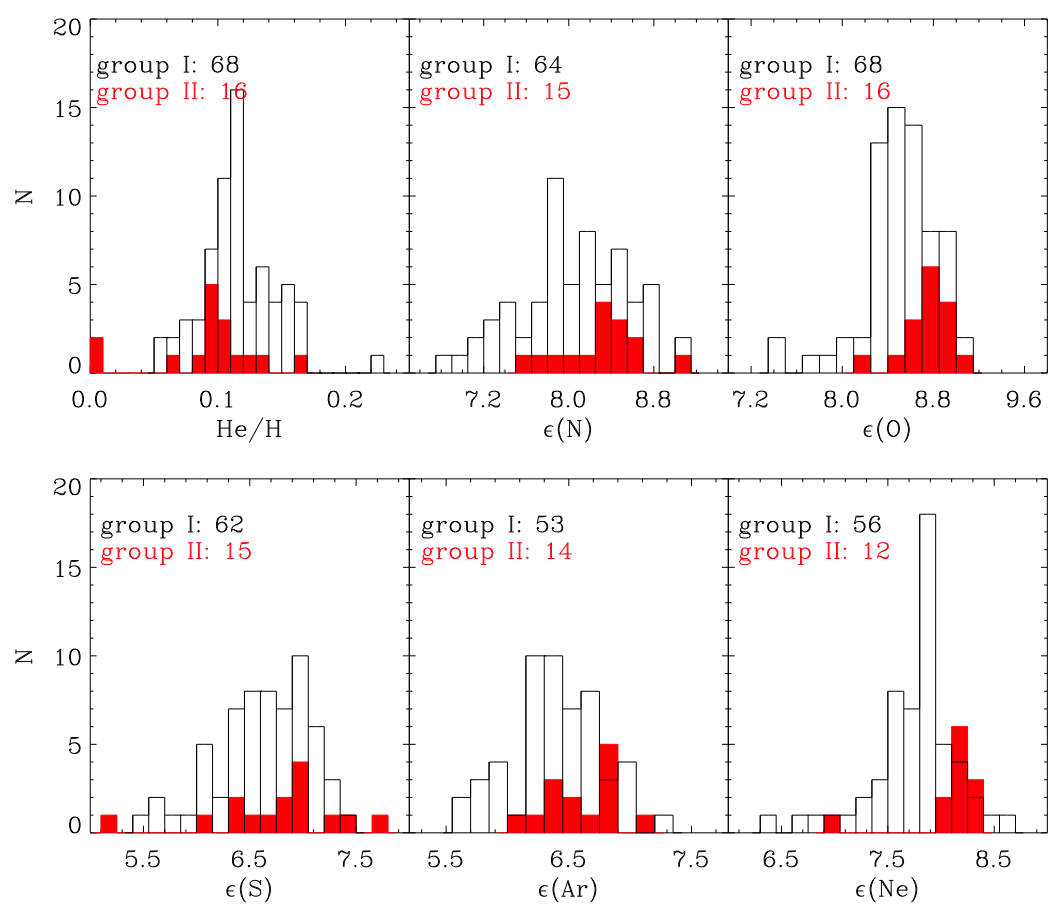

Fig. 6. The same as Figure 5 for the SSV08 distance scale. 
TABLE 4

AVERAGE ABUNDANCES OF GROUPS I AND II FOR EACH DISTANCE SCALE

\begin{tabular}{|c|c|c|c|c|}
\hline \multirow[b]{2}{*}{ Element } & \multicolumn{2}{|c|}{ SSV08 } & \multicolumn{2}{|c|}{$\mathrm{Z} 95$} \\
\hline & Group I & Group II & Group I & Group II \\
\hline $\mathrm{He} / \mathrm{H}$ & $0.110 \pm 0.004$ & $0.099 \pm 0.009$ & $0.111 \pm 0.004$ & $0.117 \pm 0.004$ \\
\hline$\epsilon(\mathrm{N})$ & $8.02 \pm 0.06$ & $8.22 \pm 0.10$ & $8.07 \pm 0.06$ & $8.25 \pm 0.08$ \\
\hline$\epsilon(\mathrm{O})$ & $8.49 \pm 0.04$ & $8.69 \pm 0.06$ & $8.50 \pm 0.04$ & $8.64 \pm 0.07$ \\
\hline$\epsilon(\mathrm{S})$ & $6.62 \pm 0.05$ & $6.74 \pm 0.14$ & $6.68 \pm 0.06$ & $6.84 \pm 0.07$ \\
\hline$\epsilon(\mathrm{Ar})$ & $6.37 \pm 0.05$ & $6.56 \pm 0.07$ & $6.38 \pm 0.05$ & $6.48 \pm 0.08$ \\
\hline$\epsilon(\mathrm{Ne})$ & $7.74 \pm 0.05$ & $8.00 \pm 0.12$ & $7.64 \pm 0.07$ & $7.95 \pm 0.07$ \\
\hline
\end{tabular}

values are between 8.0 and 9.3 dex. The same trend is seen in the distributions for the SSV08 scale when compared with the Z95 scale: compared to Group I objects, the $\alpha$-element distributions for Group II show a tendency to higher abundances.

Table 4 shows the average abundances and the standard error of the mean for Group I and II objects, adopting the distances 1.5 and $2.2 \mathrm{kpc}$ for the Z95 and SSV08 scales as the limit between the two groups. Although these abundances are similar, reflecting the large dispersion of abundances found in these regions of the Galaxy, some important differences are apparent. In particular, the N, O, S, Ar, and Ne abundances are smaller for Group I compared to Group II for both distance scales. For $\mathrm{N}$ and $\mathrm{O}$ the difference between the two groups is 0.20 dex. For $\mathrm{S}, \mathrm{Ar}$, and $\mathrm{Ne}$ it is $0.12,0.19$ and 0.26 dex, respectively. In spite of the fact that these differences are not larger than the individual errors in the abundances, we can draw important conclusions about these results. The standard error of the mean is small since both groups have several objects and therefore the difference between both groups is statistically significant. This can be seen considering the lower and upper $90 \%$ and $68 \%$ confidence limits of each group. Although there are some overlaps between the distributions, for $\mathrm{N}, \mathrm{O}, \mathrm{Ar}$, and Ne they are statistically significantly different considering the $68 \%$ confidence limit of each group for the SSV08 distance scale. Only the $\mathrm{S}$ distributions are not statistically different considering this method. For the Z95 distance scale, the distributions of N, O, and S of each group are significantly different considering the same confidence limit. The Ne distributions are statistically different considering the $90 \%$ confidence limit for this scale. These results are an important indication that bulge nebulae (Group I) do not follow the trends observed in the inner-disk (Group II), as we will discuss in $\S 4$.
Relaxing the assumption that objects with adopted negative galactocentric distances belong to the bulge would not change the derived conclusions. We performed some tests excluding these objects, and the main conclusions are unchanged: bulge objects have lower $\alpha$-element abundances than those in the inner disk. Adopting positive distances for these objects makes the group separation less clear, as the mixing of both populations is enhanced, but even in this case bulge objects still have lower abundances compared to inner disk objects.

The galactocentric distance of $1.5 \mathrm{kpc}$ for the Z95 distance scale marks the limit at which the Groups I and II are more likely to separate from the point of view of the chemical abundances, as shown by the Kolmogorov-Smirnov test. On the other hand, the galactocentric distance of $2.2 \mathrm{kpc}$ for the SSV08 scale was chosen from eye inspection in the radial abundances distributions, marking the limit in the $\alpha$ elements abundances. In this case too, objects from Group II, whose galactocentric distances are greater than $2.2 \mathrm{kpc}$, have higher abundances than those from Group I, whose distances are lower than this limit.

Since the bulge and the disk display different chemical abundance characteristics, such as for example the radial abundance gradients found in the disk, or the large abundance distribution found in the bulge, as we discussed in $\S 1$, we expect the existence of a galactocentric distance which better separates the two populations. Our analysis point to a separation at $R_{L}=1.5 \mathrm{kpc}$ for the Z95 distance scale and $R_{L}<2.9 \mathrm{kpc}$ for the SSV08 scale. Therefore, we can assign to Group I those objects that pertain to the bulge, and to Group II those that pertain to the inner-disk.

\section{DISCUSSION}

There are other evidences that point to a transition from the bulge to the inner-disk at a galactocen- 
tric distances similar to the distances found in this work. Indeed, infrared observations of the bulge, like those from the COBE/DIRBE satellite (Weiland et al. 1994), support these results. From their Figure 1, it is clear that the nuclear radius of the bulge is between $10^{\circ}$ and $15^{\circ}$. For the canonical solar distance to the galactic center of $8 \mathrm{kpc}$ adopted in this work, the bulge longer radius is between 1.4 and $2.1 \mathrm{kpc}$.

From the point of view of giant stars, Tiede \& Terndrup (1999) performed photometric and spectroscopic observations of 503 stars in four windows toward the bulge, with coordinates $(\ell, b)$ of $\left(-28.8^{\circ},-6^{\circ}\right),\left(-8.7^{\circ}, 6.0^{\circ}\right),\left(8.4^{\circ},-6.0^{\circ}\right)$ and $\left(24.4^{\circ}\right.$, $\left.6.1^{\circ}\right)$. According to their results, the abundance distribution in the inner Galaxy presents a discontinuity. The authors argue that such a difference is larger than any bias in the sample selection and not due to errors in the abundances. As we are suggesting, they assign the difference found to the different populations in the line of sight.

Smartt et al. (2001) observed type-B stars located between 2.5 and $5 \mathrm{kpc}$ from the galactic center. Due to the young nature of these stars, their photospheric abundances reflect the present day abundances of the ISM. Their results agree with ours in the sense that the oxygen abundance decreases for distances smaller than $3 \mathrm{kpc}$, as can be seen from their Figure 3. However, the error bars are large and it is only possible to say that the oxygen abundances do not follow the radial gradient of the disk toward the galactic center, since they are 0.3 to 0.4 dex lower than what we expected from the Rolleston et al. (2000) radial gradient, given their position.

In the light of recent studies using PNe, Gutenkunst et al. (2008) point to a discontinuity in the abundance gradient towards the galactic center, in the sense that the abundances of bulge PNe do not follow the trend of those from the disk, as can be seen in their Figure 4. The same trend can be seen in Figure 3 of Stanghellini \& Haywood (2010). Considering PNe type III as defined by Peimbert (1978), which represent the old disk population, it is possible to note from their figure that oxygen abundances are smaller for galactocentric distances of less than $4 \mathrm{kpc}$.

Finally, Mishurov, Lépine, \& Acharova (2002) proposed a galactic formation model where the spiral arms are inductors of stellar formation and they can exist only between the internal and external Lindblad resonances. As a consequence, the SFR decreases strongly outside these limits, and the chemical abundances are depleted in these regions. Combining these evidences with our results, we can point out to a bulge-disk interface for the intermediate mass population, marking therefore the transition between the disk and the bulge populations, at a galactocentric distance of 1.5 for the Z95 distance scale. On the other hand, for the SSV08 distance scale the Kolmogorov-Smirnov test was not conclusive, and we can point out that, for galactocentric distances smaller than $2.9 \mathrm{kpc}$, the $\alpha$-elements abundances do not follow the disk radial gradient towards the center of the Milky Way galaxy.

\section{SUMMARY AND CONCLUSION}

This work reports an important result concerning PNe and the chemical evolution of the Galaxy. In addition to our previous work (Cavichia et al. 2010, Paper I), where we presented the chemical abundances and the analysis of these abundances for a sample of $56 \mathrm{PNe}$ in the direction of the galactic bulge, among which $35 \mathrm{PNe}$ have their abundances derived for the first time, we extended our data base to $140 \mathrm{PNe}$ in order to study the chemical abundance distribution in the inner disk and bulge of the Galaxy.

In this work, a statistical analysis was performed in order to find the galactocentric distance where bulge and disk characteristics intersect. Two distance scales were used: Zhang (1995) and Stanghellini et al. (2008). Applying the Kolmogorov-Smirnov test, the former results in a distance of $1.5 \mathrm{kpc}$, while for the latter the test was not conclusive. Nevertheless, the radial $\alpha$-elements abundance distributions for both scales indicate that they do not follow the trend of the disk. On average, the abundances for objects with galactocentric distances smaller than 1.5 and $2.2 \mathrm{kpc}$ for the Z95 and SSV08 distance scales, respectively, are lower than for objects with distances greater than this limit, although this difference is not larger than the errors in individual abundances. Considering the SSV08 distance scale, the abundance difference between the two groups of PNe is based on 68, 62, 53, and $56 \mathrm{PNe}$ of Group I (bulge) for O, S, Ar, and Ne, respectively, and 16, 15, 14, 12 PNe of Group II (inner disk) for the same elements. For the Z95 distance scale, the abundance difference is based on $72,66,50$, and 43 PNe of Group I, and 41, 39, 28, 29 of Group II, for the same elements. Furthermore the combined error of the four elements $(\mathrm{O}, \mathrm{S}, \mathrm{Ar}, \mathrm{Ne})$ of each group is considerably smaller than the abundance difference between the two groups derived from the average difference of the four elements.

Taking into account the results derived in this work as well as other evidences from the literature, we propose the galactocentric distance of $1.5 \mathrm{kpc}$ (for 
the Z95 distance scale) as the mark of the transition between the bulge and the inner-disk of the Galaxy.

Part of this work was supported by the Brazilian agencies FAPESP and CNPq. O.C. would like to acknowledge FAPESP for his graduate fellowship (processes 05/03194-4 and 07/07704-2). We also thank the referee for his/her comments and suggestions.

\section{REFERENCES}

Acker, A., Marcout, J., Ochsenbein, F., Stenholm, B., \& Tylenda, R. 1992, Strasbourg-ESO Catalogue of Galactic Planetary Nebulae (Part 1 and 2; Garching: ESO)

Andrievsky, S. M., Luck, R. E., Martin, P., \& Lépine, J. R. D. 2004, A\&A, 413, 159

Binney, J. 2009, in IAU Symp. 254, The Galaxy Disk in Cosmological Context, ed. J. Andersen, J. BlandHawthorn, \& B. Nordström (Cambridge: Cambridge Univ. Press), 145

Cahn, J. H., Kaler, J. B., \& Stanghellini, L. 1992, A\&AS, 94, 399 (CKS92)

Carigi, L., Peimbert, M., Esteban, C., \& García-Rojas, J. 2005, ApJ, 623, 213

Cavichia, O., Costa, R. D. D., \& Maciel, W. J. 2010, RevMexAA, 46, 159 (Paper I)

Chiappini, C., Górny, S., Stasińska, G., \& Barbuy, B. 2009, A\&A, 494, 591

Chiappini, C., Matteucci, F., \& Romano, D. 2001, ApJ, 554,1044

Costa, R. D. D., Escudero, A. V., \& Maciel, W. J. 2005, in AIP Conf. Proc. 804, Planetary Nebulae as Astronomical Tools, ed. R. Szczerba, G. Stasińska, \& S. K. Górny (Melville: AIP), 252

Costa, R. D. D., Maciel, W. J., \& Escudero, A. V. 2008, Baltic Astron., 17, 321

Cuisinier, F., Maciel, W. J., Köppen, J., Acker, A., \& Stenholm, B. 2000, A\&A, 353, 543 (CMKAS00)

Cunha, K., Sellgren, K., Smith, V. V., Ramirez, S. V., Blum, R. D., \& Terndrup, D. M. 2007, ApJ, 669, 1011

Daflon, S., \& Cunha, K. 2004, ApJ, 617, 1115

Davies, B., et al. 2009, ApJ, 696, 2014

de Freitas Pacheco, J. A., Maciel, W. J., \& Costa, R. D. D. 1992, A\&A, 414, 211

Escudero, A. V., \& Costa, R. D. D. 2001, A\&A, 380, 300

Escudero, A. V., Costa, R. D. D., \& Maciel, W. J. 2004, A\&A, 414, 211

Exter, K. M., Barlow, M. J., \& Walton, N. A. 2004, MNRAS, 349, 1291

Fu, J., Hou, J. L., Yin, J., \& Walton, N. A. 2009, ApJ, 696,668

Gerhard, O. 2002, in ASP Conf. Ser. 273, The Dynamics, Structure and History of Galaxies, ed. G. S. Da Costa \& H. Jerjen (San Francisco: ASP), 73
Gillessen, S., Eisenhauer, F., Trippe, S., Alexander, T., Genzel, R., Martins, F., \& Ott, T. 2009, ApJ, 692, 1075

Górny, S. K., Stasińska, G., Escudero, A. V., \& Costa, R. D. D. 2004, A\&A, 427, 231

Gutenkunst, S., Bernard-Salas, J., Pottasch, S. R., Sloan, G. C., \& Houck, J. R. 2008, ApJ, 680, 1206

Henry, R. B. C., Kwitter, K. B., Jaskot, A. E., Balick, B., Morrison, M. A., \& Milingo, J. B. 2010, ApJ, 724, 748

Hou, J. L., Prantzos, N., \& Boissier, S. 2000, A\&A, 362, 921

Howard, C. D., et al. 2009, ApJ, 702, L153

Köppen, J., Acker, A., \& Stenholm, B. 1991, A\&A, 248, 197

Maciel, W. J. 2000, in IAU Symp. 198, The Light Elements and their Evolution, ed. L. da Silva, R. De Medeiros, \& M. Spite (San Francisco: ASP), 204

Maciel, W. J., Lago, L. G., \& Costa, R. D. D. 2005, A\&A, 433, 127 2006, A\&A, 453, 587

Maciel, W. J., \& Pottasch, S. R. 1980, A\&A, 88, 1

Maciel, W. J., \& Quireza, C. 1999, A\&A, 345, 629

Milingo, J. B., Kwitter, K. B., Henry, R. B. C., \& Souza, S. P. 2010, ApJ, 711, 619

Mishurov, Y. N., Lépine, J. R. D., \& Acharova, I. A. 2002, ApJ, 571, L113

Mollá, M., \& Díaz, A. I. 2005, MNRAS, 358, 521

Nishiyama, S., et al. 2006, ApJ, 647, 1093

Peimbert, M. 1978, in IAU Symp. 76, Planetary Nebulae, ed. Y. Terzian (Dordrecht: Reidel), 215

Peimbert, M., Luridiana, V., \& Torres-Peimbert, S. 1995, RevMexAA, 31, 147

Perinotto, M., \& Morbidelli, L. 2006, MNRAS, 372, 45

Perinotto, M., Morbidelli, L., \& Scatarzi, A. 2004, MNRAS, 349, 793

Portinari, L., \& Chiosi, C. 1999, A\&A, 350, 827 2000, A\&A, 355, 929

Ratag, M. A., Pottasch, S. R., Dennefeld, M., \& Menzies, J. W. 1992, A\&A, 255, 255 1997, A\&AS, 126, 297

Rich, R. M. 1988, AJ, 95, 828

Rolleston, W. R. J., Smartt, S. J., Dufton, P. L., \& Ryans, R. S. I. 2000, A\&A, 363, 537

Ruffle, P. M. E., Zijlstra, A. A., Walsh, J. R., Gray, M. D., Gesicki, K., Minniti, D., \& Comeron, F. 2004, MNRAS, 353, 796

Samland, M., Köppen, J., Acker, A., \& Stenholm, B. 1992, A\&A, 264, 184

Shen, J., Rich, R. M., Kormendy, J., Howard, C. D., De Propris, R., \& Kunder, A. 2010, ApJ, 720, L72

Smartt, S. J., Venn, K. A., Dufton, P. L., Lennon, D. J., Rolleston, W. R. J., \& Keenan, F. P. 2001, A\&A, 367, 86 
Stanghellini, L., \& Haywood, M. 2010, ApJ, 714, 1096

Stanghellini, L., Shaw, R. A., \& Villaver, E. 2008, ApJ, 689, 194 (SSV08)

Stasińska, G., Richer, M. G., \& McCall, M. L. 1998, A\&A, 336, 667

Tiede, G. P., \& Terndrup, D. M. 1999, AJ, 118, 895
Tylenda, R., Siódmiak, N., Górny, S., Corradi, R. L. M., \& Schwarz, H. E. 2003, A\&A, 405, 627

Weiland, J. L., et al. 1994, ApJ, 425, L81

Zhang, C. Y. 1995, ApJS, 98, 659 (Z95)

Zoccali, M., et al. 2006, A\&A, 457, L1

Zoccali, M., et al. 2003, A\&A, 399, 931

O. Cavichia, R. D. D. Costa, and W. J. Maciel: Departamento de Astronomia, Instituto de Astronomia, Geofísica e Ciências Atmosféricas Universidade de São Paulo, Rua do Matão, 1226, Cidade Universitária, 05508-900 São Paulo-SP, Brazil (cavichia, roberto, maciel@astro.iag.usp.br). 


\title{
Chemical evolution of the Milky Way bulge and disk with radial gas flows
}

\author{
O. Cavichia ${ }^{1 \star}$, M. Mollá ${ }^{2}$, R. D. D. Costa ${ }^{1}$ and W. J. Maciel ${ }^{1}$ \\ ${ }^{1}$ IAG, University of São Paulo, 05508-900, São Paulo-SP, Brazil \\ ${ }^{2}$ CIEMAT, Universidad Complutense de Madrid, Spain
}

Accepted 1988 December 15. Received 1988 December 14; in original form 1988 October 11

\author{
ABSTRACT \\ In preparation.
}

Key words: circumstellar matter - infrared: stars.

\section{INTRODUCTION}

In preparation.

\section{THE CHEMICAL EVOLUTION MODEL}

The chemical evolution model is an update of the model developed by Mollá \& Díaz (2005). The main differences are the inclusion of radial gas flows and the central bulge. Here we breafily describe some important aspects of the model, referring for a more detailed description the original papers.

The central bulge was included in the code following Molla \& Ferrini (1995). The bulge mass is calculated using the relation from ? which is given by

$M(R)=\frac{V^{2} R}{G}+\frac{\sigma^{2} R^{3}}{G h^{2}}$

where $V$ is the circular velocity, $R$ is the bulge radius, $h$ is the disk scale lenght, $\sigma$ is the velocity dispersion, and $G$ the gravitational constant. Howard et al. (2009) find a dispersion velocity of $116 \pm 1 \mathrm{kms}^{-1}$ and Hammer et al. (2007) give a disk scale lenght of $2.3 \pm 0.6 \mathrm{kpc}$. Nakasato \& Nomoto (2003) define the bulge radius as $<2 \mathrm{kpc}$. So that in this work we adopt the bulge radius as $2 \mathrm{kpc}$. From ?, one can estimate the circular velocity at a radius of $2 \mathrm{kpc}$ been $\approx 63 \mathrm{~km} \mathrm{~s}^{-1}$. Using these values, equation 1 results in a bulge mass of $4.732 \times 10^{9} M_{\odot} . ?$

The multiphase model of Mollá \& Díaz (2005) is a generalization of the model developed by Ferrini et al. (1992) for the solar neighborhood, and later applied to the whole Galaxy by Ferrini et al. (1994) and other spiral galaxies by Mollá et al. (1996); Mollá \& Roy (1999). The enriched material is originated from the stars at the end of their evolution, taking in to account their nucleosynthesis, initial mass function (IMF) and the final fate, through a quiet evolution, or type I and II supernovae explosions. In the multiphase

* E-mail: cavichia@astro.iag.usp.br model, the star formation is a two-step process: first the diffuse gas forms molecular clouds. Then stars form from cloud-cloud collisions or by the interaction between massive stars and the molecular gas. The former is called spontaneous star formation and the latter induced star formation.

The model uses an IMF from Ferrini et al. (1990) given by

$\Phi(m)=2.1853 \times 10\left(\frac{-(0.73+\log m \times(1.92+2.07 \times \log m))^{0.5}}{m^{1.52}}\right)$.

The original model was modified to include metallicity dependent yields. The stellar yields are from Woosley \& Weaver (1995), while those from low mass stars are from Gavilán et al. (2005). Type I supernovae releases are considered including the model revised by Iwamoto et al. (1999).

In this model, the Galaxy is described as a three phase system with a halo a disk and a bulge. The total initial halo mass is asssumed to be in the form of gas. The total mass $M$ and its radial distribution $M(R)$ are calculated from the respectives rotation curves. These rotation curves are derived from the universal rotation curve from Persic et al. (1996). The galaxy is divided into concentric cylindrical regions, each of $2 \mathrm{kpc}$ wide. From the rotation curve, one be able to calculate the radial mass distribution $M(R)$ using the expression

$M(R)=2.32 \times 10^{5} R \quad V(R)^{2}$.

The halo gas colapses to fall in the equatorial disk, originating the disk or bulge as a secondary structure. The infalling halo gas is parametrized by $f_{g_{h}}$, where $g_{h}$ is the halo mass gas and $f$ is the infall rate. The mass which remains in the halo gives a ratio $M_{\text {halo }} / M_{\text {disk }}$ for the baryonic component. The collapse time-scale, which defines this infalling gas rate, depends on the galactocentric distance through the expression:

$\tau(R)=\tau_{0} e^{\frac{R-R_{c}}{R_{d}}}$,

where its assumed that the total mass surface density follows the surface brightness exponential shape. In this equation, 
$\tau_{0}=4 \mathrm{Gyr}, R_{d}=2 \mathrm{kpc}$ is the disk scale length, and $R_{c}=$ $R_{\text {opt } / 2}=6.5 \mathrm{kpc}$ is the characteristic disk radius. For more details about the collapse-time scale see Mollá \& Díaz (2005) and Ferrini et al. (1994). For the bulge, in order to reproduce the giant stars metallicity distribution function, the collapse time-scale is fixed to be $0.7 \mathrm{Gyr}$, which is shorter than the disk collapse time-scale at $\mathrm{R}=0 \mathrm{kpc}$.

The mass in the different phases of each region changes by the processes associated with the stellar formation and death by: the star formation due to spontaneous fragmentation of gas in the halo; formation of gas clouds in the disk from the diffuse gas; induced star formation in the disk due to the interaction between massive stars and gas clouds; and finally, the restitution of the diffuse gas associated to these process of cloud and star formation. In the halo, the star formation rate for the diffuse gas follows a Schimidt law with a power $n=1.5$. In the disk, the stars form into two steps: first, molecular clouds are formed from the diffuse gas also following a Schimidt law with $n=1.5$ and a proportionality factor $\mu$. The stars are produced by a spontaneous process associated with cloud-cloud collisions at a rate which is proportional to a parameter $\mathrm{H}$, and a stimulated star formation process proportional to $a$ is assumed.

\subsection{Radial flows}

The complete set of equations for each zone is given by Mollá et al. (1996) and Ferrini et al. (1992). Here we just describe the processes associated with the variation of the gas mass in each radial zone.

$\frac{d g}{d t}=-\mu g^{n}+a^{\prime} c s_{2}+H^{\prime} c^{2}+f g_{H}+W+f g_{r f}$

The first term in this equation is related with the cloud formation from diffuse gas, the second is the induced star formation via massive star-cloud interaction, the third is the star formation from cloud collisions, the fourth is the infalling gas from the halo, the fifty is the restitution of the mass due to the death of stars. The novelty in this equation is the last term, which is responsible for the radial flows between each radial zone. This term is defined as:

$f g_{r f}(k)=F_{2}(k)-F_{1}(k)$,

where $F_{1}(k)$ and $F_{2}(k)$ are functions which define the quantity of gas that is leaving and entering in the shell $r_{k}$, as illustrated in figure 1.

Each of these functions can be separated into two others functions as:

$$
F_{2}(k)=F_{21}(k)+F_{22}(k) \quad F_{1}(k)=F_{11}(k)+F_{12}(k) .
$$

These functions are illustrated in figure 1 and correspond to flows in the directions:

- Inward the shell $r_{k}$ from the shells $r_{k+1}\left(F_{21}\right)$ and $r_{k-1}\left(F_{22}\right)$.

- Outward the shell $r_{k}$ to the shells $r_{k+1}\left(F_{11}\right)$ and $r_{k-1}\left(F_{12}\right)$.

The flows in the $k$ shell can be written in terms of the gas density $g(k)$ and the velocity $v(k)$ as:

$$
\begin{aligned}
& F_{21}(k)=v_{k+1 / 2}(k)\left[\chi\left(v_{k+1 / 2}(k)\right) \times g(k+1)\right] \\
& F_{22}(k)=-v_{k-1 / 2}(k)\left[\chi\left(-v_{k-1 / 2}(k)\right) \times g(k-1)\right]
\end{aligned}
$$

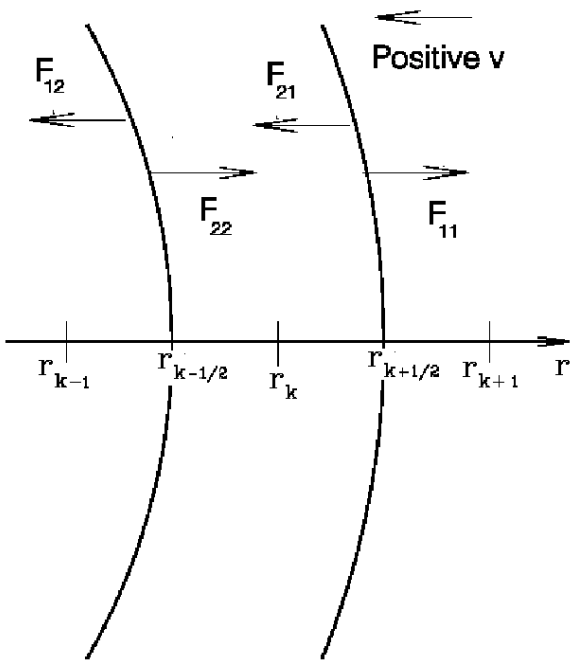

Figure 1. Scheme for the radial flows in the shell $r_{k}$.

$F_{11}(k)=-v_{k+1 / 2}(k)\left[\chi\left(-v_{k+1 / 2}(k)\right) \times g(k)\right]$
$F_{12}(k)=v_{k-1 / 2}(k)\left[\chi\left(v_{k-1 / 2}(k)\right) \times g(k)\right]$,

where the function $\chi(x)$ is a step function defined as:

$\chi(v(k))= \begin{cases}1 & \text { if } v(k)>0 \\ 0 & \text { if } v(k)<0\end{cases}$

As discussed by Lacey \& Fall (1985), gas flows in the disk can be generated by the viscosity $\nu$ in the gas layer. This viscosity will induce an inward flow in the inner parts of the Galaxy and an outward in the outer parts with velocity $|v| \propto \nu / r$. The authors estimate that $\nu \approx 1 \mathrm{~km} \mathrm{~s}^{-1} \mathrm{kpc}$ for HI clouds. So that, in our models, the velocities of the flows are given by $v(k)=v_{0} / r_{k}$, where $0<v_{0}<5 \mathrm{~km} \mathrm{~s}^{-1}$. Since there are no direct measurements of the velocities of the gas flows, one can vary $v_{0}$ between these limits in order investigate the effects of the radial gas flows in the distributions of gas, SFR and chemical abundances in the bulge, inner disk, and outer disk of the Galaxy.

\section{RESULTS}

In order to include the effects of the Galactic Bar in the inner few kpc os the MW, we adopt the radial flow velocity pattern described by Portinari \& Chiosi (2000) in their figure 15. In this case, the Galactic Bar ends in correspondence to its CR around $3 \mathrm{kpc}$, and it has an OLR around $4.5 \mathrm{kpc}$. Gas-dynamical models (?Fux 1999) give a range of $3<R_{c r}<4.5 \mathrm{kpc}$. In this work, we adopt the Bar corotation radius to be $R_{c r} \sim 3 \mathrm{kpc}$. In all models with radial flows, we consider that the disk radial flows start at the beginning of the MW formation and last to the present time. So that in these models, the gas flow is outward the CR toward the OLR where it accumulates. The age of the Galactic $\operatorname{Bar}\left(T_{b a r}\right)$ is not well established. Cole \& Weinberg (2002) propose that $3<T_{b a r}<6$ Gyr. Here we adopt $T_{b a r}=5$ Gyr. In this case, the Galactic Bar have formed 5 Gyr ago and the flows induced by the Galactic Bar start at $T_{b a r}$. On the other hand, inflows in the disk are expected to occur during the entire evolution of the Galaxy. We have compute 
Table 1. Model parameters used.

\begin{tabular}{lcccccc}
\hline \hline Model & $v_{\text {in }}\left(\mathrm{km} \mathrm{s}^{-1}\right)$ & $v_{\text {out }}\left(\mathrm{km} \mathrm{s}^{-1}\right)$ & $\alpha_{d}$ & $\ell_{d}$ & $\epsilon_{\mu \odot}$ & $\epsilon_{1 h \odot}$ \\
\hline $\mathrm{A}$ & 0.0 & 0.0 & - & 0.5 & 0.3651 & 0.1353 \\
$\mathrm{~B}$ & +1.0 & +1.0 & - & 0.5 & 0.3651 & 0.1353 \\
$\mathrm{C}$ & -1.0 & +1.0 & - & 0.5 & 0.3651 & 0.1353 \\
$\mathrm{D}$ & variable (fig. ) & 1.6 & & & \\
$\mathrm{E}$ & \multicolumn{2}{c}{ variable (fig. ) } & 1.7 & & & \\
\hline
\end{tabular}

two variable flow velocities which are show in figure ??. The plus and minus signs in the velocities give the direction of the flows. As already mentioned, a positive velocity means that the flow is toward the centre of the Galaxy, meanwhile a negative velocity means that the flow is in the opposite direction.

The parameters of the models used in this work are described in table 1 . The first column in this table indicates the name adopted for the model, the second and third columns the gas flow velocity and direction inside and outside the Bar corotation, respectively. The fourth column is the scale factor used in the pattern velocity of Portinari \& Chiosi (2000), the fifty column is the scalelength of the exponential collapse time-scale. The sixth and seventh columns are the efficiencies of molecular cloud formation and cloud-cloud collision for the solar neighborhood. As discussed by Mollá \& Díaz (2005), the ratio $\left\langle\ln \epsilon_{\mu} / \ln \epsilon_{H}\right\rangle \sim 0.4$ for a sample of galaxies with 11 morphological types. Taking this into account, we fixed this ratio for the solar neighborhood and let $\epsilon_{\mu}$ vary radially since the spiral density waves are more concentrated in the inner regions than in the outer ones. This behaviour is not expected for $\epsilon_{H}$, so it is kept constant along the Galactic disk.

In figure 2 it is shown the metallicity distribution function (MDF) for the bulge. The histogram is the data from Zoccali et al. (2008) for 204 bulge RGB stars. The models are represented by the lines. In this work we adopt as solar abundances those published by Asplund et al. (2009). The overall agreement between the models and the data is quiet good. Both model and observations peak at $[\mathrm{Fe} / \mathrm{H}]=$ ???? dex. So that, in order to reproduce the bulge MDF, it is required the scenario where the bulge is formed by the fast collapse of primordial gas accumulating in the centre of the MW, as noted by many other authors as (?) and references therein. Galaxy. important to note that models which have radial flows do not show differences in the MDF in a level that observations would be able to constrain. This can be explained looking to figure ??, that shows the time evolution of the bulge SFR. Since the bulk of the bulge stars form at the first Gyr of the MW formation, the effects of the radial flows are not seen in the SFR at this point. Only after $T \sim 2$ Gyr it is possible to note an appreciate difference in the SFR due to radial flows.

The model predictions for the bulge metallicity time evolution are show in figure 5. Again, the effects of the radial flows are most noted in the las few Gyr of the MW evolution. It is interesting to note that radial flows as adopted in this paper tend to deplete the SFR and abundances in the bulge.

The superficial gas density profile predictions are show in figure 6. ? notice that the gas profile peak at $4 \mathrm{kpc}$ is

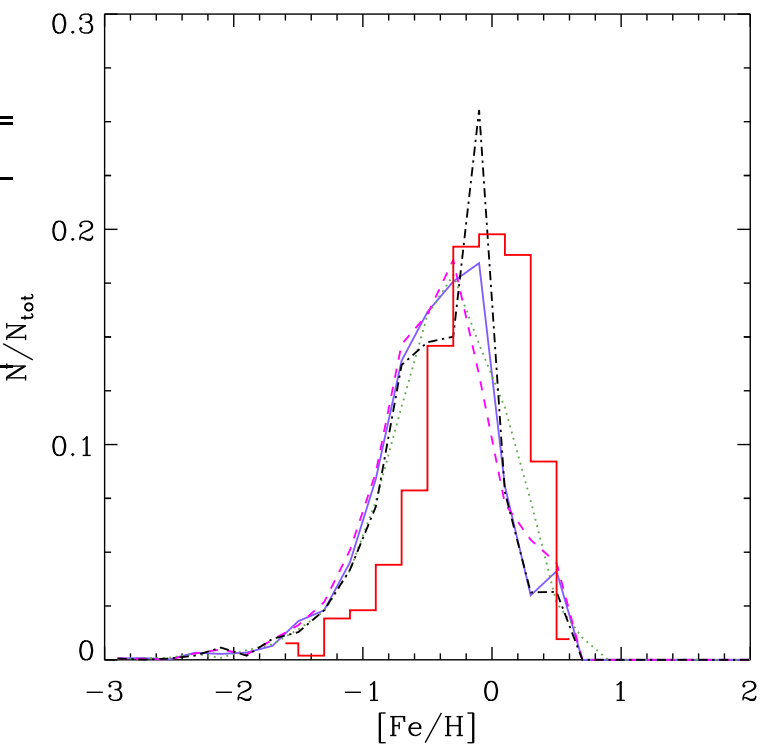

Figure 2. Iron distribution (histogram) for 204 RGB stars from Zoccali et al. (2008) compared with our models using different radial flows. The continuous line is the standard model without radial gas flows. The dotted line is the model with a radial inflow velocity of $1 \mathrm{~km} \mathrm{~s}^{-1}$, the dashed line is the model with a radial outflow velocity of $1 \mathrm{~km} \mathrm{~s}^{-1}$ and the dot dashed line is model with a radial flow towards the Bar corotation with velocity of 1 $\mathrm{km} \mathrm{s}^{-1}$.

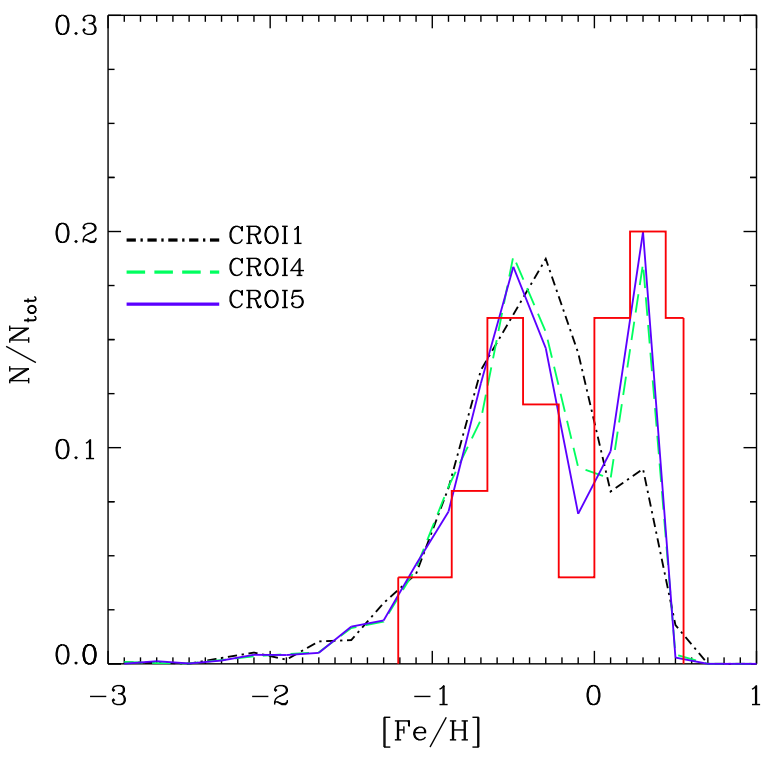

Figure 3. Bimodal iron distribution (histogram) for 25 bulge microlensed dwarf stars from Bensby et al. (2010) and Bensby et al. (2011). A comparison with our models using different radial flows velocities are shown.

due to dynamical influence of the Galactic Bar and that static chemical evolution models are not able to reproduce if other constraints like the disk metallicity gradient are match as well. The model of MD05 is not an exception in this case. The static model predicts a much lower $\sigma_{\mathrm{HII}}$ than the observations do for $\mathrm{R}<6 \mathrm{kpc}$. The molecular ring at $4 \mathrm{kpc}$ 


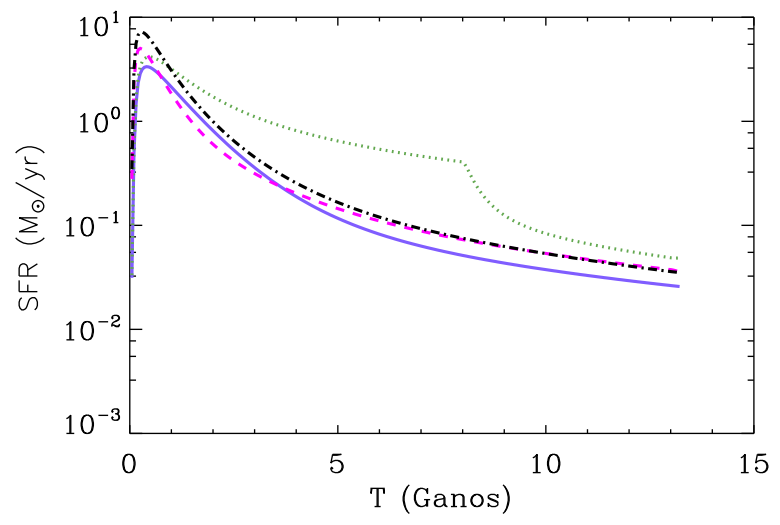

Figure 4. Bulge star formation rate as a function of time for models with radial flows compared with the standard model.

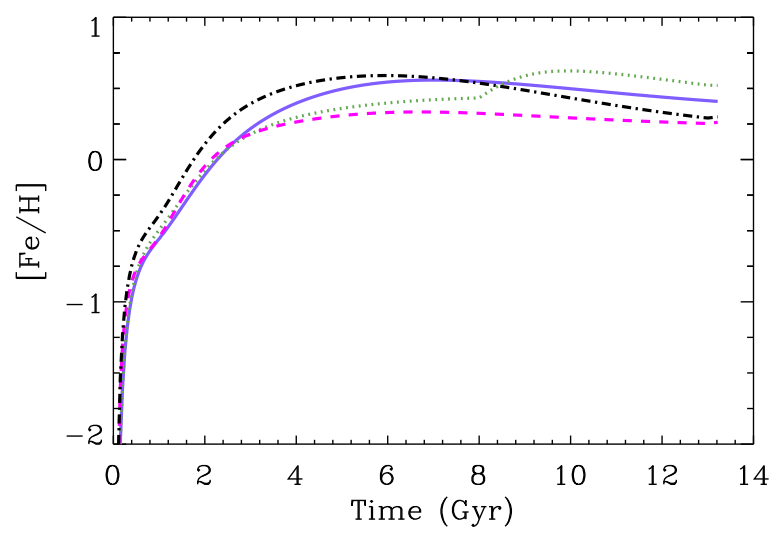

Figure 5. Bulge iron metallicity as a function of time.

is only reproduced using radial gas flows. In particular, the model that includes the Bar is able to fit the gas profile at 4 kpc.

One advantage of the models with radial flows is that it is possible to fit, for the first time, the present disk SFR profile. The predictions of the models are show in figure 7 . The observational data are from Stahler \& Palla (2005) and are based on supernova remnants, pulsars, and HII regions. The best fit is achieved when the velocity scale factor is 1.7. That is, in order to reproduce de SFR profile, one need a faster velocity profile than PC00 used in their work.

\section{DISCUSSION AND CONCLUSION}

In preparation.

\section{ACKNOWLEDGMENTS}

\section{REFERENCES}

Alves-Brito A., Meléndez J., Asplund M., Ramírez I., Yong D., 2010, A\&A, 513, A35

Andrievsky S. M., Bersier D., Kovtyukh V. V., Luck R. E., Maciel W. J., Lépine J. R. D., Beletsky Y. V., 2002, A\&A

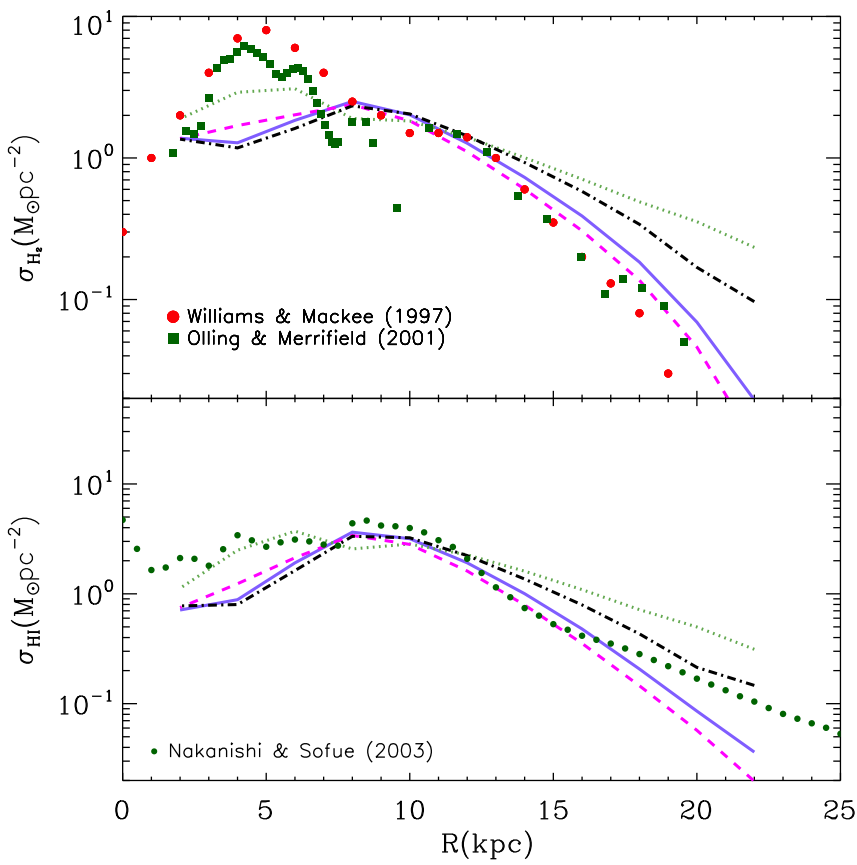

Figure 6. Top: Molecular gas superficial density radial distribution for each model, compared to the observational data from Williams \& McKee (1997) and Olling \& Merrifield (2001). Bottom: Diffuse gas superficial density radial distribution. The observational data (circles) is from Nakanishi \& Sofue (2003). The lines for the models are as in figure 4.

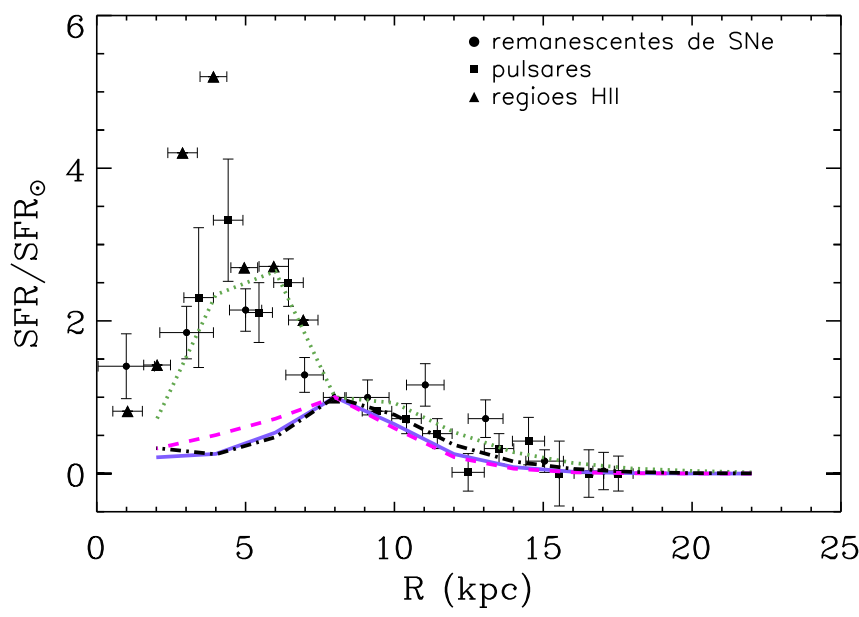

Figure 7. Star formation rate as a function of the galactocentric distance. The observational data (circles, squares and triangles) are from Stahler \& Palla (2005). Lines represent our models and are as in figure 4.

Andrievsky S. M., Kovtyukh V. V., Luck R. E., Lépine J. R. D., Bersier D., Maciel W. J., Barbuy B., Klochkova V. G., Panchuk V. E., Karpischek R. U., 2002, A\&A Asplund M., Grevesse N., Sauval A. J., Scott P., 2009, ARA\&A, 47, 481

Bensby T., Adén D., Meléndez J., et al. 2011, A\&A, 533, A134

Bensby T., Feltzing S., Johnson J. A., Gould A., Adén 


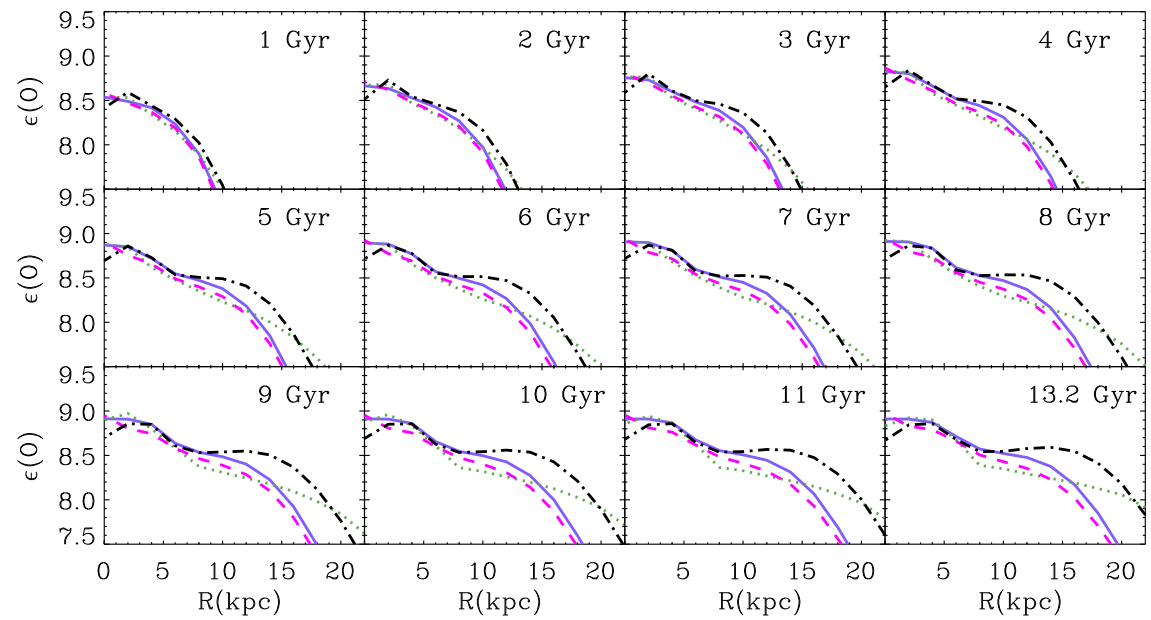

Figure 11. Time evolution of the oxygen radial gradient. At the top right of each figure is indicated the age of the Galaxy at the moment of the simulation. The colors and lines styles are as in figure 4 .

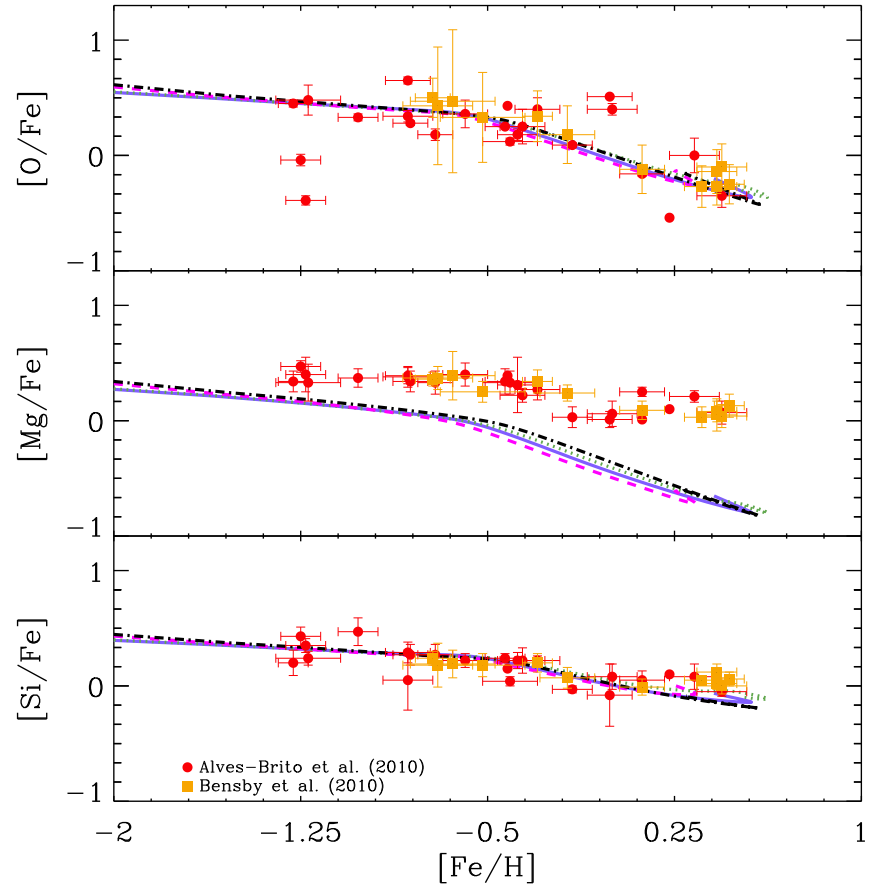

Figure 8. Comparison between the predictions of our model using different flows velocities and the literature data for $[\alpha / \mathrm{Fe}]$ where $\alpha$ stands for $\mathrm{O}, \mathrm{Mg}$, and $\mathrm{Si}$, vs. $[\mathrm{Fe} / \mathrm{H}]$. The observational data for the bulge are filled circles from Alves-Brito et al. (2010) and filled squares from Bensby et al. (2010).

D., Asplund M., Meléndez J., Gal-Yam A., Lucatello S., Sana H., Sumi T., Miyake N., Suzuki D., Han C., Bond I., Udalski A., 2010, A\&A, 512, A41

Cole A. A., Weinberg M. D., 2002, ApJ, 574, L43

Ferrini F., Matteucci F., Pardi C., Penco U., 1992, ApJ, 387,138

Ferrini F., Molla M., Pardi M. C., Diaz A. I., 1994, ApJ, 427,745

Ferrini F., Penco U., Palla F., 1990, A\&A, 231, 391

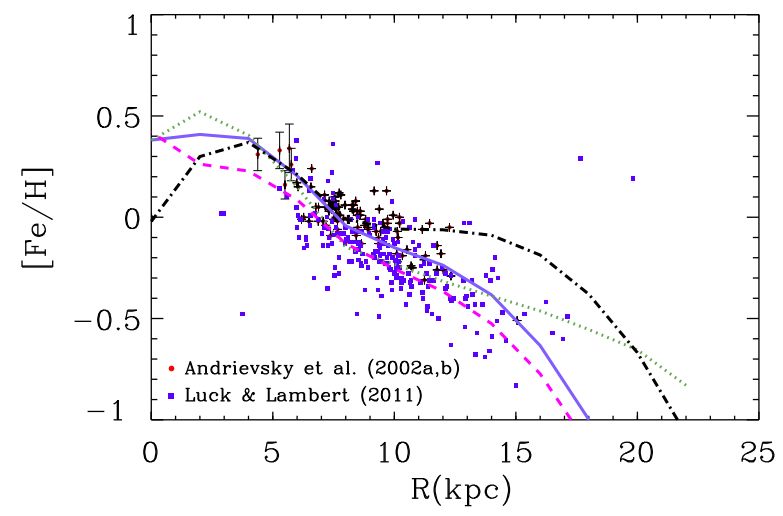

Figure 9. Iron radial distribution for Cepheids stars from Andrievsky et al. (2002,?) and Luck \& Lambert (2011) compared with our models using different radial flows.

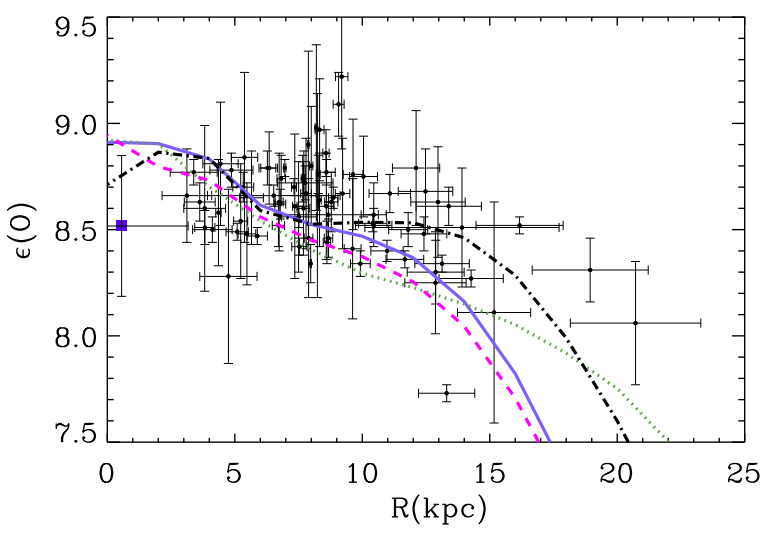

Figure 10. Oxygen radial distribution for disk PNe from compared with our models using different radial flows.

Fux R., 1999, A\&A, 345, 787

Gavilán M., Buell J. F., Mollá M., 2005, A\&A, 432, 861 Hammer F., Puech M., Chemin L., Flores H., Lehnert M. D., 2007, ApJ, 662, 322 
Howard C. D., Rich R. M., Clarkson W., Mallery R., Kormendy J., De Propris R., Robin A. C., Fux R., Reitzel D. B., Zhao H. S., Kuijken K., Koch A., 2009, ApJ, 702, L153

Iwamoto K., Brachwitz F., Nomoto K., Kishimoto N., Umeda H., Hix W. R., Thielemann F.-K., 1999, ApJS, 125,439

Lacey C. G., Fall S. M., 1985, ApJ, 290, 154

Luck R. E., Lambert D. L., 2011, AJ, 142, 136

Mollá M., Díaz A. I., 2005, MNRAS, 358, 521

Molla M., Ferrini F., 1995, ApJ, 454, 726

Mollá M., Ferrini F., Diaz A. I., 1996, ApJ, 466, 668

Mollá M., Roy J. R., 1999, ApJ, 514, 781

Nakanishi H., Sofue Y., 2003, PASJ, 55, 191

Nakasato N., Nomoto K., 2003, ApJ, 588, 842

Olling R. P., Merrifield M. R., 2001, MNRAS, 326, 164

Persic M., Salucci P., Stel F., 1996, MNRAS, 281, 27

Portinari L., Chiosi C., 2000, A\&A, 355, 929

Stahler S. W., Palla F., 2005, The Formation of Stars

Williams J. P., McKee C. F., 1997, ApJ, 476, 166

Woosley S. E., Weaver T. A., 1995, ApJS, 101, 181

Zoccali M., Hill V., Lecureur A., Barbuy B., Renzini A., Minniti D., Gómez A., Ortolani S., 2008, A\&A, 486, 177 